\title{
Designing attractive stores How the spatial layout of physical stores affects consumers' responses
}

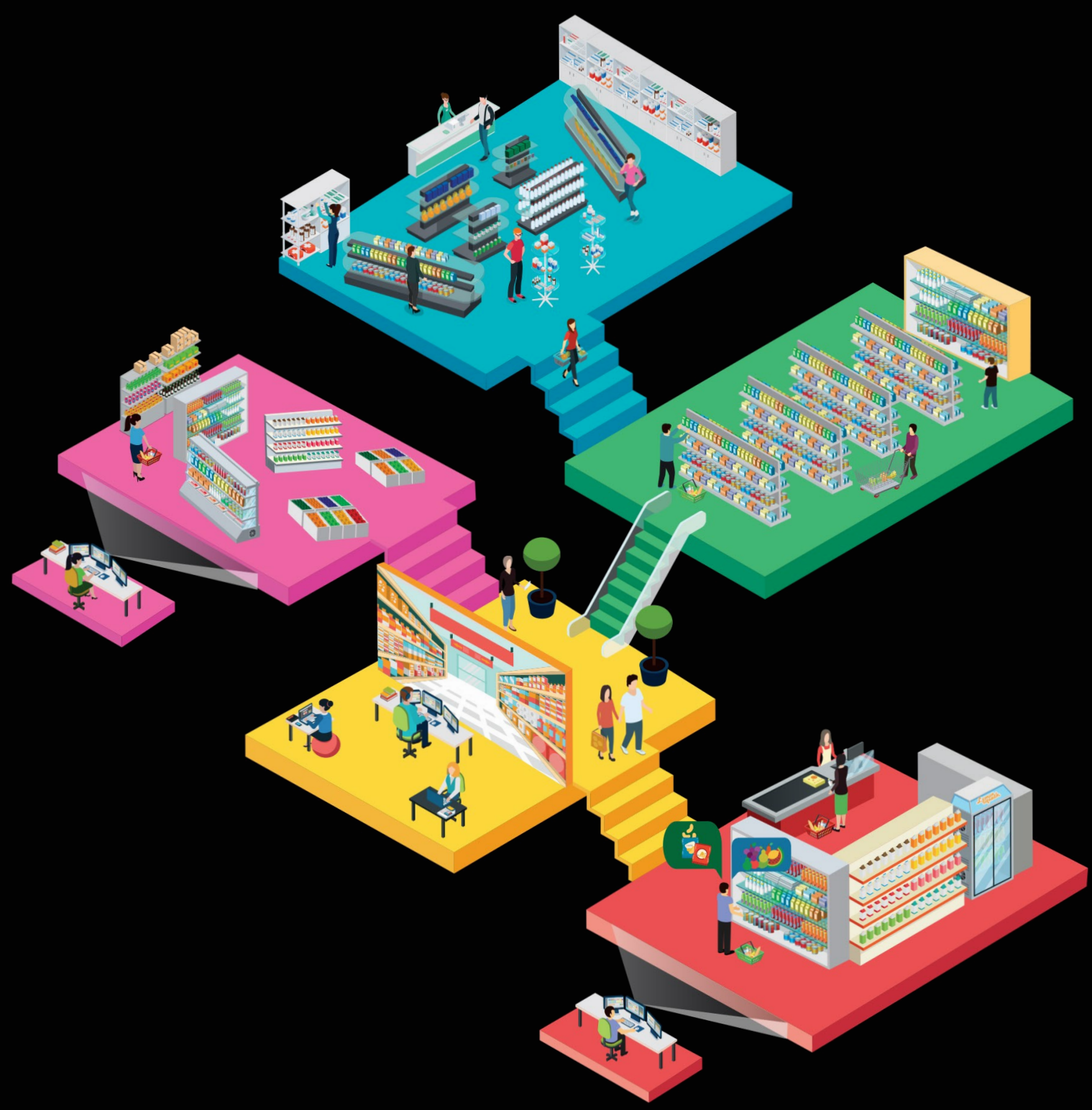

Kunala i Ploydanai 


\section{Designing attractive stores}

\section{How the spatial layout of physical stores affects consumers' responses}

\section{Kunalai Ploydanai}




\section{Propositions}

1. The traditional typology of store layout (grid versus free-form) does not suffice to guide store layout design.

(this thesis)

2. A store is not needed to conduct proper store layout research. (this thesis)

3. Pre-registration is the future of science.

4. In the marketplace of research ideas, publication pressure turns the researcher from a fun shopper into a run shopper.

5. Traveling is an eye-opener for creativity also in research.

6. Food is the glue that unites international Ph.D. candidates.

Propositions belonging to the thesis, entitled:

"Designing attractive stores

How the spatial layout of physical stores affects consumers' responses"

Kunalai Ploydanai

Wageningen, Monday 1 July 2019 


\section{Thesis committee}

\section{Promotors}

Prof. D rJ.C.M. van Trijp

Professor of Marketing and Consumer Behaviour

Wageningen University \& Research

\section{Co-promotor}

Dr Erica van Herpen

Associate professor, Marketing and Consumer Behaviour G roup

Wageningen University \& Research

\section{0ther members}

Prof. D r E.W.M.L. de Vet, Wageningen University \& Research

Prof. D r K. Koelemeijer, Nyenrode Business Universiteit, Breukelen

Prof. D r K. van Ittersum, University of G roningen

Prof. Dr M. Geuens, G hent University, Belgium

This research was conducted under the auspices of the Wageningen School of Social Sciences (WASS). 


\section{Designing attractive stores \\ How the spatial layout of physical stores affects consumers' responses}

\section{Kunalai Ploydanai}

Thesis

submitted in fulfilment of the requirements for the degree of doctor at Wageningen University by the authority of the Rector Magnificus, Prof. Dr A.P.J. Mol, in the presence of the

Thesis Committee appointed by the Academic Board

to be defended in public

on Monday 1 July 2019

at 11 a.m. in the Aula. 
Kunalai Ploydanai

D esigning attractive stores: How the spatial layout of physical stores affects consumers' responses,

292 pages.

$\mathrm{PhD}$ thesis, Wageningen University, Wageningen, the Netherlands (2019) With references, with summary in English

ISBN: 978-94-6343-958-9

D O I: https:/ / doi.org/ 10.18174/ 476192 


\section{Table of Contents}

Chapter 1 General introduction

Chapter 2 How store layout affects consumers' expected

29 in-store shopping efficiency, shopping enjoyment, perceived store image and intention to visit stores

Chapter 3 The role of store-layout complexity and orderliness

73 in determining intention to visit stores

Chapter 4 Using a virtual store as a research tool to investigate

119 consumer in-store behavior

Chapter 5 Stationing snacks in the supermarket:

151

D oes merchandise layout affect the (un)healthy snack choices made by consumers with different degrees of trait self-control?

Chapter 6 General discussion

205

Summary

235

References

239

Appendixes

263

Acknowledgment

279

About the author

283

Completed Training and Supervision Plan

285 



\section{Chapter 1 \\ General introduction}

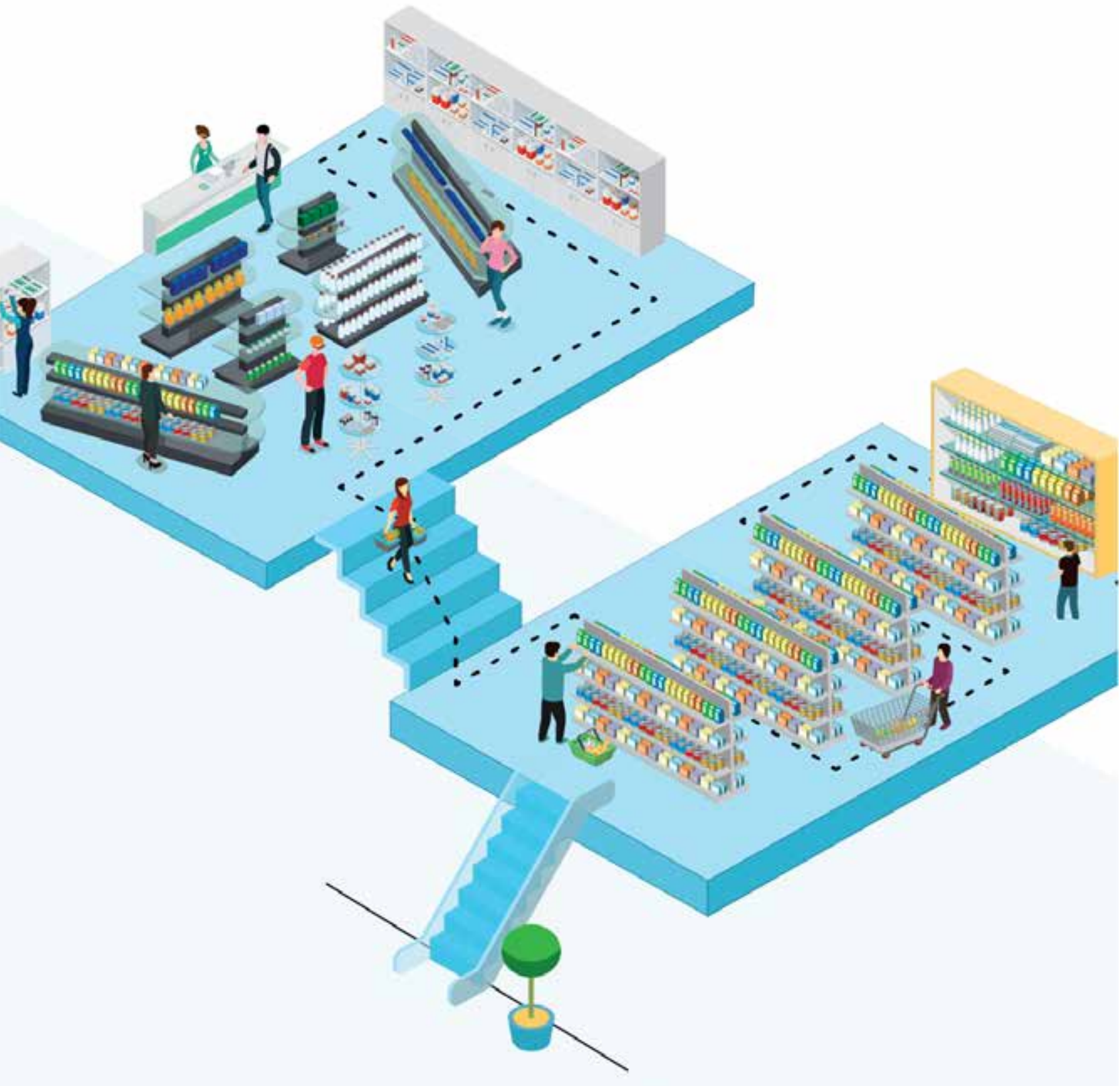




\subsection{Introduction}

The transformation of retailing from physical-based to online-based stores has unavoidably challenged retailers to adapt their strategies to survive in the rapidly changing market. This technological development combined with modern lifestyle has driven e-commerce to be currently ubiquitous. Consequently, the popularity of conventional physical stores has gradually decreased. Statistics indicate that the market share of e-commerce in the US has steadily increased from $5.8 \%$ in 2011 to $11.1 \%$ in 2018 and it is predicted to be $13.3 \%$ in 2021 ("Why O nline Isn't the End of the Physical Retail Store", 2017). In contrast, the number of physical stores has greatly plummeted (e.g., 7066 stores in America were closed in 2017; Weinswig, 2018). Retailing experts have argued that the remarkable reduction in physical stores is due to retailers not fully exploiting the unique features of physical stores that are intrinsically absent in online stores ("Why Physical Stores Are Still So Important", n.d.). Store owners who realize this point can beneficially turn the crisis into an opportunity (Mannino, 2018).

There are numerous inherent advantages of physical stores over online counterparts. Physical stores enable retailers to personally and directly interact with consumers to create brand awareness whereas online stores cannot provide this benefit easily. Attractive physical stores can stimulate store visits and provide chances for retailers to make their brands stand out from competitors. Moreover, the physical stores can offer consumers unique and compelling experiences to touch, feel and try products before purchase (Winter, 2017). Physical stores with appealing showrooms decorated by unique wallpaper, layout, and scent allow consumers to interactively experience products to consequently increase appreciation (Mannino, 2018). In contrast, web pages of online stores typically only show a list of items and pictures of products on a screen, so that consumers cannot directly touch or experience the products (Winter, 2017). Furthermore, the rapid growth in online retailing has accelerated 
the online market to be extremely competitive. It is getting more difficult for online retailers to be superior to competitors due to the tremendous number of brands selling online (Mannino, 2018).

The unique benefits of physical stores compared with the online ones suggest that the retailers possessing physical stores (with or without having an online channel) likely have more opportunities to succeed than retailers who rely only on e-commerce (G euens, Brengman, \& S'Jegers, 2003; Importance of Physical Stores, 2017). In line with this, evidence shows that consumers spend most of their money on retailers that have physical stores for all major product categories (Importance of Physical Stores, 2017). Indeed, retailers who apply multiple channels (integration of physical stores and online channels (e.g. website, social media, mobile, tablet)) likely succeed in the future market. The multi-channel strategy allows retailers to reach customers and provide products, services, and experiences anytime and anywhere. D espite the number of channels retailers may focus on, the transformation of the market emphasizes the needs to improve physical stores to continue to attract consumers, motivate store visit, create experience and enhance product sales.

Physical store environments can be designed and implemented as a marketing tool to influence consumers' behaviors and create desired effects for retailers (Kotler, 1973). The store environment is a "silent language" or a cue that communicates the stores' image and purpose to potential customers (Bitner, 1992; Kotler, 1973). Considering the store as a product that retailers want to sell, the store environment can be seen as the package of the store, which conveys information about the store's potential benefits to consumers (Solomon, 1985). Therefore, store managers can exploit the store environment to draw customers' attention, to enhance their expectations of shopping trips and to increase their intention to visit the store (Baker, Parasuraman, Grewal, \& Voss, 2002). Once the consumers get into the stores, the environment can motivate them to browse 
and explore products, as well as influence the types and the number of products purchased.

The store environment can be categorized into ambient, social, and design factors (shown in Figure 1.1; Baker et al., 2002). The ambient factors represent the nonvisual elements that are the background characteristic of the store (e.g. music, noise, temperatures, and scent). The social factors refer to the presence of employees and customers, and interpersonal interaction between them (Baker et al., 2002). The design factors involve the visual elements of the store (e.g., layout, color, architectural elements: exterior display window, flooring, carpeting) that tend to be processed at a more conscious level than the ambient factors (Wakefield \& Baker, 1998).

Impacts of store environment on consumers' cognitive responses (i.e., expectations and perceptions of environment; Baker et al., 2002) and affective responses (pleasure and arousal; Helmefalk, \& Hultén, 2017; Turley \& Milliman, 2000) have been investigated by many researchers since Kotler (1973) proposed the concept of store environment (atmospheric in Kotler, 1973) as a marketing tool. Among the store environmental factors, scholars have predominantly focused on the impacts of ambient or social factors (how specific factors influence consumers' responses) or on the combined impacts of ambient factors, social factors and design factors (to what extent environmental factors influence consumers' perceptions and shopping behaviors). They have investigated effects of ambient factors such as music, noise, and temperature on consumers' perceptions toward store image, merchandise price, merchandise quality, perceived visual appeal, perceived shopping enjoyment, perceived shopping efficiency, consumers' pleasure and arousal, and time spent in the store (for reviews, see Turley \& Milliman, 2000; Vieira, 2013). Scholars have increasingly studied the social factors (presence of salesperson, presence of other customers, and their interaction within the store) since these factors greatly impact 
consumers' perceptions toward a store, consumers' emotion and perceived shopping experiences, perceived crowding as well as consumers' shopping behaviors and chances of revisit (Demirgüneş, 2015; D. Han, 2010; for reviews see R. Singh, 2006; Turley \& Milliman, 2000; Vieira, 2013).

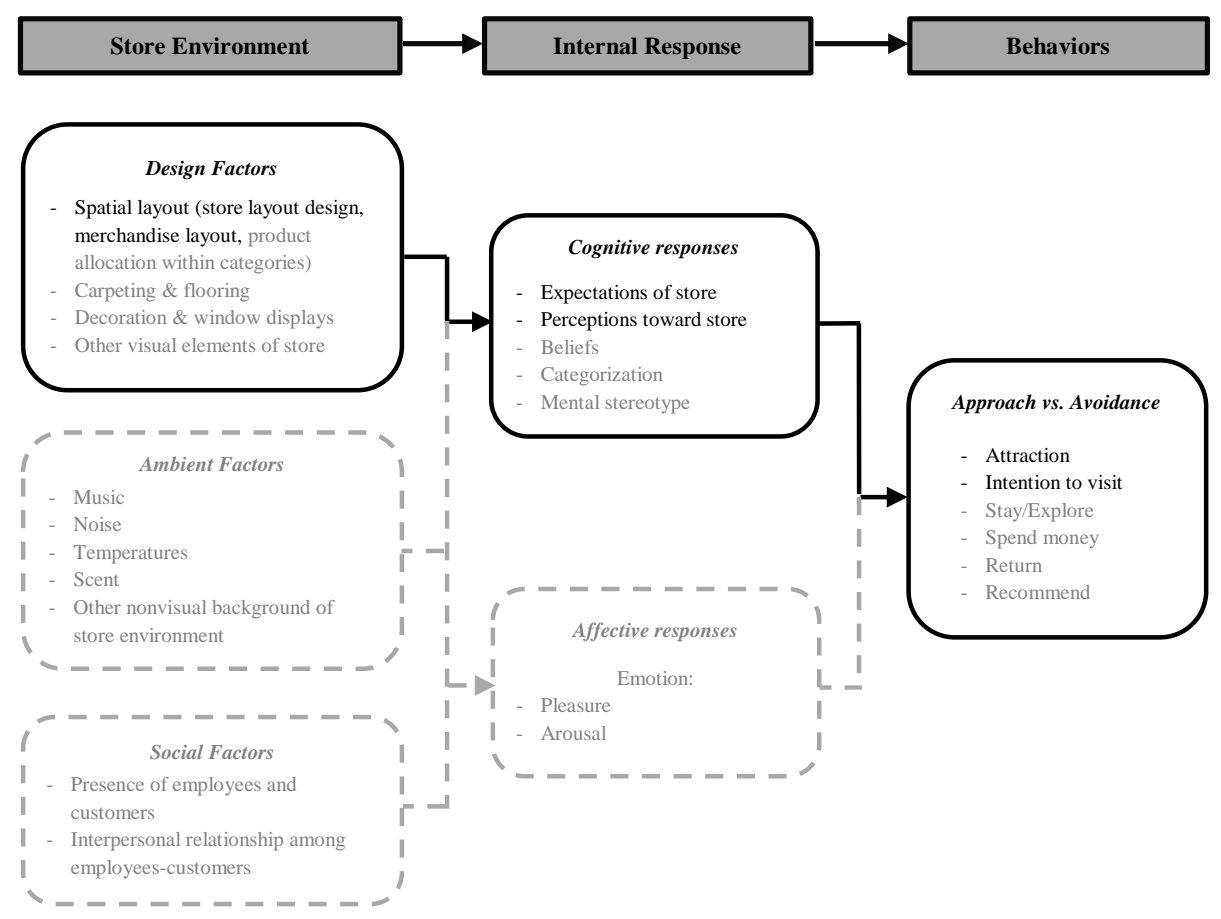

Figure 1.1: A conceptual model of store environmental impacts on consumers' responses to the store (adapted from Baker et al., 2002; Bitner, 1992)

Note: The black blocks and letters represent the scope covered in this thesis.

Store design factors (color, exterior display window, flooring, carpeting, allocation of product on shelves) have also been shown to significantly alter consumers' perceptions and shopping behaviors (Baker et al., 2002; Garlin \& O wen, 2006; Fiore, Yah, \& Yoh, 2000; R. Singh, 2006; Turley \& Milliman, 2000). A part from the impacts of store decorations and shelf and floor space allocation, 
there is surprisingly little empirical evidence showing detailed impacts of the spatial layout of a store, especially how specific store layout design, and merchandise layout (or location of merchandise) influence consumers' cognitive responses (expectations of the store), store choice and product choices.

In retailing, spatial layout refers to the way in which stores' physical elements (e.g. shelves, racks, product displays, and furniture) are arranged and positioned throughout the store, the size and shape of those elements and the spatial relationships among them (Bitner, 1992; van Rompay, Tanja-Dijkstra, Verhoeven, \& van Es, 2012). More in-depth knowledge regarding the impacts of spatial layout of the store is vital since the spatial layout is a primary concern for retailers when designing or remodeling their stores (Ghosh, Tripathi, \& Kumar, 2010). D espite potential impacts of a store's spatial layout, the currently available literature has explored only overall impacts of store's spatial layout or impacts of broadly defined layout such as simple/ complex layout (Turley \& Milliman, 2000), spacious/ cluttered layout (van Rompay et al., 2012) on specific consumers' responses (perceptions toward store, perceived crowding, emotion, shopping behaviors and intention to visit or revisit the store). This available knowledge may not suffice for store managers who plan to refurbish their stores to attract modern consumers. Moreover, since retailers are recently transforming toward smaller size stores that aim to enhance shopping experience rather than providing as many products as possible, knowledge of store's spatial layout requires an update (Petersen, 2018).

Inspired by the lack of knowledge in the area, this thesis aims to provide empirical support to verify and comprehend the impacts of store's spatial layout on consumers' responses. Two main factors of store's spatial layout are considered, namely store layout design and merchandise layout. The store layout design refers to the size (length and height) and shape of shelves, and the placement pattern (orientation) as well as the spatial relationship among shelves. 
The merchandise layout refers to the location where specific product categories are placed in the store. Additionally, the underlying processes that explain the impacts of those factors on consumers' intention to visit the store and purchasing choices are investigated. Understanding the role of store layout design and merchandise layout on consumers' responses can assist store managers in choosing an appropriate space plan that potentially attracts more customers and increases chances of success for physical retailers (Cil, 2012).

This thesis consists of three main parts. The first part focuses on store layout design and its impacts on consumers' expectations and intention to visit the store. The second part focuses on merchandise layout and its impacts on consumers' purchasing choices where the tool used is the virtual store. The third part focuses on the methodology how to apply the virtual store in marketing and retailing research that aims to investigate in-store shopping and purchasing behaviors. Basic concepts regarding store layout design, merchandise layout and research tools used throughout this thesis (i.e., virtual reality) are briefly introduced in the following parts.

\subsection{Store's spatial layout}

Store's spatial layout is defined as the arrangement and positioning of a store's physical elements (e.g. shelves, racks, product displays, cash register and furniture), the characteristics of those elements (e.g. size and shape) and spatial relationships among them throughout the store (Bitner, 1992; van Rompay et al., 2012). The store's spatial layout is a key store-related cue that can promptly be noticed by consumers even without entering a store, especially when consumers walk past stores of which the entrances are wide and transparent. The store's spatial layout affects the overall perception of stores. It can communicate with consumers and create expectations and impressions about stores as well as offered benefits (Underhill, 2000). In other words, by using 
attractive spatial layout retailers can increase the possibility that potential consumers enter the store. Furthermore, after entering stores, the store's spatial layout can influence which shopping routes consumers take, and which products they are exposed to. It thus can be used as choice architecture to influence product choices (Mohan, Sivakumaran, \& Sharma, 2013). The layout can also enhance the customer's shopping experience, which may accordingly motivate more impulsive purchases (Baker, G rewal, \& Parasuraman, 1994, Levy \& Weitz, 2012). Retailers have considered store's spatial layout as one of the priority factors when designing or remodeling their stores (Bäckström \& Johansson, 2006). Prior research has also shown that consumers value spatial layout of the store as one of their store choice criteria (Bäckström \& Johansson, 2006; Baker et al., 2002; G hosh et al., 2010). Store's spatial layout is a cue that consumers use to make inferences and expectations about the store's benefits and costs when visiting new stores (Baker et al., 2002).

\subsubsection{Store layout design}

Store layout design has traditionally been categorized into three types, namely grid, free-form and racetrack layouts. These 'prototypical' layouts are claimed to provide distinct benefits and drawbacks for consumers and retailers because of the resultant of different concrete attributes of designs (e.g., length and shape of shelves) and arrangements of shelves. The grid layout consists of identical long and rectangular shelves and aisles that are placed parallel to one another. The arrangement of the grid layout appears in a repetitive pattern. The grid layout can facilitate effective space allocation, and effective product search whereas it is less visually exciting than the other layouts (Titus \& Everett, 1995). This type of layout is, therefore, suitable for consumers with a planned purchase and is generally applied to groceries and drugstores. 
The free-form layout consists of a variety of shelf lengths and shelf shapes. It represents an unrestricted arrangement of shelves and aisles. This layout can offer a more spacious, relaxing and enjoying environment and can consequently stimulate browsing. However, the use of space in this layout is less efficient than in the grid layout. The efficiency of product search is probably reduced due to the undefined shopping route (Levy \& Weitz, 2012; Lewison, 1994). Thus, the free-form layout likely increases shopping time and impulsive purchase (Levy \& Weitz, 2012). Because of these reasons, we usually see the free-form layout in specialty and upscale stores.

The racetrack layout (also known as loop) comprises displays that are organized into individual, semi-separate areas or departments with a particular theme. It provides a major aisle to facilitate the walking paths of consumers that can enter the store from multiple entrances. Despite the loop arrangement, the design and orientation of displays in the racetrack layout have not been specified. It can include either grid design or free-form design in each department. The racetrack layout is stated to create interesting and entertaining shopping experiences. It also increases impulsive purchase as consumers are naturally motivated to move around to experience an unusual shopping theme (Lewison, 1994). Y et, the racetrack layout tends to require more space to place products in stores and may lower shopping efficiency. The racetrack layout is usually found in department stores (Levy \& Weitz, 2012).

Even though the argued benefits and drawbacks of each type of store layout design on shopping behaviors have been well documented in retailing literature (Levy \& Weitz, 2012), empirical evidence to testify the potential impacts of store layout design is scarce. There have been a few prior works which mainly focused on the impacts of store layout on pedestrian routes or on efficient space allocation (Aloysius \& Binu, 2013; Botsali \& Peters, 2005; Groeppel-Klein \& Bartmann, 2007). In addition, other studies (P. Singh, Katiyar, \& Verma, 2014; 
Turley \& Milliman, 2000) investigated the effects of store environments on consumer responses by using store layout as part of a broader manipulation of environmental factors (together with signage, decoration, and the arrangement of products). These studies manipulated all factors simultaneously so that one cannot disentangle the effect of an individual factor. Surprisingly, no detailed guidelines from empirical studies are available to assist store managers in deciding their store layout design. In particular, there is no conclusive information about the impacts of store layout design on modern consumers' expectations and perceptions. This suggests that retailers in the past designed, built and changed their spatial layout by relying on the traditional belief from the typology of store layout design without understanding in detail its impacts on consumers. Evidence to support this is that many retailing consultant websites still explain impacts of store's spatial layout based on the typology previously introduced (e.g., Fabregas, 2018; The Essential Guide to Retail Store Layouts, n.d.). Accordingly, it is possible to speculate that retailers have followed trial and error approaches when designing store's spatial layout rather than systematic research. This is likely due to the difficulty and expensiveness of spatial layout manipulation. Also, changing the spatial layout in the field can interfere with sales because consumers are very sensitive to even a minor change in store environment (Turley \& Milliman, 2000). Yet, thanks to the advancement of virtual reality technology, investigation of store layout design's effects can nowadays be more conveniently performed. This thesis aims at establishing an initial step to explore the potential impacts of store layout design on consumers' expectations and perceptions toward the store as well as on consumers' intention to visit the store. Virtual reality is applied to enable our store's spatial layout research.

This thesis concentrates on detailed impacts of the grid and the free-form layouts that are frequently applied to the majority of individual stores. The racetrack layout is excluded from the current study because it is usually applied to 
department stores only. Since the physical retailers are moving toward small or private stores where they can enhance consumer interaction and shopping experiences (Thomas, 2017), the grid and free-form layouts are likely used more frequently in the future than the racetrack.

To provide insight and expand the typology of store layout design, store layout design attributes (such as shelf length, shelf shape and shelf orientation) used to characterize grid versus free-form layout are examined deeper in this thesis. These store layout design attributes potentially explain the different impacts of grid versus free-form layout. For example, the reason that the free-form layout induces relaxing and enjoyable feelings is possibly because it consists of a variety of design and orientation of the shelves (shape, length, and orientation). The grid layout, in contrast, has only rectangular shelves oriented in a parallel pattern. It thus facilitates product search, but it may be less interesting for consumers.

\section{Impacts of store layout design}

Store layout design attributes are related to functional benefits (efficiency in finding and getting products) and hedonic benefits (enjoyment), and consumers may thus use store layout design to infer the stores' shopping efficiency and shopping enjoyment in the store. Moreover, research has also shown that store layout design influences the general store image that is perceived in consumers' mind (Baker et al., 2002). In the absence of prior knowledge, specific perceptions may rely on mental stereotypes in which experience toward one type of store can be transferred to another store with a similar layout. For example, long shelves and parallel orientation (a grid layout) may trigger perceptions of a discount store that provides less shopping enjoyment but more functional benefits (cheap products). In contrast, various shapes and arrangements of displays may trigger a perceived upscale store image and lead consumers to expect that their shopping trip will be enjoyable but less efficient. The expectations of shopping efficiency, shopping enjoyment and perceptions of 
store image can influence consumers' intention to visit the store because consumers likely choose only the physical stores that can benefit their shopping trips (high shopping efficiency and/ or high shopping enjoyment).

\section{Shopping motivation}

The impacts of store layout design on the intention to visit the store may differ from one shopping trip to another since consumers shop with varying purposes or motivations (Babin, D arden, \& G riffin, 1994). Sometimes consumers shop because of the necessity to buy products without searching for enjoyment (utilitarian motivation). At other times, consumers may primarily aim to enjoy the shopping activity (hedonic motivation). These two motivations can also occur together. Consumers can thus have both a utilitarian and a hedonic shopping motivation or have mainly a utilitarian, or mainly a hedonic motivation during a shopping trip (Babin et al., 1994; Li, Zhou, Nicholls, Zhuang, \& Kranendonk, 2004). This thesis will focus on the more extreme cases in which the shopping trip is characterized dominantly by a utilitarian shopping motivation or dominantly by a hedonic shopping motivation. The shopping motivation may alter the importance of the underlying drivers of store choice. For example, consumers with a utilitarian motivation likely prefer a simple layout such as a grid layout because it facilitates shopping efficiency. In contrast, consumers with a hedonic motivation may select a more complex layout such as a free-form layout because of the challenging, more enjoyable atmosphere. The current project examines this possible moderation of shopping motivation on the underlying process of store layout's impacts. 


\subsubsection{Complexity and orderliness of stores}

In addition to the typology and concrete attributes of store layout design, this thesis explores the roles of complexity and orderliness, as the abstract attributes that may provide deeper understanding of the impacts of store layout design, on consumer responses. The grid and free-form typology of store layout design are broad categories and as such provide limited guidance to retailers, whereas the effects of concrete attributes of store layout design are probably too specific to be very helpful. Thus, more abstract attributes may be needed to help retailers design and understand the impacts of store layout.

Complexity and orderliness have been proposed by environmental psychologists as common and higher order attributes that explain impacts of environments on people's responses to the environments both in nature (van den Berg, Vlek, \& Coeterier, 1998) and urban environments (Health, Smith \& Lim; 2000; Nasar, 1994). Complexity and orderliness have received attention from the retailing research community (G ilboa \& Rafaeli, 2003; Jang, Baek \& Choo, 2018; Orth \& Wirtz, 2014). Gilboa and Rafaeli (2003) were the first to verify the beneficial roles of complexity and orderliness of stores in predicting consumers' responses to store environments.

\section{Complexity}

Complexity represents visual richness, ornamentation, information rate, diversity and variety of information or elements in an environment (Nasar, 2000). It relates to the multiplicity of elements. For example, the complexity of stores increases when there is more variety of shelf elements or arrangement patterns (Gilboa \& Rafaeli, 2003). In relation to store layout design typology, we may state that the free-form layout is more complex than the grid. This is because the former comprises a variety of shelves and unrestricted shelf arrangements whereas the latter consists of rectangular shelves arranged in a 
single parallel pattern. Among the numerous layouts categorized as free-form, the level of complexity can be quite different though, likely depending on the richness and variety of store's elements in the specific layouts (quantity of shelves, variety of shelf shape and shelf orientation).

\section{O rdenliness}

O rderliness denotes a degree of organization, coherence, fittingness, congruity and legibility of information or elements (Kaplan, 1987; Nasar, 1994). It represents the congruity of relationships among different parts of entire elements (Arnheim, 1971). For example, a symmetric or parallel arrangement of elements can increase store orderliness. In relation to the typology of store layout design, the grid layout tends to be more orderly than the free-form that typically has less coherence or an asymmetric arrangement pattern.

We propose that complexity and orderliness may help explain the overall effect of store layout design that cannot be covered by the unique effect of each concrete attribute such as shelf length, shelf shape, and shelf orientation. Moreover, since perceived complexity and orderliness have been used to explain the effects of multiple store environment factors, retailers may use perceived complexity and orderliness to assess effects of store layout design when combined with other store environment factors (color, design or placement of products; Gilboa \& Rafaeli, 2003; Jang et al., 2018). Understanding the role of complexity and orderliness can help store managers and researchers who aim to examine more abstract attributes of store layout design or to change multiple environmental factors in the future.

\subsubsection{Merchandise layout}

After successfully attracting consumers to visit the store, store managers subsequently face the challenging task to turn them into paying customers. They 
are in need to find strategies to motivate product purchases and to increase the conversion rate. In addition to store layout design, another possible strategy that is easy to implement and increasingly becoming popular is designing the merchandise layout or the location where whole product categories are placed in the store (Kroese, Marchiori, \& de Ridder, 2015; Thorndike, 2017). Location, where products are placed, can influence consumers' perceptions toward the store, and more importantly, it can influence consumers' purchasing choices. Researchers and marketers have increasingly applied merchandise layout as one of the choice architecture interventions to guide and help consumers make a desirable choice (such as healthy food choice), in a predictable way.

Retailers know that the merchandise layout (e.g., prime location, end of aisles, front-middle of the store, at the checkout counter, at the storefront) can be exploited as a strategy to increase product sales (Escaron, Meinen, Nitzke, \& Martinez-D onate, 2013). However, knowledge on how the specific merchandise layout of the store or a particular location of product categories in the store can affect consumers' choice is scarce. The reported studies have concentrated primarily on two prime locations: an end-of-aisle display (Nakamura, Pechey, Suhrcke, Jebb, \& Marteau, 2014) and the check-out counter (Cohen \& Babey, 2012; van G estel, Kroese, \& de Ridder, 2018), which are demonstrated to draw consumers' attention and stimulate sales. Another location that researchers suggested to bring potential impacts on sale is the store entrance (Walmsley, Jenkinson, Saunders, Howard, \& Oyebode, 2018). To the best of our knowledge, this location has been examined by only one study revealing that placing fruit and vegetables around the entrance (compared to placing at the back) increases the sale of those products in grocery stores (Walmsley et al., 2018). As suggested by several previous studies (Cohen \& Babey, 2012; van Gestel et al., 2018; Walmsley et al., 2018), the location of product categories in stores can be used as an intervention to influence consumers' choices (both types and quantity of products purchased). Understanding how merchandise layout shapes 
consumers' choices can help retailers and policymakers identify an appropriate location of product categories that stimulates consumers to make choices which are in their own best long-term interest.

\section{Potential impacts of merchandise layout on consumers' products purchased}

The impact of merchandise layout on types and quantity of products purchased may be driven by many underlying factors such as the decision-making process that consumers apply, the specific purposes of the product purchases, consumers' personality traits and so on. The underlying factors also likely depend on the choice alternatives that are accessible to consumers to choose from. For example, product location may have a minor or no influence on the choices of products that consumers have a strong commitment to (brand loyalty). In contrast, product location may strongly influence the choices of products when consumers experience conflict in choosing or when they are indifferent to the options.

O ne conflict that consumers often experience is choosing between healthy food that provides long-term benefits (e.g., future healthy life) versus indulgent food that gives immediate pleasure (e.g., enjoying the good taste). When facing these conflicts, many consumers may fail to control themselves to resist such temptations (Tangney, Baumeister, \& Boone, 2004) and tend to act toward their short-term rather than long-term benefits (Lynch \& Zauberman, 2006).

Many studies have suggested the role of "salience/ attention" as a driver for the impact of product location on choices (Cohen \& Babey, 2012; Nakamura et al., 2014; Sorenson, 2009; van G estel et al., 2018; Walmsley et al., 2018). The prime location has been applied to draw consumers' attention to a specific product category. Once consumers' attention is drawn to a category (e.g., fruit placed at the entrance or cash-register), other products in another location are out of their 
attention. Consumers' choices therefore heuristically go to the most salient option.

In addition to attention biases, the ability of self-control or self-regulation has been shown to greatly affect consumers' choices of healthy versus indulgent food. Self-control refers to the ability to attain control over impulses and to engage in behavior that is in line with long-term desirable goals (Ainslie, 1975; Baumeister, 2002b). Consumers need self-control to make desirable choices that are consistent with their long-term goal (healthy choice). Research has shown that acts of self-control expend cognitive resources that are limited (Baumeister, 2002a; Muraven, Tice, \& Baumeister, 1998). These cognitive resources are depleted over time after acts of self-control (Vohs et al., 2008). In return, the reduction in this resource leads to a state called ego-depletion in which consumers become more impulsive and less self-controlled (Baumeister, Sparks, Stillman, \& Vohs, 2008; Vohs \& Faber, 2007). Therefore, when consumers lack in self-control resource, they likely opt for the indulgent choice that gives an immediate pleasure (van Kleef \& van Trijp, 2018). Marketers and policymakers may help consumers to make the desired choice by employing a merchandise layout that exposes consumers to the conflicting product categories (e.g. healthy and indulgent snacks) at a point of time during the shopping trip where consumers are still able to control themselves.

This thesis proposes that the location of healthy and indulgent food at the entrance or at the end of a shopping trip may influence consumers' ability to control themselves during a conflicting choice between healthy and indulgent food. D uring a shopping trip, consumers follow a navigation path in which they are exposed to the product shelves located around the entrance before moving to the shelves located further away in the store (Larson, Bradlow, \& Fader, 2005). Therefore, the location of a product category (near the entrance or further away near the exit) tends to determine the number of choices (few or many) 
consumers have made prior to encountering the choice conflict. In turn, the number of prior choices consumers make is suggested to influence success or failure of self-control on subsequent choices because research has shown that making choices expends the same pool of cognitive resources that consumers need to assert self-control (Vohs et al., 2008). Placing healthy and indulgent food at the end (beginning) of a shopping trip likely increases (decreases) indulgent food choices whereas it potentially decreases (increases) healthy food choices because consumers may be depleted (less or not depleted) from many (few) prior choices that they have made.

To the best of our knowledge, there is no empirical evidence showing how selfcontrol is affected by the location of product categories and how self-control depletion (ego-depletion) affects the choices made in stores. Research to date typically focuses on the healthiness of a single purchase or consumption when participants are allowed to choose one product (i.e., choose between a healthy or an indulgent product; Honkanen, Olsen, Verplanken, \& Tuu, 2012; Maas, de Ridder, de Vet, \& de Wit, 2012; Wills, Isasi, Mendoza, \& Ainette, 2007). Consumers in real shopping situations can freely choose many products in any number that they prefer. Existing research has supported that purchasing is a dynamic process that depends on consumers' response to earlier purchase decisions (Gilbride, Inman, \& Stilley, 2015; van der Heide, van Ittersum, \& van D oorn, 2016). Even though there has been no study examining the effects of product location on a series of choices yet, van der Heide et al. (2016) investigated healthy-shopping dynamics throughout the shopping trip and their findings seem to support our speculation. They showed that a group of shoppers (overweight shoppers) chose relatively healthy options in the first half of their shopping trip, whereas they purchased relatively unhealthy options during the second half of the trip. However, the authors have not examined the underlying process of this dynamic. We speculate that self-control is an underlying process. To enable retailers to design an appropriate merchandise layout, it is, therefore, 
important to understand the possible effects of the merchandise layout on a set of choices in a realistic choice set up. This thesis aims to provide insight into how the merchandise layout (location of product categories in the store) influences consumers' choices in a shopping trip. The possible process (self-control) that may drive consumers' choices in the supermarket is investigated, as well as the influence of consumers' trait self-control.

\subsection{Tools used for studying impacts of the physical store environment on consumers' expectations and shopping behavior}

The lack of empirical evidence on how consumers respond to the physical environment, especially store's spatial layout, limits retailers to design spatial layout by trial and error. Since the manipulation of spatial layout and other tangible factors in a real store is difficult and expensive and it may induce negative impacts on consumers (Liu \& Jang, 2009), research to date has provided limited understanding of store's spatial layout. Even though some store environmental factors are easy to be changed and can be investigated in a lab experiment, consumers' responses to the lab stimuli may not fully resemble behaviors that happen in a real purchase context. Fortunately, the current development of virtual reality technologies enables consumer behavior researchers to solve such limitations by creating close-to-reality store environments in the lab where researchers can carefully control other factors (Slater, 2009). Virtual reality thus provides insight into consumers' behaviors and improves fidelity and generalizability (external validity) of research findings compared to traditional lab experiment (Morales, Amir, \& Lee, 2017). D espite the promising benefits of the virtual store, expertise in usage of a virtual store is vital to ensure timely and accurate preparation and implementation of research. The current thesis has developed and employed virtual reality technology to explore the effects of store layout design and merchandise layout on consumers' 
expectations and in-store behaviors. This thesis also provides a methodological contribution by describing a detailed protocol with steps to use the desktop virtual store to investigate consumers' in-store behaviors.

In this thesis, two formats of virtual reality have been applied to manipulate the store's spatial layout (store layout design and merchandise layout) and to provide close-to-reality shopping environments for participants (van Herpen, Immink, \& van den Puttelaar, 2016).

\subsubsection{The SketchUp 3D modeling program}

The SketchUp 3D modeling program is used to create images of stores (SketchUp, 2018). SketchUp is a web-based application that provides a wide range of drawing applications in architectural, interior design, landscape architecture, civil and mechanical engineering, film and video game design. It comprises an open library from which users can download models of buildings and elements to create our own environments (e.g., products, shelves, decoration, cash-register). This Ph.D . thesis uses SketchUp to manipulate store layout design while controlling for other environmental factors. The created images are presented to participants to examine their expectations of the stores.

\subsubsection{The virtual store}

The virtual store deploys virtual reality technology to create close-to-realistic and immersive three-dimensional virtual store environments in which people can actively interact with objects in the store. Virtual stores have been utilized as a managerial aid for several purposes. For example, they have been used to assist companies in developing a shelf plan for their products. Virtual environments have also been used in clinical settings, to measure emotional responses to food for patients with an eating disorder (G orini, Griez, Petrova, \& Riva, 2010) or as a screening tool for mild cognitive impairment (Zygouris et al., 2015). Moreover, 
virtual reality has been used in marketing and consumer research to assess consumers' in-store behaviors and consumers' responses to store environments or their product choices. For example, prior studies have focused on point-ofsale displays (A. Kim et al., 2014), price changes (Waterlander, Mhurchu, \& Steenhuis, 2014; Waterlander, Blakely et al., 2016), packaging (van Herpen, Immink, \& van den Puttelaar, 2016) and nutritional labels (D ucrot et al., 2016). Furthermore, a virtual store has been used to help create and test public health interventions to stimulate children's healthier food choices (Berneburg, 2007).

A virtual store is employed in the current project to manipulate store layout design and merchandise layout. It enables us to conduct research in a tightly controlled, flexible and cost-efficient, yet realistic setting. In addition to the main studies, the procedures to create and use the virtual supermarket environment to conduct in-store consumer behaviors and marketing research are developed and summarized in this thesis to guide future research.

\subsection{Scope and outline of the thesis}

Researchers, retailers, and consumers have realized the considerable impacts of store's spatial layout on consumers' responses to a store (Bäckström \& Johansson, 2006; Baker et al., 2002; Levy \& Weitz, 2012). Store's spatial layout is one of the primary factors that store managers consider (Bäckström \& Johansson, 2006). Moreover, consumers also value the store's spatial layout when making their store choices (Bäckström \& Johansson, 2006). Despite the potential role of spatial layout on consumers' responses, the empirical evidence to enhance understanding of spatial layout's impacts on consumer responses to retail stores remains scarce. To date, previous empirical studies only showed the extent to which a store's spatial layout is important for retailers and consumers. Other studies revealed the overall impacts of store layout on consumers' responses, but the investigated layouts were broadly defined (simple/ complex 
layouts; Turley \& Milliman, 2000, crowded/ spacious layouts; van Rompay et al., 2012). Moreover, the studies on merchandise layout emphasized only the cashregister or end-of-aisle location of products; other products location which can potentially increase sales have not been examined yet. Without knowing the detailed impacts of spatial layout, store managers seem to have no other options except using a trial-and-error approach and primarily relying their store's layout design on the broadly defined categories (grid/ free-form typology of the layout, simple/ complex layouts, crowded/ spacious layouts). Therefore, retailers can be guided to design and use the most appropriate spatial layout by information obtained from consumer behavior studies such as which store layout design enhances consumers' expectation and approach behaviors or which merchandise layout is the most effective in increasing sales (Turley \& Milliman, 2000). This thesis aims at filling the gap in knowledge on store's spatial layout by exploring detailed impacts of store layout design (length, shape, and orientation of shelves) as well as merchandise layout to provide more theoretical and practical insights into store's spatial layout knowledge. Moreover, to enable research on the spatial layout of stores, this thesis provides guidelines on how to use the virtual store as a methodological contribution.

The overall aim of this thesis is to examine the impacts of store layout design and merchandise layout on consumers' responses to the store (e.g., expectations and perceptions toward the store and shopping process, intention to visit the store, shopping behaviors, and product choices). The following research questions will be addressed. 
1. How does store layout design determine consumers' intention to visit the store?

a. How do store layout design's attributes explain the impacts of store layout on consumers' cognitive responses and intention to visit the store?

b. What are the underlying processes explaining the impacts of store layout design on intention to visit the store?

c. How does the underlying process differ among consumers with utilitarian and hedonic shopping motivation?

2. How does the merchandise layout (location of snacks in the store) shape consumers' purchasing choices of healthy and indulgent snacks?

a. How does self-control depletion drive the effects of merchandise layout on purchasing choices?

b. How does self-control depletion impact healthy and indulgent choices of consumers with a different trait self-control?

These questions are addressed in Chapters 2, 3 and 5. Meanwhile, the procedures to employ the desktop virtual store in marketing and consumer behavior research, as well as an example of in-store behavior research conducted with the virtual store, is presented in Chapter 4. A schematic summary of the entire Ph.D. thesis is shown in Figure 1.2. 


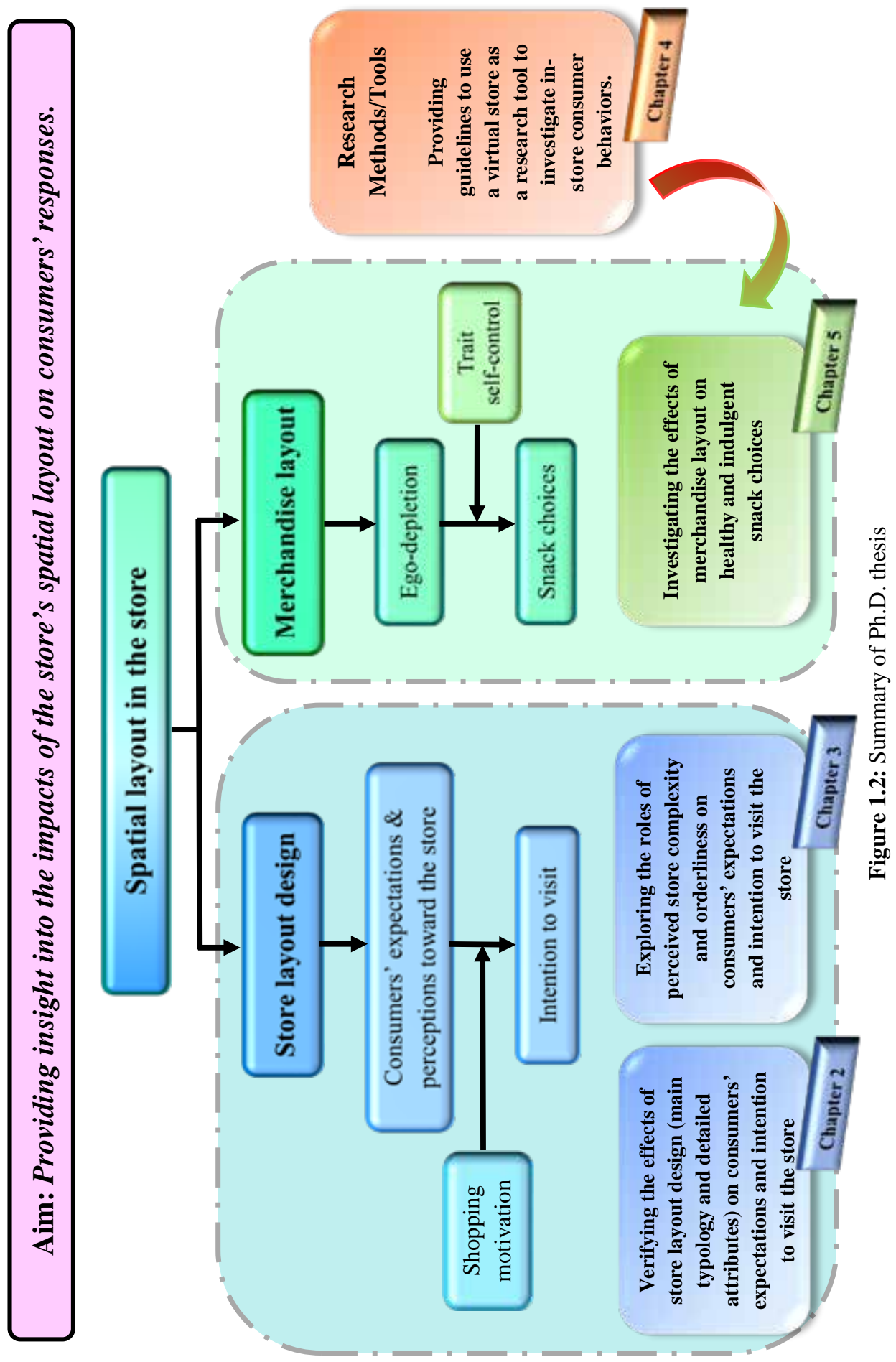




\section{Chapter 2}

Chapter 2 examines the impacts of store layout design on consumers' intention to visit the store and its possible underlying process under different shopping motivations (research questions 1a - 1c). 3D pictures of pharmacy stores with various layouts are employed in three studies (two quantitative experiments and one qualitative study) to explore consumers' expectations and intention to visit the store. This chapter presents impacts of store layout design typology (grid versus free-form) and store layout design's attributes (shelf length and shelf orientation) on consumers' expectations and subsequent intention to visit. The different impacts of free-form layouts compared to the grid layout reveal the limitation of using the typology of store layout design (grid vs. free-form) to predict consumer responses. Finally, this chapter proposes abstract attributes (i.e., store layout complexity and orderliness) generated from consumers to explain the impacts of store layout.

\section{Chapter 3}

As proposed in the previous chapter, Chapter 3 establishes an initial step to elucidate the roles of abstract attributes of store layout (perceived complexity and perceived orderliness) on the intention to visit the store. The underlying process (expected shopping efficiency, expected shopping enjoyment and perceived store image) and the moderating roles of shopping motivation are investigated. In the study, 3D images of pharmacy stores are evaluated via an online survey. Store layout design's concrete attributes (shelf length, shelf orientation, and shelf shape) are systematically varied to manipulate perceived complexity and perceived orderliness of store layouts (24 layouts). This chapter provides guidelines regarding the concrete attributes and abstract attributes of the store layout design that store managers should consider when designing their stores. 


\section{Chapter 4}

Chapter 4 provides methodological guidelines to researchers who want to bring realism to lab experiments for in-store consumer research. This chapter presents information and guidelines on how to use the desktop virtual store in conducting consumer behavior research to study impacts of store environments on shopping behaviors (e.g., store layout design and merchandise layout). D etailed procedures to create stimuli, to set up and conduct an experiment, and to record and extract recorded data are given. In addition, this chapter provides an example of store's spatial layout research within the virtual store. The research is conducted to investigate the impacts of shelf length and shelf orientation on consumers' shopping behaviors (i.e., shopping time, walking distance, number of products examined and purchased) and perceptions toward the store. The benefits, drawbacks and important cautions that researchers should consider when conducting research with the virtual store are discussed.

\section{Chapter 5}

Chapter 5 examines the potential impacts of merchandise layout or snack categories' location on healthy/ indulgent snack choices that consumers make in the supermarket. Additionally, the role of ego-depletion predicted to be an underlying process and the role of trait self-control predicted to be a moderator are investigated (research question $2(a-b)$ ). Four lab experiments are conducted within the virtual store environment. The first experiment tests the assumption that common and familiar choice tasks in the supermarket can evoke egodepletion and impair subsequent self-control performance. The second and third experiment further investigate the impacts of merchandise layout on healthy and indulgent snack choices from different snack altematives. The fourth experiment attempts to verify the effects of self-control depletion caused by another self-control task (i.e. crossing out of a letter) on snack choices. O ur study aims to provide insight into the impacts of merchandise layout (through 
self-control depletion) on food choices when consumers have the chance to buy as many products as they want.

\section{Chapter 6}

Chapter 6 concludes the main findings of the thesis and addresses the research questions how store layout design and merchandise layout contribute to consumers' expectations, intention to visit the store, shopping behaviors, and the purchasing choice. Finally, limitations of the studies and recommendations for future research will be given. 

Chapter 2

\section{How store layout affects consumers' expected in-store shopping efficiency, shopping enjoyment, perceived store image and intention to visitstores}

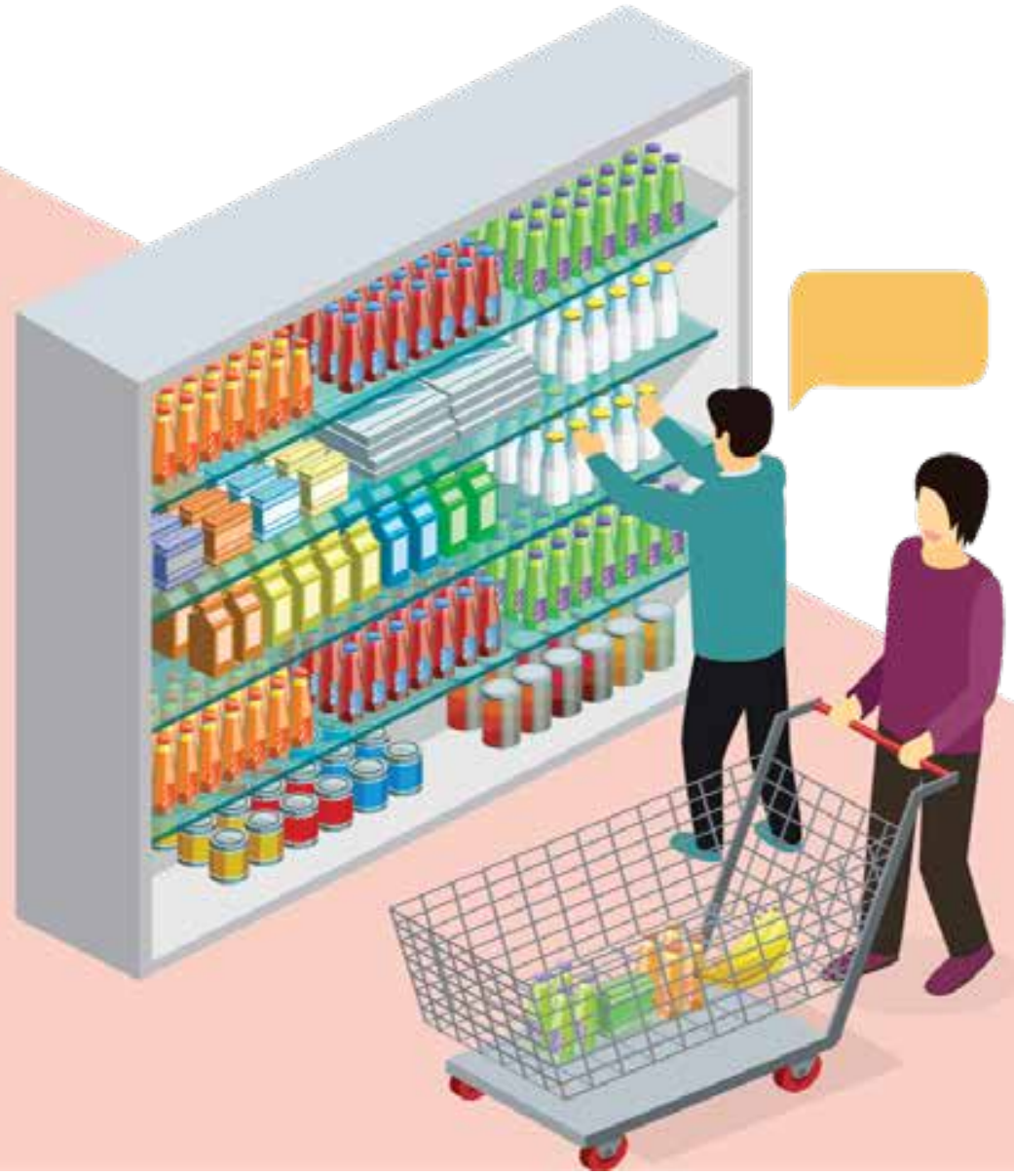

This chapter has been prepared by

Ploydanai, K., van Herpen, E., \& van Trijp, J. C. M. H. 


\section{Abstract}

Store layout is assumed by marketers and retailers to influence consumers' perception, store choice and intention to visit the store. However, the detailed impacts of store layout design, especially from a consumers' perspective have hardly been empirically studied. Therefore, this chapter applies pictures of 3D stores in three sequential empirical studies to examine how the store layout design can affect consumers' expectations about the shopping process (shopping efficiency and enjoyment), perceived store image and intention to visit the store. O ur studies confirm the impacts of store layout design on expected shopping process and perceived store image, which in turn positively affect the first intention to visit the store. The first study verifies the effects of a free-form layout (compared to a grid layout conceptualized in retail management literature) to enhance expected shopping process and perceived store image. The second study examines two key underlying attributes of store layout design: shelf length and shelf orientation and shows contradictory findings for these. The attributes related to the free-form layout (short shelves and mixed orientation) do not have similar effects on the dependent variables: whereas consumers appreciate short shelves they dislike a mixed orientation. This manifests that the distinction between the grid and free-form layouts does not capture consumer expectations adequately. Finally, the third study therefore explores these expectations using self-generated distinctions made by consumers. We find that the abstract attributes of complexity, onderliness, and spaciousness can explain the impacts of store layout design. This provides more understanding of store layout design and guides directions for future research. 


\subsection{Introduction}

Imagine you walk through a new shopping street. Along the way you see many stores of which you have limited information. To choose which store to visit, you may rely on the immediate information you see at the front of the store (e.g., products display, promotion, decoration). Apart from these well-known cues, shelf arrangement or store layout design is also a key store-related cue that customers can promptly notice even without entering the store. At the first visit, consumers may also rely on store layout design to make inferences and subsequently form expectations for product costs, offered benefits, and the likely shopping experience (Baker et al., 1994; Underhill, 2000). In other words, store layout design can influence shoppers' first impression and intention to visit a store (Alawadhi \& Yoon, 2016). Hence, understanding how layout affects consumers' expectations of the store can beneficially assist in attracting new customers (Cil, 2012).

Store layout design is classified into three main types namely the grid, the free-form and the racetrack layouts (G hosh, 1994; Levy \& Weitz, 2012; Lewison, 1994). The grid layout consists of a strict and well-organized pattern of shelves that are arranged parallel to one another, whereas the free-form layout contains a playful and unrestricted pattern of shelves. The racetrack layout organizes the shelves into semi-separated areas according to a particular shopping theme. The specific types of layout design are appropriate to certain kinds of shops. For instance, the grid layout is generally found in grocery and discount stores. The free-form counterpart is often used in specialized or fashion stores. Besides, the racetrack layout is usually seen in big department stores offering diverse product categories. The grid and free-form layouts are intensively used in a variety of retail stores in our daily shopping activities and both are applied to similar types of (competing) stores (e.g., pharmacy stores with grid versus free-form layouts). It is thus intriguing to explore how these two layouts compare to each other. 
In contrast, the racetrack layout is almost exclusively applied to department stores and therefore out-of-scope for the current chapter. We will focus on exploring how grid and free-form layout affect store attractiveness.

The grid and the free-form layouts have been stated to provide various benefits according to retailing literature, and to lead to different consumers' perceptions. The grid layout is stated to facilitate shopping efficiency, whereas the free-form layout is stated to increase shopping enjoyment (Levy \& Weitz, 2012; Lewison, 1994). Moreover, the grid layout is associated with a downscale store image, while the free-form relates to an upscale store image (Burstiner, 1986). There have been some reported studies which have proposed impacts of store layout design on consumers' expectations toward stores (Puccinelli et al., 2009; Spies, Hesse, \& Loesch, 1997; Titus \& Everett, 1995). For example, Titus and Everett (1995) have proposed that stores with a simplified aisle pattern (i.e., a grid layout) tend to be perceived as being easier to walk through and search for products, but less stimulating than those with a more complex aisle configuration. However, empirical investigations, especially the comprehensive study of consumer behaviors (e.g., perceptions and expectations about the store in relation to the store layout design) remain limited.

The absence of empirical evidence has motivated several comparative studies of stores with a variety of environmental factors (e.g., music, lighting, sign, decoration) and layouts (Baker et al., 1994; Spies et al., 1997). Some studies employed store layout design as part of the store environment and examined how the combined store environmental factors influence store perceptions, including perceived complexity and orderliness of the store (Gilboa \& Rafaeli, 2003; Jang et al., 2018). Even though these studies have verified the importance of store layout design, the findings cannot unambiguously address the role of the grid versus free-form layouts on consumers' expectations or intention to visit the store because store layout design was not the only store element that was 
changed. There has been a recent study addressing the main effect of store layout design (Alawadhi \& Yoon, 2016) which shows that a grid layout brings higher approach tendencies (i.e., patronage and repatronage intention, desire to stay, desire to explore and word-of-mouth) than a free-form in the context of a supermarket. However, this finding contradicts the existing retailing literature. Therefore, more research is required to further examine this inconsistency because the layout is a primary concern for retailers (Alawadhi \& Yoon, 2016) and consumers generally rate store layout as one of the main factors that determine their store choices (G hosh et al., 2010).

The current chapter combines the model of Baker, Parasuraman, Grewal and Voss (2002) and knowledge from retailing literature (e.g., Levy \& Weitz, 2012) to investigate how store layout design affects consumers' intention to visit the store. We propose that consumers' expectations of the perceived costs and the benefits that a store offers during the shopping process (expected shopping efficiency and expected shopping enjoyment) as well as perceived store image (upscale vs. downscale store image) are the underlying process explaining the effects of store layout design. The expected shopping processes and perceived store image are proposed because they are known as potential store layout benefits (Levy \& Weitz, 2012) and they resemble the store choice criteria that explain the effects of store environments on intention to visit the store (Baker et al., 2002). In addition, the current study provides further insights into store layout design by exploring store layout design's attributes (shelf length and shelf orientation) to provide more concrete guidelines to store managers. Finally, the potential moderating role of shopping motivation is investigated. Shopping motivation refers to the goal that consumers are keen to fulfill during their shopping trip. Consumers with a utilitarian shopping motivation desire to buy products as efficiently as possible, whereas those with a hedonic shopping motivation enjoy their browsing and shopping (Babin et al., 1994; Holmqvist \& Lunardo, 2015; Kaltcheva \& Weitz, 2006). Since stores with different layouts are 
expected to provide the distinct levels of costs and benefits, intention to visit the store and store choice may differ according to shopping motivation.

The studies are divided into three sequential parts. The first study examines the effect of the grid versus the free-form layout by simultaneously manipulating four concrete layout design's attributes (shelf length, orientation, height, and shape). The second study investigates shelf length and shelf orientation separately, as the two key layout design's attributes distinguishing grid and free-form layouts. Disentangling the effects of shelf length and orientation shows that these attributes lead to vastly different consumer responses. The diverse effects of store layout designs, especially the free-form layout found in the first two studies suggest that other abstract attributes may be needed to clarify the effects of store layout designs. Hence, the third part uses a free elicitation technique to explore the abstract attributes that consumers use to classify the different store layout designs. This enhances understanding of the abstract attributes that differentiate store layout designs.

This chapter contributes to the retailing literature by providing insights into the potential impacts of store layout design on consumers' expectations and intention to visit. Evidence on the effects of store layout design as well as store layout design's concrete attributes (shelf length and shelf orientation) on intention to visit under different motivations is given. In addition, the underlying process to explain the impacts of store layout design on consumers' intention to visit the store is examined. Finally, practical guidelines of how store managers can select an appropriate store layout designs are suggested. This chapter is one of a few empirical studies that reveals the effects specifically for store layout design. The knowledge provided is suitable for predicting the effects of store layout design from the view of consumers in the situation that a store is new for them. 


\subsection{Theoretical framework}

\subsubsection{Store layout design}

Most consumers share the experience that, regardless of the products, some stores are inviting, while other stores feel uncomfortable even before entering. In today's markets, stores usually employ wide entrances or transparent windows which allow shoppers to see inside. Therefore, the store layout design can be easily recognized and accordingly be one of the main factors that influence such store perceptions (Puccinelli et al., 2009; Rintamäki, Kanto, Kuusela, Spence, 2006; Underhill, 2000). Baker and colleagues (2002) also support that store layout design is one of the store environmental factors shoppers use to decide whether or not to visit a store. In the current chapter, we examine the grid and free-form layouts.

The gid layatis a rectangular arrangement of displays and aisles that are placed parallel to one another. Mostly, the size and shape of the display areas and the length and width of the traffic aisles are homogeneous throughout the store. It is commonly used in the grocery sector such as in supermarkets and drug stores. For the retailer, this layout is claimed to be cost-efficient since it makes efficient use of store space (Levy \& Weitz, 2012; Lewison, 1994). The freformlayat involves an unrestricted arrangement of displays. It employs a variety of sizes, shapes, and styles of display allocated in an informal and unbalanced arrangement. It is mainly used by fashion stores but can also be seen in drug stores. Table 2.1 summarizes the key differences between the grid and free-form layouts, as these are currently conceptualized in the retail management literature. 
Table 2.1: Differences between the grid and free-form layout

\begin{tabular}{|c|c|c|}
\hline $\begin{array}{l}\text { Concrete } \\
\text { attribute }\end{array}$ & Grid layout & Free-form layout \\
\hline Shelf length & Long shelves (aisles) & Variety of shelf length \\
\hline $\begin{array}{l}\text { Shelf } \\
\text { orientation }\end{array}$ & Parallel shelves & $\begin{array}{l}\text { Shelves in an unrestricted } \\
\text { pattern }\end{array}$ \\
\hline Shelf height & High shelves & Variety of shelf height \\
\hline Shelf shape & Rectangular shelves & Variety of shelf shapes \\
\hline
\end{tabular}

\subsubsection{Impacts of store layout design on consumers' expectations and intention to visit}

The grid and free-form layouts likely bring different impacts on consumers' expectations/ perceptions of the store, and consequently on their intention to visit the store (Grewal, Baker, Levy, \& Voss, 2003; Griffin, Babin, \& Attaway, 1996). Following prior literature, these expectations likely center on two managerially-important constructs that shape the "expected shopping process", relating to the costs of shopping (i.e., effort / efficiency in the decision-making process) and the benefits of shopping (i.e., enjoyment with the shopping and the assortment) (Diehl, van Herpen, \& Lamberton, 2015). Efficiency and enjoyment need not be related, and stores can be both effortful and enjoyable at the same time (Iyengar \& Lepper, 2000). In addition to the expected shopping process, store layout design also influences overall perceptions about the store (store image) which affect intention to visit (Baker et al., 1994). The image of the store reflects other benefits that a store may offer such as merchandise price, merchandise quality and service quality. Perceptions toward store image thus potentially enhance or prevent store visit. In general, intention to visit the store should be higher when the expected shopping process and perceived store image are more positive (Baker et al., 1994; 2002; Kumar, G upta \& Kishore, 2014). 


\section{Shopping efficiency}

Store layout design can help consumers minimize their search and decisionmaking effort, by diminishing wasted steps, time, and effort in the shopping process (Cil, 2012). When consumers see an arrangement of shelves from the front of the store, they likely infer how easy or difficult it will be to walk around the store. Store layout design should thus influence the expected amount of effort needed when navigating through the store (Baker et al., 2002; Titus \& Everett, 1995), thereby affecting the expeted efficiengy of shopping in a store. The grid layout represents a clean and efficient shopping environment. With its simple pattern, the grid layout is claimed to facilitate product search (Levy \& Weitz, 2012) because the aisles are organized in a symmetric and an easily understandable pattern, allowing easy identification of where to go (Rayburn \& Voss, 2013). In contrast, a free-form layout can be less efficient because of its complexity. Consumers may think that they need to make extra steps to walk around in a free-form layout. We thus expect that:

H 1: A store with a grid layout has a higher expected shopping efficiency than a store with a free-form layout.

\section{Shopping enjoyment}

Many consumers seek enjoyment during their shopping trip. Retailers thus generally attempt to create shopping environments that enhance shopping enjoyment in addition to facilitating shopping efficiency (Arnold \& Reynolds, 2003; Vazquez \& Bruce, 2002), a process called 'shoppertainment' (Pine \& Gilmore, 1998). Customers who enjoy the shopping experience are claimed to pursue more unplanned purchases and to be more eager for future purchases (Bloch \& Richins, 1983; H. Kim \& Y. Kim, 2008). Unusual and interesting shopping environments can create entertainment for customers and enhance the store performance. 
The differences between the grid and free-form layouts could affect expected shopping enjoyment. The playful manner in which the shelves in the free-form layout are placed exposes people to various unexpected shelves and paths and may enhance a navigational challenge and an arousing shopping trip. This may contribute to expectations of a feeling of pleasure and fun. The free-form layout also provides customers with a perceived freedom to relax and move in any direction within the store (Baker et al., 1994). The grid layout, in contrast, provides a task-oriented environment and is generally seen as more boring (Machleit \& Eroglu, 2000; Titus \& Everett, 1995; Vrechopoulos, O'Keefe, D oukidis, \& Siomkos, 2004). Thus, we expect that:

H2: A store with a grid layout has a lower expected shopping enjoyment than a store with a free-form layout.

\section{Store image}

Store layout design also likely leads to a different overall image of the store as an upscale or downscale store (Baker et al., 1994). Currently, the grid layout is commonly used in discount stores because it facilitates efficient space allocation. The grid layout allows retailers to present a large number of products in a small space. In contrast, the free-form layout appears more in an upscale store. Since most consumers develop images for categories of stores (Mazursky \& Jacoby, 1986) and learn over time, it is likely that they will link an unknown store with stores they have seen. When they see a grid layout, they may automatically expect lower price and lower quality merchandise from the store (a discount store image). Also, they may expect lower service quality levels than provided by a store with a free-form layout (an upscale image). In support, research shows that specific attributes of stores are related to a high or upscale image versus a discount store image (Gardner \& Siomkos, 1986; Zimmer \& Golden, 1988). Baker and colleagues (1994) operationalized grid and free-form layout as part of the store design in their study and argued that the free-form layout is linked 
to a prestige-image environment and the grid layout to a discount-image environment. Hence, we propose that:

H3: Consumers perceive a more upscale store image for a store with the free-form layout than for a store with the grid layout.

\section{Intention to visit the store}

The impacts of store layout design on intention to visit the store are potentially determined by the expected shopping process and perceived store image. Research has supported the positive impacts of consumers' expectations and perceptions toward store choice criteria, including shopping efficiency and shopping enjoyment on intention to visit (Baker et al., 2002; Lu \& Seo, 2015; Shamsher, 2015; Srivastava \& Natu, 2014). The studies show that in both traditional retailing and online retailing, consumers report more intention to visit and revisit the store that they expect to enhance shopping efficiency and shopping enjoyment. Besides, most research shows that consumers generally report positive impacts of store image on intention to visit (Baker et al., 1994; Srivastava \& Natu, 2014). O ur prediction is thus based on previous research. Since the free-form layout is predicted to bring higher expected shopping enjoyment and an upscale image, we, therefore, predict higher intention to visit the stores with the free-form layout than the store with the grid layout. Following hypotheses are formed:

H 4a: Impacts of store layout design on intention to visit the store are mediated by expected shopping process (efficiency and enjoyment) and perceived store image.

H 4b: The free-form layout attracts higher intention to visit than the grid layout because it enhances higher expected shopping enjoyment and perceived store image although it brings lower expected shopping efficiency. 
Figure 2.1 provides a graphical display of the proposed relationships that will be tested.

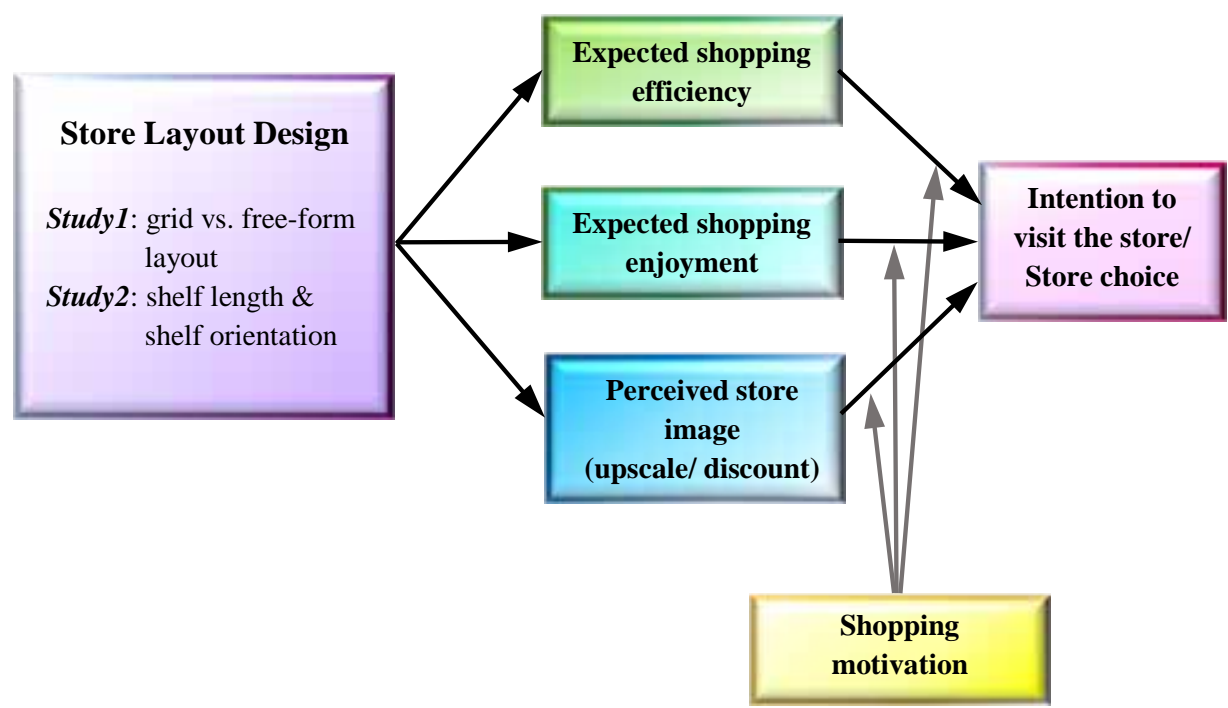

Figure 2.1: Conceptual framework

\subsection{Study 1: Grid versus free-form layout}

Study 1 investigates the effects of grid versus free-form layout on consumers' expectations about the shopping process, store image, and intention to visit the store. It simultaneously manipulates all four concrete attributes of store layout design that have been distinguished by prior retail literature in the conceptualization of grid versus free-form layout (see Table 2.1, p.36).

\subsubsection{Method}

\section{Participants}

Participants ( $\mathrm{n}=81,79 \%$ female) were D utch native speakers. Their age ranged from 16 to $83(M=35)$. Of the participants, $46 \%$ were employed, $41 \%$ student, $1 \%$ job seeker, and $12 \%$ retired or disabled. 


\section{Design}

The study had a 2-group (layout: grid vs. free-form) within-subject design. Presentation order was counterbalanced and controlled for in the analyses. The grid layout had high, long and rectangular shelves which were placed parallel to each other. The free-form layout had both high and low, long and short, rectangular and round shelves which were placed in a playful manner. Pictures and descriptions of the layouts were created so that participants could imagine the design of the grid and free-form layout (Appendix 2.1). The pictures were developed using SketchUp, a program that enables the 3D design of a store.

\section{Procedure}

Participants evaluated both stores via a computer-based questionnaire using Q ualtrics. They were asked to imagine that they would go shopping in the store. After seeing each of the two stores, participants were asked to indicate their expectations about shopping efficiency, shopping enjoyment, and store image, as well as their intention to visit the store. The study took approximately 12 - 15 minutes and as a reward, participants had a chance to win one of two €20 vouchers.

\section{Measures}

Expected shopping efficiency, shopping enjoyment, perceived store image and intention to visit the store were measured using sliders. Participants saw only the position of their answer without any numeric score. The answers were saved on a 0 - 100 point scale. Expetedshqpingefficiengywas measured with two items: 'This store is well organized' and 'I think I can find easily what I am looking for' on a 'strongly disagree - strongly agree' slider bar (cf. Beauchamp \& Ponder, 2010; $\left.\alpha=.91^{1}\right)$. Expeted shoping eijoment was based on the pleasure scale for retail

\footnotetext{
1 Reliability of the scales is calculated separately for a grid and a free-form layout. The reported Cronbach's $\alpha$ is an average of Cronbach's $\alpha$ of the grid and the free-form layout.
} 
environments developed by Donovan and Rossiter (1982). The items used in this study were 'D epressed - Contented', 'Unhappy - Happy', 'Unsatisfied Satisfied', 'Annoyed - Pleased' $(\alpha=.92)$.

Streimageis measured using items (product price, product quality, and service quality) based on prior research (Baker et al., 1994; K umar et al., 2014; Mazursky \& Jacoby, 1986; Zimmer \& Golden, 1988). Items came from the perceived quality indicator scale of D odds, Monroe and G rewal (1991), the monetary price perceptions from the study of Baker and colleagues (2002), and the retail service quality scale developed by Dabholkar, Thorpe and Rentz (1995). Items are shown in Appendix $2.2(\alpha=.88)$.

Intention to visit the stare were tapped by asking participants to indicate their agreement with the statement 'I would like to visit this store'. This was measured after participants saw each store.

\subsubsection{Analysis plan}

A repeated measure ANOVA was used to examine the main effects of store layout design and presentation order and their interaction on consumers' expected shopping process, perceived store image and intention to visit the store. Store layout design was included as a within-subject factor. Order of presentation and the interaction between store layout design and order of presentation were included as the between-subject factors.

The MEMORE macro for SPSS (Montoya \& Hayes, 2015) was used to test the indirect effect of store layout design on intention to visit the store where expected efficiency, expected enjoyment, and store image were mediators. The parallel multiple mediator model was selected for the analysis of the twocondition repeated measure design. 


\subsubsection{Results}

\section{Expected shopping efficiency}

In contrast to $\mathrm{H} 1$, results show that participants expected a marginally higher shopping efficiency in the store with a free-form layout than in the store with a grid layout $\left(\mathrm{M}_{\text {rree form }}=60.48\right.$ and $\left.\mathrm{M}_{\mathrm{G} \text { rid }}=51.51, \mathrm{~F}(1,79)=3.53, \mathrm{p}=.06\right)$. According to Cohen's standard, the effect of store layout design was quite small though $\left(\eta_{\mathrm{p}}^{2}=0.04\right)$. Neither order $(\mathrm{F}(1,79)=0.09, \mathrm{p}=.77)$ nor its interaction with store layout design $(\mathrm{F}(1,79)=0.49, \mathrm{p}=.49)$ had a significant influence on expected shopping efficiency.

\section{Expected shopping enjoyment}

As predicted by $\mathrm{H} 2$, participants expected a higher feeling of enjoyment in the store with a free-form layout than in the store with a grid layout $\left(\mathrm{M}_{\text {rree form }}=\right.$ 64.44 and $\left.\mathrm{M}_{\mathrm{G} \text { rid }}=48.46, \mathrm{~F}(1,79)=31.64, \mathrm{p}<.001\right)$. Store layout design showed the moderate impact on expected shopping enjoyment $\left(\eta_{\mathrm{p}}^{2}=.23\right)$. In addition, the order $x$ layout interaction was significant $\left(F(1,79)=3.88, p=.05, \eta_{\mathrm{p}}^{2}=0.05\right)$. Expected shopping enjoyment in the free-form layout was rated higher when this layout was presented after the grid layout $\left(\mathrm{M}_{\mathrm{G}-\mathrm{F}}=68.98\right)$ compared to when it was presented before the grid layout $\left(\mathrm{M}_{-\mathrm{E}}=60.02, \mathrm{p}<.05\right)$. The score for shopping enjoyment in a store with a grid layout did not depend on presentation order $\left(\mathrm{M}_{\mathrm{G}-\mathrm{F}}=47.30, \mathrm{M}_{-\mathrm{G}}=49.59, \mathrm{NS}\right)$. O verall, customers clearly expected more pleasure in a free-form layout than in a grid layout. 


\section{Perceived store image}

In line with our prediction (H3), the store with a free-form layout was perceived to have a more upscale store image than the store with the grid layout ( $\mathrm{M}_{\text {Free form }}$ $=57.84$ and $\left.\mathrm{M}_{\mathrm{G} \text { rid }}=48.69, \mathrm{~F}(1,79)=6.25, \mathrm{p}<.05\right)$. It showed a moderate size of effect $\left(\eta_{p}^{2}=.07\right)$. Neither presentation order nor the interaction was significant $\left(\mathrm{F}_{\text {presentation order }}(1,79)=2.21, \mathrm{p}=.14 ; \mathrm{F}_{\text {interaction }}(1,79)=1.68, \mathrm{p}=.20\right)$.

\section{Intention to visit the store}

A repeated measures ANOVA showed that participants reported higher intentions to visit the store with a free-form layout than the store with a grid layout $\left(\mathrm{M}_{\text {reer form }}=65.60\right.$ and $\left.\mathrm{M}_{\mathrm{G} \text { id }}=41.20, \mathrm{~F}(1,79)=41.41, \mathrm{p}<.001\right)$. As expected, results confirm a large impact of store layout design on intention to visit $\left(\eta_{\mathrm{p}}^{2}=.34\right)$. The order $\mathrm{x}$ layout interaction was significant and moderately strong $\left(F(1,79)=5.83, p<.05, \eta_{\mathrm{p}}^{2}=.07\right)$. The difference was stronger when the free-form layout was seen first than when the grid layout was seen first (grid first: $\mathrm{M}_{\text {Free form }}=72.25$ and $\mathrm{M}_{\text {Grid }}=38.52, \mathrm{p}<.001$; free-form first: $\mathrm{M}_{\text {Free form }}=59.12$ and $\mathrm{M}_{\mathrm{G} \text { id }}=43.80, \mathrm{p}<.05$ ), yet the free-form layout always had a higher intention to visit.

\section{Direct and indirect effects of store layout design on intention to visit the store}

The results revealed both a direct effect $(b=8.59, p=.001)$ and indirect effects of store layout design on intention to visit the store through expected shopping enjoyment $(b=15.50 ; 95 \% \mathrm{CI}[9.43,22.13])$ and marginally through expected shopping efficiency $(b=1.73 ; 90 \% \mathrm{CI}[0.07,4.18])$. This implies that, as expected, shopping enjoyment and (marginally) shopping efficiency mediated the effect of store layout design on intention to visit the store. In contrast with our expectations, no mediation effect of store image was found on intention to visit $(b=-0.15 ; 95 \%$ CI $[-0.41,0.10])$. 
All in all, the free-form layout attracted higher intention to visit than the grid layout because the free-form layout induced higher expected shopping efficiency and higher expected shopping enjoyment. Therefore, $\mathrm{H} 4 \mathrm{a}$ and $\mathrm{H} 4 \mathrm{~b}$ are partly supported.

\subsubsection{Discussion}

Study 1 has shown that a store with a free-form layout triggers expectations of shopping enjoyment and an upscale store image to a larger extent than a store with a grid layout. O pposite to what we expected, we also find a marginal effect indicating that expectations of shopping efficiency tend to be higher for the store with the free-form layout than for the store with the grid layout. In general, participants in our study have a higher intention to visit a store with a free-form layout than a store with a grid layout. O ur findings also confirm the mediating effect of both expected shopping efficiency and expected shopping enjoyment.

In conclusion, most of our findings confirm our expectations about the effect of the grid and free-form layouts, with a notable exception for the effects of layout on shopping efficiency. A potential reason may be that the effects of store layout design on consumers' expectations differ from the effects on real experience stated in the retailing literature (Levy \& Weitz, 2012). Another reason might be that the grid and the free-form layouts are different by multiple aspects: the grid layout contains long shelves that are placed parallel, whereas the free-form layout contains shorter shelves that are placed at various angles. It could be that consumers respond to the layout in the different ways to shelf length and shelf orientation, with one improving expected efficiency and another deteriorating expected efficiency. The next study explores this in more detail by investigating the effects of these two underlying attributes. 
In addition, a specific shopping context expressed as the dominant shopping motivation will be examined. This factor is important because consumers shop according to different purposes/motivations over time, and the determinants of intention to visit the store may be specific to each shopping trip. Consequently, one store layout design is probably not always preferred over another. Intention to visit the store and reasons behind choice made by the same person likely changes over shopping trips. The underlying reasons probably depend on the personal shopping motivation. In the next section, we will discuss store layout design's attributes (length and orientation) as well as elaborate shopping motivation and its possible moderating roles.

\subsection{Extension of the theoretical framework}

\subsubsection{Shelf length and shelf orientation}

Shelf length and shelf orientation are key concrete attributes that are easily noticeable but to our knowledge, there are no empirical studies in retailing that examine their effects. We will provide speculations about how shelf length and shelf orientation may affect the variables of interest in our model, without formally stating hypotheses, due to the exploratory nature of these effects.

\section{Shelf length}

Length of shelves likely determines perceived ease of navigating, browsing, and finding the right products (Cil, 2012), because shelf length affects the distance that consumers need to walk before being able to go to a different aisle. Short shelves allow consumers to make a short cut, whereas long shelves restrict them to follow a route along these shelves. As most consumers tend to walk short distances into aisles (Larson et al., 2005), this could affect expectations for shopping efficiency. Additionally, we speculate that the use of short shelves may also potentially stimulate browsing due to the more open area, and this could 
increase expected shopping enjoyment compared to longer shelves. Moreover, it is likely that shelf length might also affect perceived store image because of the common use of long versus short shelves in existing retail outlets. Long shelves allow retailers to display a large number of products and they tend to be favored by discount stores, whereas more upscale stores often use shorter shelves to introduce a sense of luxury. Therefore, we speculate that consumers perceive a more downscale image when they see a store with long shelves as opposed to the more upscale image associated with shorter shelves.

\section{Shelf orientation}

O rientation of shelves, that is, whether shelves are placed in parallel or at different angles, likely influences the effort required when shopping. A simple pattern of straight shelves placed parallel requires less effort in shopping, and thus can facilitate product search (Levy \& Weitz, 2012). In contrast, expected shopping enjoyment is likely enhanced when shelves are placed at diverse angles compared to when the shelves are placed straight and parallel. The use of diverse angles for the shelves should create more visual variation and may introduce excitement and surprise in product search and browsing. Therefore, we speculate that consumers expect higher shopping enjoyment in a store with shelves at diverse angles than in a store with parallel oriented shelves. In addition, perceived store image may be affected as well. It is likely that placing shelves at different angles increases a sense of uniqueness of the store, which is linked to an upscale image, whereas a store with parallel oriented shelves might be linked to a discount store image as it looks more condensed.

Effects of shelf length and shelf orientation on intention to visit the store may, however, differ among shopping situations such as shopping motivation. As people with different motivation look for different benefits, one type of attributes may be preferred over another depending on the shopping motivation in that visit. 


\subsubsection{The moderating role of shopping motivation}

Two main shopping motivations that a person may hold during a shopping trip have been distinguished based on consumers' shopping goals (Babin et al., 1994). A utilitarian shoppingmotivation refers to a desire to achieve functional or practical benefits (goals). Customers with only a utilitarian shopping motivation shop because of necessity. They want to get things done as efficiently as they can (Jones, Reynolds, \& Arnold, 2006) and perceive no internal satisfaction from the shopping trip itself (Kaltcheva \& Weitz, 2006). In contrast, a heedonic shoping motivationinvolves a desire to satisfy an emotional goal rather than to complete a certain task (Holbrook \& Hirschman, 1982). Consumers with a hedonic shopping motivation value the pleasure of the shopping experience (Babin et al., 1994; Fischer \& Arnold, 1990). The two motivations can occur independently from each other, and consumers can thus have mainly a utilitarian, mainly a hedonic, or both a utilitarian and a hedonic shopping motivation during a shopping trip (Babin et al., 1994; Li et al., 2004). In our investigation, we will examine the more extreme cases in which one or the other dominates, that is, in which the shopping trip is characterized mainly by a utilitarian shopping motivation or mainly by a hedonic shopping motivation.

Under these different shopping motivations, consumers are predicted to prefer different store layout design's attributes. During a shopping trip that is characterized by a utilitarian motivation, consumers are likely to prefer a layout in which it is easy to locate products in the store, and which contributes to an efficient and fast shopping trip (i.e., layouts with short shelves or parallel orientation). In contrast, under a hedonic shopping motivation, consumers are likely to prefer a layout using exciting and complex displays that may give a pleasant and entertaining shopping experience (i.e., a playful orientation; Holmqvist \& Lunardo, 2015; Kaltcheva \& Weitz, 2006). In other words, motivation should moderate the effects of store layout design on intention to 
visit the store. This effect will be explored in study 2.

\subsection{Study 2: Shelf length and orientation}

Shelf length and orientation are two key concrete attributes of store layout design, which were manipulated simultaneously in Study 1, in line with the conceptualization proposed in the retailing literature. Because the underlying attributes have, to the best of our knowledge, not been examined empirically, there is a need for a systematic approach in examining the effects of store layout design's attributes. We offer a first start to as such systematic approach by examining the two key attributes of shelf length and orientation. To disentangle their effects and explore if these indeed lead to similar consumer expectations (as one would expect if these are attributes underlying abstract conceptualizations of grid versus free-form layout), Study 2 manipulates these attributes separately.

In addition to this, Study 2 also differs from Study 1 in a few other ways. Specifically, the moderating role of shopping motivation is explored. In addition to general intention to visit (measured in Study 1), intention to visit the store and willingness to spend time under both utilitarian and hedonic motivation are investigated. To assess the robustness of effects, Study 2 furthermore uses a between-subject design, so that participants do not have a chance to compare between store layout designs. 


\subsubsection{Method}

\section{Participants}

The online experiment was sent to 290 D utch persons, of whom 190 completed the questionnaire (response rate of $66 \% ; 60 \%$ female). Participants' age ranged from 17 till 79 years $(M=33.04)$. Of the participants, 36.32\% were employed, $52.11 \%$ student, $5.26 \%$ job seeker, and $6.32 \%$ retired or disabled. Gender, age, and occupation were not significantly different among conditions.

\section{Design}

The experiment had a 2 (shelf length: short vs. long) x 2 (shelf orientation: parallel vs. diverse angles) between-subject design. Pictures and descriptions of each store layout design were created (see Appendix 2.3). Shelf length was manipulated by either placing long shelves that run the whole length of the store or splitting each of these into two shorter shelves with space in between. Shelf orientation was manipulated by placing shelves straight and parallel to the wall and to each other or placing shelves in diverse angles (not parallel to each other). Descriptions contained information on the length of the shelves and their angle, as well as whether it is possible to cut across and skip parts of an aisle.

\section{Procedure}

The procedure was identical to that in Study 1, except that only one store was evaluated. Besides, participants additionally reported their intention to visit the store and willingness to spend time under both utilitarian and hedonic shopping motivation. The utilitarian shopping motivation was described as follows: "Imagnethat you are shoping with a predtemineel shoping list. Yau only want to gather theproduds on your list and then immedately leave the store" The hedonic shopping motivation was described as: "Imaginethat thistimeyaugshoppingbecauseyaulikeit. Yauwant toenjoy theshopingactivityitsdf andarendinneed of anyproduds" The survey 
took about 15 minutes and participants had a chance to receive one of five $€ 20$ vouchers in return.

\section{Measures}

Measures were identical to Study 1, with the following exceptions. Expeted shoppingefficiengywas measured with these additional items added to the items of Study 1: 'This store would enable me to search and buy products fast', 'This store would save me shopping time', and 'I think it will be easy to move without obstructions in this store' on a 'strongly disagree - strongly agree' slider bar (cf. Seiders, Berry, \& Gresham, 2000; $\alpha=$.94). For expeted shoping enjoyment, statements were used that more explicitly specify the expected entertaining feeling. Items were: 'I think it will be easy to browse in this store', 'I think that this store would give entertaining shopping experiences', 'I think shopping in this store will be pleasant', and 'I think shopping in this store will be fun' (cf. Nysveen, Pederson, \& Thorbjørnsen, 2005; $\alpha=.85$ ).

As participants saw only one store, consumers' intention to visit the stare under utilitarian and hedonic motivation was asked by the question "Would you like to visit this store?", for each shopping motivation. Participants indicated their answer with "yes" or "no". Willingness to spend time under each shopping motivation was measured by asking "If you have unlimited time for shopping, how much time would you be willing to spend in this store?" Answer options were treated as a 1 - 7 scale that represented 'Less than 5 minutes', '5-10 minutes', '10-15 minutes', '15-20 minutes', '20-25 minutes', '25-30 minutes' and 'More than 30 minutes'.

\subsubsection{Analysis plan}

Univariate ANOVAs were used to analyze the main and interaction effects of shelf length and shelf orientation (independent variables) on expected shopping 
efficiency, expected shopping enjoyment, perceived store image, and intention to visit the store. The PROCESS macro for SPSS (Hayes, 2013) was applied to explore the direct and indirect effects of shelf length, shelf orientation and their interaction on intention to visit the store. The parallel multiple mediator model (model 4 with coded shelf length: -0.5 long, 0.5 short, and coded shelf orientation: -0.5 parallel, 0.5 diverse angles) was selected. The model included expected shopping efficiency, expected shopping enjoyment and perceived store image as mediators.

Moreover, two separated logistic regressions based on shopping motivation were employed to examine the moderating role of shopping motivation on the total and indirect effects of shelf length and shelf orientation on intention to visit the store. The models included shelf length (-0.5: long, 0.5: short), shelf orientation (-0.5: parallel, 0.5: diverse angles) and their interaction as predictors, and intention to visit as dependent variable (1: yes, 0: no). Besides, two separate univariate ANOVAs were used to analyze willingness to spend time under each motivation.

\subsubsection{Results}

\section{Expected shopping efficiency}

Results showed significant effects of both shelf length $(F(1,186)=18.08, p<$ $.001)$ and shelf orientation on expected shopping efficiency $(F(1,186)=122.02$, $\mathrm{p}<.001)$. Shelf length and shelf orientation exerted a moderate $\left(\eta_{\mathrm{p}}^{2}=.09\right)$ and a strong $\left(\eta_{\mathrm{p}}^{2}=.40\right)$ effect, respectively. In line with our suggestion, participants expected a higher shopping efficiency in the store with short shelves $(M=49.23)$ than in the store with long shelves $(M=36.00)$. Moreover, participants also expected higher shopping efficiency in the store with parallel oriented shelves $(\mathrm{M}=57.56)$ than in the store with shelves placed in diverse angles $(\mathrm{M}=28.31)$. There was no significant interaction effect $(\mathrm{F}(1,186)=0.49, \mathrm{p}=.49)$. 


\section{Expected shopping enjoyment}

We also found significant effects of shelf length $(F(1,186)=11.53, p=.001)$ and of shelf orientation $(\mathrm{F}(1,186)=47.74, \mathrm{p}<.001)$ on expected shopping enjoyment. Concerning the effect size, the effect of shelf length was small $\left(\eta_{\mathrm{p}}^{2}=\right.$ .06), whereas the effect of shelf orientation was moderate $\left(\eta_{\mathrm{p}}{ }^{2}=.20\right)$. The interaction had no significant impact $(\mathrm{F}(1,186)=0.00, \mathrm{p}=.99)$. We suspected that a space between short shelves would introduce higher expectations about shopping enjoyment, and results indeed show that participants expected a higher shopping enjoyment in a store with short shelves $(M=51.05)$ than a store with long shelves $(\mathrm{M}=41.05)$. Interestingly, participants expected lower shopping enjoyment in a store with diverse angles shelves $(M=37.18)$ than in a store with parallel oriented shelves $(M=55.28)$, while our initial notion was that the effect would run in the opposite direction.

\section{Perceived store image}

Results showed only a significant effect of shelf orientation $(F(1,186)=13.51$, $\mathrm{p}<.001$ ). In contrast to our initial thoughts, the store with parallel oriented shelves was perceived to have a more upscale store image $(M=53.36)$ than the store with diverse angles shelves $(M=47.07)$. The effect was however small $\left(\eta_{\mathrm{p}}^{2}=.07\right)$. Neither shelf length nor the interaction of shelf length and shelf orientation significantly influenced perceptions of store image $\left(\mathrm{F}_{\text {length }}(1,186)=\right.$ $2.43, \mathrm{p}=.12$ and $\mathrm{F}_{\text {length }}{ }^{*}$ orientation $\left.(1,186)=1.05, \mathrm{p}=.31\right)$.

\section{Intention to visit the store}

We found significant effects of shelf length $(F(1,186)=10.88, p=.001)$ and of shelf orientation $(F(1,186)=23.06, p<.001)$ on intention to visit the store. The shelf length had a small impact $\left(\eta_{\mathrm{p}}{ }^{2}=.06\right)$ whereas the shelf orientation had a moderate impact on intention to visit $\left(\eta_{\mathrm{p}}^{2}=.11\right)$. Participants reported a higher intention to visit the store with short shelves $(M=52.00)$ than to visit the store with long shelves $(M=40.36)$ and a higher intention to visit the store with 
parallel oriented shelves $(M=54.30)$ than to visit the store with diverse angles shelves $(M=38.32)$. The interaction effect was not significant $(F(1,186)=0.06$, $\mathrm{p}=.80)$.

\section{Direct and indirect effects of store layout design's attributes on intention to visit the store}

Results showed that the effects of shelf length were fully and uniquely mediated by expected shopping enjoyment $(b=6.83 ; 95 \%$ CI $[1.63,12.82])$. The effects of shelf orientation were fully mediated by a combination of shopping enjoyment $(\mathrm{b}=-13.99 ; 95 \%$ CI [-21.38, -7.59] and perceived store image $(\mathrm{b}=-1.84 ; 95 \%$ CI $[-4.26,-0.06])$. Again, there was no significant direct and indirect effect of the interaction between shelf length and shelf orientation.

\section{The moderating role of shopping motivation}

\section{1). Themodeatingrode of shoppingmativation on thetdal effets of starelayait design's attributes onintention tovisit thestare}

Participants reported their intention to visit the store they saw (yes/ no) under a specific motivation. Results showed that the stores with short shelves led to the higher probability to be visited than those with long shelves under both motivations (utilitarian: $\mathrm{P}_{\text {short }}=0.56$ and $\mathrm{P}_{\text {long }}=0.43, \mathrm{e}=1.68, \chi^{2}=8.01, \mathrm{p}<.01$; hedonic: $\mathrm{P}_{\text {short }}=0.71$ and $\left.\mathrm{P}_{\text {long }}=0.62, \mathrm{e}=1.47, \chi^{2}=4.91, \mathrm{p}<.05\right)$. The stores with parallel oriented shelves also attracted the higher probability to be visited than those with diverse angle shelves, regardless of shopping motivations (utilitarian: $\mathrm{P}_{\text {parallel }}=0.65$ and $\mathrm{P}_{\text {diverse-angles }}=0.34, \mathrm{e}=0.28, \chi^{2}=48.08, \mathrm{p}<.001$; hedonic: $\mathrm{P}_{\text {parallel }}=0.74$ and $\mathrm{P}_{\text {diverse-angles }}=0.59, \mathrm{e}=0.50, \chi^{2}=15.99, \mathrm{p}<.001$ ). In addition, the interaction effect of shelf length and shelf orientation on the decision to visit under hedonic motivation was significant $\left(e x=0.68, \chi^{2}=4.91\right.$, $\mathrm{p}<$.05). Results and Figure 2.2 show that under hedonic motivation, shelf length significantly influenced the decision to visit exclusively when the shelves were 
placed in parallel $\left(\mathrm{P}_{\text {short-parallel }}=0.90\right.$ and $\left.\mathrm{P}_{\text {long-parallel }}=0.65\right)$, but not when they were placed in diverse angles $\left(\mathrm{P}_{\text {short-diverse angles }}=0.50\right.$ and $\left.\mathrm{P}_{\text {long-diverse angles }}=0.50\right)$.

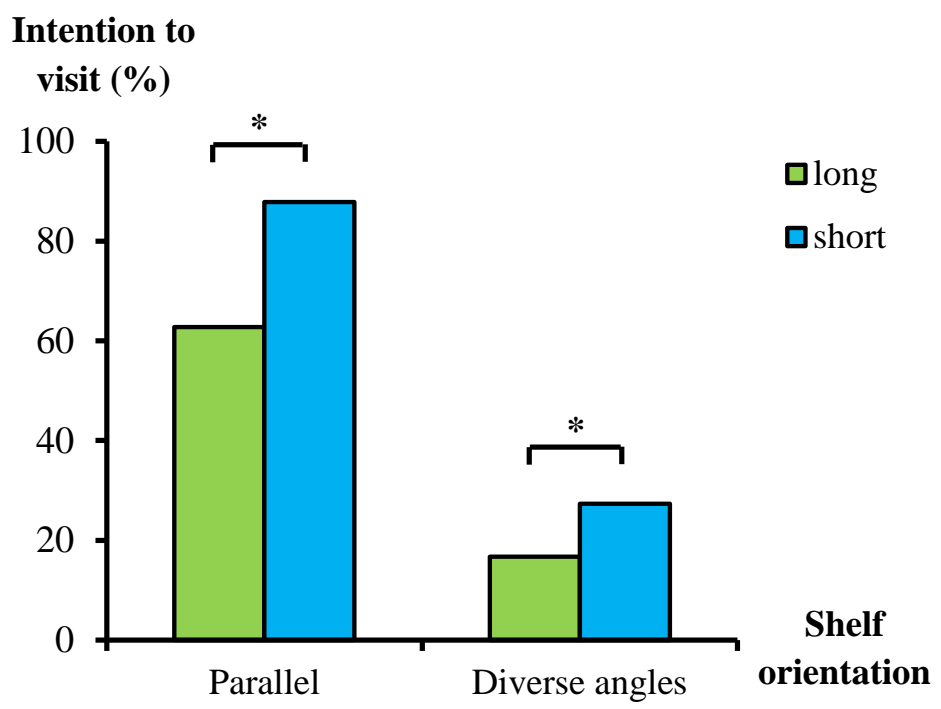

Utilitarian Motivation

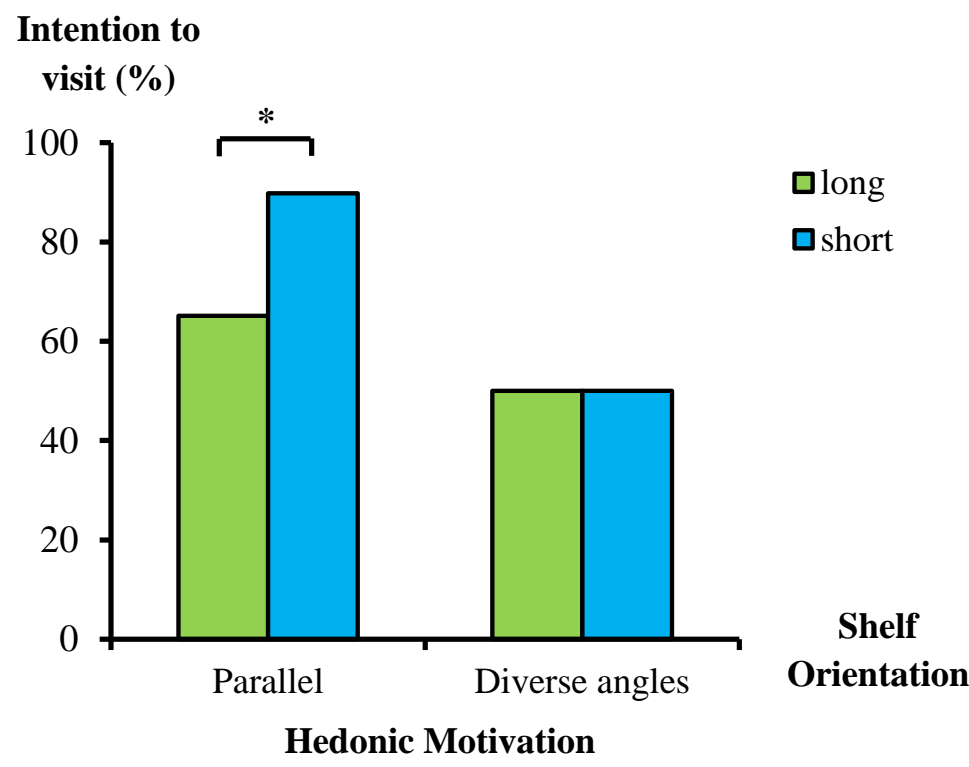

Figure 2.2: Intention to visit the store under utilitarian (top figure) and hedonic motivation (bottom figure) 


\section{2). Themodaratingrde of shopingmodivation on theindiret ffeets of starelayat desig's attributes onintention tovisit thestare}

Results showed a different mediation process for the two shopping motivations (shown in Table 2.2). Under utilitarian motivation, results showed that effects of shelf length and shelf orientation on intention to visit were significantly and fully mediated by expected shopping efficiency ( $\mathrm{b}_{\text {ength }}=0.61 ; 95 \%$ CI $[0.14,1.54]$; $b_{\text {rientation }}=-1.27 ; 95 \%$ CI $\left.[-2.66,-0.38]\right)$ and expected shopping enjoyment $\left(\mathrm{b}_{\text {ength }}=0.24 ; 95 \%\right.$ CI $[0.01,0.71] ; b_{\text {rientation }}=-0.50 ; 95 \%$ CI [-1.18, -0.01$\left.]\right)$. In contrast, under hedonicmotivation the indirect effects of both shelf length and shelf orientation on intention to visit were fully and uniquely mediated by expected shopping enjoyment alone ( $\mathrm{b}_{\text {ength }}=0.48,95 \%$ CI $[0.09,1.07]$ and $b_{\text {rientation }}=-0.98,95 \%$ CI $\left.[-1.84,-0.40]\right)$.

\section{3). Themodkatingrdeof shoppingmotivation on thetdal ffeets of starelayaut design's attributes on willingness tospend time}

Results showed only significant effects of shelf orientation on willingness to spend time (utilitarian motivation: $\mathrm{F}(1,186)=3.92, \mathrm{p}<.05$; hedonic motivation: $F(1,186)=14.39, p<.001$ ). The effect is however quite small (utilitarian motivation: $\eta_{\mathrm{p}}^{2}=0.02$, hedonic motivation: $\eta_{\mathrm{p}}^{2}=0.07$ ). On average, participants with both motivations were willing to spend more time in a store with parallel oriented shelves $\left(\mathrm{M}_{\text {utilitaran }}=2.12\right.$ and $\left.\mathrm{M}_{\text {hedonic }}=3.37\right)$ than in a store with diverse angles shelves $\left(\mathrm{M}_{\text {tilitaran }}=1.81\right.$ and $\left.\mathrm{M}_{\text {nedonic }}=2.52\right)$. The main effect of shelf length and the interaction were not significant under both motivations (utilitarian motivation: $F_{\text {length }}(1,186)=1.54, p=.22$ and $F_{\text {length }}{ }_{\text {orientation }}(1,186)=$ $1.21, p=.27$; hedonic motivation: $F_{\text {length }}(1,186)=2.81, p=.10$ and $F_{\text {length }}{ }^{*}$ inentation $(1,186)=0.10, p=.75)$. 


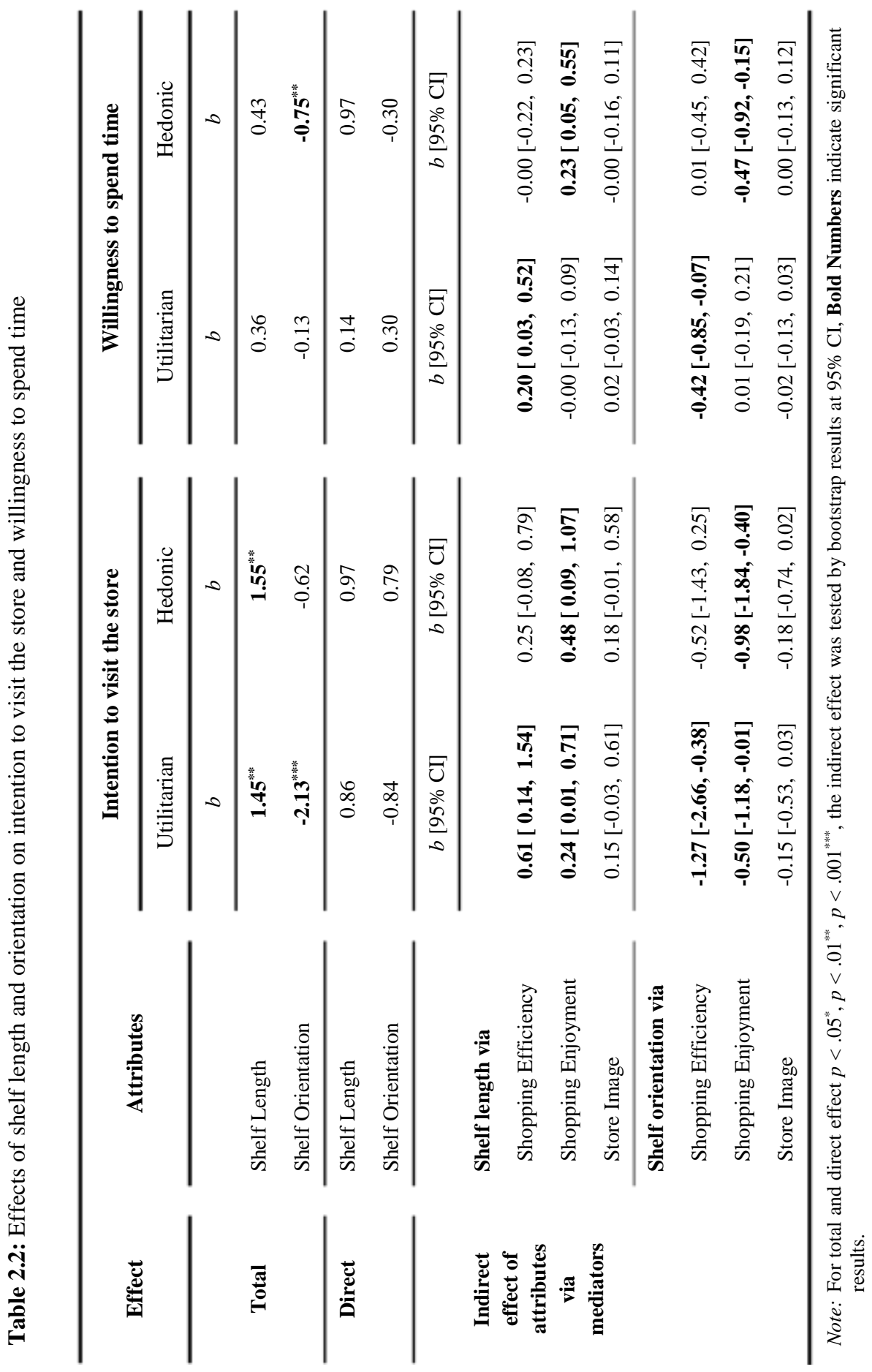




\section{4). Themodaratingrde of shopingmodivation on theindiret ffeets of starelayat design's attributes on willingness tospend time}

In line with our suggestions, results showed that under utilitarian mdivation the effect of shelf orientation on willingness to spend time was fully mediated by expected shopping efficiency ( $b_{\text {rientation }}=-0.42 ; 95 \%$ CI $[-0.85,-0.07]$ ). Conversely, under hedonicmotivation the effect of shelf orientation on willingness to spend time was fully mediated by expected shopping enjoyment $\left(b_{\text {rientation }}=-0.53 ; 95 \%\right.$ CI $\left.[-0.98,-0.21]\right)$. Store image did not mediate the effects of shelf orientation on willingness to spend time.

\subsubsection{Discussion}

This second study has disentangled the effects of two concrete attributes, shelf length, and shelf orientation, that differ between the grid and the free-form layout. Moreover, the moderating effects of shopping motivation were examined. These latter results are in line with expectations. Specifically, consumers with a hedonic shopping motivation base their intention to visit the store on expected shopping enjoyment. In contrast, consumers with a utilitarian shopping motivation base their intention to visit the store and willingness to spend time on shopping efficiency, even though they do not ignore shopping enjoyment. The effects of shelf length and shelf orientation, however, are only partially in line with expectations and the results of Study 1 and cast doubt on the distinction between the grid and free-form layout.

The effects of shelf length are consistent with our prediction and with the effects of layout found in Study 1. Participants report higher expected shopping efficiency and enjoyment as well as higher intention to visit the store and willingness to spend time for a store with short shelves than for a store with long shelves. Yet, for shelf orientation, the results differ from expectations. Contrary to our proposition that placing shelves in diverse angles could stimulate the fun 
of shopping, results show negative effects on all constructs. This is especially troubling because both shelf length and shelf orientation are assumed to determine the distinction between free-form and grid layouts, with free-form layout having short and diverse angles shelves as opposed to the long and parallel shelves found in the grid layout. Thus, whereas the first study indicated that the free-form layout is evaluated more positively than the grid layout, the current study has shown that this does not imply that all underlying attributes of the free-form layout are positively evaluated. Using shorter shelves is evaluated positively, but placing shelves in diverse angles is not. The next study, Study 3 , will explore why these differences occur. Specifically, as the concepts of grid versus free-form layout can broadly lead to more possible impacts than stated in the theory, the subsequent study explores consumer perceptions in more detail, using self-generated distinctions between store layout designs. The study aims to find additional variables that may help explain the impacts of store layout design.

\subsection{Study 3: Identifying the underlying perceptions that differentiate store layout designs}

This study takes a qualitative bottom-up approach building on means-end chain theory (Gutman, 1982; Lin \& Yeh, 2013), which proposes that consumers' inferences about achieving shopping goals find their basis in relevant consequences ("what the store has to offer them") that result from attribute perceptions regarding the store ("what the store is like"). To this purpose, we expose participants to the stimulus materials from Studies 1 and 2 in a systematic manner (using Kelly's Repertory G rid; Steenkamp, van Trijp, \& Berge, 1994) to elicit their perceptions regarding similarities and differences of alternative store layout designs. As Repertory G rid tends to yield relatively concrete attributes (Steenkamp \& van Trijp, 1997), we also ask consumers to interpret the identified attributes in terms of shopping consequences and shopping process. To allow 
unguided free elicitation, the stimulus material is presented visually, without the verbal descriptions that we used in Studies 1 and 2.

\subsubsection{Method}

\section{Participants}

Participants were 18 international students from various nationalities $(60 \%$ female; age between 20 and 40 years with a mean age of 24).

\section{Procedure}

In an adapted version of Kelly's Repertory Grid, participants were presented with all 20 possible "triads" of combinations of 3 out of the 6 store layout designs ( 2 from Study 1 and 4 from Study 2). These triads were presented online in random order. For each triad, participants were asked to group the layouts into two that were (more) similar to each other and distinct from the third. This was guided by the question "Please look at the stores bodow and sdet the store that is diffeent from the ther two stares inyaur qinion. In which way dbyau think the the two stresarealikeanddifferentfromyoursdetedstore? Think of thepositiveandnegativefeatures which would affeet your shoping trips and you would baseyour hiceon when you sdet a stareto visit." Participants subsequently typed in both how they would describe the two similar stores and how they would describe the third store that is different. As a result, two attributes were elicited per triad, which may or may not be exact antonyms. If exact antonyms were provided, these were counted as one attribute and coded by their endpoint (e.g., long vs short). In the instructions, participants were encouraged to mention as many attributes as possible, rather than repeating the same associations over and over again. Hence the focus is on an identification of associations, not on a quantitative description of the frequency with which associations occur. For each elicited attribute pair per triad, participants were asked to articulate the relevant consequence (in terms of shopping process), by describing how the store attributes that they generated 
could influence their shopping trip. Participants were allowed to spend as much time as they wanted. The survey took about 20 - 25 minutes and at the end, participants received a small monetary payment for their participation (2.50€).

\subsubsection{Analysis plan}

Out of the maximum possible 720 open-ended answers, 439 different verbalizations were obtained, because several triads were not completed, and many participants used antonyms. These verbalizations were content analyzed and grouped into verbalizations with similar meaning. These concerned (a) concrete physical attributes of the layouts (height, length, orientation, shape, and "other", consisting of number of shelves and product presentation), (b) abstract perceptual attributes of the store layout designs (complexity, diversity of arrangement, diversity of shelf shapes, clearness, orderliness, organization, and spaciousness), and (c) consequences with regards to the shopping process (ability to look and see products, accessibility, comfortability, pleasure, interestingness, store style and decoration). In a final step in the analysis, these groupings were combined into broader categories of (a) physical shelf characteristics (concrete attributes), (b) the abstract attributes of complexity, orderliness, and spaciousness, and (c) the shopping process consequences.

In addition, the level of each coded verbalization (e.g., short or long for shelf length) was assigned to store layout designs. When two stores were perceived as similar (e.g., both short shelves) and different from the third store (e.g., long shelves), each of the three stores was assigned with the relevant attribute level. In 104 triads participants used different attributes to describe the similarity and difference between store layout designs. In these cases, attribute levels were assigned to all layout designs in the triad by using the opposite polar of the mentioned levels. For example, when the similar stores were described as having 
short shelves and the different store was described as having less space, we assigned the two similar stores with short shelves and more space and assigned the different store with long shelves and less space. The reason of assigning these levels to all stores in the triad is that participants were explicitly asked how the two stores are similar and different from another store. So, it can be assumed that the mentioned attributes should apply to all stores in the triad.

\subsubsection{Results}

Table 2.3 shows content-coded verbalizations (i.e., concrete attributes, abstract attributes and consequence related attributes) that participants used to distinguish store layout designs. Figure 2.3 indicates the level of coded verbalization/ attributes that consumers used to describe each store layout design (e.g. short/ high shelf, short/ long length, less/more variety of shapes, high/ low complexity, high/low shopping efficiency).

\section{Concrete attributes of store layout design}

The content-coded verbalizations of concrete attributes reflect the manipulated differences between layouts (see Table 2.3). Examining the store perceptions based on assigned attributes, depicted in Figure 2.3, confirms that participants not only mentioned the manipulated concrete attributes, but also used these in distinguishing between layout designs as expected. Specifically, participants recognized the key attributes of the grid and free-form layout applied in Study 1 (top row in Figure 2.3), in terms of their differing shelf lengths, shelf orientations, shelf shapes, and shelf heights. The same holds (pictures in the second and third rows in Figure 2.3) for the store layout designs from Study 2 that were systematically varied in shelf lengths and shelf orientations. 
Table 2.3: Consumers' perceptions toward the store

\section{\# mentioned}

\section{Factor}

\section{Concrete Attributes}

Shelf orientation 67

Shelf length 66

Shape of shelves

Height of shelves

Other (e.g. number of shelves, product presentation)

\section{Abstract Attributes}

Diversity of arrangement/ walking direction 20

Complexity

Diversity of shelf shape

10

$$
\text { (Total = 162) }
$$

(2)

Organization

Order

Clearness

Space

\section{5}

42

9

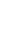

Complexity

$($ Total $=48)$

10
Orderliness

$($ Total $=116)$

\begin{tabular}{ccc}
\hline Space & 32 & $\begin{array}{c}\text { Spaciousness } \\
\text { (Total }=32 \text { ) }\end{array}$ \\
\hline
\end{tabular}

\section{Consequences}

Accessibility (to products or shelves)

$\begin{array}{cc}42 & \text { Shopping } \\ 5 & \text { Efficiency } \\ 2 & \text { (Total }=49 \text { ) }\end{array}$

Ability to look and see products throughout the store 2

Convenience

Comfortability

Interesting / Attractive

14

Pleasure / Enjoyment

6

3

\begin{tabular}{lll}
\hline Store Image & 5 & Image (Total = 5) \\
\hline Other consequences (e.g. safety) & 4 & Other (Total = 4) \\
\hline
\end{tabular}

Note: The left column shows content-coded verbalization consumers used to distinguish the store layout designs, the middle column shows a number of time that each verbalization is mentioned, and the right column shows the general categories that each verbalization is grouped. 


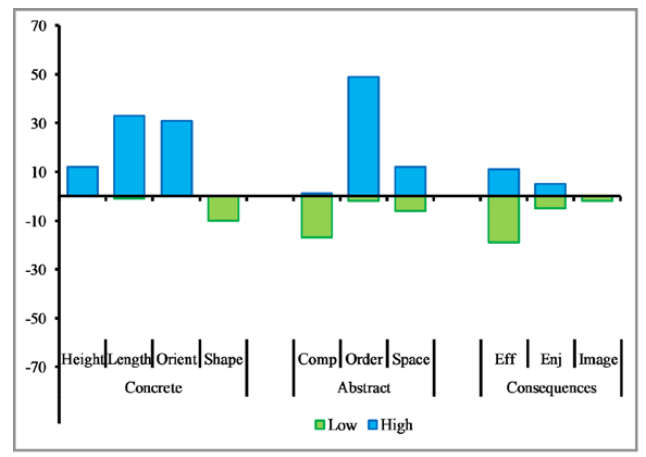

Grid (Study1)

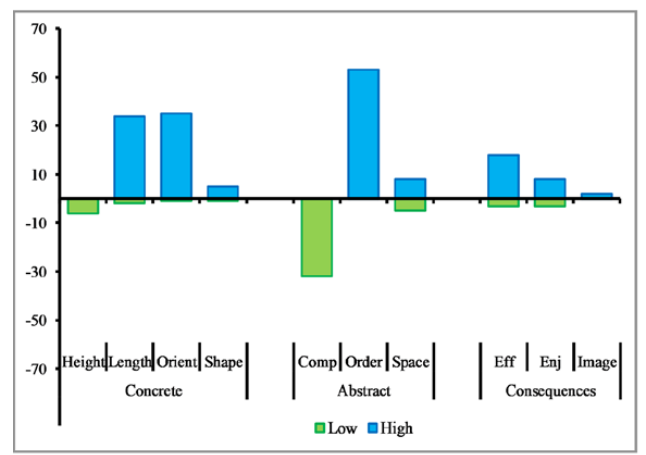

Long-parallel shelves (Study 2)

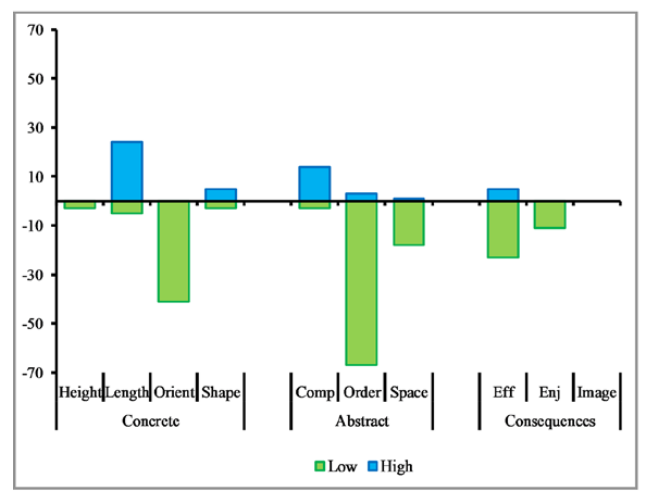

Long-diverse angles shelves (Study 2)

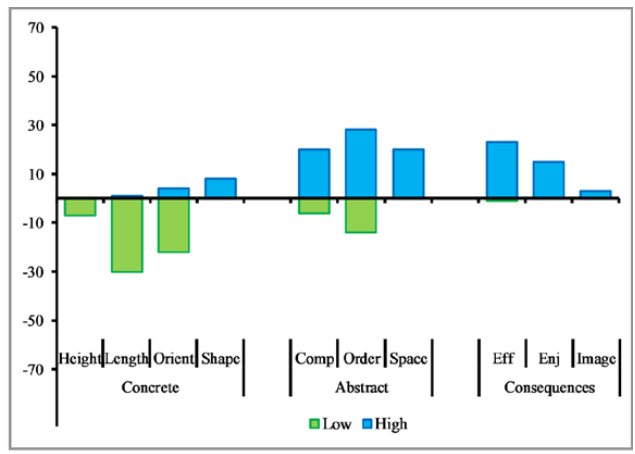

Free-form (Study1)

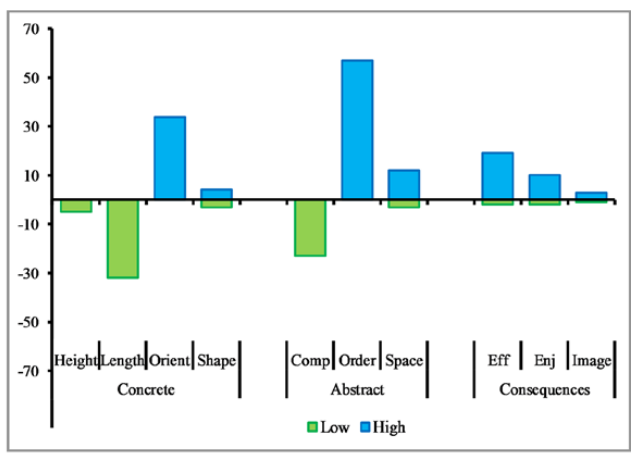

Short-parallel shelves (Study 2)

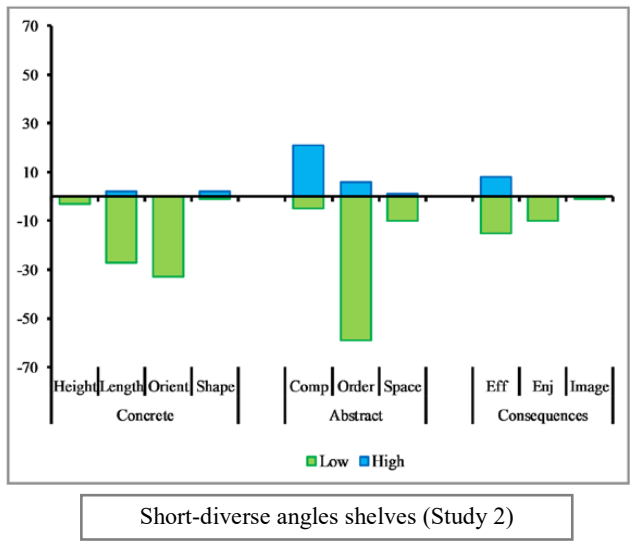

Figure 2.3: Consumers' perceptions toward store layout designs (elicitation task)

Note: Bar chart indicates levels of coded verbalization/attributes used to describe the store layout designs. The positive (top of chart) and negative values of Y-axis (bottom of chart) indicate a number of time that the high level (or long or more variety) and low level (or short or less variety) of concrete, abstract and consequence attributes were mentioned, respectively. 


\section{Abstract attributes of store layout design}

In addition to the concrete attributes, the research identified three abstract attributes: perceived complexity, orderliness, and spaciousness. Perceived complexity included the diversity in shelf orientations and shelf shape (Table 2.3). The free-form layout used in Study 1 was associated with (relatively) high complexity, compared to the grid layout. The stimulus material from Study 2 further revealed that high perceived complexity mainly arose from shelves oriented under diverse angles. Perceived orderliness in the store layout designs was even more strongly related to shelf orientation. Parallel shelves contributed to orderliness, whereas diverse angles shelves were associated with low orderliness. This is reflected in the high level of the perceived orderliness of the grid layout in Study 1, but much less so for the free-form layout. In fact, the free-form layout of Study 1 was generally (albeit not unanimously) seen as both high in complexity and high in orderliness, which is remarkable given that in all other layouts complexity and orderliness were negatively related. Perceived spaciousness tended to vary primarily with shelf orientation, as seen from the stimulus material from Study 2. Yet, the free-form layout from Study 1 was associated with spaciousness.

So overall, it seems that the results of the grid layout in Study 1 are largely in line with the grid layout of Study 2. This is confirmed when we examined the triads in which both occurred: in $62.5 \%$ of those triads, these two layout designs were judged as similar. This was much more than would be expected by random chance $\left(\chi^{2}(1)=37.68, p<.001\right)$. However, the results of the free-form layouts appeared more varied. Not only was the free-form layout from Study 1 perceived as both complex and orderly at the same time, it was also seen as spacious, whereas the free-form layout of Study 2 was seen as not spacious. These differences between the two free-form layouts were confirmed when we examined the triads in which both layouts were present: in $38.9 \%$ of these triads 
were the two layouts judged as similar, only slightly more than random chance $\left(\chi^{2}(1)=4.34, \mathrm{p}<.05\right)$

\section{Shopping-related consequences}

Shopping efficiency and enjoyment were mentioned often and varied primarily with shelf orientation. Specifically, parallel shelves contributed to higher shopping efficiency and higher shopping enjoyment compared to shelves under diverse angles. Store image did not have a high prominence in the participants' mind when they first saw the store layout designs.

\section{Relationships between attributes and shopping related consequences}

Shopping-related consequences were specifically probed further for each attribute elicited. Table 2.4 shows the linkages between concrete and abstract attributes on the one hand and shopping-related consequences on the other hand. For the concrete attributes, results were in line with those of Studies 1 - 2.

Table 2.4: Influences of store layout design's attributes on a shopping trip

\begin{tabular}{|c|c|c|c|c|c|c|c|c|c|}
\hline & & \multicolumn{2}{|c|}{$\begin{array}{l}\text { Shopping } \\
\text { efficiency }\end{array}$} & \multicolumn{2}{|c|}{$\begin{array}{l}\text { Shopping } \\
\text { enjoyment }\end{array}$} & \multicolumn{2}{|c|}{ Store image } & \multicolumn{2}{|c|}{$\begin{array}{l}\text { Store choice, } \\
\text { Willingness to } \\
\text { spend time/ } \\
\text { buy products }\end{array}$} \\
\hline & & low & high & low & high & low & high & no & yes \\
\hline \multicolumn{10}{|c|}{ Concrete attributes } \\
\hline Shelf height & Higher & 5 & 1 & 5 & 2 & 2 & 0 & 2 & 0 \\
\hline Shelf length & Shorter & 6 & 43 & 3 & 18 & 0 & 1 & 2 & 7 \\
\hline Shelf orientation & Parallel & 1 & 60 & 5 & 6 & 0 & 1 & 1 & 6 \\
\hline Shelf shape & Mixed & 0 & 3 & 1 & 8 & 1 & 0 & 0 & 2 \\
\hline \multicolumn{10}{|l|}{ Abstract attributes } \\
\hline Complexity & Higher & 18 & 2 & 17 & 7 & 0 & 1 & 4 & 1 \\
\hline Orderliness & Higher & 2 & 64 & 3 & 36 & 0 & 0 & 1 & 23 \\
\hline Spaciousness & Higher & 0 & 16 & 1 & 14 & 0 & 0 & 0 & 12 \\
\hline
\end{tabular}

Note: Entries in the table reflect how an attribute level relates to consequences relative to the opposite attribute level. So, when participants note that high shelves relate to low shopping efficiency, and when they note that low shelves relate to high shopping efficiency, this is both incorporated in the association between higher shelf height and low shopping efficiency. 
Concerning the effects of abstract attributes (i.e., complexity, orderliness and spaciousness) the results reflected a positive relationship between orderliness and shopping efficiency and a negative relationship between complexity and shopping efficiency. For spaciousness, participants linked high spaciousness with high shopping efficiency. Moreover, abstract attributes were also linked with shopping enjoyment. High orderliness, low complexity, and high spaciousness were mostly perceived to provide high enjoyment. Yet, there were also cases in which stores with higher complexity were also seen as more enjoyable.

For the effects of abstract attributes on intention to visit the store, willingness to spend time and willingness to buy, orderliness was dominantly mentioned. O rderliness had a positive relationship with the intention to visit and to shop in the store. Effects of spaciousness were mentioned as well, and higher spaciousness was related to higher intentions to visit and to shop in the store. The link between complexity and intention to visit was not often mentioned.

\subsubsection{Discussion}

This study has shown that the free-form layouts used in Studies 1 versus 2, which are constructed to be similar on concrete attributes and also perceived as such, are seen as very different on the abstract attributes of orderliness and spaciousness. Although both layouts have short shelves and shelves placed in various angles, the resulting overall holistic layouts are different. This leads us to conclude that what matters are not only the concrete attributes themselves but also, and perhaps more importantly, how these are operationalized and combined. Store layout designs that seem similar when described based on distinct concrete attributes, may nonetheless be perceived very differently when evaluated on more abstract attributes based on the whole layout design. 
Consumers take such abstract attributes into account spontaneously and can relate these to expected shopping experiences. Relevant abstract attributes are complexity, orderliness, and spaciousness of the store, whereas shopping efficiency and shopping enjoyment are relevant consequences. Effects on perceived store image as a result of store layout design have rarely been mentioned. This could be a reflection that when consumers form the first impression about the store and then decide their intention to visit, store layout design is only related to the expected shopping process. At the first encounter, consumers do not consider store image (which is related to characteristics of the store) as an aspect of the shopping trip.

\subsection{General discussion}

Over the past decades, retailing handbooks have consistently and exclusively focused on the distinction between the grid and free-form store layouts when discussing how store layout design affects consumer responses (Ghosh, 1994; Levy \& Weitz, 2012; Lewison, 1994). Y et, amazingly, these layout concepts, especially in consumer viewpoint, have received little empirical scrutiny. This empirical chapter takes an initial step to examine the effects of store layout design on consumer first expectations and prior intention to visit the store. The finding is applicable to the situation when consumers have limited knowledge about the store such as when visiting a new shopping place or newly-renovated store. We add new insights and several important contributions to existing literature.

The distinction between grid and free-form layouts is broad and it depends on multiple concrete layout attributes. The current study has revealed that the distinction only classified by concrete attributes is not fine-grained enough. Especially for the free-form layout, it is apparent (Study 1 versus Study 2) that different layouts that could be classified as free-form may lead to vastly different 
consumer responses in terms of expected shopping efficiency and enjoyment. This implies that additional attributes are needed to informatively help the retail managers decide the store layouts. When examining the store layout designs from our studies, a grid layout can be more adequately described by concrete attributes than a free-form layout. Parallel shelves and long aisles more uniquely define a store layout design than shelves in 'different' angles or of 'different' types. Free-form layouts can be constructed in many different ways within the boundaries posed by the concrete attributes. The free-form layout is therefore described too loosely, and this provides incomplete guidelines for retail managers. In line with previous research (Alawadhi \& Yoon, 2016), this also implies that results found for a specific free-form layout are not necessarily generalizable to other free-form layouts.

Even though it is intuitive to distinguish store layout designs by concrete attributes, it appears to be useful to additionally consider store layout designs in terms of abstract attributes. We found that the relevant abstract attributes are complexity (related to the diversity of shelves and number of shelves), orderliness (related to the organization of the store, order in the store, clearness) and spaciousness (related to the space between shelves, how crowded it feels). This conforms to research in environmental psychology, where complexity and orderliness have been used to study people's response to the natural and urban environment and to esthetic content in the store environment (Greenland \& McG oldrick, 2005; Nasar, 1994). However, to the best of our knowledge, these constructs have only been applied to retailing studies twice (Gilboa \& Rafaeli, 2003; Jang et al., 2018). Moreover, no study has directly examined the relationship among store layout design and perceived complexity and orderliness.

The current chapter provides empirical support for the mediating role of expected shopping efficiency and enjoyment in intention to visit the store. These 
shopping consequences can aid retail managers in understanding the underlying reasons for consumers to visit the store. In relation to the impact of store layout design on the first visit, perceived store image appears to play a more minor role, and does not seem to be a mediator of the effects. Under limited knowledge about the store, the effects on prior intention to visit the store and willingness to spend time furthermore depend on shopping motivation. Consumers with a hedonic motivation base their intention to visit the store and willingness to spend time on shopping enjoyment, whereas consumers with a utilitarian motivation base their intention to visit the store and willingness to spend time primarily on shopping efficiency, and base intention to visit to some extent on shopping enjoyment.

\subsection{Managerial implications}

Because adjusting the layout of a store is costly and requires considerable time and effort, store managers need to think wisely before deciding on their store layout. This research shows that relying on available guidelines about store layout design that are commonly based on the distinction between grid versus free-form layouts, may not suffice. While grid layouts (long shelves) can provide more space to allocate products, they may reduce intention to visit the store of consumers. Conversely, retail managers may aim to provide a joyful shopping experience by using a free-form layout with diversely orientated shelves, but this layout may be complex and lead to negative expectations. We suggest that store managers should also focus on abstract attributes and use a combination of concrete attributes as instrumental in influencing the abstract attributes when designing store layouts. Orderliness and spaciousness of store layouts appear especially relevant for promoting store choice. 


\subsection{Limitations and recommendations for future research}

The empirical research has shown differences in concrete and abstract attributes, as well as shopping consequences on the basis of six store layout designs. Given that free-form layouts are broadly defined in their concrete attributes, the conclusion is not generalizable to all store layout designs. Moreover, we focused on two shelf attributes: shelf length and shelf orientation (Study 2). Other attributes such as shelf height, shelf shape, and the space between aisles also matter (Studies 1 and 3). Concrete attributes together create abstract attributes. Nevertheless, their combined effects are complex and unknown yet and future research should explore the individual and combined effects of these concrete attributes. Study designs that systematically vary these attributes to gain insights on the effects of layout design's concrete attributes on important abstract attributes (perceived complexity, order and spaciousness) will benefit store managers in designing preferred store layouts.

Another limitation concerns measurement and study design. It may be argued that the discrepant finding concerning the free-form layout (from previous research, Studies 1 and 2) is attributed to different measurements and study designs (within-subject in study1 and between-subject in Study 2). Even though Study 3 verified that participants also explicitly indicated the difference between free-form layouts used in Studies 1 and 2 and expected different impacts, the impacts of different patterns of free-form layouts should be verified in future quantitative research.

Moreover, the associations between attributes and shopping consequences are based on a small-scale study. Future research should quantitatively confirm these relationships with larger groups of participants. This should help retail managers 
in designing store layouts that tailor to the shopping motivation of their target group.

Another limitation is that this study has focused on consumers' expectations and intention to visit the store when consumers see the store for the first time, but we have not investigated consumers' real experiences while shopping in the store and their expectations after the first visit. As it is difficult and costly to do a field study in a real store, more advanced research tools, such as a video of store visits or virtual store simulators could be employed to examine the effect of store layout design on consumers' shopping experiences. Comparison between expectations and experiences resulting from different store layout designs as well as prior intention to visit and intention to revisit will provide more insight into retailing in general and store layout design effects in particular.

Lastly, it is important to note that the store layout design factors will not work individually. The combined effects of store layout design factors and other environmental factors such as color, interior decoration, music, or number of sale-persons should be examined in future research. The moderate complexity of store layout design in combination with the use of warm colors for the interior design might increase perceived crowding and be less attractive. Alternatively, it could be postulated that cool colors for the interior store design may reduce the negative effects of a very complex store layout. 


\section{Chapter 3}

\section{The role of store-layout complexity and orderliness in determining intention to visit stores}

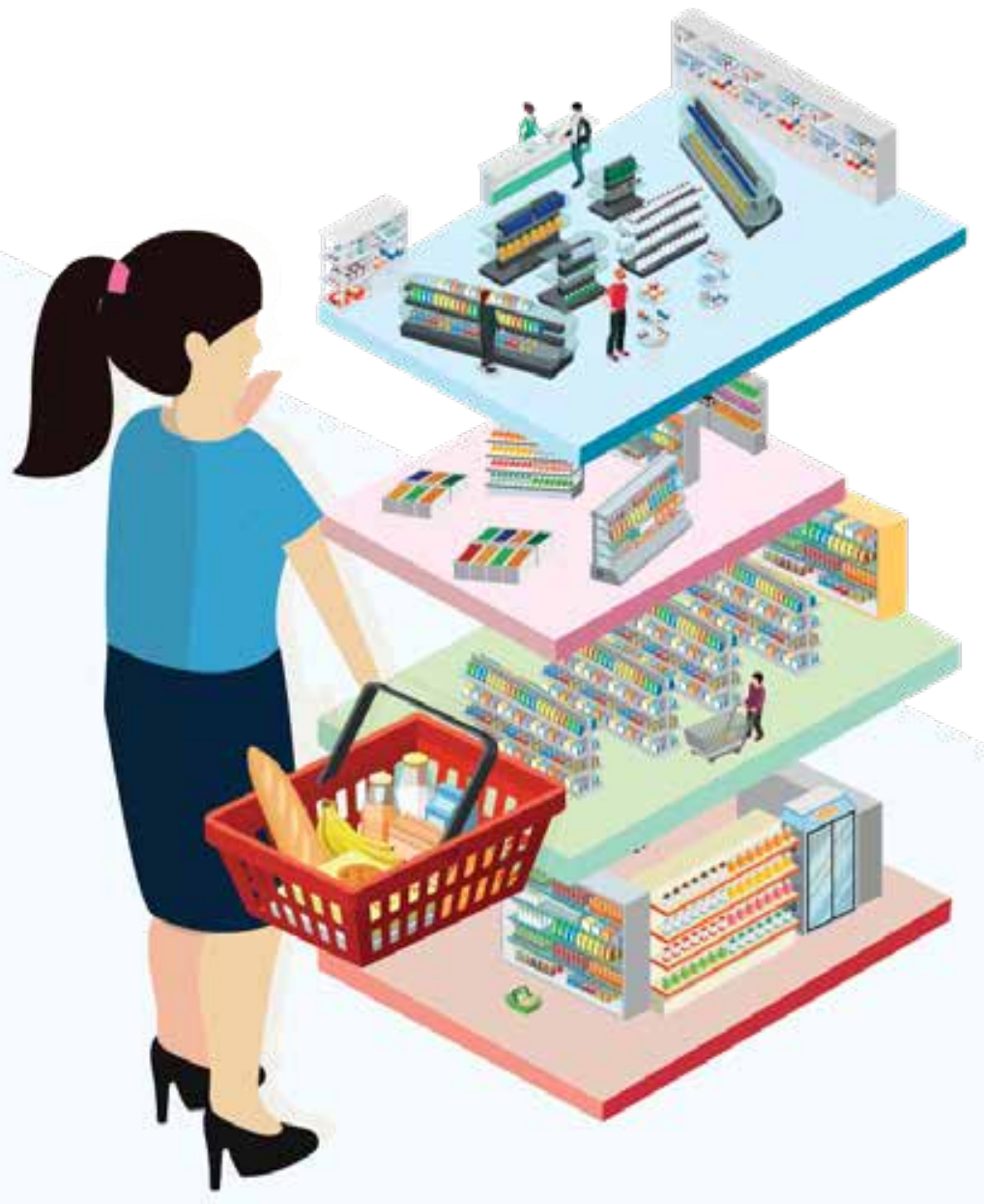

This chapter has been prepared by

Ploydanai, K., van Herpen, E., van der Lans, I., and van Trijp, J. C. M. H. 


\section{Abstract}

Store layout designs may form the basis for consumers' expectations (i.e., shopping efficiency, shopping enjoyment and store image), and intention to visit the store. However, typical layouts introduced in the literature are broadly defined and therefore they are less useful in explaining consumers' responses to the stores. This study presents complexity and orderliness as common higher-order attributes that explain the effects of store layout designs on consumers' expectations and, finally, intention to visit. In our study, various layout attributes (i.e., shelf length, shelf orientation and shelf shape) are systematically manipulated to obtain layouts that differ in perceived complexity and orderliness. The study also examines whether particular effects are moderated by shopping motivation. The findings show that complexity and orderliness explain consumers' expectations and intention to visit the stores as expected. Impacts of orderliness surpass complexity on all dependent variables for both hedonic and utilitarian shopping motivations. Orderliness enhances expected efficiency, expected enjoyment, store image and intention to visit. We additionally show that expected shopping efficiency and enjoyment, and store image can partly explain the effects of complexity and orderliness on intention to visit. 


\subsection{Introduction}

Competition among retail shops and the rising popularity of online shopping have challenged conventional retailers to improve store attractiveness and to create pleasurable shopping experiences (P. Singh et al., 2014). Numerous storedesign factors (store layout designs, interior decoration and window display, just to name a few; Baker et al., 1994; Underhill, 2000) can be used to draw consumers' attention and increase their intention to visit the store. This is because consumers may gather information from different store designs that they encounter when walking through a shopping street or shopping mall and choosing stores to visit, especially when they are unfamiliar with the stores. Consumers can use acquired information from store layout design to create expectations of the offered benefits and these may consequently determine intention to visit. For example, a store which is very spacious and has few shelves may trigger expectations as a luxurious store. Consumers likely expect the store to provide an enjoyable shopping experience, good service, and luxurious products.

Among various store-design factors, store layout design is a vital factor to consider (Alawadhi \& Y oon, 2016). Store layout design in modern stores can be easily recognized at first glimpse since stores usually employ a wide entrance or transparent front-windows. The layout design thus initiates different expectations and intention to visit the store even before entering (Baker et al., 2002; Chapter 2). Previous studies have shown that consumers who are unfamiliar with a store, apply store layout design to create expectations of shopping efficiency, shopping enjoyment and store image (Chapter 2) as well as to make inferences about costs and benefits offered by the store (Baker et al., 2002). Moreover, the store layout design also influences shopping experiences and shopping behaviors during and after the store visit, such as feelings of pleasure and arousal, impressions and perceptions toward the store (Alawadhi \& 
Yoon, 2016; Ballester et al., 2004), circulation and traffic density (Ballester et al., 2004), buying pattern (P. Singh et al., 2014), product search, time spent, impulsive purchase, store evaluation and shopping experience (Levy \& Weitz, 2012).

Despite that several studies on the topic have appeared, as exemplified above, the impacts of store layout design remain inconclusive, as becomes evident by contradictory findings about effects of the free-form layout (Alawadhi \& Yoon, 2016; Baker et al., 2002; Chapter 2). These contradictory effects of free-form layout may have occurred because this layout is loosely defined as an unrestricted pattern of store layout design's attributes that consists of a variety of sizes, shapes, lengths, and orientations (Levy \& Weitz, 2012). For example, a free-form layout that consists of rectangular- and round-shaped shelves arranged in a playful manner may raise relatively high expectations of shopping efficiency, shopping enjoyment, and store image, and attract high intention to visit (Baker et al., 2002; Chapter 2). In contrast, a free-form layout that arranges shelves in various angles and according to an unorganized pattern, leads to low expectations of shopping efficiency, shopping enjoyment and store image (Chapter 2) and low intention to visit (Alawadhi \& Yoon, 2016).

Possible interactions among store layout design's attributes (e.g., shelf shape, length and orientation) may be the reason for a number of different effects of free-from layouts across studies. In the literature, more abstract attributes, like complexity and orderliness, have been proposed to provide an understanding of the effects of the arrangement of store elements (Gilboa \& Rafaeli, 2003).

Complexity and orderliness have been widely used to predict responses to physical and natural environments (e.g., preferences, affective responses and approach tendencies; Heath et al., 2000; Nasar, 2000; van den Berg et al.,1998) and consumers' responses to esthetic content in the store environment 
(Alexander, 1979; G ilboa \& Rafaeli, 2003; Hekkert \& Leder, 2008; Lauer, 1985; Murray, Elms, \& Teller, 2015). Complexityis defined as visual richness, number of independent elements, information rate, and variety of information in an environment (Nasar, 1994). Ordediness represents the degree of organization of elements, coherence, fittingness, congruity, legibility, redundancy and compatibility of information (Kaplan \& Kaplan, 1989; Nasar, 1994). Whereas complexity concerns the multiplicity of elements, orderliness deals with the congruity relation among different parts of an entity (Amheim, 1971). For example, complex stores consist of a higher quantity and variety of store elements (e.g., products, furniture, lighting and wall patterns) than simple stores. High orderly stores arrange products and store elements in a coherent manner (e.g., similar products are placed together) and logical format (e.g., placing hats on upper shelves and shoes on lower platforms; Jang et al., 2018). A store with a variety of elements (highly complex) can be well-organized (more orderly) or unorganized (less orderly). Gilboa and Rafaeli (2003) have verified that complexity and orderliness of stores (created by multiple store environmental factors such as products, furniture, wall and floor patterns) are perceived in this way by consumers, and a qualitative study in Chapter 2 also uncovered that consumers use complexity and orderliness to classify store layout designs. A layout design with long shelves arranged in a parallel pattern (a grid layout) was found to be more orderly and less complex than an unorganized free-form layout with diverse-shaped shelves. Participants also reported different expectations of shopping efficiency, shopping enjoyment and store image of those store layouts. These findings indicate the potential of using complexity and orderliness to understand the impact of store layout design. In addition, complexity and orderliness also affect approach-avoidance behaviors (i.e., intention to visit and revisit, intention to explore, intention to interact with a salesperson, intention to stay and do any activities in the store). A combination of moderate complexity and high orderliness results in the highest level of approach tendencies (Gilboa \& Rafaeli, 2003). 
The aims of this study are to examine how perceived complexity and orderliness of store layout design contribute to intention to visit the store and how this effect is mediated by consumers' expectations about the shopping process (shopping efficiency and shopping enjoyment) and about store image. In line with Baker et al. (2002), our findings are specific for the shopping situation when consumers have limited prior knowledge about the store (e.g., when consumers go to a new place during vacation) or when a store is new or renovated.

The present work provides important contributions to retailing theory in several ways. First, it combines retailing theory and environmental psychology attributes (proposed by Gilboa and Rafaeli, 2003) by concentrating on the impacts of perceived complexity and perceived orderliness (in relation to store layout design's attributes) on consumers' expectations of the store and intention to visit. Second, we also show effects of perceived complexity and orderliness on intention to visit under different shopping motivations, namely hedonic and utilitarian. Last, we expand the retailing paradigm, which primarily focuses on the impacts of store layout design typology (e.g., grid vs. free-form layout; Levy $\&$ Weitz, 2012), by providing information on how store layout design's concrete attributes (shelf length, shelf shape, and shelf orientation) contribute to perceived complexity and orderliness. This chapter aims to provide guidelines for retailers to help arrange their store. 


\subsection{Theoretical framework}

This section explains how perceived complexity and orderliness influence consumers' expectations of shopping efficiency, shopping enjoyment and perceived store image, which in turn may determine intentions to visit the store. The framework is depicted in Figure 3.1.

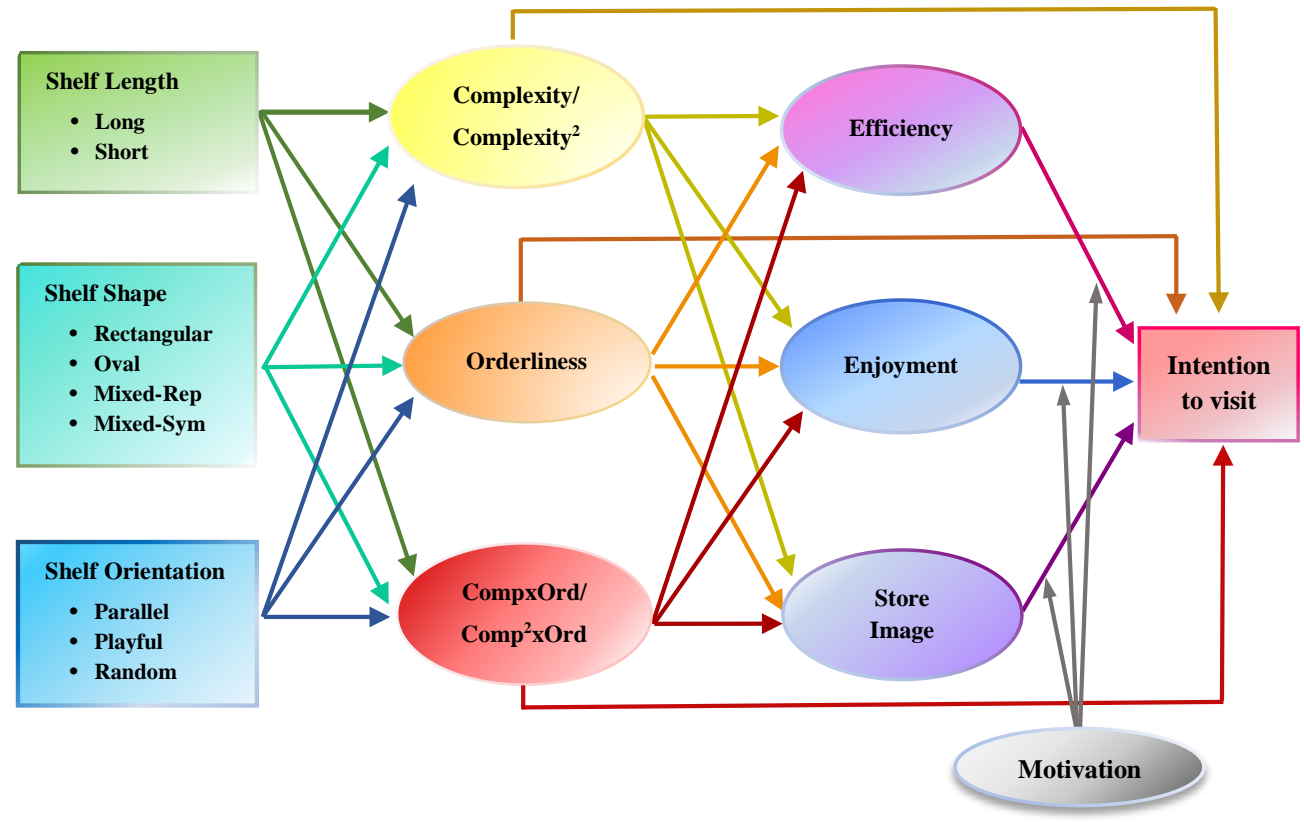

Figure 3.1: Theoretical Framework

Complexityconcerns the (visual) richness, information rate, diversity and variety of elements in an environment (Nasar, 2000). An increase in complexity appears when there is more richness to an environment and when the elements manifest large variance and little redundancy (Nasar, 1994). In the context of the store environment, store complexity is determined by the diversity and quantity of elements and products in the store as well as designs and decoration of all elements (Gilboa \& Rafaeli, 2003; Jang et al., 2018; Orth \& Wirtz, 2014). For example, stores with various patterns of shelves are more complex than stores with the same pattern of shelves (Jang et al., 2018). 
Ordediness refers to the degree of coherence among elements of a whole group (Arnheim, 1971). Orderliness is related to the extent of organization, coherence and congruity of an environment (Nasar, 2000). In a retailing context, orderliness associates with spatial features (e.g., symmetry, logical arrangement, repetitive pattern of arrangement; Jang et al., 2018).

The roles of complexity and orderliness on people's responses to environments such as buildings, rural and urban areas have received ample attention from environmental psychologists (Heath et al., 2000; Nasar, 2000; van den Berg et al.,1998). However, the impacts of complexity and orderliness on consumers' responses to retail stores have been examined in two retailing studies only (i.e., in a context of a supermarket; Gilboa \& Rafaeli, 2003, and a fashion store; Jang et al., 2018, as we will elaborate on later).

\subsubsection{Effects of perceived complexity and orderliness on consumers' intention to visit the store}

Environmental psychology studies have not yet empirically tested the relationship between complexity/ orderliness and intention to visit the places (e.g., building, urban, national park). However, researchers have proposed a possible link between them based on information theory (Baron, 1994; Huffman \& Khan, 1998) as explained further.

\section{Complexity}

Based on information theory, people likely avoid very complex environments because these environments contain too much information to be processed. The study of consumers' processing of interior service environments has revealed a negative effect of complexity on constructs related to approach-avoidance (in this case attractiveness; Orth \& Wirtz, 2014). In contrast, very low complex environments provide low information and consequently create uncertainty. 
Because both extremes are unpleasant, information theory suggests that people will search for a moderate level of complexity (Baron, 1994; Huffman \& Khan, 1998). Similar to the prediction by information theory, researchers have verified inverted-U effects of complexity on people's responses such as the perceived aesthetic of landscapes (van der Jagt, Craig, Anable, Brewer, \& Pearson, 2014), preference in texture pattem (Friedenberg \& Liby, 2016), and preference in natural and urban scenes (Kaplan, 1987; Nasar, 2000). The inverted-U effects indicate that complexity can yield both positive and negative effects on approach-avoidance behaviors depending on the level of complexity. Overall, people prefer moderate levels of complexity.

In a retail store context, Gilboa and Rafaeli (2003) examined the effects of complexity and orderliness by presenting photographs of four sections of a supermarket (frozen foods, pasta, fruits and vegetables, and dairy) taken from two grocery stores. Afterwards, they measured perceived complexity (and orderliness) from one group of participants and measured emotional responses and approach tendencies from another group of participants. Jang, Baek and Choo (2018) examined the effects of complexity (and also orderliness) in a fashion store using a different approach. Their study manipulated the levels of complexity (i.e., low, medium and high) by varying the quantity and variety of products, furniture, lighting, and patterns on the walls and floor (carpets and wallpaper). In line with studies from environmental psychology, both retailing studies also found an inverted-U relationship between complexity in the store environment and tendency to visit the stores (G ilboa \& Rafaeli, 2003; Jang et al., 2018). Based on these findings, we thus hypothesize that:

H 1a: Complexity of stores has a curvilinear (inverted-U) effect on consumers' intention to visit the store. 


\section{Ordenliness}

For impacts of orderliness, information theory supports that orderliness facilitates fluency, recognition, and interpretation of stimuli (Reber, Schwarz, \& Winkielman, 2004). In the context of environmental psychology, positive impacts of orderliness on preference (Kaplan, 1987), on perceived beauty or attractiveness of the environment (van der Jagt et al., 2014) as well as on approach behavioral tendencies (Kaplan, 1987) have been reported. The retailing studies also examined the effects of orderliness in a supermarket environment (Gilboa \& Rafaeli, 2003) and a fashion store environment (Jang et al., 2018) on consumers' approach-avoidance tendencies. Together with complexity of the store, Gilboa and Rafaeli (2003) measured the perceived orderliness of different sections of the supermarket (shown in several images) on consumers' approachavoidance tendencies. Jang, and colleagues (2018) manipulated orderliness (low and high) by varying the arrangement and placement of products and store elements. For example, high orderly stores arranged hats on upper shelves, shoes on lower platforms, and a cash register at the back of the store (Jang et al., 2018). Both studies reported a positive relationship between orderliness and approach tendencies including intention to visit the store. Based on these previous studies, we hypothesize that:

H lb: O rderliness of stores has a positive effect on consumers' intention to visit the store.

In addition to the main effects, several studies have supported aninteradion ffeet of complexity and addiness on approach-avoidance tendencies (Berlyne, 1971; Nasar, 2000). Nasar (2000) reveals that while complexity provides richness, diversity, and variety of information, orderliness arranges this diversity and helps reduce the information overload. 0 ther environmental psychology studies have also revealed a significant interaction effects of complexity and orderliness on appraisals of scenic beauty (van der Jagt et al., 2014). The previous studies 
support that orderliness decreases people's preference toward low complex environments or objects such as packages, products, and textile, and increases preference toward complex environments or objects (Berlyne, 1971; Reber et al., 2004). However, previous studies in environmental psychology have not explicitly specified the pattern of the relationship between complexity and approach tendencies at a low and a high level of orderliness. They only suggested that people require orderliness to be able to cognitively and emotionally deal with information in highly complex environments or objects (Berlyne, 1971; Reber et al., 2004). Besides, they state that environments or objects with moderate complexity and high orderliness are preferred the most. Retailing studies, in contrast, have explored the pattern of relationship between complexity and approach tendencies at different levels of orderliness (Gilbao \& Rafaeli, 2003; Jang et al., 2018). Still, they have found different interaction patterns. Jang, Baek and Choo (2018) discovered an inverted-U effect of complexity on approach tendencies at low orderliness and a positive effect of complexity at high orderliness. In contrast, Gilbao and Rafaeli (2003) found insignificant interaction effects of complexity and orderliness. There thus appears no consensus about the interaction effect of complexity and orderliness. However, in the case of rather extreme low/ high complexity and rather extreme low/ high orderliness (covered in Jang et al. (2018), and this study), we expect that high orderliness can reverse the negative effects of high complexity. In other words, a similar pattern as found by Jang, Baek, and Choo (2018) is expected. Therefore, we hypothesize that:

H 1c: At low to moderate orderliness, the effect of complexity on intention to visit appears in an inverted-U shape, whereas at high orderliness the effect of complexity is positive. 


\subsubsection{The mediating role of expected shopping efficiency, expected shopping enjoyment and perceived store image}

Inference theory states that people judge an unknown environment based on the information they receive from the available cues (Huber \& McCann, 1982). The available cues are combined with prior knowledge and schemas to guide inference and prediction (Fiske, 2014) and consequently shape expectations in a new environment (Fiske \& Linville, 1980). Accordingly, consumers' intentions to visit an unknown store are likely determined by expectations of shopping costs and benefits that are inferred from the store environmental cues such as store layout design (Baker et al., 2002; Fiske \& Linville, 1980; Huber \& McCann, 1982). The expected shopping costs and benefits that are based on store environmental cues are likely to be elements of the shopping process, namely effort/ efficiency in the decision-making process and enjoyment with the shopping and the assortment (D iehl et al., 2015; Chapter 2). The importance of shopping efficiency and enjoyment are also considered by retailers when choosing store layout design (Levy \& Weitz, 2012). It is stated that the optimal layout should both facilitate product search and provide a pleasurable shopping environment for shoppers (Alawadhi \& Y oon, 2016; Baker et al., 2002).

In addition, consumers also base their intentions to visit on the overall perception of the store (store image; Baker et al., 1994). Consumers likely form perceptions toward store image by consulting the arrangement of products and shelves in the store as one of the cues (Baker et al., 2002; Chapter 2). For example, Chapter 2 has shown that consumers associate a parallel arrangement of rectangular shelves (a grid layout) with a discount store and expect to find cheap products, but not very pleasurable services. In contrast, they associate a store with diverse shelf orientations (playful pattern), shelf shapes and shelf lengths with a luxurious or upscale image and expected to find luxurious products with high price (Chapter 2). 
As previously explained, consumers' expectations and perceptions of stores likely mediate the effect of store layout design on intention to visit the store. Looking into the potential mediating role of expected shopping process and perceived store image, the model can be divided into two parts based on the available literature of environmental psychology and retailing. The first part describes how perceived complexity and orderliness influence consumers' expected shopping process and perceived store image. The second part relates to how those expectations subsequently affect intention to visit the store. Whereas previous research can support predictions of the latter, knowledge of the former remains absent. D etails are explained in the next sections.

\section{Effects of complexity and orderliness on consumers' expected shopping process and perceived store image (mediators)}

The effects of perceived complexity and orderliness on the mediators (i.e., expected shopping efficiency, shopping enjoyment and perceived store image) have not been studied yet. However, we speculate possible impacts of perceived complexity and perceive orderliness on mediators by applying relevant theories and empirical studies.

\section{E ffects of perceived complexity on mediators}

Stores with low complexity consist of fewer store elements or simple aisles, which are easy to understand during information processing (Im, Lennon \& Stoel, 2010; Orth \& Wirtz, 2014). Consumers should be able to figure their ways when searching for products in the low complex (simple) layout faster than in the more complex layout (Titus \& Everett, 1995). In other words, low complex stores likely increase expected shopping efficiency.

Low complex stores may be perceived as being boring (Machleit \& E roglu, 2000; Titus \& Everett, 1995; Vrechopoulos et al., 2004). Y et, very complex stores may make consumers feel overwhelmed and lead to less pleasurable shopping 
experience (G ilboa \& Rafaeli, 2003; van der Jagt et al., 2014; Jang et al., 2018). Therefore, we speculate a curvilinear (inverted-U) relationship between perceived complexity and expected shopping enjoyment. A moderate level of store complexity is predicted to bring the highest expected shopping enjoyment.

Low complex stores with less variety of store layout design's attributes such as parallel orientation, single shelf shape and long shelf (fewer shelves in the store) likely have a discount image. This is because these stores seem to make less attempt on store decoration (Chapter 2). In contrast, luxurious stores may provide a more moderate level of complexity, for instance using few store elements but with a variety of shelf shapes an orientation. Very complex layouts (e.g., layouts that consist of many shelf elements and a high variety of shelf orientation) may bring a negative perception toward the store. This is because consumers may feel overwhelmed. They may also perceive that the store is likely a discount store that aims to sell cheap products and save management costs by allocating as many products in the store as possible (Chapter 2). We thus speculate that consumers link either very low or very high complex stores with discount stores, whereas they link moderate complex stores with a more upscale store image (Chapter 2). In other words, like the effect on expected shopping enjoyment, a curvilinear effect (inverted-U) of complexity on perceived store image (discount or upscale image) is expected.

According to the stated explanation, we hypothesize that:

H2: Complexity of stores has a negative effect on consumers' expected shopping efficiency ( $\mathrm{H} 2 \mathrm{a})$, whereas it has a curvilinear (inverted-U) effect on consumers' expected shopping enjoyment (H2b) and perceived store image (H2c). 


\section{Effects of perceived ordenliness on mediators}

Orderliness of stores represents consistency of the stores and therefore enhances cleamess or understanding of the environment (Nasar, 2000), which could ease navigation and product search (Aghazadeh, 2005). Well-organized stores should minimize information overload and help consumers move and find products faster. Consequently, we expect a positive effect of orderliness on expected shopping efficiency.

Environmental psychology research has found that orderliness also enhances pleasantness of natural environments (Nasar, 2000). Besides, retailing studies confirm a positive effect of orderliness on pleasantness of retail stores (Chapter 2; Gilboa \& Rafaeli, 2003; Jang et al., 2018). We thus speculate that consumers have higher expectations of shopping enjoyment in a more orderly store than a less orderly counterpart.

Like the effects on expected shopping process, more orderliness brings a more positive image of stores than less orderliness. A positive effect of orderliness on store image has been found in studies of fashion stores (Merray, Elms \& Teller, 2015) and pharmacy stores (Chapter 2). Consumers evaluate stores with wellorganized layouts to have a more upscale store image, whereas they assess stores with less organized layouts to have a discount image (Chapter 2). Therefore, we predict that orderliness of the store also positively affects perceived store image.

H3: Orderliness of stores has a positive effect on consumers' expected shopping efficiency (H3a), expected shopping enjoyment (H3b) and perceived store image (H3c). 


\section{Interaction effects of perceived complexity and perceived orderliness on mediators}

As explained previously, complexity increases obstacles in product search, while orderliness facilitates and improves information processing and product search in complex stores. Thus, we predict that the negative impact of complexity on expected shopping efficiency is stronger in low orderly stores than in moderate and high orderly stores.

Regarding shopping enjoyment, previous research shows that when complex visual patterns have some order, they induce interest. In contrast, when simple stimuli are ordered, they bring boredom (Berlyne, 1971; Tinio \& Leder, 2009). However, the pattem of the interaction effect of complexity and orderliness on pleasure or enjoyment has not been explicitly shown yet. We speculate that the interaction effect between perceived complexity and perceived orderliness on expected shopping enjoyment is similar to the interaction effect on intention to visit (as stated in H1c). When stores are less organized, complexity may become overwhelming at a certain point, whereas when stores are organized, consumers are likely to enjoy higher level of complexity as there are more and more varied elements to explore.

As moderate complexity and high orderly scenery is perceived to be the most beautiful (van der Jagt et al., 2014), we speculate that consumers link stores having these attributes with the most upscale image as well. The previous chapter also supported that consumers link moderately complex and high orderly stores (e.g., store layout designs with shelves in various shapes and lengths that are arranged in symmetry pattern) with an upscale image (Chapter 2). In contrast, low or high complex stores with low orderliness are linked to a discount store image (e.g., stores with rectangular shelves oriented in a diverse-angle pattern or stores with various shelf shapes and length oriented in diverse-angle pattern). Besides, upscale stores in the market usually emphasize orderliness (an organized 
and harmonious store arrangement) more than discount stores. Like effects on intention to visit, we predict that high orderliness may even reverse the negative effect of high complexity. Thus, we hypothesize that:

H4a: The negative effect of complexity on expected shopping efficiency is stronger at lower orderliness than at higher orderliness.

H4b-c: At low to moderate orderliness, the effect of complexity on expected shopping enjoyment ( $\mathrm{H} 4 \mathrm{~b})$ and perceived store image (H4c) appears in an inverted-U shape, whereas at high orderliness, the effect of complexity is positive.

\section{Impact of expected shopping efficiency, expected shopping enjoyment and perceived store image (mediators) on intention to visit the store}

The positive impacts of consumers' expectations and perceptions toward store choice criteria (shopping efficiency, shopping enjoyment and store image) on intention to visit have been supported by many studies (Baker et al., 2002; Chapter 2; Lu \& Seo, 2015; Shamsher, 2015; Srivastava \& Natu, 2014). The studies show that in both traditional retailing and online retailing, consumers report higher intention to visit and revisit the store where they expect high shopping efficiency, shopping enjoyment, and perceived store image. The following hypothesis is formed:

H5: Expectations of shopping efficiency, shopping enjoyment and store image positively affect intention to visit.

Regarding the potential effects of expected shopping process and perceived store image in relation to store layout design explain previously, we propose that: 
H6a-c: The effects of complexity (H6a), orderliness (H6b) and their interaction (H6c) on consumers' intentions to visit the store are mediated by consumers' expected shopping efficiency, expected shopping enjoyment and perceived store image.

\subsubsection{The moderating role of shopping motivation}

Retailing research has shown that consumers' responses to the store (e.g., intention to visit the store, perceived experience, and shopping behaviors) depend on consumers' shopping goals or shopping motivation (Davis, Peyrefitte, \& Hodges, 2012; Kaltcheva \& Weitz, 2006; Wagner, 2007). As consumers search for different benefits from the shopping trip, they likely prefer the store from which they expect to fulfill their goal. A utilitarian shoping motivation refers to a desire to achieve functional or practical benefits (Kaltcheva \& Weitz, 2006). In contrast, a hedmic motivation involves a desire to satisfy an emotional goal or to value the pleasure of shopping (Babin et al., 1994; Fischer \& Arnold, 1990; Holbrook \& Hirschman, 1982).

We expect that the indirect effects of perceived complexity and perceived orderliness on intention to visit are likely moderated by shopping motivation. Consumers with utilitarian versus hedonic shopping motivation are likely to attach different weights to expected shopping efficiency, shopping enjoyment, and store image when deciding which store to visit. This is because they search for different shopping benefits. A previous study supports that shopping motivation alters how the shopping process and store image mediate store layout design's effects (Chapter 2). It is also shown that intention to visit the store of consumers with utilitarian motivation is mostly influenced by shopping efficiency, followed by shopping enjoyment. In contrast, intention to visit the store of consumers with hedonic motivation is mostly influenced by shopping enjoyment and minorly by perceived store image. 
Orth and Wirtz (2014) also examined the moderating role of shopping motivation on the relationship between the complexity of interior service environment and store attractiveness. They have revealed that the negative effect of complexity on perceived attractiveness of the environment is stronger for consumers with utilitarian motivation than those with hedonic motivation (Orth \& Wirtz, 2014). In contrast, orderly stores may be more attractive to consumers with utilitarian shopping motivation because orderly stores should help consumers complete their utilitarian goal faster as it enhances understanding of the environment (Nasar, 2000). This suggests that shopping efficiency is more important to consumers with utilitarian shopping motivation than hedonic shopping motivation. In contrast, research has shown that consumers with hedonic motivation report higher pleasantness with more complex and/ or less orderly stores (more arousing stores in Kaltcheva \& Weitz, 2006). As consumers with hedonic motivation focus on shopping enjoyment, we speculate that they have higher intention to visit the store with more complex and/ or less orderly stores than those with utilitarian motivation. The direction of the effects of complexity and orderliness on intention to visit are, however, expected to be the same for consumers with utilitarian and hedonic motivation. O nly the effect sizes of abstract attributes are predicted to be different.

Therefore, we hypothesize that

H7: Under hedonic shopping motivation, the indirect effects of complexity and orderliness through shopping efficiency are weaker and the effects through expected shopping enjoyment and perceived store image are stronger than those effects under utilitarian motivation. 


\subsection{Experiment}

This experiment examines the role of complexity and orderliness on consumers' expectations of the shopping process, perceived store image and intention to visit the store. Additionally, this study explores how perceived complexity and perceived orderliness of stores can be created by store layout design's attributes. In this experiment, the store layout designs are systematically varied by shelf length and orientation, which have been examined in Chapter 2, and also by shelf shape.

\subsubsection{Method}

\section{Stimuli}

Pictures of pharmacy store layout designs with different complexity and orderliness levels were created using the SketchUp program that enables making 3D designs of a store. For each store layout design, four pictures of the layout from a top view, a front view, a back view and a middle-aisle view were created (see Appendix 3.1).

In relation to store layout design's attributes, we expect that perceived complexity may be increased by a higher variety of shelf shape and orientation as well as higher numbers of shelves. For example, the first image in Figure 3.2 is expected to be less complex than the last image. Perceived orderliness may be more related to shelf orientation. Perceived orderliness is likely raised by the inclusion of a coherent pattern of arrangement, such as a parallel orientation and symmetric arrangement of shelves. This study employs various self attributes (2 types of length, 3 patterns of orientation and 4 styles of shape) to manipulate different levels of perceived complexity and orderliness. The shelf length was varied by either placing long shelves running almost the whole length of the store or splitting each of the long shelves into two shorter shelves with space in 
between (higher quantity of shelves). Shelf orientation was manipulated by 1) placing shelves parallel to the wall of the shop and to each other (parallel orientation) or 2) placing the middle shelves perpendicular to shelves on the sides (playful orientation) or 3) placing shelves in diverse angles (diverse angles orientation). Whereas shelves with playful orientation were arranged in a more varied pattern compared to those with parallel orientation, they had a more systematic pattern than a diverse angles orientation format. The shelf shape was 1) in a rectangular shape or 2) in an oval shape or 3) a mixture of oval and rectangular shapes in a repetitive pattern (Mixed shapes - repetitive pattern; MR) or 4) a mixture of oval and rectangular shapes with a symmetric pattern (Mixed shapes - symmetric pattern; MS). MR was a pattern in which the rectangular and oval shelves were alternatively placed next to each other, while MS represented a pattern in which the oval shelves were symmetrically placed in the middle of the rectangular shelves. The repetitive and symmetric pattern of arrangement were introduced to explore different arrangements of mixed shape. Combining the different shelf lengths, shelf orientations, and shelf shapes, 24 store layout designs were created. Apart from these store layout design's attributes, other factors (i.e., type and number of products shown in the stores, space on the shelves and other interior design) were kept constant. Figure 3.2 shows all store layout designs used in this study.

\section{Participants}

Participants were recruited via a Qualtrics panel. They were Dutch native speakers who lived in the Netherlands. The online survey was initiated by 486 persons, of whom 311 completed the questionnaire (63.99\% completed). Three participants who evaluated expected shopping process and store image of four to eight store layout designs with zero variance scores and two participants who gave more than $50 \%$ of their answers on the default position were excluded from analysis. This is because they seemed to not take the questionnaire seriously. Thus, in total 306 participants were included in the analysis (51\% female). 
Participants' age ranged from 18 till 83 years $(\mathrm{M}=44.51)$. Of the participants, $51.6 \%$ was employed, $5.1 \%$ student, $8.5 \%$ job seeker, and $24.1 \%$ retired or disabled. Gender, age, and occupation of participants were not significantly different among conditions.

\section{Shelf Shape}

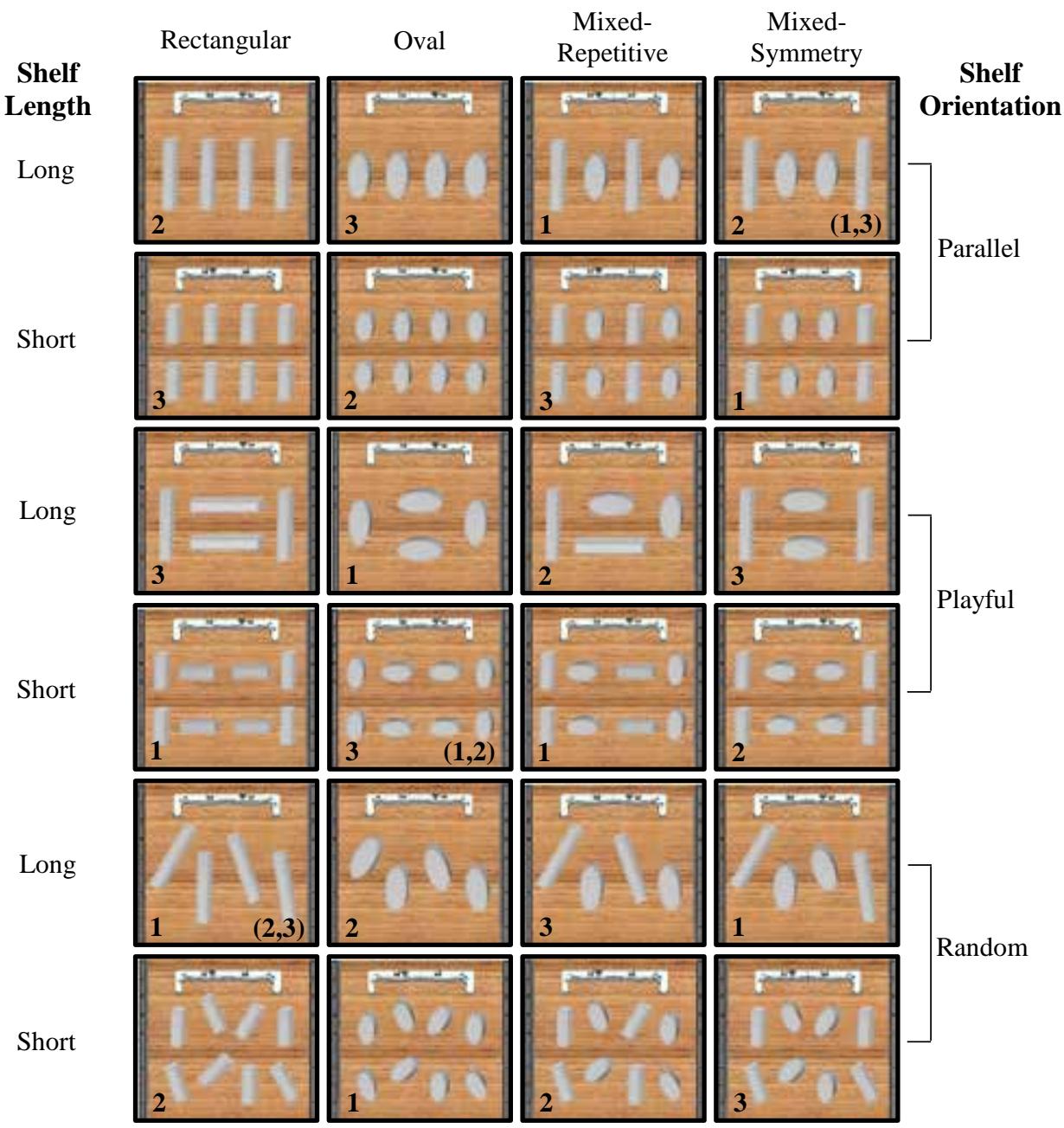

Figure 3.2: Store layout designs with their concrete attributes and the block in which they were presented

Note: The number at the left bottom indicates the block number in which each layout was presented. The number at the right bottom indicates other blocks in which the layouts (3 layouts) were presented. 


\section{Design}

The experiment had a 2 (shelf length: short vs. long) x 3 (shelf orientation: parallel vs playful vs unorganized) $\mathrm{x} 4$ (shelf shapes: rectangular vs. oval vs. mix of shapes with repetitive pattern (MR) vs. mix of shapes with symmetric pattern (MS)) design. The evaluation of 24 store layout designs is effortful and time consuming for participants, who may get tired and try to finish the task with a minimum of effort. Therefore, we simplified the survey by breaking the 24 layouts into three blocks or subsets (eight layouts per block) yielding three different versions of the questionnaire. The design maintained maximum Defficiency for the main effects of shelf length, shelf orientation and shelf shape, and balance within each block (Kuhfeld, 2010). Each participant was randomly assigned to one of the three blocks and was asked to evaluate the layouts therein.

Apart from these eight layouts in each version, two additional layouts were added, picked from the other two blocks. One of the additional layouts was presented first, to familiarize participants with the task, and another was presented last, to prevent the end of task effect where participants hurry up to finish the task. This means that participants in each version evaluated ten layouts in total. To examine the effect of store layout design, the analysis included the evaluations of the eight store layout designs from each balanced block and left out those layouts used for warming up and avoiding rushing-to-the-end effects.

\section{Procedure}

Participants were recruited using the Qualtrics Research Services. They were asked to complete the survey (in the Dutch language) via a computer-based questionnaire using Q ualtrics. They started by reading a consent form informing them about the tasks that they needed to do. After consenting their participation, participants were randomly assigned to one of the versions of the questionnaire. They were asked to imagine that they would go shopping and then asked to evaluate each store layout design. First, participants reported their expectations 
of shopping efficiency and shopping enjoyment, and their perceived store image of each layout. The layouts were presented in an order of which the main store layout designs (eight layouts of each block) were randomly presented in $2^{\text {nd }}$ to $9^{\text {th }}$ order.

Subsequently, participants were randomly assigned to one of two, manipulated, shopping motivation conditions (utilitarian vs. hedonic), which were adapted from a previous study (Kaltcheva \& Weitz, 2006). The utilitarian shopping motivation was elicited by instructing participants to "Imagnethat you aregaingto shop with a predtemined shopinglist. You want toenter theshop, gather only theprodurts on your list and then leave the stareimmediatdy." The hedonic shopping motivation was elicited by instructing "Imaginethat you go shoppingbecauseyou likeit. You want to ejioy a shopingadivity itsdf and arend in need of any produds" Then participants indicated their intention to visit each of the stores under one of the manipulated motivations (either hedonic or utilitarian).

Afterward, the participants reported their perceived complexity and orderliness of all stores. Definitions of complexity and order were provided (Gilboa \& Rafaeli, 2003) to help them understand these two attributes:

The enironmental or stare complexity is defined as comprising visual nidhess, information rate, divesity and variey of dements or informationin an environment.

An incresein complexity appens i) when thereis nurenidness and mrevanidy of storedenets, ii) when thestredements dond maintain a chenent pattem, andiii) when thestaredements showlittleredundang. 
The oddeliness of store arrangenent rdates to the extent of acganization, coheence, fittingness, congrity, legibility, dutter, symmery and danity of an enironment.

An incresein ardaliness appersi) when streshdves arenettlyarganizedin a more cheet pattem, ii) when the organization of shives across the store fits better (high congrity andfittingness), iii) when consumes can seeall storedentents andareableto find ther way esily (high danity and legibility), and iv) when thereis less dutter and moresymmery of shdf arangement.

At the end of the survey, socio-economic status (i.e., age, gender, and occupation) and Change Seeker Index were measured. The survey took approximately 15 - 25 minutes and participants received collecting points as a reward.

\section{Measures}

All the items used to measure expected shopping efficiency, expected shopping enjoyment, perceived store image and intention to visit the store were selected from previous studies (Baker et al., 2002, Chapter 2). For each item to measure expectations, intention to visit the store, perceived complexity and perceived orderliness of stores, participants were asked to indicate their agreement with a statement on a slider bar with anchors 'Strongly disagree' (0) and 'Strongly agree' (100). They saw only the position of their answer without any numeric score. For our analyses, the positions on the slider bar were translated into a 0-100 point scale.

Expeted shoppingeffiaengy was measured with two items: 'I think this store would enable me to search and buy products fast.' and 'I think this store would save me shopping time.' (cf. Seiders et al., 2000; Cronbach's $\alpha=.96$ ). 
To measure expetedshopingeijgment, the items 'I think that this store would give entertaining shopping experiences.' and 'I think shopping in this store will be fun.' (cf. Nysveen et al., 2005; Cronbach's $\alpha=.95$ ) were used.

Similar to previous studies (Chapter 2) store image was measured by perceptions toward price, quality of products and level of service provided in the store. The items 'I feel that the products in this store are expensive.' 'I think that the products in this store are more expensive than in others.', ' I think that the workmanship of the products in this store is very high.', 'I have the feeling that the products in this store are of good quality.', and 'I think this store will provide good services' were used (Cronbach's $\alpha=.90$ ).

Intention tovisit thestarewas measured by asking participants "Pleaseindicatetowhat extent you arewilling to visit this stare" on a slider bar from "Not willing to visit at all" to "I am extremely willing to visit".

Peceived complexity and percived addiness were measured by statements "Please indicateto what extent you think this streis complex" and "Plesseindicateto what extent youthink this streis adaly" Participants indicated their agreement on a slider bar with 'Not at all complex/ orderly' and 'Extremely complex/ orderly' as anchors.

\subsubsection{Analysis plan}

The data of this experiment were analyzed and results are presented in three parts.

Thefirst part (Section 3.4.1) focused on the effect of perceived complexity and perceived orderliness on consumers' intention to visit the store. Randomintercept mixed models that included the effect of complexity (linear and curvilinear) and orderliness (linear) and their interaction on intention to visit the 
store were applied. Complexity and orderliness scores were grand-mean centered before squaring and multiplying them, to create the terms for capturing the curvilinear and the (linear-linear and curvilinear-linear) interaction effects. In this way the coefficient for the main effect of perceived complexity reflects its effect at the mean value of perceived orderliness, and vice versa. Models with and without curvilinear terms were compared.

Moreover, shopping motivation (utilitarian coded as - 1 versus hedonic coded as 1) and its interaction with perceived complexity and perceived orderliness were included in the model to verify the moderating role of shopping motivation on the effects of perceived complexity and orderliness. Models with and without shopping motivation and its interaction with other predictors were compared.

The seond part (Section 3.4.2) investigated the mediating roles of expected shopping process and perceived store image in the relation between complexity and orderliness on intention to visit the store. The analyses followed the fourstep procedure proposed by Baron and Kenny (1986). The principal idea of this approach is to statistically verify all the relevant effects on a step-by-step basis. The first step of the Baron and Kenny (1986) procedure coincides with the analyses that are described in Section 3.4.1. It tested the total effects of complexity and orderliness on intention to visit the store (analyzed in Section 3.4.1). The second step verified the effects of perceived complexity and perceived orderliness on the mediators (in Section 3.4.2a.). The third step tested the effects of expected shopping process and the perceived store image, (mediators) on intention to visit the store (Section 3.4.2b.). The last step subsequently examined the conditional direct and indirect effects of perceived complexity and perceived orderliness on intention to visit the store under different motivations (moderator, Section 3.4.2c.). Similar models and analyses as used in the first part were applied in all steps except the third step. The third step replaced complexity and orderliness by expected shopping process and 
store image as predictors. To test the effects of the predictors on the outcomes in each step, the random-intercept mixed models included linear and quadratic terms of complexity and the linear term of other predictors were used. The scores were also grand-mean centered.

In the first and the second part of the data analysis, differences in perceived complexity and orderliness were taken for granted, regardless of how they relate to differences in store layout design's attributes. Thethird part (Section 3.4.3) explored how perceived complexity and perceived orderliness of the store vary by the store-layout design's attributes (shelf length, shelf shape, and shelf orientation). A random-intercept linear mixed model was employed to test the attributes' effect and the LSD procedure for post hoccomparisons was used to test for pairwise differences in the mean values between the levels of each store layout design's attribute.

Estimates of effect sizes except the size of indirect effects, were based on Cohen's f (Selya, Rose, Dierker, Hedeker, \& Mermelstein, 2012). These were calculated by comparing the full model (including all effects) with models that left out the effect of interest. In addition, when calculating effect sizes, to avoid any confounding between the effects of the higher-order (multiplicative and quadratic) terms and simpler (e.g., linear) terms all lower-order terms were partialled out from the higher-order terms (e.g., the partial quadratic term for complexity was constructed by taking the residuals from a regression of the squared complexity scores onto the linear terms for complexity, orderliness, and motivation). In this way, we gave priority to the lower-order effects, similar to the Type II sum of squares in analysis of variance (Landau \& Everitt, 2004, p.164). 
Estimates of the size of indirect effects were based on two calculation methods, namely fullystandardizedmediation fffetsizeand propationmediatedmeasure(Miočević, O 'Rourke, MacKinnon, \& Brown, 2018). The fully standardized mediation effect size represents the predicted change on the dependent variable, measured in standard deviations, due to the indirect effect of a one-standard-deviation increase in the independent variable (Miocevic et al., 2018). Even though there is no consensus about the best indirect effect size measure for models with more than two mediators, the fully standardized mediation effect size has been shown to be relatively unbiased and efficient in the two-mediator model compared to proportion or ratio measures (Miocevic et al., 2018). However, there is no standard rule of thumb to label indirect-effect size as small, medium, or large. Thus, we additionally reported the proportion mediated measure that represents the proportion of indirect effect compared to the total effect (Miocevic et al., 2018). This measure can give an idea of how large the indirect effects are compared to the total effect even without a rule of thumb.

The result section emphasizes solely effects of predictors with medium or large total or direct effect sizes $(\geq 0.15)$. Effects with a small or negligible effect size are not explained, but they are shown in the Tables 3.1 - 3.3 or Appendixes $3.2-3.3$.

\subsection{Results}

\subsubsection{Effects of perceived complexity and perceived orderliness on consumers' intention to visit the store}

Total effects of perceived complexity and perceived orderliness on intention to visit the store are shown in Table 3.1. Perceived complexity and perceived orderliness had a negative correlation of $\mathrm{r}=-.44, \mathrm{p}<.001$. Perceived complexity had low negative correlation with intention to visit $(r=-.34, p<.001)$, whereas 
perceived orderliness had a moderate positive correlation with intention to visit $(\mathrm{r}=.68, \mathrm{p}<.001)$. The quadratic term of complexity and its curvilinear-linear interaction with perceived orderliness were included in the model because their joint contribution to the model is significant $\left(\chi^{2}(2)=32.64, \mathrm{p}<.001^{2}\right)$. In other words, this suggests a significant curvilinear effect of perceived complexity and/ or the curvilinear-linear interaction effect of perceived complexity and perceived orderliness. In this section, all the predictors were still included in the model to prevent overestimation of orderliness' effects, even though some effects (e.g., effect of perceived complexity on mediators) were small.

Results revealed a significant and strong effect of perceived store orderliness on intention to visit the store. In line with $\mathrm{H} 1 \mathrm{~b}$, more orderly stores attracted higher intentions to visit than less orderly stores ( $b=0.42, p<.001$ ). In contrast, even though we found significant effects of other predictors (i.e., a negative linear effect of perceived complexity $(b=-0.04, p<.050)$ and a complexity $x$ orderliness interaction (curvilinear - linear; $b=0.12 \times 10^{-3}, p<.001$ )), their effects were either small or negligible (Cohen's $\mathrm{f} \leq .015)$. The main effect of complexity and the interaction effect of complexity x orderliness (curvilinear - linear) also deviated from our prediction regarding a curvilinear effect of complexity on intention to visit (H1a) and a positive effect of complexity at high orderliness (H1c). H1a and H1c are accordingly not supported.

\section{Modkatingrde of shoppingmativation on total effets of percived complexity and ordediness} onintention tovisit. The addition of shopping motivation and its interaction effects resulted in a significant improvement in the fit of the models with linear terms $\left(\chi^{2}(4)=13.66, \mathrm{p}<.010^{3}\right)$, but they did not significantly improve the model with

\footnotetext{
2 A comparison of 1 ). the model with and 2). the model without the quadratic term of complexity and its curvilinear-linear interaction with perceived orderliness was made.

${ }^{3} \mathrm{~A}$ comparison of 1). the linear model with shopping motivation (Predictors: Comp, O rd, Comp x Ord, Motiv, Comp x Motiv, Ord x Motiv, Comp x Ord x Motiv) with 2). the linear model without shopping motivation and its linear-linear interaction with other predictors.
} 
linear and quadratics terms $\left(\chi^{2}(2)=0.77, \mathrm{NS}^{4}\right)$. We found that effect sizes of the interaction between orderliness/complexity with shopping motivation were negligible (Cohen's $\mathrm{f}^{2}=.000$ ). Therefore, overall effects of complexity/ orderliness on intention to visit the store did not depend on shopping motivation.

Table 3.1: Effects of complexity, orderliness, and shopping motivation on intention to visit the store

\begin{tabular}{|c|c|c|c|c|}
\hline & \multicolumn{4}{|c|}{ Effect of $\mathrm{X}$ and $\mathrm{MO}$ on $\mathrm{Y}$} \\
\hline & \multicolumn{4}{|c|}{ Intention to visit } \\
\hline & $b$ & $S E$ & $p$ & $f^{2 *}$ \\
\hline \multicolumn{5}{|c|}{ Average effect across motivation } \\
\hline Complexity (Comp) & -0.04 & 0.02 & .032 & .02 \\
\hline Orderliness (Order) & 0.42 & 0.02 & .000 & .58 \\
\hline Comp*Order & $0.92 \times 10^{-3}$ & $0.59 \times 10^{-3}$ & .115 & .00 \\
\hline Comp $^{2}$ & $-0.96 \times 10^{-3}$ & $0.64 \times 10^{-3}$ & .133 & .00 \\
\hline Comp $^{2 *}$ Order & $0.12 \times 10^{-3}$ & $0.02 \times 10^{-3}$ & .000 & .02 \\
\hline \multicolumn{5}{|c|}{ Difference (hedonic - utilitarian) } \\
\hline Motivation (Motiv) & -0.52 & 0.59 & .380 & .00 \\
\hline Comp*Motiv & 0.03 & 0.02 & .076 & .00 \\
\hline Order*Motiv & 0.01 & 0.02 & .628 & .00 \\
\hline Comp*Order*Motiv & $1.08 \times 10^{-3}$ & $0.59 \times 10^{-3}$ & .064 & .00 \\
\hline Comp $^{2 *}$ Motiv & $0.04 \times 10^{-3}$ & $0.64 \times 10^{-3}$ & .946 & .00 \\
\hline Comp $^{2 *}$ Order*Motiv & $-0.02 \times 10^{-3}$ & $0.02 \times 10^{-3}$ & .303 & .00 \\
\hline Intercept (mean) & 0.81 & 0.59 & .172 & - \\
\hline variance & 61.03 & 6.94 & .000 & \\
\hline Pseudo $\mathrm{R}^{2}$ & 0.49 & & & \\
\hline
\end{tabular}

Note: $\mathrm{MO}=$ moderator, * effect size of predictor $\left(f^{2}\right)=\frac{R_{A B}^{2}-R_{A}^{2}}{1-R_{A B}^{2}}$ : small $f^{2} \geq 0.02$, medium $f^{2} \geq 0.15$, large $f^{2} \geq 0.35$.

\footnotetext{
4 A comparison of 1). the quadratic model with shopping motivation (linear model and Comp2, Comp ${ }^{2}$ x Ord, Comp ${ }^{2}$ x Motiv, Comp ${ }^{2}$ x Ord x Motiv) with 2). the quadratic model without shopping motivation and its linear-linear and linear-quadratic interaction with other predictors.
} 


\subsubsection{The mediating role of expected shopping efficiency, expected shopping enjoyment and perceived store image}

It was predicted that the expected shopping process and perceived store image mediated the effects of complexity and orderliness on intention to visit the store. The relevant hypotheses are tested in the following sections following Baron and Kenny's procedure of mediation analysis.

\section{a. Effects of complexity and orderliness on consumers' expected shopping process and perceived store image (mediators)}

Table 3.2 presents the effects of complexity (curvilinear) and orderliness (linear) and their interaction on expected shopping efficiency and enjoyment, and perceived store image. Inclusion of the quadratic term of complexity and its interaction with perceived orderliness improved the fit of the models predicting expected shopping efficiency $\left(\chi^{2}(2)=28.75, \mathrm{p}<.001\right)$, expected shopping enjoyment $\left(\chi^{2}(2)=33.88, \mathrm{p}<.001\right)$ and perceived store image $\left(\chi^{2}(2)=21.64\right.$, $\mathrm{p}<.001)$.

\section{1). Expeted shqppingefficiengy}

Results seem to support our predictions ( $\mathrm{H} 2 \mathrm{a}$ and $\mathrm{H} 3 \mathrm{a}$ ) for a negative linear effect of perceived complexity $(b=-0.06, p<.010)$, and a positive linear effect of perceived orderliness on expected shopping efficiency $(b=0.36, p<.001)$, respectively. However, only perceived store orderliness possessed a large effect size (Cohen's $f^{2}=.36$ ). More orderly stores were expected to facilitate a higher shopping efficiency than less orderly stores. The effect of complexity was small (Cohen's $f^{2}=.02$ ). The perceived complexity x perceived orderliness interaction (linear-linear) was insignificant ( $b=0.00, N S)$, which does not support H4a.

In addition, results showed that the curvilinear-linear interaction effect of complexity $\mathrm{x}$ orderliness was highly significant $(\mathrm{p} \leq .001)$, but its effect size was 
negligible (Cohen's $f^{2}=.01$ ). Thus, only the positive effect of orderliness on shopping efficiency is large enough to be considered relevant.

\section{2). Expeted Shopingerjomett}

Similar to the effects on shopping efficiency, the findings support (H3b) that perceived store orderliness significantly increased expected shopping enjoyment $(b=0.26, p<.001)$. This effect was moderate in size (Cohen's $f^{2}=.27$ ). In contrast, the effect of perceived complexity on expected shopping enjoyment was insignificant ( $b=0.01, \mathrm{NS}$ ), and $\mathrm{H} 2 \mathrm{~b}$ is not supported. Besides, the curvilinear-linear interaction effect of perceived complexity $\mathrm{x}$ perceived orderliness on expected shopping enjoyment was significant $(b=0.26, p<.001)$. However, the patterns of interaction deviated from prediction. At low to moderate orderliness effects of complexity were in an inverted-U-pattern as predicted. In contrast, at high orderliness the effect of complexity was in a U-pattern (instead of the expected positive linear pattern). Moreover, its effect size was also negligible (Cohen's $\mathrm{f}^{2}=.01$ ). Therefore, $\mathrm{H} 4 \mathrm{~b}$ is not supported and these interaction effects are not discussed further.

\section{3). Perceived stareimage}

Results support H3c for the significant effect of perceived orderliness on perceived store image $(b=0.16, p<.001)$. This effect had a moderate effect size (Cohen's $f=.19$ ). Higher perceived store orderliness led to a more upscale image. Again, even though the effects of perceived complexity (a positive linear term; $b=0.03, p<.010$ ) and perceived complexity x perceived orderliness interaction (a curvilinear-linear interaction; $b=0.00, p<.001$ ) were significant, their contribution was negligible (Cohen's $f \leq .01$ ). Therefore, H2c regarding the curvilinear effect of complexity and $\mathrm{H} 4 \mathrm{c}$ regarding the curvilinear-linear interaction of complexity and orderliness are not supported. 


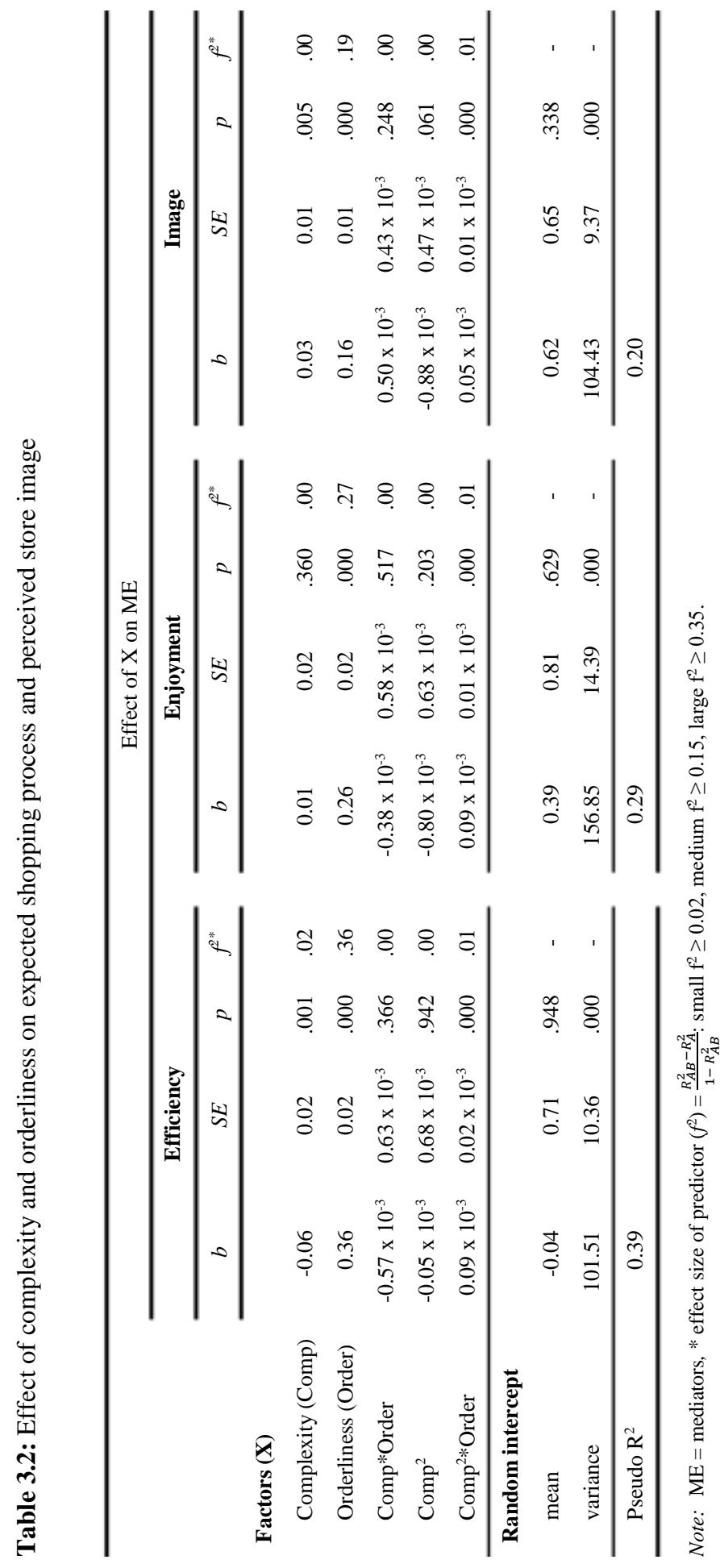




\section{Insummary}

All in all, the results showed that the effects of orderliness on expected shopping efficiency, expected shopping enjoyment and perceived store image were positive. In contrast, effects of complexity and the interaction effects of complexity and orderliness on all mediators were either small or negligible and the patterns of effects deviated from our predictions. G enerally, we can conclude that the effects of orderliness on all mediators surpassed the effects of complexity and complexity $\mathrm{x}$ orderliness interaction.

\section{b. Impact of expected shopping efficiency, expected shopping enjoyment and perceived store image on intention to visit the store}

Correlations among expected shopping efficiency, expected shopping enjoyment and perceived store image were examined to check for multicollinearity problems. All the predictors were highly correlated (efficiencyenjoyment: $\mathrm{r}=.79, \mathrm{p}<.001$; efficiency-image: $\mathrm{r}=.61, \mathrm{p}<.001$; enjoymentimage: $\mathrm{r}=.68, \mathrm{p}<.001$ ). They did, however, not show a multicollinearity problem (tolerance's $>0.37, \mathrm{VIF}^{\prime} \mathrm{s}<2.70$ ).

Results from the mixed model showed significant positive linear effects of expected shopping efficiency $(b=0.39, p<.001)$, expected shopping enjoyment $(b=0.24, p<.001)$ and perceived store image $(b=0.14, p<.001)$ on intention to visit the stores across shopping motivations. $\mathrm{H} 5$ seems to be supported. However, only expected shopping efficiency gave a small effect size (Cohen's $\mathrm{f}^{2}$ $=.08$ ). Effects of expected shopping enjoyment and perceived store image were negligible (Cohen's $\mathrm{f}^{2}=.01$ ). The effects of shopping motivation and its interaction with other factors were insignificant; therefore, shopping motivation does not seem to moderate the effects of expected shopping efficiency and enjoyment, and perceived store image. 


\section{c. Direct and indirect effects of perceived complexity and perceived ordenliness on intention to visit the store}

The significant direct and indirect effects of perceived complexity and perceived orderliness on intention to visit are summarized in Figure 3.3. Like the previous parts, this part presents the effects that are significant and large or medium. D etailed effects (i.e., coefficient of indirect effect, Sobel test, pvalue and indirect effect size) of perceived complexity, perceived orderliness, and their interaction from the moderated mediation analysis are shown in Appendixes 3.2 and 3.3.

Results showed significant direct and indirect effects of orderliness on intention to visit the store. High orderly stores directly enhanced intention to visit compared to low orderly stores $(b=0.31, \mathrm{p}<.001)$. The direct effect of perceived orderliness on intention to visit was moderately strong (Cohen's $\mathrm{f}^{2}=$ .27). Moreover, the effect of orderliness on intention to visit was partially mediated by the expected shopping efficiency $(b=0.04,95 \%$ CI $[0.02,0.06])$, the expected shopping enjoyment $(b=0.06,95 \% \mathrm{CI}[0.04,0.07])$ and the perceived store image $(b=0.01,95 \%$ CI $[0.00,0.02])$. Therefore, H6b, which predicted full mediating effects of expected shopping process and perceived store image on relation of perceived orderliness and intention to visit the store, is partially supported. The standardizedindiret effet sizeof store orderliness driven through expected shopping efficiency, expected shopping enjoyment and perceived store image was 0.05, 0.06, and 0.01, respectively. The propation of indiret effet of orderliness through expected shopping efficiency, expected shopping enjoyment and perceived store image was $9.5 \%, 13.5 \%$ and $3 \%$, respectively, of the large total effect of orderliness $(b=0.42$, Cohen's $f=.58)$. $\mathrm{O}$ ur predictions regarding the indirect effects of perceived complexity (H6a) and indirect effects of complexity x orderliness interaction (H6c) were not supported due to the insignificant or the significant, but small or negligible indirect effect size of them. 


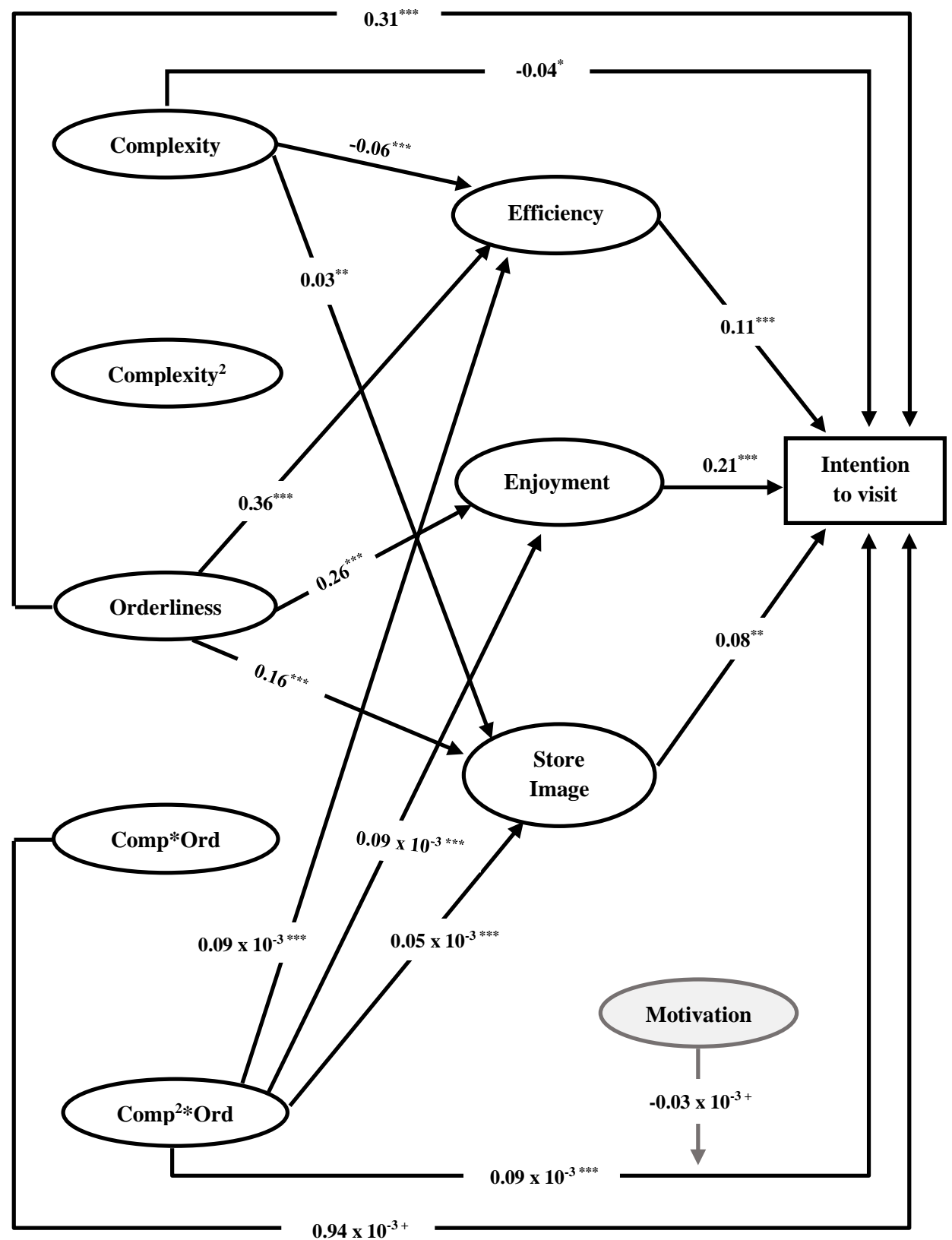

Figure 3.3: Significant direct and indirect effect of complexity and orderliness on intention to visit the store

Note: The models for the moderated-mediation analysis included all direct and indirect effects, but this figure presents only significant effects. Significance of the indirect effects was assessed using the Sobel test.

Significant level: $p<.10^{+}, p<.05^{*}, p<.01^{* *}, p<.001^{* * *}$ 
In terms of the moderator, the addition of shopping motivation and its interaction effects to model with complexity/ orderliness, their interactions and mediator resulted in a significant improvement in the fit of the models with linear terms $\left(\chi^{2}(7)=16.69, \mathrm{p}<.050^{5}\right)$, but they did not improve the model with linear and quadratics terms $\left(\chi^{2}(2)=3.29, \mathrm{NS}^{6}\right)$. The effect size of the interaction between orderliness/ complexity with shopping motivation was again negligible (Cohen's $f^{2}=.000$ ). Therefore, in contrast to H7, shopping motivation did not moderate any total (see section 3.4.1), direct and indirect effects of orderliness ( $p>$.221). This means that orderliness is equally important for the intention to visit regardless of consumers' shopping motivation. The standardized indirect effects of other predictors were smaller than .01 (see Appendixes 3.2 and 3.3).

\subsubsection{Effect of store-layout design's attributes on perceived store complexity and orderliness}

Table 3.3a gives the statistical significance and size of the different effects of store layout design's attributes and Table 3.3b gives observed marginal means and standard deviations.

O verall, results confirmed that store layout design's attributes (length, shape and orientation) led to significant differences in perceived complexity and perceived orderliness (which had a negative correlation of $\mathrm{r}=-.44, \mathrm{p}<.001$ ). However, considering the effect size, only shelf orientation showed sizeable contributions, with a moderate effect on perceived complexity (Cohen's $f^{2}=.21$ ) and a large effect on perceived orderliness (Cohen's $f^{2}=.91$ ). Especially shelves at diverse

\footnotetext{
5 A comparison of 1). the linear model (linear and linear-linear interaction terms of predictors and mediators) with shopping motivation and its linear-linear interaction with other predictors, with 2). the linear model without shopping motivation and its linear-linear interaction with other predictors. ${ }^{6}$ A comparison of 1). the model with linear and quadratic terms (linear, linear-linear interaction, quadratics and quadratics-linear interaction terms of predictors) with the shopping motivation and its linear-linear and linear-quadratic interaction with other predictors and 2). the similar model without shopping motivation and its interactions.
} 
angles led to higher perceived complexity and lower perceived orderliness. These effects outweighed all other effects including shelf length main effect, shelf shape main effect, shelf shape $x$ shelf orientation interaction effect on perceived complexity/ orderliness, and shelf shape $x$ shelf orientation $x$ shelf length interaction effect on perceived orderliness. Among these significant effects, only two effects (shelf length main effect on perceived complexity and shelf shape $x$ shelf orientation interaction effect on perceived orderliness) were small (Cohen's $\left.\mathrm{f}^{2} \mathrm{~S}=.02\right)$ and the rest was negligible (Cohen's $\left.\mathrm{f}^{2} \mathrm{~S} \leq .01\right)$.

Table 3.3a: Effects of store layout design's attributes on perceived complexity and perceived orderliness of stores

\begin{tabular}{|c|c|c|c|c|c|c|}
\hline \multirow{2}{*}{$\begin{array}{l}\text { Effect of store layout } \\
\text { design's attributes }\end{array}$} & \multicolumn{3}{|c|}{ Complexity } & \multicolumn{3}{|c|}{ Orderliness } \\
\hline & $F(d f 1, d f 2)$ & $p$ & $f^{*}$ & $F(d f 1, d f 2)$ & $p$ & $f^{2}$. \\
\hline \multicolumn{7}{|l|}{ Main effects } \\
\hline Length & $40.21(1,2142)$ & $<.000$ & .02 & $30.22(1,2142)$ & $<.000$ & .01 \\
\hline Shape & $4.19(3,2142)$ & .006 & .01 & $6.84(3,2142)$ & $<.000$ & .01 \\
\hline Orientation & $229.94(2,2303)$ & $<.000$ & .21 & $977.52(2,2303)$ & $<.000$ & .91 \\
\hline \multicolumn{7}{|l|}{ Two- way interactions } \\
\hline Length*Shape & $0.28(3,2142)$ & .844 & .00 & $0.23(3,2142)$ & .876 & .00 \\
\hline Length*Orientation & $0.24(2,2447)$ & .787 & .00 & $0.70(2,2447)$ & .498 & .00 \\
\hline Shape*Orientation & $3.98(6,2035)$ & .001 & .01 & $7.04(6,2034)$ & $<.000$ & .02 \\
\hline \multicolumn{7}{|l|}{$\begin{array}{l}\text { Three-way } \\
\text { interactions }\end{array}$} \\
\hline \multicolumn{7}{|l|}{ Random Intercept } \\
\hline Mean (SE) & $66.60(2.06)$ & $<.000$ & & $27.99(1.86)$ & $<.000$ & \\
\hline Variance (SE) & $79.65(10.18)$ & $<.000$ & & $65.44(8.35)$ & $<.000$ & \\
\hline Pseudo $\mathrm{R}^{2}$ & 0.21 & & & 0.50 & & \\
\hline
\end{tabular}

Note: * Cohen's $f^{2}$ indicates the size of a main or interaction effect of the store layout design's attributes. It is calculated by $f^{2}=\frac{R_{A B}^{2}-R_{A}^{2}}{1-R_{A B}^{2}}$, where $R_{A B}^{2}$ is the pseudo $\mathrm{R}^{2}$ of the model that includes all effects and $R_{A}^{2}$ is the pseudo $\mathrm{R}^{2}$ of the model that includes all effects except for the effect of interest. Small $\mathrm{f}^{2} \geq 0.02$, medium $\mathrm{f}^{2} \geq 0.15$, large $\mathrm{f}^{2} \geq 0.35$. 
Table 3.3b: Effects of store layout design's attributes on perceived complexity and perceived orderliness of stores (estimated marginal means and standard deviations)

\begin{tabular}{|c|c|c|c|c|c|}
\hline \multirow{2}{*}{\multicolumn{2}{|c|}{$\begin{array}{c}\text { Effect of store layout design's } \\
\text { attributes }\end{array}$}} & \multicolumn{2}{|c|}{ Complexity } & \multicolumn{2}{|c|}{ Orderliness } \\
\hline & & $M$ & $S D$ & $M$ & $S D$ \\
\hline \multirow[t]{2}{*}{ Length } & Long & $48.62^{\mathrm{b}}$ & 22.52 & $56.57^{\mathrm{a}}$ & 24.31 \\
\hline & Short & $53.45^{\mathrm{a}}$ & 22.95 & $52.83^{b}$ & 25.28 \\
\hline \multirow[t]{4}{*}{ Shape } & Rectangular & $49.19^{c}$ & 24.77 & $56.98^{\mathrm{a}}$ & 26.88 \\
\hline & Oval & $51.26^{\mathrm{ab}}$ & 21.39 & $55.00^{\mathrm{b}}$ & 22.67 \\
\hline & Mix-Rep (MR) & $53.03^{\mathrm{a}}$ & 21.85 & $52.42^{\mathrm{c}}$ & 24.70 \\
\hline & Mix-Sym (MS) & $50.65^{\text {bc }}$ & 23.19 & $54.40^{\mathrm{b}}$ & 24.89 \\
\hline \multirow[t]{3}{*}{ Orientation } & Parallel & $42.91^{\mathrm{c}}$ & 21.72 & $68.98^{\mathrm{a}}$ & 17.36 \\
\hline & Playful & $47.73^{\mathrm{b}}$ & 20.37 & $62.04^{\mathrm{b}}$ & 18.56 \\
\hline & Diverse Angles & $62.50^{\mathrm{a}}$ & 21.78 & $33.01^{\mathrm{c}}$ & 21.98 \\
\hline
\end{tabular}

Note: The characters a - c indicate pairwise significant differences from post hoc LSD tests at 95\% confident interval, for the main effect of each store layout design's attribute. Means that share the same character are not significantly different from one another.

\subsection{Discussion}

The current study has investigated the role of perceived complexity and perceived orderliness in explaining the effects of store layout designs on consumers' intention to visit the store. We expanded the existing retailing literature on store layout design (Levy \& Weitz, 2012) by applying attributes from environmental psychology (i.e., perceived complexity and perceived orderliness; Nasar, 2000) and subsequently addressed their effects as a function of store layout design's attributes. Moreover, the effects of consumers' expected shopping efficiency, shopping enjoyment and store image that potentially mediate the relationship of perceived complexity, perceived orderliness and intention to visit were examined. Lastly, beyond the conventional store layout design typology (e.g., grid or free-form layout), we provided more detailed information on how store managers could use concrete attributes of store layout design (shelf orientation, shelf length and shelf shape) to manipulate perceived complexity and orderliness, as well as the corresponding consequences of this manipulation. 
This study shows that complexity and orderliness have an effect on cognitive responses, in addition to the effects of complexity and orderliness of environments on emotions, preferences and approach behaviors that have been found in previous studies (D evlin \& Nasar, 1989; Gilboa \& Rafaeli, 2003; Kaplan, 1987; O ostendorp \& Berlyne, 1978). Specifically, effects on expected shopping process and perceived store image have been confirmed. Results show that the effects of the perceived orderliness of a store surpass the effects of perceived complexity and their interaction effect.

The effect of perceived orderliness is consistent with previous studies (Chapter 2; D evlin \& Nasar, 1989; Gilboa \& Rafaeli, 2003; O ostendorp \& Berlyne, 1978): orderliness of stores enhances expected shopping efficiency, expected shopping enjoyment, perceived store image, and intention to visit. Moreover, the findings show that perceived orderliness has a stronger impact on expected shopping efficiency than on expected shopping enjoyment. This can be ascribed to the fact that orderliness represents organization, legibility, and congruity in the stores. Therefore, it facilitates product search.

We confirm that expected shopping efficiency, expected shopping enjoyment and perceived store image can partly explain the effects of perceived complexity and perceived orderliness of a store on intention to visit the store. Regarding the underlying effect of orderliness, an indirect effect through expected shopping enjoyment gives the highest contribution, followed by expected shopping efficiency and perceived store image. The explanation for these findings is that even though perceived orderliness has weaker influences on expected shopping enjoyment than on expected shopping efficiency, the expected shopping enjoyment exhibits greater impacts on intention to visit. Consequently, the expected shopping enjoyment leads to the stronger indirect effect compared with other mediators. 
In addition to the mediation, we have explored the moderating role of shopping motivation because the effects of perceived complexity and perceived orderliness on intention to visit are expected to be stronger when consumers shop with a utilitarian motivation than with a hedonic motivation. A previous study (Orth \& Wirtz, 2014) has shown that perceived complexity is more dominant for consumers with a utilitarian motivation than for those with a hedonic motivation (stronger negative linear and curvilinear effects at the various levels of orderliness). Even though the statistical significance of results of our study support this previous study, this moderating effect of shopping motivation is very small.

O ur findings demonstrate that the manipulation of concrete attributes of the store layout design have an effect on perceptions of layout complexity and orderliness. The results, however, show only strong impacts of shelf orientation on perceived complexity and perceived orderliness. The former can be dominantly increased by introducing variability in shelf orientation. In contrast, the latter can be intensified by uniform shelf orientation, specifically by parallel orientation.

All in all, the results in our study verify that shelf orientation influences perceived orderliness, and that perceived orderliness affects expected shopping efficiency, expected shopping enjoyment, perceived store image, and intention to visit the store. Effects of perceived complexity and interaction effects of perceived complexity and orderliness are very small and they deviate from previous results (Gilboa \& Rafaeli, 2003; Jang et al., 2018; Orth \& Wirtz, 2014) to some extent. Whereas the previous studies have generally found dominant effects of perceived complexity on pleasure and approach-avoidance behaviors (inverted-U effects; Jang et al., 2018; Kaplan, 1987; Nasar, 2000; positive effects; Gilboa \& Rafaeli, 2003), this study has found relatively stronger effects of perceived orderliness on all expectations and intention to visit. Moreover, the 
effects of perceived complexity on expected shopping enjoyment are insignificant. In addition, the linear-linear and curvilinear-linear interaction effects are insignificant and negligible, respectively. The differences in findings may be attributed to differences in the stimuli used in each study--the current study manipulated only store layout design whereas other studies manipulated multiple elements of environments such as furniture, shelves, products, wall and floor (Jang et al., 2018). When consumers acquire information from store layout design to form their expectations and to make choices, the relation of elements of the entity (shelves and products) or orientation of shelves (orderliness) may be more obvious and easier to process than the details of elements (e.g., quantity and variety of shelf design: complexity). In contrast, when consumers acquire information from the environments consisting of multiple different elements, complexity may be easier to perceive because more elements can bring extremely different perceptions especially for complexity of the store. Therefore, it is important to note that our findings are suitable for explaining effects of complexity and orderliness (in relation to unique effects of store layout design) on intention to visit the store where consumers have limited knowledge or limited real experience with the store.

\subsection{Implications}

For practical implications, this study can guide store managers to choose appropriate store layout designs and their concrete attributes to effectively attract consumers. We suggest that the orderliness of stores is a vital factor that store managers should consider in designing store layout because it enhances positive expectations and intention to visit. The perceived orderliness can be primarily varied by the orientation of shelf arrangement. 
Moreover, even though store layout design itself exerts a smaller effect on perceived complexity and its accompanying consequences, it may intervene the effects of other store elements (e.g., placement of products or store decoration) on perceived complexity. A high number or variety of store elements themselves could lead to higher perceived complexity (Jang et al., 2018) and complex layout could intensify those effects. Therefore, store managers should employ a simple orientation when they plan to build stores with various products and store elements to maintain the appropriate level of complexity. However, when store managers plan to display only a few products or employ very simple decorations, they are recommended to choose a more complex layout, such as those with a playful orientation, to attract consumers' intention to visit.

\subsection{Limitations and recommendations for future research}

There are several limitations that can be addressed in future research. First, as explained before, our findings are limited to consumers' prior expectations (cognitive response) and the first intention to visit new stores. Effects of perceived complexity and orderliness on expectation and intention to visit likely differ from their effects on real experiences and intention to revisit the store (Nadal, Munar, Marty, \& Cela-Conde, 2010). Future works are recommended to compare the effects of complexity and orderliness (as a function of store layout design) on first expectations and real experiences and behavior in a longitudinal study. O ne can focus on the learning and adaptation processes that come into play when consumers visit stores for several times, which are proposed to diminish the effects of store layout design once consumers know the stores (Park, Iyer \& Smith, 1989). The use of 3D simulators can provide chances for researchers to manipulate store layout designs and investigate experiences in settings that closely resemble real settings. 
Second, the results may be specific to our store layout design manipulation. The stores presented in this study may be strongly related to perceived orderliness because other related factors (e.g., products, space and the total area of shelves, customers and other interior designs in the stores) have been controlled. We acknowledge that the effects of store layout design on consumers' responses are not univocal. However, it is also important to know the effects of store layout design in a single controlled setting in terms of other store attributes before combining with the other design factors that can be easily adjusted. Future research should look at the generalisability of our results to other settings (e.g., numbers of products and of store elements, music, decoration) to attain comprehensive guidelines for store managers.

Third, another limitation relates to experimental procedures that may influence how consumers evaluate the stores. Two different procedures were applied when asking participants to evaluate the stores in the current study. The first part asked participants to report their expected shopping process and perceived store image by evaluating an individual layout before moving to the next one. The second part asked participants to evaluate one construct (e.g., intention to visit the store) of all stores together before moving to other construct (i.e., perceived complexity and orderliness). The second procedure may lead to a more relative evaluation than the first one because the second procedure allowed participants to see all store layout designs next to each other on one screen. The results of both parts may depend on a specific reference point that participants applied (Runquist, 1965; van Ittersum, Pennings, Wansink, van Trijp, 2005). However, to the best of our knowledge, there is no study comparing the effects of these different procedures on consumers' evaluation and reference point yet. To clarify this point, future research can explore how the procedures influence consumers' evaluation of stores. It may also provide an understanding of results from different research designs. 
An additional limitation relates to the type of store that we used. This study has employed the layouts of pharmacy stores because D utch pharmacy stores sell both utilitarian (medicine and vitamins) and hedonic products (cosmetics and accessories). We, therefore, expect that consumers can go to the stores with either a utilitarian or a hedonic motivation. Still, consumers' responses to the pharmacy store layout designs may differ from their responses to, for instance, fashion store layout designs (more hedonic focus) and the interpretation of our findings might be somewhat store-specific (Jang et al., 2018; Pan \& Zinkhan, 2006). Moreover, since a specific layout is traditionally applied to a certain type of stores, consumers likely develop their expectations and preferences toward specific store layout design's attributes (stereotype of the store). For the hedonic store (utilitarian store), the complexity of store may be more (less) enjoying whereas orderliness may show the opposite effect. Future studies should compare our findings with the effects of complexity and orderliness in other types of stores.

Lastly, this study presented the stores with various layouts from different perspectives. In reality, the perspective from which people see the store likely depends on the height of people. Taller people may see the store in a better and boarder view than shorter people. For example, if the shelves are low, taller people may be able to see throughout the store even before entering the store. Future research may use the virtual store to customize the perspective that people take according to their height to examine this further. 


\section{Chapter 4}

\section{Using a virtual store as
a research tool to investigate
consumer in-store behavior \\ Using a virtual store as
a research tool to investigate
consumer in-store behavior \\ Using a virtual store as
a research tool to investigate
consumer in-store behavior}

S

8
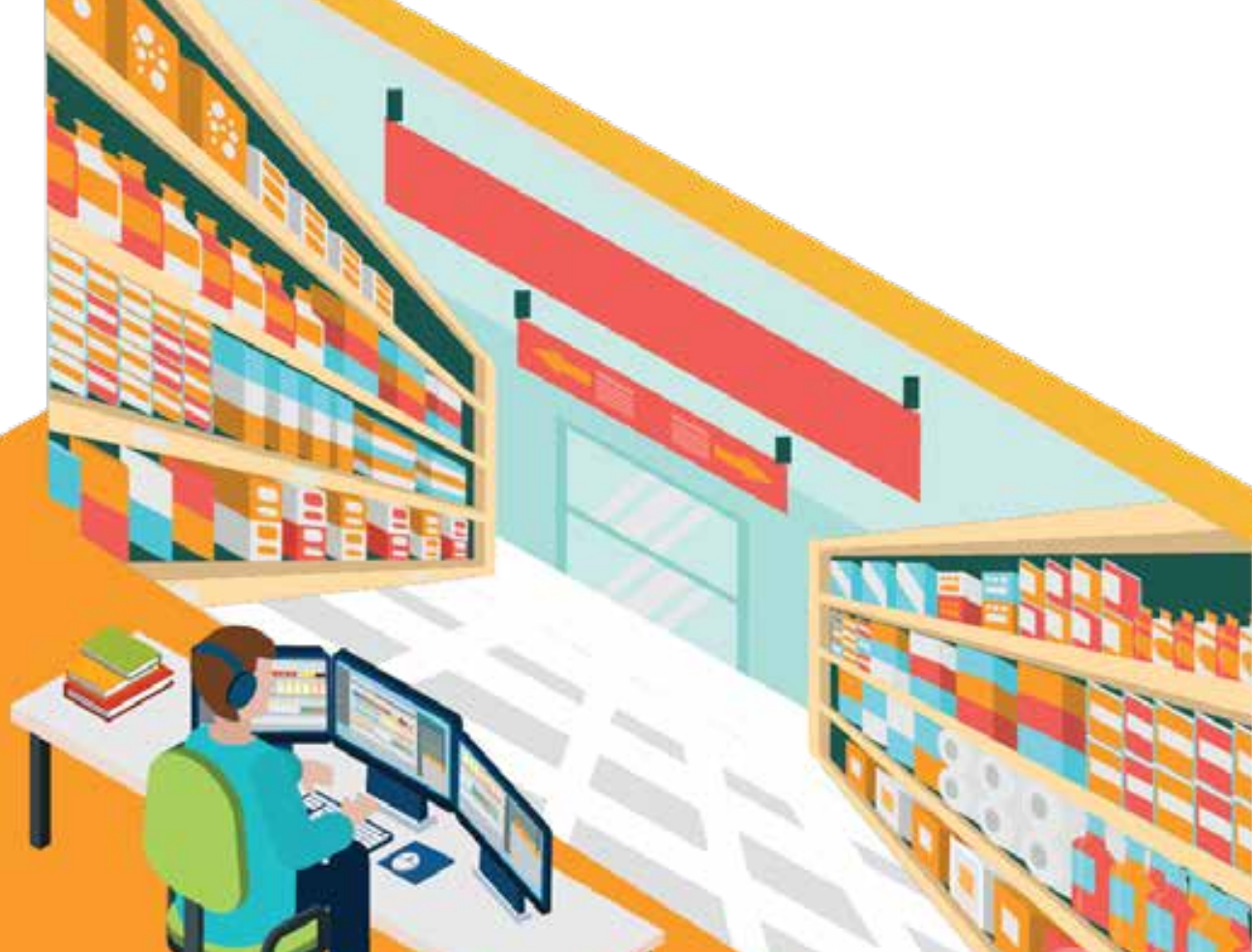

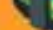

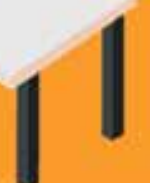

This chapter is published as: Ploydanai, K., van den Puttelaar, J., van Herpen, E., \& van Trijp, J. C. M. H. (2017). Using a virtual store as a research tool to investigate consumer in-store behavior. Journal of Visualized Experiments, (125), e55719, 1-15.doi:10.3791/55719 


\section{Abstract}

People's responses to products and/ or choice environments are crucial to understanding in-store consumer behaviors. Currently, there are various approaches (e.g., surveys or laboratory settings) to study in-store behaviors, but the external validity of these is limited by their poor capability to resemble realistic choice environments. In addition, building a real store to meet experimental conditions while controlling for undesirable effects is costly and highly difficult. A virtual store developed by virtual reality techniques potentially transcends these limitations by offering the simulation of a 3D virtual store environment in a realistic, flexible, and cost-efficient way. In particular, a virtual store interactively allows consumers (participants) to experience and interact with objects in a tightly controlled yet realistic setting. This chapter presents the key elements of using a desktop virtual store to study in-store consumer behavior. Descriptions of the protocol steps to 1) build the experimental store, 2) prepare the data management program, 3) run the virtual store experiment, and 4) organize and export data from the data management program are presented. The virtual store enables participants to navigate through the store, choose a product from alternatives, and select or return products. Moreover, consumer-related shopping behaviors (e.g., shopping time, walking speed, and number and type of products examined and bought) can also be collected. The protocol is illustrated with an example of a store layout experiment showing that shelf length and shelf orientation influence shopping- and movement-related behaviors. This demonstrates that the use of a virtual store facilitates the study of consumer responses. The virtual store can be especially helpful when examining factors that are costly or difficult to change in real life (e.g., overall store layout), products that are not presently available in the market, and routinized behaviors in familiar environments. 


\subsection{Introduction}

It is undeniable that understanding consumers' in-store behavior is of critical importance to achieve effective retail marketing. To aid in this understanding, advanced virtual reality technology, known as the virtual store, can enable studies of consumer behavior using computationally created virtual environments. The virtual-store approach uses a virtual reality system to generate realistic and immersive three-dimensional virtual store environments in which people can interact with the objects in the store. In such virtual store environments, people experience artificially created sensory experiences. Virtual store environments can be either realistic representations of store environments that exist in reality, or imaginary store environments. In addition, the virtual store can be seen as an intermediate tool between traditional consumer research (i.e., text-based surveys, focus groups, or lab experiments), controlled field experiments (i.e., in mock store environments), and field studies (i.e., video captures, personal observations, or tests of product sales promotion; G orini et al., 2010).

Virtual reality applications have considerable research history. As early as 1965, Sutherland (1965) described his "ultimate display" concept, which includes a virtual world that provides sound and tactile feedback. O riginally, attention was mainly focused on the technological hardware, but as this does not provide insights into the effects of virtual reality systems, attention has shifted to the human experience (Steuer, 1992; Witmer \& Singer, 1998). The sense of "presence," of being in the computer-generated world, has consequently become a key to virtual-reality experiences (Baños, et al., 2000; Lessiter, Freeman, Keogh, \& Davidoff, 2001). Presence has been defined as the "subjective experience of being in an environment, even when one is physically situated in another" (Witmer \& Singer, 1998, p 225). From this point of view, "sense of presence" can be retrieved from a participant and refers to the extent to which a person perceives him/ herself to be in an environment. Alternatively, 
Slater (2009) has distinguished between the concepts of presence and immersion, called "place illusion" (PI) and "plausibility illusion" (Psi). PI relates to having a sensation of being in a real place. It is assessed by a set of valid actions or responses that participants can perform to change their perceptions or the environment (e.g., moving the head and eye to change the gaze direction or grasping some object to move it). PI is high when a similar set of responses to change perceptions are required in the virtual reality system compared to the response expected in an equivalent physical environment. Psi accounts for what is perceived in the virtual reality, referring to the illusion that it is actually occurring. A vital component that can lead to Psi is for the virtual reality to provide the illusion that events in the virtual environment over which a participant does not have direct control refer directly to him/ herself. Psi can be measured by tracing any actions or responses that people manifest in response to changes in the virtual reality that originated from outside. For example, if people's heart rates increase when they see an avatar in the virtual environment, this can represent a similar reaction to the real world. Thus, this virtual reality system provides high Psi.

The virtual store technology has been introduced in business and academics to serve several purposes. It can be used as a managerial aid, for instance, to assist category managers of companies in developing a shelf plan for their products. Virtual stores also have their use in clinical settings, to measure emotional responses to food for patients with an eating disorder (G orini et al., 2010) or as a screening tool for mild cognitive impairment (Zygouris et al., 2015). A more common use of virtual stores in research, however, is to assess consumer in-store behaviors and consumer responses to changes in the store environment, such as price changes (Waterlander, Blakely et al., 2016; Waterlander, Mhurchu, \& Steenhuis, 2014; Waterlander, Steenhuis, de Boer, Schuit, \& Seidell, 2012), different setups of point-of-sale displays (A. Kim et al., 2014), different packaging options (van Herpen, Immink, \& van den Puttelaar, 2016), different 
nutritional labels on the backsides of product packages (D ucrot et al., 2016), and stock levels (van Herpen, Pieters, \& Zeelenberg, 2009). In addition, the virtual store is currently used to help create and test public health interventions to stimulate healthier food choices among children (Berneburg, 2007). Due to various benefits stated previously, virtual store technology and hardware are in rapid development. Therefore, this chapter will focus on the human experience and describe the essential elements of studies using virtual reality in general. All essential information obtained from the current virtual store system will be demonstrated.

Currently available virtual store systems can be briefly categorized as: 1) non-immersive (e.g., desktop), 2) semi-immersive (e.g., projection, CAVEsystems), and 3) fully-immersive (e.g., head-mounted displays). Each system likely brings different levels of immersion, presence, PI, and Psi depending upon the support system. However, because the measures of immersion, presence, PI, and Psi are bound to the specific sensorimotor contingencies that each system supports, a comparison of these indicators across different systems has been deemed impossible (Slater, 2009). In recent years, desktop virtual stores have received more attention and have been used increasingly in research. Even though the virtual store has been regarded as a promising tool for in-store consumer behavior research, expertise on how to use such a virtual store is required to ensure the timely and correct preparation and implementation of experiments. However, up to now, reported studies that comprehensively describe the procedure to conduct virtual store experiments are very scarce. Therefore, this work aims to describe a protocol for conducting consumer research with the desktop virtual store, which is of vital importance.

Generally, research with a virtual store requires: 1) equipment to display the virtual environment, 2) an editor program to enable researchers to build the virtual environment, 3) a virtual representation of the studied object (e.g., several 
elements of a store and products), 4) a consumer interface to navigate the virtual environment and make choices, 5) procedures for running the data collection itself, and 6) a data management system that facilitates data storage and analysis. Most of these will likely be managed by a virtual shop company and a programmer. Researchers should know: 1) how to create a retail store for an experiment in an editor program, 2) how to run data collection with the consumer interface, and 3) how to organize all outputs in the data management program and export outputs to be put into a statistical program. The current chapter will address this information by giving detailed protocol steps for conducting experiments with the desktop virtual store. Additionally, advantages and limitations of using the virtual store in consumer research will be discussed. The detailed protocol described in this chapter can be used to help researchers start and conduct virtual store research.

The desktop virtual store used in this chapter requires hardware (i.e., personal computers (PC), liquid-crystal display (LCD) screens, a three-dimensional (3D) space navigator, a mouse, and a keyboard) and software (i.e., to design a shop and to shop like a consumer in a 3D virtual store). This particular system has been used in prior studies (van Herpen, Immink, \& van den Puttelaar, 2016; van Herpen, van den Broek, van Trijp, \& Yu, 2016).

\subsection{Protocol}

The protocol adheres to the "Generic Protocol Food Choice Simulator," which complies with the Netherlands Code of Conduct for Scientific Practice and has been approved by the Social Sciences Ethics Committee of Wageningen University. 


\subsubsection{Setting up the virtual store equipment}

1. Prepare a sufficiently spacious location for the virtual store display. Prepare all equipment for both the virtual store and the data management program.

Note: The equipment includes two computers (PCs; 1 virtual store PC with a high-capacity memory card for displaying the virtual store, and 1 PC for the data management programs), three 42-inch LCD screens, a computer screen for displaying the data management programs, connecting cables, electronic sockets, a 3D space navigator, 2 mice, and 2 keyboards.

2. Connect all the equipment together, as demonstrated in Figure 4.1.

1). Connect one PC to a computer screen, a keyboard, and a mouse to use the data management program.

2). Place 3 LCD screens next to each other and adjust the left and right screens to give a $180^{\circ}$ field-of-view of the virtual store that appears on the screens.

3). Connect the virtual store PC with the 3 LCD screens, the 3D space navigator, a mouse, and a keyboard. Connect the virtual store PC with the data management PC.

4). Turn both PCs on and adjust the screen resolution of the virtual store PC to "extend multiple displays." Set the left screen to be the main display.

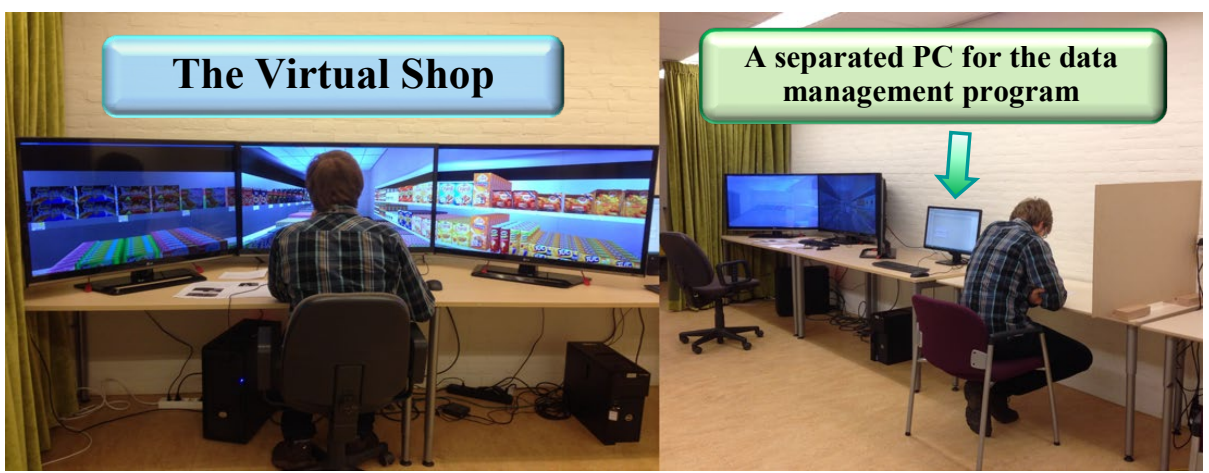

Figure 4.1: The virtual store setup

Note: The virtual store uses one PC equipped with three 42 -inch LCD screens that render $180^{\circ}$ visibility. A separated PC is added to accommodate the data management program. This PC enables a research coordinator to monitor the progress and to start new virtual environments without interrupting participants. 


\subsubsection{Building virtual stores for experiments}

1. Open the virtual store builder interface (called the editor) by double-clicking on the "VirtualShop_Editor.exe" icon on the desktop.

2. O pen a store template that is suitable for the study by clicking "File" and clicking "open." Select the desired store template, "Name.ShopConfig" (e.g., Supermarket001.ShopConfig).

3. Modify the store regarding the experimental conditions.

Note Before modifying the store, a plan of the virtual store should be made based on the research questions and objectives of the study. This includes the type, placement, and number of shelves; the location of product categories on these shelves; and the type and location of products within the product categories.

1). Replace existing products with products of interest, where needed.

a. Use the "up" and "down" arrow keys on the keyboard to zoom in and out from the products, respectively.

b. Click on the icons on the left menu bar to change the view of the virtual store (i.e., left yellow face $=$ front view, top yellow face $=$ top view, right yellow face $=$ side view, and all lateral yellow faces $=$ home view (looking from the top-left of the store)).

c. D ouble-click on a shelf or product and click on the icons on the left menu bar to change the view of this shelf or product.

d. D ouble-click on a shelf of interest and click on the "yellow spot" in the left menu bar to select the isolation mode.

Nde The isolation mode enables the researcher to isolate a shelf with products and to filter out other objects from the screen. This is helpful when filling the shelf.

e. D ouble-click on an existing product and subsequently press the "D elete" button on the keyboard to delete this product.

f. Click on the "blue arrow" in the menu bar to open the product library (see Figure 4.2). Afterwards, click "Product Category" and then select the product category of interest (e.g., fruit). 
g. Drag a selected product (e.g., a tray of apples) by holding the left mouse button and place the product on the desired shelf.

h. Add or replace all the products to match the research interests by repeating the steps from $\mathrm{e}-\mathrm{g}$.

2). Relocate entire shelves.

a. Double-click a shelf that needs to be relocated. Move the shelf to the desired location by left-clicking the entire shelf and dragging the shelf to a new location.

b. Rotate the shelf (if necessary) by holding down the "Ctrl" key and left-clicking the shelf. Turn or move the shelf to the desired angle by moving the mouse.

c. Relocate all necessary shelves to match research interests by repeating steps $2 \mathrm{a}$. - $2 \mathrm{~b}$.

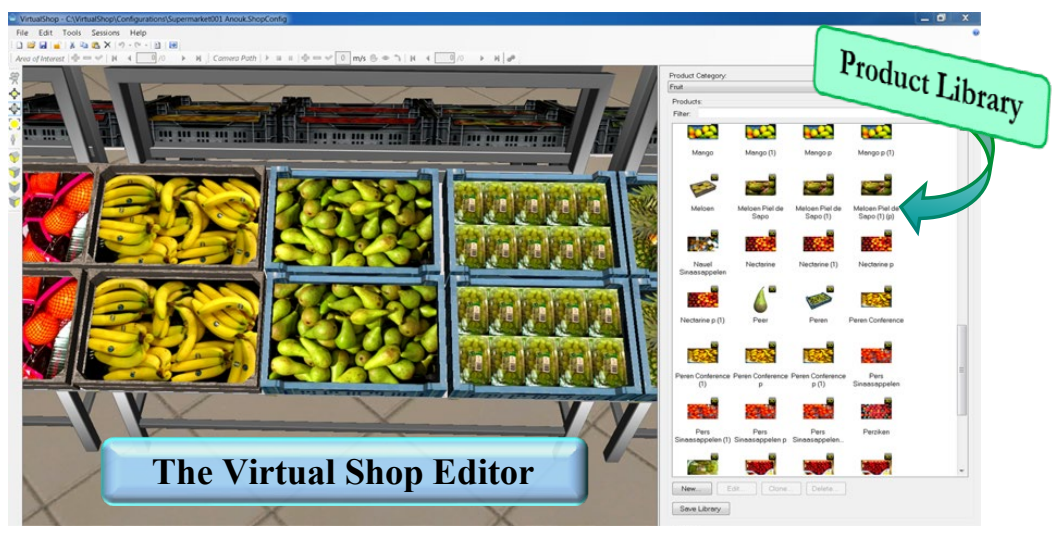

Figure 4.2: The virtual shop editor and examples of products in the product library

Note: The editor has a drag-and-drop interface to allow researchers to easily select products from the library and directly place them on the shelves. In addition, a pop-up window can be used to either add or edit a product by clicking on a product in the library.

4. Save the completed store configuration by using a file name that is nondescriptive of the research condition. Click "File" $\rightarrow$ "save as" $\rightarrow$ "Name.ShopConfig" $\rightarrow$ "save."

Note: It is also possible to build a store from an empty store template. Start by selecting and adding shelves and products from the product library to the empty store. The same procedure from step 3 in 4.2 .2 can be applied. 
5. Build a separated store for a practice session and build more stores according to the experimental conditions, such as supermarkets with different store layouts, following previous steps 1 - 4 in 4.2.2.

Ncte The example study uses a pharmacy store as a practice store.

6. Ask the program creator (see the Table of Materials/ Reagents for contact details in Appendix 4.1) to create new walking paths and decision points for participants if the store layouts are different than the existing store templates.

Nde Shopping paths and decision points are available for the existing store templates. It is also possible to allow participants to walk freely in the store, without predetermined shopping paths.

\subsubsection{Preparing the data management program to record data}

1. D ouble-click on the data management program icon on the desktop to start the program.

2. Open the "Virtual Shop Exp_StartUp" project to create a new project. Select "Open" on the pop-up window $\ddagger$ "Virtual Shop Exp_StartUp" $\ddagger$ "Virtual Shop Exp_StartUp.vop."

3. Click on "Set up project" and select "Live Observation" as an observation source. Select "Continuous Sampling" as an observation method and select "Open-ended observation" as an observation duration.

4. Add input variables that represent the experimental conditions (e.g., the store layout and shopping motivation), if desired.

1). Click on "Set up" in the top menu bar and then click on "Independent Variable." Click on "Add variable" to add more user-defined variables.

2). Fill in necessary details, such as variable name, variable type, predefined value, and so on.

5. Save the project by clicking on "File" $¥$ "Save as." Name the project, "Name of project.vop" and click "Save." 


\subsubsection{Participant selection criteria}

1. Recruit participants without eye disorders, such as color blindness.

\subsubsection{Preparation for the experiment}

1. Prepare all the documents needed to carry out the experiments.

2. Invite a participant to the experiment room. Provide a consent form and request that the participant reads and signs the form prior to the study.

3. Provide experimental instructions that the participant must follow. See Appendixes 4.2 and 4.3.

Note Participants should be informed that visiting a virtual store can lead to virtual reality sickness (K han, Nuijten, \& D eslé, 2011), and they should be urged to report it to the study coordinator when they start experiencing symptoms. If a participant expresses that he/ she is experiencing virtual reality sickness, participation in the experiment should be stopped.

4. Seat the participant in front of the middle LCD screen, at a short distance from the middle screen $(\sim 60 \mathrm{~cm})$. Adjust the chair until the participant's eye level matches the position of the screens.

\subsubsection{Running a practice test}

1. Inform the participant that he/ she will be trained in a practice session to control and get familiar with the virtual store. Encourage the participant to ask questions when he/ she does not fully understand the instructions.

2. Open the virtual store for a practice session.

1). Start the virtual shop program by double-clicking on the VirtualShop_Uviewer icon on the desktop. Click "Begin" to enter the store.

2). Press the " ' " key on the top-left of the keyboard to open the menu bar of the virtual shop program. 
3). Select "SpaceNav" in an "Input" box to choose the type of walking behavior that allows the participants to look and to decide their walking direction freely.

Ncte "SpeceNav" allows participants to look freely through the virtual environment, in any direction, using the 3D space navigator. It also enables participants to decide their own walking direction. Nevertheless, it restricts participants to following predetermined walking lines.

4). Select the "Name of a practice store" in the ShopConfig box and type the "Name of environment" to specify the store environment, such as the Practice Store [e.g., Pharmacy 001].

5). Click on "Reload shop" to open the practice store, and a "Begin" box will subsequently appear.

3. Provide the mouse, 3D space navigator, and keyboard to the participant. Ensure that the front side of the 3D space navigator faces the participant to enable the correct navigation direction.

4. Provide instructions on how to maneuver in the virtual store and instructions for the practice session to the participant. The instruction assigns two practice tasks that request that the participant searches for specific products and selects and/ or returns some products.

Ncte Examples of instructions on how to maneuver in the virtual store and instructions for the practice session are shown in Appendixes 4.2 and 4.3, respectively. A practice session should include all tasks that a participant may need to perform during the main test.

5. Allow the participant to freely practice until he/ she feels familiar with the virtual store. Ensure that the participant understands clearly how to maneuver in the virtual store before starting the main study. Correct or clarify if the participant has made any mistakes.

6. Remind the participant to check the shopping cart (by pressing "F1") before ending the task. Eventually, remind the participant to end the shopping task by pressing "Esc" and then clicking on "Restart."

Ncte It is not necessary to close the virtual shop program because it is faster to load the shop for the main test via an opened interface. 


\subsubsection{Running the main test}

1. Move the participant to another area while the virtual store is prepared for the main test. Inform the participant of the tasks that will follow.

Note Depending on the research objectives, this can include a task to manipulate an independent factor outside the virtual store (in the extensive example, this is a memory task to manipulate shopping motivation), a shopping task (in the virtual store), and a shopping evaluation task (questionnaire).

2. Administer a task to manipulate an independent variable outside the virtual store when relevant to the study objectives. For example, ask participants to describe in detail a recent shopping situation in which they had either hedonic or utilitarian shopping motivations (see Appendix 4.4).

3. Prepare the virtual store for the main study.

1). Click on "Begin" to enter the store and press the " ' " button on the top-left of the keyboard to open the menu bar of the virtual shop program.

2). Load the virtual store and select the virtual environment (walking path), according to the experimental conditions.

3). Keep "SpaceNav" at the box of the Input to obtain the same type of walking behavior as in the practice session.

4). Select the "Name of store condition" in the ShopConfig box and type the "Name of store environment" in the environment box, such as "Supermarket001 [Supermarket001]."

5). Click on "Reload shop" to open the store for the main test; the "Begin" box will appear.

4. Open the data management program on another computer (in which the data management program is installed). Record the data by double-clicking on the data management program icon on the desktop. 
5. Open the project by double-clicking on the "Name of project.vop" that the researcher has previously saved when preparing the data management program.

6. Create a new observation by clicking on "Observe" in the top menu bar and then clicking on "Observation" and "New." Name the observation (e.g., observation 1) and click "OK."

7. Start recording by pressing the red circle button and fill in user-defined variables, such as an experimental condition (e.g., store layout $=1$ and shopping motivation $=1$ (utilitarian motivation)). Click "OK".

Note: The recording button will change from a circle shape (record) to a square shape (stop).

8. Ensure that the program starts recording data.

1). Ensure that the "Status data plugin" and "Status event plugin" windows show green checkmarks.

2). Ensure that "time" is elapsing.

3). Ensure that the number of "sample" column in the "Status data plugin" window is growing (shown in Figure 4.3).

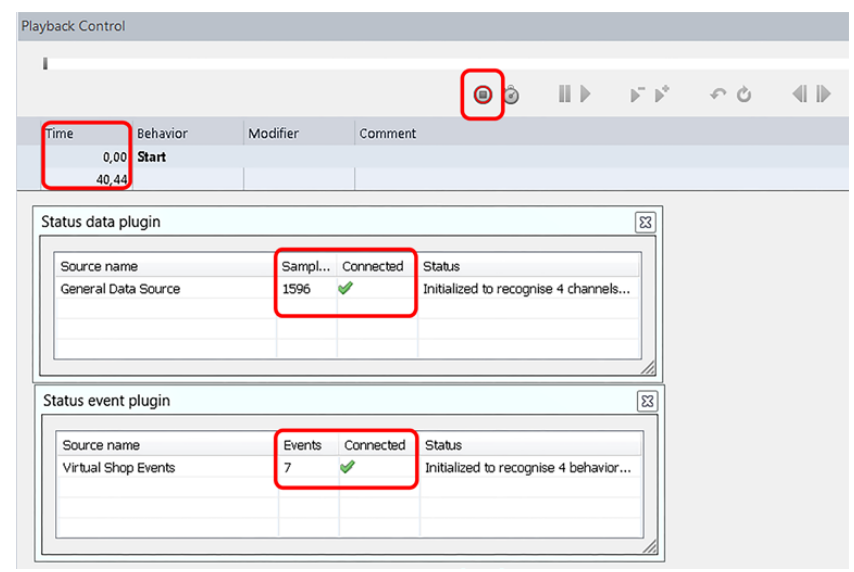

Figure 4.3: An example of the observation window that signals the recording of data

Note: When the data management program is recording data, the "Status data plugin" window and the "Status event plugin" show a green mark. Also, time should be elapsing, and the number of samples should be growing. 
9. Move the participant from the area in which they have been provided with instructions and (optional) a task to manipulate an out-of-store variable, such as shopping motivation, back to the virtual store after he/ she finishes the manipulation task.

1). Seat the participant in front of the middle LCD screen and at a short distance from the middle screen $(\sim 60 \mathrm{~cm})$. A djust the chair until the participant's eye level matches the position of the screens.

10. Provide the mouse, 3D space navigator and keyboard to the participant. Ensure that the front side of the 3D space navigator faces the participant to enable the correct navigation direction.

11. Provide instructions on how to maneuver in the virtual store (see Appendix 4.2), shopping task instructions, and a shopping list for the main study (see Appendix 4.5).

12. Instruct the participant to press "begin" to start visiting the store. Subsequently, leave the participant alone to shop without interruption.

13. Check the data management program on another computer and ensure that the data is recording by checking the "Status data plugin" and the "Status event plugin;" these windows should show an increasing number of samples and events.

14. Wait until the participant finishes shopping in the virtual store. Remind the participant to check the shopping cart (by pressing "F1") and to press "Esc" to complete the shopping task.

Ncte It is very important to press " $E$ sc" to mark the end of the shopping trip and to obtain a correct measurement of the shopping duration.

15. Press the "stop" button of the data management program on the other computer to stop recording (the square button will change back to a circle).

Note Two small windows- "Please wait for receiving event data to finish" and "Please wait for receiving external data to finish" - will pop up during the termination. These windows will close automatically after 2-3 s. 
16. Ask the participant to move to another area and ask him/her to fill out a questionnaire measuring, for example, the participant's shopping experiences, perceptions about the store, and willingness to revisit the store.

17. Return to the data management program and click on the "Visualize" button to check the recorded data; the graph and data of bought products should be shown, and examples of visualized data are shown in Figure 4.4.

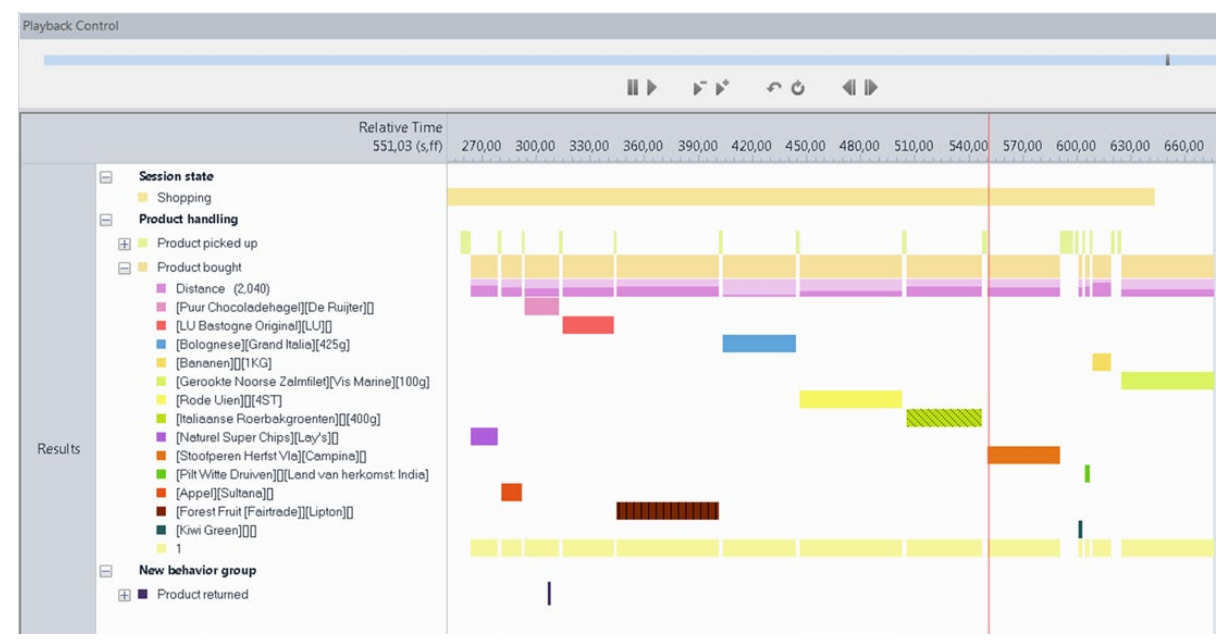

Figure 4.4: The visualization window displayed in the data management program

Note: The orange bar represents the entire shopping time since the participant entered the store until he/she pressed "Esc" to indicate the end of the shopping trip. The green bar denotes the time spent on the examined products. These outputs can be converted into tables that are easy to use in combination with SPSS or other statistical programs.

18. Debrief and give a reward (e.g., a snack product or monetary payment) after the participant finishes.

19. Reload a practice store for a new participant by following substeps 2 - 5 from the step 2 in 4.2.6.

20. Press F9 to close the virtual store after the last participant has finished.

21. Save the data as frequently as possible to avoid data loss. 


\subsubsection{Export the data}

1. Export the data of shopping-related behavior.

1). Set up a filter to select the data of shopping-related behavior.

a. Click "D ata Profile" under the "Analyses" folder on the left menu column; the window will show the data components and the main diagram of the data profile filter.

b. Select the "Nest over Behaviors" box under the "Select Intervals" heading; the box of Nested Behaviors will appear.

c. Select all the behaviors of interest (e.g., shopping duration, products picked up, products bought, and products returned) and click "OK."

d. D rag the "Nested Behaviors" box and drop it between the "Start" and "Results" boxes.

e. Ensure that all boxes are connected with arrows (see Figure 4.5) and that the "Results" box shows the correct number of observations.

Note If the boxes are not automatically connected, a researcher can connect them by clicking the mouse on one box, holding, and making a line to the next box.

2). Click on "Behavior Analyses" under the "Analyses" folder and then click "New Behavior Analysis" to open the table of behavior-related results.

3). Click on "Calculate" on the top left of the menu bar to extract the results. Ensure that the shopping behaviors per participant are shown in separate rows.

Ncte A researcher can change the format of the presented results via a "Setting display."

4). Click the "Export" button to export the data. Name the exported file "Name.xlsx."

Ncte This file will be saved in the "Export" folder of the data management program folder. 


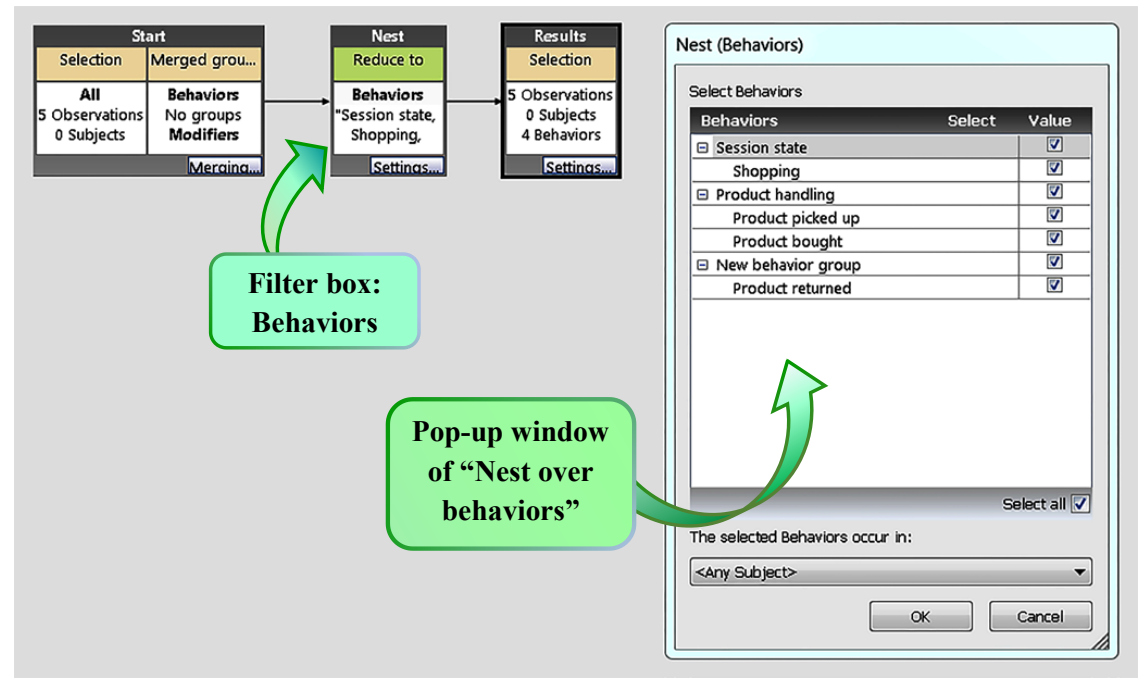

Figure 4.5: Data profile filter scheme for exporting shopping-related behaviors

Note: The data profile filter allows researchers to select and export the data of interest. For example, this scheme opts for shopping-related behaviors (e.g., shopping duration, number of products examined, number of products purchased, and number of products returned).

2. Export the movement-related data.

1). Set up a filter to select the movement-related data.

a. Click "Data Profile" under the "Analyses" folder on the left menu column. Select the "Nest over Speed" box under the "Select Intervals with External Data" heading; the "Nested Speed" box will appear.

b. Set the interval criteria to "Limitation" $\rightarrow$ "Higher than" $\rightarrow$ " 0.100 meters per second (m/sec)" and then click "OK."

Note: This filter will export only the data (e.g., walking speed and time) that occurs when the participant moves in the store.

c. Drag the "Nested Speed" box and drop it between the "Nested behaviors" and "Results" boxes.

d. Ensure that all boxes are connected (i.e., "Start" box $\rightarrow$ "Nested Behaviors" box $\rightarrow$ "Nested Speed" box $\rightarrow$ "Results" box (shown in Figure 4.6) and that the "Results" box shows the correct number of observations. 


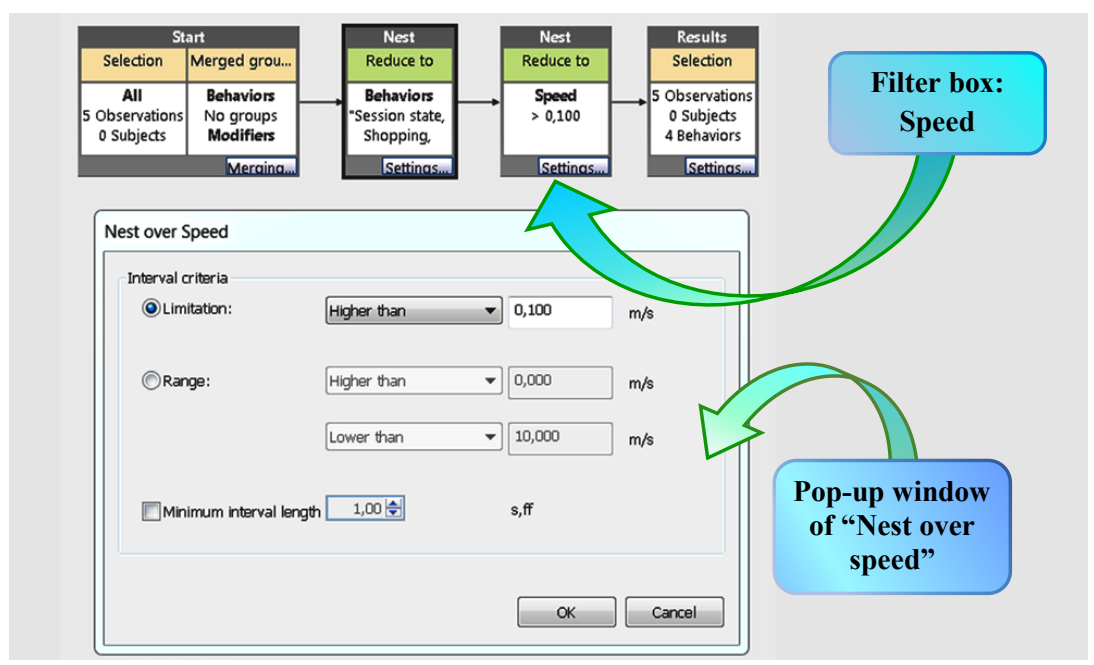

Figure 4.6: Data profile filter scheme for exporting movement-related behavior

Note: This scheme filters the movement-related behaviors (e.g., moving speed and moving time) that occur when participants move in the store (speed $>0.100 \mathrm{~m} / \mathrm{s}$ ). The behaviors and times when participants stand still are filtered out.

2). Export the walking time.

a. Click "Behavior Analyses" under the "Analyses" folder and then click "New Behavior Analysis" to open the table of behaviorrelated results.

b. Click "Calculate" on the top left of the menu bar to extract the results. Ensure that the shopping behaviors per individual are shown in separate rows.

Note: The results should show a lower shopping duration compared to results from shopping related behaviors (substep 1.3, section 4.2.8) because the shopping duration in this part accounts for the time that a participant has walked in the store. These results exclude the time for product examination and for picking up products.

c. Click the "Export" button to export the data. Name the exported file, "Name.xlsx," with a name that differs from the first exported shopping-related data; this file will also be saved in the "Export" folder of the data management program folder. 
3. Export the walking speed.

1). Click "Numerical Analyses" under the Analyses folder and then click "New Numerical Analysis" to open the table of movement-related results.

2). Click "Calculate" on the top left of the menu bar to extract the results. Ensure that the movement-related results, such as speed per participant, are shown in separate rows.

3). Click the "Export" button to export the data. Name the exported file "Name.xlsx;" this file will be saved in the "Export" folder of the data management program folder.

\subsection{Representative results}

The virtual store displayed using a PC with three 42-inch LCD screens has been applied to examine the effects of supermarket layout on consumer shopping behavior (e.g., total shopping time, movement duration and speed, total number of products examined, and total number of products purchased) and perceived shopping experience. The virtual store enables the researcher to flexibly modify the concrete attributes of store layout design (i.e., shelf length and shelf orientation) and to examine these effects in a laboratory setting.

As an example, results from the store layout design study are provided. In the study, supermarket stores were built using 4 different layouts, in which shelf length (short versus long shelves) and shelf orientation (paralleled orientation versus unparalleled orientation) were varied. These stores are depicted in Figure 4.7. 


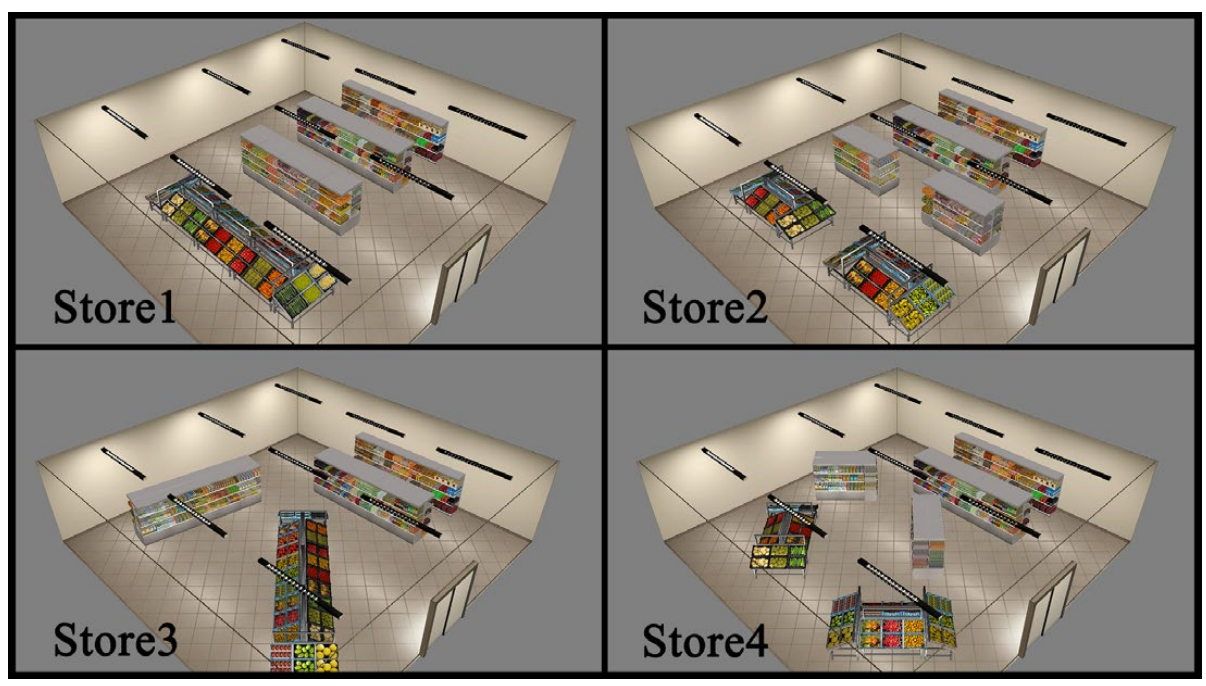

Figure 4.7: Pictures of four store layouts in the store layout experiment

Note: The layout designs differ in shelf length and shelf orientation: 1) store with long and parallel shelves, 2) store with short and parallel shelves, 3) store with long and unparallel shelves, and 4) store with short and unparallel shelves.

The study was performed in accordance with the "Generic Protocol Food Choice Simulator" and approved by the Social Sciences Ethics Committee of Wageningen University. All participants signed an informed consent form prior to participating in the experiments. In the present example, participants $(n=241$, $71 \%$ female) were divided into four groups; each group visited one of four store layouts. Participants were trained on how to use the virtual store in a practice session. Next, they completed a shopping motivation manipulation task that asked them to recall shopping trips with either hedonic or utilitarian shopping motivation. Subsequently, the participants started the main test, in which they were requested to shop for a dinner using a shopping list. Participants were asked to imagine that they were shopping with either hedonic or utilitarian motivation (the same motivation as in the previous recall task was assigned). The shopping list consisted of fixed-choice (8 pre-determined types of products) and freechoice products (undetermined products from the fruit and vegetable category). The free-choice products were used to test the effects of store layout design on 
the number of products purchased. Once the participants finished shopping, they filled in a computer-based questionnaire to evaluate their shopping experiences, perceptions about the store, and willingness to revisit the store.

The data management program recorded shopping behavior (e.g., total shopping time, moving speed, and total number of products purchased). Afterwards, variables were exported from the data management program to 3 separated tables: Tables 4.1, 4.2 and 4.3. Table 4.1 presents the total shopping time, the total number of products examined, and the total number of products purchased/ returned by each participant. Table 4.2 presents the total movement duration (i.e., shopping time) that was selected from a filter of speeds higher than $0.001 \mathrm{~m} / \mathrm{s}$. Table 4.3 presents the moving speed that can subsequently be used to calculate the walking distance (walking distance $(\mathrm{m}$.$) = average moving$ speed $(\mathrm{m} / \mathrm{s}) \mathrm{x}$ total moving time $(\mathrm{s})$ ).

Table 4.1: Examples of shopping-related behavioral data from each participant (i.e., total shopping time, total number of products examined, total number of products purchased, and total number of products returned), exported from the data management program

\begin{tabular}{|c|c|c|c|c|c|c|c|c|c|c|}
\hline$a^{5^{2}}$ & Behaviors & Mean & $\begin{array}{c}\text { Total } \\
\text { duration }\end{array}$ & $\begin{array}{c}\text { Rate per } \\
\text { minute } \\
\text { (observation } \\
\text { duration) }\end{array}$ & $\begin{array}{c}\text { Total } \\
\text { number }\end{array}$ & Mot & Store & Duration & $\begin{array}{l}\text { Start } \\
\text { time } \\
(P M)\end{array}$ & $\begin{array}{l}\text { Stop } \\
\text { time } \\
(\mathrm{PM})\end{array}$ \\
\hline 1 & Shopping & 578.632 & 578.632 & 0.0590102 & 1 & 1 & 1 & 1016.77 & $12: 02: 43$ & $12: 19: 40$ \\
\hline 1 & Product picked up & 3.55356 & 113.714 & 1.88833 & 32 & 1 & 1 & 1016.77 & $12: 02: 43$ & $12: 19: 40$ \\
\hline 1 & Product bought & 28.1741 & 366.264 & 0.767132 & 13 & 1 & 1 & 1016.77 & $12: 02: 43$ & $12: 19: 40$ \\
\hline 2 & Shopping & 400.5 & 400.5 & 0.0887163 & 1 & 1 & 1 & 676.314 & 1:00:08 & $1: 11: 24$ \\
\hline 2 & Product picked up & 2.50967 & 37.645 & 1.33074 & 15 & 1 & 1 & 676.314 & 1:00:08 & 1:11:24 \\
\hline 2 & Product bought & 29.0326 & 377.423 & 1.15331 & 13 & 1 & 1 & 676.314 & 1:00:08 & 1:11:24 \\
\hline 2 & Product returned & - & - & 0.0887163 & 1 & 1 & 1 & 676.314 & 1:00:08 & $1: 11: 24$ \\
\hline
\end{tabular}

Note: All shopping-related behavioral data from each participant should be organized in one row before transferring it to SPSS or other statistical programs. This exported data will be stored in a file called "Behavioral data" in the export folder of the data management program. 

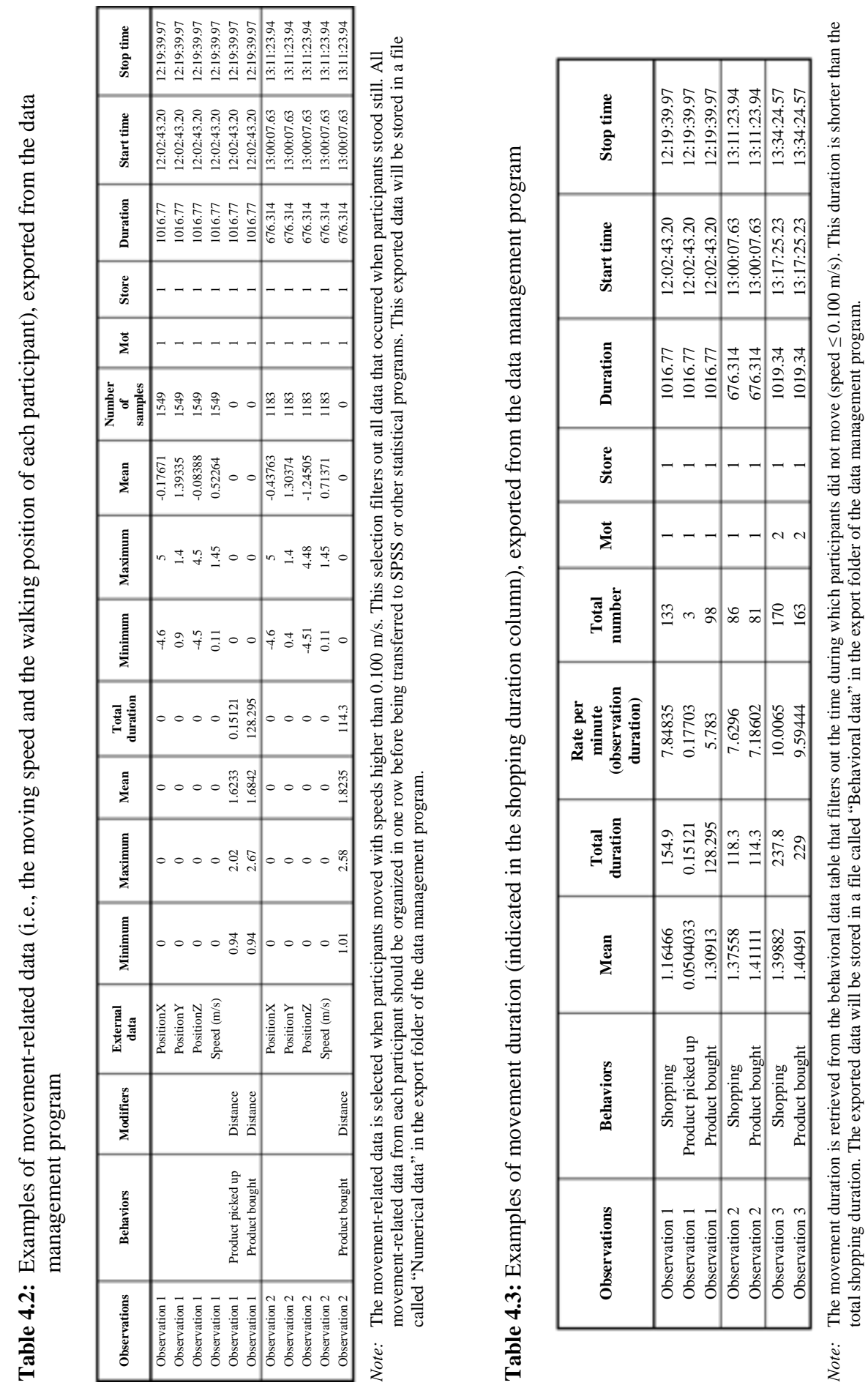
O nce the data was exported, univariate ANOVA was applied to analyze the effects of shelf length and shelf orientation on in-store shopping behavior. The effects of store layout can be presented in various forms, such as bar charts and tables.

Figure 4.8 displays the total number of products examined and the total number of products purchased in the supermarkets with different store layout designs. The results from the virtual store confirmed that store layout attributes, specifically the interaction of shelf length and shelf orientation, influenced the number of products examined $\left(\mathrm{F}(1,237)=4.66, \mathrm{p}<.05, \eta_{\mathrm{p}}^{2}=.02\right)$ and the number of products purchased $\left(\mathrm{F}(1,237)=3.47, \mathrm{p}=.06, \eta_{\mathrm{p}}^{2}=.01\right)$. The findings showed that when shelves were placed in parallel, the length of the shelves did not affect the number of products examined $\left(\mathrm{M}_{\text {hhort }} \pm \mathrm{SD}_{\text {short }}=16.12 \pm 5.37\right.$, $\left.\mathrm{M}_{\text {long }} \pm \mathrm{SD}_{\text {long }}=17.12 \pm 5.99, \mathrm{~F}(1,237)=0.81, \mathrm{p}=.37, \eta_{\mathrm{p}}{ }^{2}=.00\right)$, nor the number of products purchased $\left(\mathrm{M}_{\text {short }} \pm \mathrm{SD}_{\text {short }}=12.00 \pm 2.77, \mathrm{M}_{\text {ong }} \pm \mathrm{SD}_{\text {long }}=12.22 \pm\right.$ $\left.2.37, \mathrm{~F}(1,237)=0.24, \mathrm{p}=.63, \eta_{\mathrm{p}}{ }^{2}=.00\right)$. In contrast, when the orientation of the shelves was unparalleled, shorter shelf lengths stimulated a higher number of products examined $\left(\mathrm{M}_{\text {hort }} \pm \mathrm{SD}_{\text {short }}=17.62 \pm 6.48, \mathrm{M}_{\text {ong }} \pm \mathrm{SD}_{\text {long }}=15.23 \pm\right.$ $\left.6.45, \mathrm{~F}(1,237)=4.65, \mathrm{p}<.05, \eta_{\mathrm{p}}^{2}=.02\right)$ and purchased than longer shelf lengths $\left(\mathrm{M}_{\text {short }} \pm \mathrm{SD}_{\text {short }}=12.30 \pm 2.15, \mathrm{M}_{\text {ong }} \pm \mathrm{SD}_{\text {long }}=11.35 \pm 2.37, \mathrm{~F}(1,237)=4.61\right.$, $\left.\mathrm{p}<.05, \eta_{\mathrm{p}}^{2}=.02\right)$. 


\section{Total Number of Products Examined}

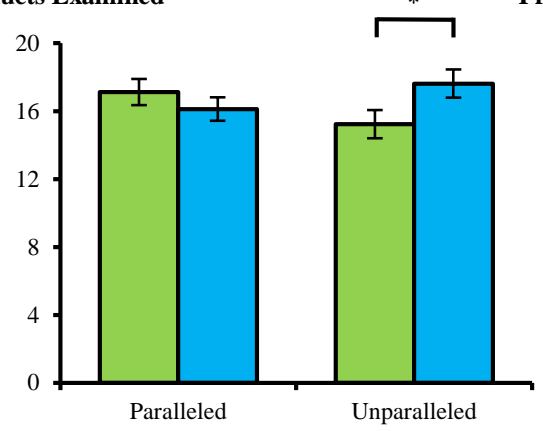

Shelf Orientation
Total Number of

Products Purchased

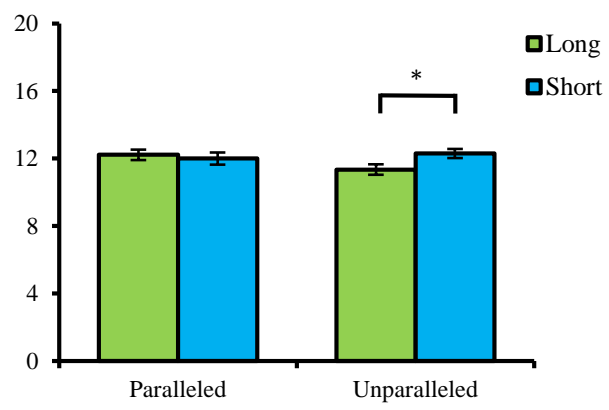

Shelf Orientation

Figure 4.8: The total number of products examined (left) and the total number of products purchased (right) in a supermarket with different store layouts (short versus long shelves placed in a paralleled or in an unparalleled orientation)

Note: The total number of products examined (packages or items) increased every time the participants clicked on a product. This number differs from the total number of products purchased (packages or items), by which the number of products in the purchase basket was recorded. Participants were allowed to return any selected products. $p<.10^{+}, p<.05^{*}, p<.01^{* *}, p<.001^{* * *}$

In addition to product choice behaviors, the virtual store can also record time and movement-related behaviors, such as the shopping time and the walking distance. Figures 4.9 and 4.10 show the effects of store layout design's attributes on the shopping time and walking distance of participants, respectively.

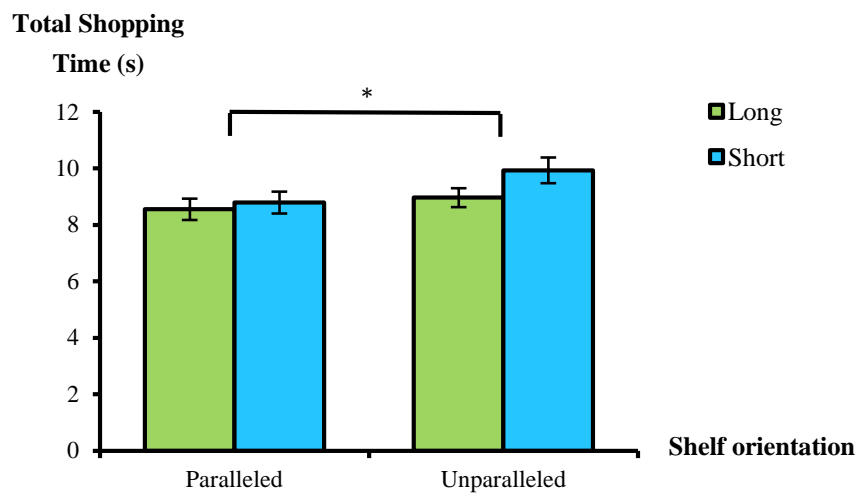

Figure 4.9: Total shopping time (s) participants spent in the supermarket with different shelf lengths and shelf orientations

Note: The total shopping time accounts for the time participants spent between entering the store and leaving the store. The data management program also allows researchers to filter out the time that participants spent in a specific area. $p<.10^{+}, p<.05^{*}, p<.01^{* *}, p<.001^{* * *}$ 


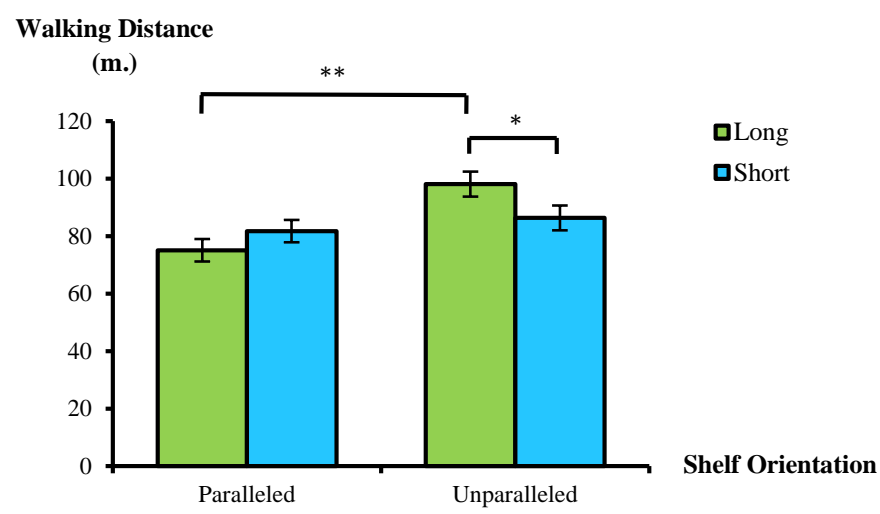

Figure 4.10: The walking distance of participants in the supermarket with different shelf lengths and shelf orientations

Note: The walking distance was determined by multiplying the moving time (s) with the average shopping speed ( $\mathrm{m} / \mathrm{s}$ ). The duration of the moving time used to calculate walking distance differs from the total shopping time because the moving time is exclusively recorded during participant movement. In contrast, the total shopping time accounts for the movement time and the time spent viewing and selecting products. Thus, the total moving time can be attained by only selecting the time during which participants move faster than $0.100 \mathrm{~m} / \mathrm{s} . p<.10^{+}, p<.05^{*}, p<.01^{* *}, p<.001^{* * *}$

In addition to the effects of store layout design's attributes, the current research also focused on shopping motivations to understand their influence on in-store shopping behavior. The results revealed significant main effects of shopping motivations on all in-store behavioral variables. Consumers with a hedonic motivation searched for (i.e., clicked on) $\left(\mathrm{M}_{\text {hedonic }} \pm \mathrm{SD}_{\text {hedonic }}=17.97 \pm 6.93\right)$ and purchased more products $\left(\mathrm{M}_{\text {hedonic }} \pm \mathrm{SD}_{\text {hedonic }}=12.25 \pm 2.42\right)$ than consumers with a utilitarian motivation (products examined: $\mathrm{M}_{\text {utilitarian }} \pm \mathrm{SD}_{\text {utilitarian }}=15.10 \pm$ 4.82, products purchased: $\mathrm{M}_{\text {utilitarian }} \pm \mathrm{SD}_{\text {utilitarian }}=11.69 \pm 2.43$ ). They also spent more time $\left(\mathrm{M}_{\text {hedonic }} \pm \mathrm{SD}_{\text {hedonic }}=607.18 \pm 205.07 \mathrm{~s}, \mathrm{M}_{\text {tilititarian }} \pm \mathrm{SD}_{\text {utilitarian }}=480.94\right.$ $\pm 134.25 \mathrm{~s})$ and walked longer distances $\left(\mathrm{M}_{\text {hedonic }} \pm \mathrm{SD}_{\text {hedonic }}=89.87 \pm 31.15 \mathrm{~m}\right.$, $\mathrm{M}_{\text {utilitarian }} \pm \mathrm{SD}_{\text {utilitarian }}=80.73 \pm 34.08 \mathrm{~m}$ ). The interaction effect of shopping motivation and store shelf attributes was not significant.

\subsection{Discussion}

The virtual store is one of the more advanced computer technologies that have been developed to create virtual environments in which people can experience and react to close-to-reality objects. G enerally, the desktop virtual store consists 
of user-friendly interfaces that require a short time to understand. However, a number of critical points need to be accounted for. First, clear research objectives are needed beforehand to specify the starting points when building the virtual store. This includes a plan about the products; the type, placement, and number of shelves; the location of product categories on these shelves; the type and location of products within the product categories; and other elements (e.g., poster, signage, and special displays). Moreover, it is important to decide which model (2D or 3D) of a digital representation of objects will be used (see Figure 4.11). The 3D models are virtual representations, with height, width, and depth, in which all sides are represented in detail. In contrast, the 2D model gives the illusion of a 3D representation by presenting an object in a cube frame (3D shape), with realistic visuals of the front of the object. The other sides of the 2D models are roughly shown without detail. Different forms of representations give rise to different user experiences and different senses of immersion. The 3D model that shows all details of an object may give a higher sense of presence and immersion (PI and Psi) than the 2D model. However, the 2D model is flexible and easy for a researcher to use, and the size of the cube frame can be easily adjusted. Thus, the choice of the virtual representation depends upon the research aims. Second, after all stores are built, the researcher should run and test all versions of the virtual store by visiting each store and picking up, selecting, and returning products to verify that the data is stored correctly. Third, because the study consists of several steps, clear instructions and detailed virtual store manuals are extremely important. The instructions should indicate what participants should and should not do in each step. Fourth, the practice session is vital to familiarizing participants with the virtual store and minimizing biases generated from different computer skills. Last, researchers should be cautioned to save data as frequently as possible to avoid any potential data loss. 


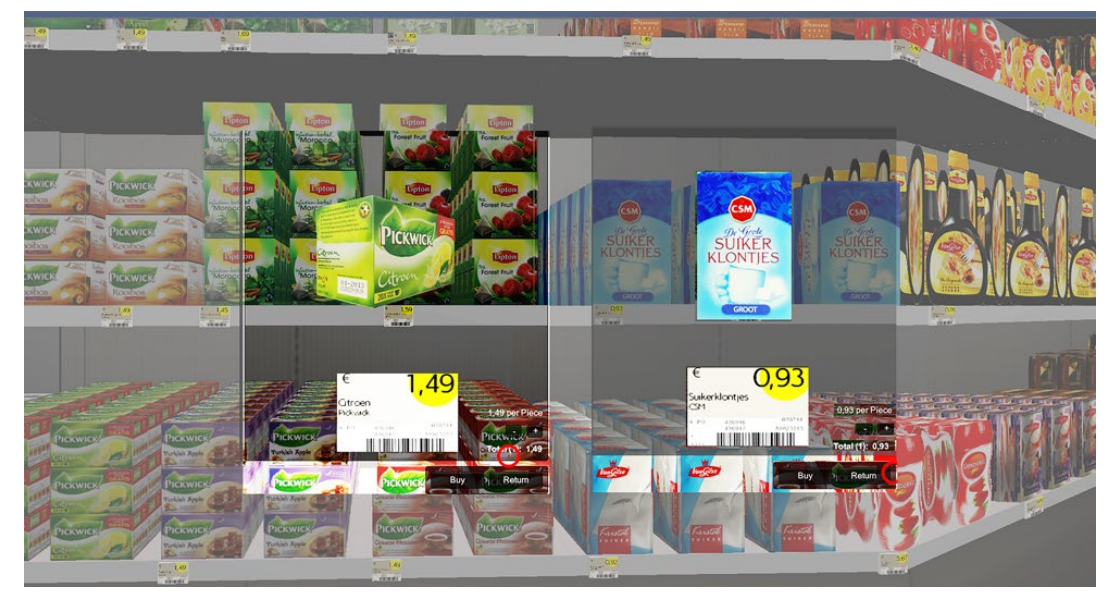

Figure 4.11: An example of a product in a 3D model (left) and a 2D model (right)

Note: When participants click on a product, the 3D model can be rotated on-screen to illustrate all sides of the product, whereas the 2D model illustrates only the front side of the product and cannot be rotated.

The use of virtual stores in consumer research has advantages over more traditional research methods. A virtual store is a tightly controlled yet realistic environment (Berneburg, 2007; Khan et al., 2011), thereby providing the internal validity of a controlled experiment while maintaining a high degree of external validity as well. It thus combines the advantages of both field and laboratory approaches (Rebelo, Duarte, Noriega, \& Soares, 2011). This implies that consumer behavior can be observed and measured in a realistic context, with less concern for socially desirable answers than in other research methods, such as surveys and focus groups (Ruppert, 2011). A recent study has indicated that, compared to a method of using photographs to display a store shelf, the use of virtual reality results in consumer in-store behavior that more closely resembles the behavior demonstrated in a physical store, based on several parameters (i.e., feelings of presence, type of brands selected, and responses to the location of products in the display; van Herpen, van den Broek et al., 2016). An additional advantage of using virtual reality is that changes in the store environment can be made without having to rely on complex implementation processes in real-life settings (Waterlander, Jiang, Steenhuis, \& Mhurchu, 2015; Waterlander, 
Mhurchu, \& Steenhuis, 2012). This provides flexibility for the researcher. As a result, the use of a virtual store has clear benefits when the objective of a study is to examine consumer responses to products that are not yet available in the market (e.g., in early stages of new product development), to examine consumer responses to factors that are costly or difficult to change in real life (e.g., overall store layout), and/ or to examine routinized behaviors in familiar environments.

Despite the stated advantages of the virtual store, several limitations need to be carefully considered. The major limitations, at this stage of development, relate to: 1) the time and space needed per participant, 2) the potential skill-related bias, 3) the costs involved in adapting new environments, and 4) real behavior and incentives. Currently, the virtual store can be used by only one person at a time. In particular, a number of participants are sampled in a virtual laboratory or an experimental area in order to run simulations. This limitation of time and physical space for the virtual store experiment restricts sample size and types of target groups. In addition, the restriction on the types of target groups is also caused by the skills required for participants to use the computer. Gamers or younger participants are likely to be able to handle the program more efficiently than the elderly or persons with low computer skills. Another limitation of the virtual store is that the adaptation of the store and the product library is in the development stage. If one wants to use a complex store design or store elements or products that are different from the available templates (e.g., enlarging the store size or including new store elements, such as display tables), the program needs to be adjusted. Thus, cost and time are incurred for the preparation of data collection. Lastly, even though previous studies have shown that the virtual store reflects behavior in the physical store more closely than does an experiment using pictorial stimuli, participants tend to buy more products in the laboratory setup than they do in actual stores. Thus, although the use of a virtual store increases realism compared to the use of pictures, several differences from reallife behavior remain (van Herpen, van den Broek et al., 2016). To be cautious, 
this must be considered when interpreting results from a study using the virtual store.

There is a vast range of different technological features and systems for virtual reality applications. These systems mainly vary on aspects of equipment mobility, user interfaces, and development costs. The costs for equipment and licenses vary and are subject to drastic changes due to technological developments. In general, the costs per participant are higher when more behavior data is needed with higher-level 3D simulations. The use of a different system or interface may counteract some of the mentioned limitations, but at a cost in terms of money or flexibility. Specifically, the first limitation, on the time and space needed per participant, can be counteracted by using smartphone technologies. Smartphones, in combination with a designated headset, can render a full, immersive, $360^{\circ}$ environment. Limitations on space are as low as possible since it does not cost more space than what one would normally use. Due to the widespread use of smartphones and the low cost of designated headsets, multiple people can use it at the same time. The downside of this technology is that smartphones have a lower computing power and thus can only handle lessdifficult environments. The second limitation is the potential skill-related bias, a limitation that any system must deal with. Some systems, such as the Cave system, simulate natural movements (Mikkelsen, Høeg, Mangano, \& Serafin, 2016), which potentially could reduce this bias. The Cave system uses projector screens and head tracking, which allows participants to physically move through a limited space and to orient their head arbitrarily. Such a system, however, is not or is hardly mobile and requires much more developmental and hardware costs. The third limitation, the costs that are involved with adapting the store products and environment, are dependent upon the degree of simulation. It is possible to simulate a stationary environment based on a picture, but as soon as more detail, such as a 3D world or 3D products, are needed, one is dependent upon the availability of these objects in 3D. The last limitation, the simulation 
of real behavior and incentives, are likely dependent on the aforementioned factors of mobility, skill bias, and, in general, the degree of immersion. Mobile units can be used in a relevant context (e.g., in the actual supermarket), thereby making the incentive and the purpose of the visit real (e.g., buying a product virtually results in actually buying the product in real life). Furthermore, it can be expected that, when the user interface closely resembles natural movement, it will better resemble real-life behavior. Lastly, the level of immersion achieved by the current virtual store is between those of a regular desktop and a semiimmersive virtual reality projection (Slater, 2009). Since other virtual store systems are in the early stages of development, studies describing and comparing different virtual store systems are scarce. A comparison of shopping behavior under different levels of immersion is yet to be conducted.

As virtual reality has become a widely used technology, outside the scope of computer games, virtual reality technology is likely to enter the market of home users (e.g., by television, internet or mobile application). This will potentially enable researchers to do virtual reality testing outside the laboratory. Moreover, this development opens up ample opportunities to measure, research, and understand the behavior of people on a broader scale in terms of groups and areas (e.g., in developing countries or rural areas with limited accessibility to technology). The external validity of the research will consequently be enhanced. With the advancement of this technology on the consumer market, virtual reality research could further develop from supporting simulations to the direct measurement and tracking of real behavior. Just like people surfing on the web or consumers choosing in a webshop are already intensely tracked to predict or influence behavior, the same type of behavioral measures exists (and will come to exist) for simulated virtual worlds. Another potential development is foreseen in the area of generating personalized environments. Several websites are already automatically adjusted to the individual who visits them. Examples of such websites are online retailers that give suggestions based upon aspects such as 
location, previous purchases, and Facebook (i.e., a social media and networking platform), which personalizes not only the advertisements, but also other content to fit personal preferences. The same could happen for virtual worlds. In practice, people could, for example, select personalized supermarkets, design or choose the manner in which they would prefer to be guided (e.g., "guide me towards sustainable product choices"), or even limit the choices they can make (e.g., only products for people with a specific disease).

In summary, unraveling the mysteries of consumer behavior cannot be achieved by any stand-alone research method. Thus, to compare or combine insights, various data collection tools must be used. The virtual reality developments have taken great steps in the last few years. Now, it is the time to link these methods to traditional methods so that new insights can emerge. There are multiple options of the virtual store, all with their respective advantages and disadvantages. The virtual store described here is unique in that there is an easy editor to build a virtual store that includes a range of options in order to collect behavioral data. An example of research with the virtual store presented here lays the groundwork as a universal way of measuring consumer behaviors in virtual-reality research. 
Chapter 5

Stationing snacks in the supermarket: Does merchandise layout affect the (un) healthy snack choices made by consumers with different degrees of trait self-control?

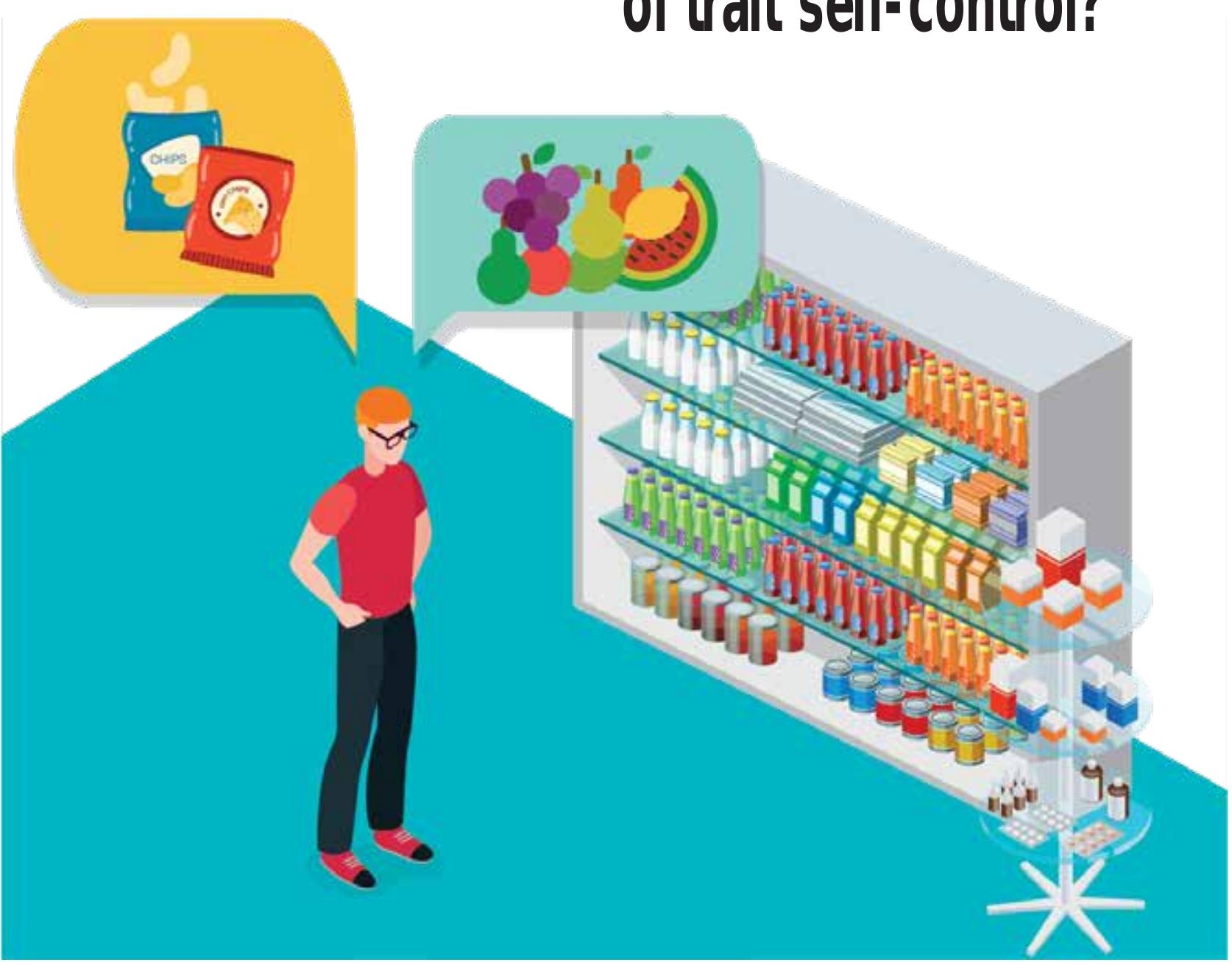

This chapter has been prepared by Ploydanai, K., van Herpen, E., and van Trijp, J. C. M. H. 


\section{Abstract}

The merchandise layout (i.e., in-store location) of food products may affect the choices that consumers make. Since an act of choice requires resources needed for self-control, locating a product category toward the end of a store implies that more prior choices were likely made and thus that depletion of self-control is more likely. This study examines the interaction between merchandise layout and trait self-control on healthy and indulgent snack choices. Four studies examine the effect of product location on the remaining level of self-control (Study 1), the interaction between merchandise layout and trait self-control in affecting healthy and indulgent snack choices in realistic choice environments created in a virtual supermarket (Studies 2 and 3), and the interaction between a depletion manipulation and trait self-control (Study 4). Results indicate that the act of making choices can lead to ego-depletion and can influence the goal that people pursue. After having made choices, people are more depleted (as shown in an unrelated self-control task, Study 1) and they report more often that they aim to highlight enjoyment in their product choices (Study 3). Y et, throughout the studies, main effects of the location of snack products on actual choices are generally absent. Additionally, interactions with trait self-control show inconsistent results throughout the studies. There appears insufficient evidence to conclude that ego-depletion and trait self-control interact in affecting snack choices. 


\subsection{Introduction}

The merchandise layout, that is, the location where products are presented, is one of the key interventions used to influence consumers' food choices. For instance, the location of salad bar dishes in a cafeteria influences the amount of food that people select from each dish (Rozin et al., 2011) and consumers are more likely to select low-calorie food when this is presented on the front-page of a menu rather than placed on the back-page (Wisdom, Downs, \& Loewenstein, 2010). In retailing, the location of product categories may likewise influence consumers' choices, but this has received relatively little prior research attention. Still, there is evidence to suggest that the location in which foods are presented in a grocery store determines consumers' choices. For instance, prime locations such as end-of-aisle display (Nakamura et al., 2014; Sorenson, 2009), the check-out counter (Cohen \& Babey, 2012; van Gestel et al., 2018) and the store entrance (Walmsley et al., 2018) can increase product sales.

Importantly, depending on where food products are located, consumers are likely to have made many or few prior product choices. Research on egodepletion argues that making effortful choices consumes the same cognitive resource that one requires to assert self-control (Vohs et al., 2008) and that this resource is limited (Baumeister, 2002a; Muraven, Tice, \& Baumeister, 1998). Exploiting this resource leads to a state of reduced self-control capacity, and when this occurs performance on a subsequent self-control task is impaired. Thereby, consumers become more impulsive and less self-controlled (Baumeister, Sparks et al., 2008; Vohs \& Faber, 2007). Making choices can involve information acquisition, deliberate thinking about options, choosing one option over others, and implementing this choice, all of which may deplete the self-control resource, and this should therefore reduce a person's performance on subsequent self-control tasks (Vohs et al., 2008). For example, people should be more likely to buy indulgent snack products after having made more rather 
than fewer prior purchases. Yet, not everyone may be affected by tasks that involve ego-depletion in the same way and to the same extent.

The effect that a first task limits resources needed for self-control affects a second, unrelated, task of self-control has been shown to differ among people and to depend on personality traits (Seeley \& Gardner, 2003; Shamosh \& G ray, 2007; Wan \& Sternthal, 2008). One relevant personality trait is trait self-control. Whereas some people can easily resist temptations, others are less able to control themselves from indulgences (Friese \& Hofmann, 2009; Tangney et al., 2004). Up to now, it has remained unclear how trait self-control interacts with preceding tasks involving ego-depletion. There are only a small number of prior studies focusing on this interaction and the results are contradictive. Four studies, focusing on the suppression of aggressive behavior and death related thinking, found that trait self-control prevents depletion. This prevention from ego-depletion is called a buffering effect (DeWall, Baumeister, Stillman, \& Gailliot, 2007; Dvorak \& Simons, 2009; Gailliot, Schmeichel \& Baumeister, 2006; Gailliot, Schmeichel \& Maner, 2007). People with high trait self-control may both have a higher level of self-control resources available to start off with, and may also be less affected by depleting tasks because they are more experienced in resisting temptations. Other studies did not find such an interaction effect (Gailliot \& Baumeister, 2007; Stillman, Tice, Fincham, \& Lambert, 2009). In contrast, a study on food consumption and risk taking behavior found an ironic effect of trait self-control in which high self-control participants were especially vulnerable to the effect of ego-depletion as they consumed more candy after high depletion than low depletion (Imhoff, Schmidt, \& G erstenberg, 2014). Therefore, evidence regarding the interplay of tasks that lead to ego-depletion and trait self-control has to be identified as inconclusive (Hagger, Wood, Stiff, \& Chatzisarantis, 2010), although most evidence seems in support of a buffering effect (de Ridder, Lensvelt-Mulders, Finkenauer, Stok, \& Baumeister, 2011). 
Extending prior research, the present study will examine both indulgent and healthy choices. Regarding indulgent food, which is usually perceived to be bad for health, high trait self-control individuals could be expected to resist temptation even when they have performed prior ego-depleting tasks (i.e., the buffering effect of high trait self-control), whereas low self-control individuals will be affected by preceding ego-depleting tasks. In contrast, choice and consumption of healthy products is likely to create no perceived conflict and is thus not subject to restraint. Consumers may not feel the need to exert selfcontrol for their choices of healthy foods. In other words, when cognitive resources are limited, consumers with high self-control may allocate most attention to control for indulgent foods and put less attention to control for healthy choices. This could lead them to buy fenerindulgent food products (more control over unhealthy choices), but, ironically, may also lead them to buy more healthy products. The current research aims to examine these possible effects.

The present study adds to existing knowledge in several ways. First, it examines the under-researched interaction between the location of food products and trait self-control. Second, in addition to indulgent choices that have been widely studied (Honkanen et al., 2012; Maas et al., 2012; Wills et al., 2007) the current study also examines effects on healthy choices. Furthermore, this study implements a realistic choice set up. Familiar products that are generally available will be used in a virtual supermarket. Investigating familiar products is important because self-control can be trained by regular self-control use (Beames, Schofield, \& Denson, 2017; Muraven, Baumeister \& Tice, 1999) and the extent to which self-control failures occur in common and familiar situations (such as grocery shopping) is of high practical relevance. 


\subsection{Theoretical framework}

\subsubsection{The strength model of self-control and ego-depletion}

Self-control refers to an ability to attain deliberative control over impulses (A inslie, 1975), to restrain from gratifying immediate needs and desires (Metcalfe \& Mischel, 1999) and to engage in goal-directed behavior that brings about longterm desirable outcomes (Baumeister, 2002b; Logue, 1988). The strength model of self-control states that acts of self-control draw from a common, global resource. This resource is limited and vulnerable to becoming depleted over time. Effortful control over dominant responses expends the resources and thus subsequently leads to impaired task performance. The reduction of self-control resources which impairs subsequent self-control task performance is known as egpdqpliion (Baumeister, Heatherton, \& Tice, 1994; Muraven, Tice, \& Baumeister, 1998). The capacity for self-control has been likened to a muscle, because even though it can be depleted after exertion of self-control in the short run, it can also be trained or improved with self-control exercise in the long run (Muraven, Baumeister, \& Tice, 1999).

Previous research has shown that making choices depletes the same resource as the resources depleted by acts of self-control. This also decreases self-control in later tasks (Vohs et al., 2008). Vohs and colleagues have shown that people who make a long series of choices (e.g., between pairs of grocery products, occupations, and educational options) perform worse on a subsequent selfcontrol task. They persist less long in holding a hand in ice water, spend less time solving unsolvable puzzles, spend less time studying and practicing for a math test and drink lower amounts of a bad-testing beverage. In line with this, making choices in the supermarket may result in ego-depletion. Y et, as grocery shopping is a common activity in day-to-day life, it could also be argued that consumers may have developed routines for these decisions. Making familiar grocery 
choices might then expend too little cognitive resources to impair subsequent decision making. In contrast, our study proposes that this still causes egodepletion as consumers need to expand effort to compare and choose among options. Moreover, when making choices, they may also need to control themselves over tempting choices. The grocery store environment provides many tempting options, presented in ways that stimulate desire, so the dominant reflex would be to purchase all products they want (Baumeister, 2002b) and resisting this urge may cause depletion. Depletion, in turn, can affect which options people choose (Rottenstreich, Sood, \& Brenner, 2007). When consumers reach the end of the supermarket, they may be more depleted due to the previous decisions that they had to make, and it may be more difficult for them to resist indulgent snacks.

Possible effects of tasks that involve ego-depletion on the purchase of healthy snacks are less obvious. Generally, healthy food is associated with inferior taste (Croll, Neumark-Sztainer, \& Story, 2001; Raghunathan, Naylor \& Hoyer, 2006; Wansink \& Park, 2002). For instance, consumers have expressed the taste of healthy food as "no taste" or "not really tasting that good to begin with" (Croll et al., 2001). At times, people may need to 'force' themselves to choose and consume these products, and ego-depletion may play a role here as well, such that depleted individuals might buy fewer healthy snacks. In support, a study of Vohs et al. (2008) has shown that people under ego-depletion drink less of a healthy beverage with a bad taste, suggesting that people might be less attracted to healthy options when they are depleted. This latter effect should depend on the attractiveness of the healthy products, though. Food categories may be tempting to different extents, and healthy foods can also be tempting. This is especially relevant in a grocery store context, because it offers a great variety of healthy options, and thereby increases the chance that a person will find products that are both healthy and appealing. For instance, Roininen and Tuorila (1999), and Rothenberg, Bosaeus, and Steen (1994) found that consumers 
generally consider fruit as healthy and pleasure-giving. If consumers like healthy options, they may not buy fewer healthy snacks after depletion. Some consumers may even buy more healthy snacks, as we will discuss next.

\subsubsection{Trait self-control}

Individuals differ in their dispositional ability to regulate or control themselves. Trait self-control is defined as a set of skills that enable "an individual to effectively shift or focus attention, contemplate alternative actions, understand the corresponding relationship between current actions and future antecedents, and effectively monitor and change behavior to achieve specified goals" (Dvorak \& Simons, 2009, p. 573). Trait self-control should affect food choices. Low self-control individuals face many self-control problems, including obesity (de Ridder et al, 2011). They are more likely to fall prey to food temptations as they have a lower ability to recognize the long-term costs of undesirable behavior. Thus, they fail to restrain their impulses (Tangney et al., 2004). In contrast, individuals with high trait self-control can resist temptations better because they are more reflective and deliberative in their behavior. They can sacrifice immediate outcomes in favor of long-term goals (de Ridder et al., 2011; Wills et al., 2007). Honkanen and colleagues (2012) show that when food related self-control is weak or compromised, the likelihood of impulsive unhealthy snacking is larger. In their study, they find that individuals with weak food related self-control show a stronger tendency for impulsive snack buying than individuals with strong food related self-control. Therefore, we predict that in general high self-control consumers will buy fewer indulgent snacks and more healthy snacks than low self-control consumers. 


\subsubsection{Interaction between tasks involving ego-depletion and trait self-control}

The interaction between tasks involving ego-depletion and trait self-control has not been well defined. However, some researchers have proposed that consumers high in self-control should be less vulnerable to ego-depletion (Dvorak \& Simons, 2009). In support, Muraven, Collins, Shiffman, and Paty (2005) have shown, in the context of alcohol consumption, that high self-control individuals are less affected by a self-control demand task than low self-control individuals. Other studies support this buffering effect (D eWall et al., 2007). There is also some evidence to suggest that ego-depleting tasks and trait self-control function independently, without interplay between them (Muraven, Pogarsky, \& Shmueli, 2006), and a study that found the opposite effect (Imhoff et al., 2014). Yet, most empirical evidence so far suggests that the self-control performance of consumers with high trait self-control will be less affected by tasks involving ego-depletion. Thus, compared to low self-control consumers, we expect that dispositionally high self-control consumers will have a higher capacity to control themselves against temptations, even after having made effortful choices.

This buffering effect, in which tasks involving ego-depletion affect people low in trait self-control more than people high in trait self-control, could be explained by two possible processes. First, trait self-control may indicate the amount of initial cognitive resources that an individual has available, implying that consumers with high trait self-control possess a larger pool of resources than consumers with low trait self-control. Thus, after performing a depleting task, consumers with high trait self-control still have enough cognitive resources to regulate their choices (Muraven, Collins et al., 2005). Another explanation is that individual differences in trait self-control may represent a different ability or skill to regulate oneself. As having a high trait self-control may be the result 
of having trained oneself over time, people with high trait self-control may need less resource to perform the same self-control task than people with low selfcontrol. In other words, the self-control task may deplete resources to a different degree depending on trait self-control. Thus, for people high in trait self-control, the subsequent self-control performance is less affected by prior tasks involving ego-depletion.

Importantly, we propose that the perceived need to control choices for indulgent versus healthy snacks may be different because these are seen as opposing or supporting a long-term health goal, respectively. Studies examining stereotypical thinking show that consumers often consider food as either bad or good ( $\mathrm{akes}$, 2005; Oakes \& Slotterback, 2005). This stereotypical thinking may mislead consumers' perception of healthy consumption. For example, research showed that a small amount of "bad" food (e.g., a mini bar of Snickers) is considered to contain more calories and to have a higher potential to promote weight gain than a large amount of "good" food (e.g., tomato soup or low fat yogurt and carrot) which in fact contains more calories (Oakes \& Slotterback, 2005). This implies that consumers selectively perceive the benefits of healthy snacks without necessarily considering the drawback of overconsumption of healthy snacks. Consumers may not feel a need or may not be motivated to keep the number of healthy products that they buy under control, and they may buy more of these when depleted than they otherwise would. Thus, consumers may strategically allocate their resources to limit purchases of unhealthy, but not of healthy items.

This strategic allocation of cognitive resources to different self-control tasks has been demonstrated in prior research (Muraven, Shmueli, \& Burkley, 2006). For instance, consumers decide to use fewer self-control resources in a task when they anticipate exerting self-control in the future. In further support, Myrseth and Fishbach (2009) show that consumers employ self-control only when they identify a self-control conflict such as when health-conscious 
consumers make a decision on potato chip consumption. This suggests that people are able to employ their self-control resources strategically, and to deliberately allocate these across different tasks. They may not only do so across different tasks over time, but also during a single task. That is, in the current context, they may decide to allocate their resources and attention to choices that they perceive as most threatening and in need of self-control, at the expense of other choices. Thus, we propose that high self-control consumers who have performed a depleting task primarily attempt to control themselves when it concerns indulgent food choices but may pay less attention to control the number of healthy food choices that they make, as this is perceived as posing no threat to their long-term health goal. Therefore, we expect that after having performed a task involving ego-depletion (compared to a task without depletion), individuals with high self-control will be able to control themselves from temptations and do not increase their choice of unhealthy snacks; however, this may lead to a boomerang effect where they lose control over the number of healthy products that they buy. This shift in resource allocation is predicted to be less likely in low self-control individuals as they will have fewer resources left to allocate after performing a depleting task. Thus, consumers with low self-control are expected to be affected by tasks involving ego-depletion and to choose more indulgent products as a result of depletion, but fewer healthy products compared to when they have not performed a depleting task.

In the present chapter we investigate the effect of merchandise layout (i.e., product location) on choices for snack foods. Product location determines the number of prior choices made when the snack choices are encountered, and is thus a task involving depletion. The first study examines whether making choices in a common context (grocery shopping) indeed leads to ego-depletion by means of subsequent task performance. The next two studies assess the interaction between product location and trait self-control on the number of healthy and indulgent options that people choose using a virtual supermarket, 
and the fourth study explores the interaction between another depleting task and trait self-control in affecting healthy and indulgent snack choices.

\subsection{Study 1}

O ur first study tests the assumption that common and familiar choice tasks in daily life can evoke ego-depletion and impair self-control in a subsequent task. It is an extension of the study of Vohs and colleagues (2008) on choices and ego-depletion with several adaptations to increase realism of the task. Whereas Vohs and colleagues asked participants to make decisions among two options only, this study uses more realistic (larger) assortments that consumers typically encounter in retail contexts and a more realistic number of choices (15 rather than 292). Furthermore, the products used in this study are commonly available in the local supermarket and are familiar to participants. Finally, we use a virtual supermarket which allows participants to shop in a virtual simulation of a supermarket (developed in collaboration with G reen Dino, www.greendino.nl). These adaptations allow us to examine the occurrence of depletion through common product choices in a close-to-realistic context.

Grocery shopping is a common and familiar activity for consumers. Choosing among familiar products may require a smaller amount of self-control than choosing from unfamiliar products because consumers may exercise self-control in grocery shopping in everyday life, making them less susceptible to depletion. It is thus important to test whether the effects found in laboratory studies using unfamiliar choices extend to more common decision making situations. The use of the virtual supermarket in the current study helps to investigate this. If choosing products from a short series of familiar categories indeed depletes self-control resources, subsequent persistence at another task should be decreased. We will examine this using an unsolvable puzzle task. 


\subsubsection{Method}

\section{Participants}

Forty-one undergraduate students of a D utch University (11 male, 30 female; age 18 - 27) participated in the study for a snack product as an incentive.

\section{Design}

The study had a 2 group between-subject design. Participants were randomly assigned to one of two groups (product choice task vs. store evaluation task). Walking through the virtual supermarket, participants either made 15 product choices according to a shopping list (e.g., snacks, coffee, tea, shampoo, hand soap) or they examined the same product categories without making choices.

\section{Procedure}

After signing a consent form, participants in the product choice task condition read a cover story that asked them to choose 15 products (food and non-food). Participants in the store evaluation condition were asked to look at the virtual supermarket and its products for later evaluation. The products were shown on shelves and were displayed similarly to the small grocery store. The virtual supermarket showed products on three 42-inch screens, set up to achieve a 180degree field of vision of the virtual environment (see Chapter 4 for a detailed description of the setup). Participants in both conditions were allowed to walk freely in the virtual supermarket for a maximum of 10 minutes.

After completing the first task, participants answered questions regarding their mood states to check that the two conditions did not create differences in mood. Next, they performed a puzzle solving task that required them to trace figures without lifting their pencil from the paper or retracing any line (cf. Glass, Singer \& Friedman, 1969; Moller, Deci \& Ryan, 2006; Vohs et al., 2008). They first 
received a solvable figure to practice and then received two unsolvable puzzles. Participants were informed that they could try as often as they wanted and that they would be judged on whether or not they finished tracing the figure; they could stop, finish or quit anytime they wanted. The time participants spent on solving the puzzles was recorded. Finally, participants provided their age, gender and education.

\section{Measures}

Participants reported their mood state by rating thirteen mood adjectives on 7-point scales ranging from 'definitely do not feel' to 'feel a lot'. These were selected from the Brief Mood Introspection Scale (BMIS; Mayer \& Gaschke, 1988). The mood state items were active, happy, loving, calm, caring, nervous, gloomy, fed up, peppy, jittery, content, sad and tired. Participants also reported their feelings of fatigue and perceived difficulty of the first task. Q uestions were "How difficult was the first task for you?", "Did you feel the desire to stop working for the first task?" and "Did you force yourself to continue?" (rated on 7-point scales ranging from 'not at all' to 'very much'). Additionally, participants evaluated the virtual supermarket on the following items: "How close to a real store does the virtual store look?" and "How easy was it to move around in the virtual store?" (rated on 7-point scales ranging from 'not at all' to 'very much'). The key dependent variable was the amount of time (in minutes) that participants spent on attempting to solve the tracing puzzles. A shorter time spent indicates a higher level of ego-depletion (Glass et al., 1969; Moller et al., 2006; Vohs et al., 2008).

\subsubsection{Analysis plan}

Individual mood states were used to calculate BMIS Subtractive Scoring for a pleasant-unpleasant scale $(\alpha=.66)$ and for an arousal-calm scale $(\alpha=.44)$. Since the reliability of arousal-calm scale was very low, we have checked 
reliability after each individual item was deleted. Finally, the item 'tired' was removed to improve reliability to $\alpha=.51$ (scale cf. Mayer \& Gaschke, 1988). ANOVAs with choice task as the between-subject factor were used to test effects on these mood scales as well as on feelings of fatigue and perceived difficulty of the first task, the evaluation of the virtual supermarket, and the time spent on the puzzle solving task.

\subsubsection{Results}

The two conditions did not differ on the pleasant-unpleasant scale $(F(1,39)=$ $.00, \mathrm{p}=.956)$ and arousal-calm scale $(\mathrm{F}(1,39)=.11, \mathrm{p}=.741)$. Thus, any difference on the performance of the unsolvable puzzles between the two conditions does not appear due to mood state. Results showed no significant difference between the two conditions on perceived difficulty of the task $(F(1,39)=2.07, p=.158)$, desire to stop working on the task $(F(1,39)=1.62$, $\mathrm{p}=.211)$ and attempt to continue on the task $(\mathrm{F}(1,39)=0.35, \mathrm{p}=.556)$. O verall, participants reported that the task was easy $(\mathrm{M}=2.46)$. They neither perceived a desire to stop working on the task $(\mathrm{M}=2.34)$ nor forced themselves to continue working on the task $(\mathrm{M}=2.71)$. Furthermore, evaluations of the virtual supermarket did not significantly differ either between the two conditions. Participants perceived the virtual supermarket to be quite close to reality $(\mathrm{M}=4.38 ; \mathrm{F}(1,39)=0.28, \mathrm{p}=.600)$, and claimed that it was moderately easy to navigate through the virtual store $(\mathrm{M}=3.85 ; \mathrm{F}(1,39)=0.15, \mathrm{p}=.697)$.

The main dependent measure was the amount of time participants persisted on the unsolvable puzzles. A one-way analysis of variance (ANOVA) showed the expected significant difference between the two conditions $(F(1,39)=6.91$, $\mathrm{p}=.012$ ). Participants in the choice condition quit sooner than those in the evaluation condition ( $\mathrm{M}_{\text {hoice }}=7.90$ minutes and $\mathrm{M}_{\mathrm{no} \mathrm{choice}}=10.64$ minutes $)$. 


\subsubsection{Discussion}

Making a series of choices impairs people's self-control performance on another task. Study 1 extends previous research (Vohs et al., 2008) and shows that even everyday choices for familiar products can lead to ego-depletion. Because we do not find significant differences among self-report measures, consumers appear unaware of their level of depletion. This suggests that a different location of snacks (when few or many prior choices have been made) may lead to a different level of ego-depletion at the moment that snack choices will be made. The next studies will test if this influences consumers' snack choices depending on individual differences in trait self-control.

\subsection{Study 2}

\subsubsection{Method}

\section{Participants}

D utch university students $(\mathrm{n}=69)$ participated for snack rewards of 2 - 3 Euros. Two participants were excluded from analysis as they did not consume snacks at all and made no snack choices. Apart from these participants, all others reported to like at least one snack option. Another two participants were excluded because they did not complete the questionnaire and three participants were excluded because of technical problems with the computer program. Moreover, one participant was excluded since data from the virtual supermarket, which recorded individual products examined, and self-reports showed that the participant had not seen/ viewed any indulgent snacks, for both chocolates and chips. 
Even though we did not have enough information to conclude whether this participant strategically ignored the indulgent categories or incidentally missed it, the latter reason is more likely given that the participant reported not seeing the indulgent snacks. Therefore, 61 participants remained in the analysis (18 male and 43 female; age from 18 to 27 years).

\section{Design}

The study had a 2 group between-subject design. Participants were randomly assigned to one of two merchandise layouts in which snacks were placed either in the beginning or in the end of the store. In both conditions, indulgent snacks (chocolates and chips) and healthy snacks (fruits, vegetable snacks and nuts) were organized in separated shelves, which were placed next to each other with indulgent snacks before healthy snacks. The order of snack options was thus controlled for, while the location of the whole snack category was manipulated. Mimicking a realistic supermarket, the healthy snacks were presented in small portions, for example, an apple or a small box of blueberry, while the indulgent snacks were presented in big portions, for example, a pack of Twix that contained 7 mini bars. In the first condition, participants encountered the snacks immediately when they entered the virtual supermarket, and afterwards they encountered 14 other (neutral) categories in which they made choices. In the second condition, the snacks were placed near the end of the store after twelve neutral categories and before two neutral categories. The neutral categories were both non-food and food categories that participants in a pretest had rated as neither healthy nor unhealthy.

\section{Procedure}

After giving informed consent, participants were given a short training session (2 minutes) in the virtual supermarket. The setup of the virtual supermarket using three screens was the same as in the first study. Participants were asked to imagine that they were doing an internship in a small town and would like to 
buy a few products from a local grocery shop. They were asked to choose 14 products (shopping list with categories provided) and to also choose the snack products which they needed for one week among their other groceries (they could choose as many as they wanted). Moreover, participants were informed that one of their choices would be given as a reward for participation in order to motivate them to make realistic choices. D uring their shopping trip, participants were free to move back and forth along the aisle.

Participants had unlimited time to choose the products. After the choice task was over, they filled in a final questionnaire. Trait self-control was included as well as the perceptions toward each product category and preference for each snack product. Preferences of snacks were measured to ensure that participants liked at least one of the snacks. Finally, participants were thanked and they could pick one of the snack products they had chosen during the shopping task as their reward.

\section{Measures}

The key dependent variable was participants' snadks dhices measured as the absolute number of indulgent and healthy snacks bought. Participants indicated their choice by selecting products in the virtual store, and the computer recorded these choices.

Foodrdatedsedf-contrd was measured with three items: "I have a hard time breaking bad food habits", "I wish I had more self-discipline when it comes to unhealthy food" and "Sometimes I can't stop myself from eating unhealthy food, even if I know it's wrong" on a 7-point 'strongly disagree - strongly agree' scale (cf. Honkanen et al., 2012). Items were reverse-coded and combined to form an index $(\alpha=.83)$. Higher scores thus indicate higher trait self-control. 
As a manipulation dhek, participants were asked to indicate the extent to which they thought each of the four snack categories in the virtual store (fruit and vegetable snacks, nuts, chocolates, and chips) were healthy on 7-point scales, with end poles labelled "not at all" to "very much". We expect the first two categories to be perceived as healthier than the latter two snack categories. Participants also indicated their preference for these snack categories in that they were asked to indicate the extent to which they like individual snacks on a 7-point 'extremely dislike - extremely like' scale. Socio-demographic information of participants included age, gender and educational background.

\subsubsection{Analysis plan}

Ratings on the healthiness of snack categories and the preference toward snacks were analyzed using Repeated Measures ANOVA's with categories of snacks (healthy vs. unhealthy) as within-subject factor, product location (contrast coded location: beginning $=-0.5$ and end $=0.5$ ), mean-centered self-control scale and their interaction as between-subject factors. Significant interaction effects were further probed using MEMORE (Mediation and Moderation in RepeatedMeasures Designs, Montoya, 2018). Health perception or preference toward healthy and indulgent snacks were included as within-subject outcome variables. Either product location or mean-centered self-control scale was included in the MEMORE model as moderator(s), unless their interaction effects with snack categories was not significant. The multiplicative multiple moderator model (model 3) was selected as it allows interaction between product location and trait self-control. For the multiplicative multiple moderator model in MEMO RE, the interaction effects of self-control with other predictors were probed at mean plus and minus one standard deviation. 
For number of indulgent and number of healthy snack choices, the independent variables product location, self-control (mean-centered scale) as well as their interaction were included in an ANOVA. Significant interaction effects were further investigated using the Johnson-Neyman region of significance (Johnson \& Neyman, 1936; Spiller, Fitzsimons, Lynch, \& McClelland, 2013). This approach has been recommended for probing moderation effects as it illuminates the entire range of the moderator to show the region for which group differences are statistically significant, rather than focusing on specific points only (Preacher, Curran, \& Bauer, 2006; Spiller et. al, 2013). We investigated this J-N region of significance by using Hayes' PROCE SS macro for SPSS (model 1: simple moderation with contrast coded location (beginning $=-0.5$ and end $=$ 0.5) and mean centred trait self-control scale; Hayes, 2013).

\subsubsection{Results}

\section{Perceptions toward snacks}

The manipulation check confirmed that, as expected, participants rated the healthy snacks ( $M=6.43)$ as significantly healthier than the indulgent snacks ( $M$ $\left.=2.07 ; \mathrm{F}(1,57)=1092.99, \mathrm{p}=.000, \eta_{\mathrm{p}}^{2}=.95\right)$. Moreover, there was a significant interaction effect between snack category and self-control $(F(1,57)=5.30, p=$ $.025, \eta_{\mathrm{p}}^{2}=0.09$ ). MEMORE revealed that participants with low, moderate and high self-control rated healthy snacks to be healthier than indulgent snacks. The differences in perceived healthiness of healthy snacks compared to indulgent snacks became smaller with a higher level of self-control $(b=-0.20, p=.025)$.

\section{Preference toward snacks}

Results on preference toward snacks showed that participants generally liked the snack products. Surprisingly, they reported a higher preference toward the healthy snacks $(M=5.05)$ than toward the indulgent snacks $(M=4.38 ; F(1,57)$ $\left.=19.61, \mathrm{p}=.000, \eta_{\mathrm{p}}^{2}=.26\right)$. Looking into detail, a significant interaction effect 
of snack category and product location $\left(\mathrm{F}(1,57)=4.98, \mathrm{p}=.03, \eta_{\mathrm{p}}^{2}=.08\right)$ showed that differences in preference toward snacks appeared only when participants saw snacks in the beginning of the store (see Table 5.1). After seeing snacks in the beginning of the store, participants preferred healthy snacks to indulgent snacks $\left(\mathrm{M}_{\text {healthy }}=5.14, \mathrm{M}_{\text {ndulgent }}=4.11 ;(\mathrm{t} 57)=4.60, \mathrm{p}<.001\right)$. Participants who saw snacks at the end of the store liked healthy and indulgent snacks to the same extent $\left(\mathrm{M}_{\text {healthy }}=4.97, \mathrm{M}_{\text {ndulgent }}=4.63\right.$; $(\mathrm{t}(57)=1.59, \mathrm{p}=.117)$. In other words, participants who saw snacks at the end gave slightly higher scores on indulgent snacks $\left(\mathrm{M}_{\text {end }}=4.63\right)$ than those seeing snacks in the beginning $\left(\mathrm{M}_{\text {beginning }}=4.12, \mathrm{~F}(1,57)=3.61, \mathrm{p}=.063, \eta_{\mathrm{p}}^{2}=.06\right)$. Participants in both conditions, however, liked healthy snacks to the same extent $\left(\mathrm{M}_{\text {end }}=4.97\right.$ and $\left.\mathrm{M}_{\text {beginning }}=5.14, \mathrm{~F}(1,57)=0.69, \mathrm{p}=.411, \eta_{\mathrm{p}}^{2}=.01\right)$. It thus appears that the depletion resulting from making other choices increased liking for indulgent snacks.

Table 5.1: Pairwise comparison and moderation in Repeated-Measures test (MEMORE) for consumers' preference toward healthy and indulgent snacks

\begin{tabular}{|c|c|c|c|c|c|}
\hline \multirow{3}{*}{ Healthy Snacks } & \multicolumn{2}{|c|}{$\begin{array}{l}\text { Beginning } \\
(n=28)\end{array}$} & \multicolumn{2}{|c|}{$\begin{array}{c}\text { End } \\
(n=33)\end{array}$} & \multirow{2}{*}{ Pairwise Comparison } \\
\hline & $M$ & $S E$ & $M$ & $S E$ & \\
\hline & 5.14 & 0.69 & 4.97 & 0.89 & $F(1,57)=0.69, p=.411$ \\
\hline Indulgent Snacks & $4.11^{\mathrm{b}}$ & 1.20 & $4.63^{\mathrm{a}}$ & 0.91 & $F(1,57)=3.61, p=.063$ \\
\hline $\begin{array}{l}\text { Repeated } \\
\text { Measure }\end{array}$ & \multicolumn{2}{|c|}{$\begin{array}{c}t(57)=4.60 \\
p<.001\end{array}$} & \multicolumn{2}{|c|}{$\begin{array}{c}t(57)=1.59 \\
p=.117\end{array}$} & \\
\hline
\end{tabular}

Note: The characters a and b indicate pairwise significant differences from post hoc LSD tests at 95\% confident interval for the main effect of product location on snack preferences. 


\section{Number of indulgent snacks chosen}

On average, participants chose 1.31 packs of indulgent snacks. Contrary to expectations, results showed no significant effects of product location $(\mathrm{F}(1,57)$ $\left.=1.49, \mathrm{p}=.227, \eta_{\mathrm{p}}^{2}=.02\right)$, self-control $\left(\mathrm{F}(1,57)=0.73, \mathrm{p}=396, \eta_{\mathrm{p}}{ }^{2}=.01\right)$ nor of their interaction $\left(\mathrm{F}(1,57)=0.11, \mathrm{p}=.740, \eta_{\mathrm{p}}^{2}=.00\right)$. This could be due to the low number of indulgent snacks chosen: $62.30 \%$ of participants bought just one or two packages of indulgent snacks. This can be explained by the lange package size of these snack alternatives (e.g., a package of Mars chocolate consisted of six mars bars or a package of Lays contained 225 grams of chips).

\section{Number of healthy snacks chosen}

In line with our expectation, results showed a marginally significant effect of product location $\left(F(1,57)=3.78, p=.057, \eta_{\mathrm{p}}^{2}=.06\right)$, a significant effect of self-control $\left(F(1,57)=5.13, p=.027, \eta_{p}^{2}=.08\right)$, and a significant interaction effect $\left(F(1,57)=4.15, p=.046,, \eta_{p}^{2}=.07\right)$. Healthy snacks placed at the end of the store $(M=5.75)$ were marginally bought more than those placed in the beginning of the store $(M=4.21)$. Moreover, level of self-control had a positive effect on the number of healthy snacks chosen $(b=0.62)$. The interaction effect was probed using the Johnson-Neyman region of significance. This indicated a lower bound of the region of significance with mean-centred self-control at 0.04 (corresponding score on the self-control scale is 4.00). Thus, participants who scored moderately high to high on self-control $(\geq 4)$ bought more healthy snacks when they encountered the snacks at the end of the store than in the beginning of the store. For participants scoring low and moderately low on self-control $(<4)$, the number of healthy snacks chosen did not depend on product location. See Figure 5.1 for a graphical display. 


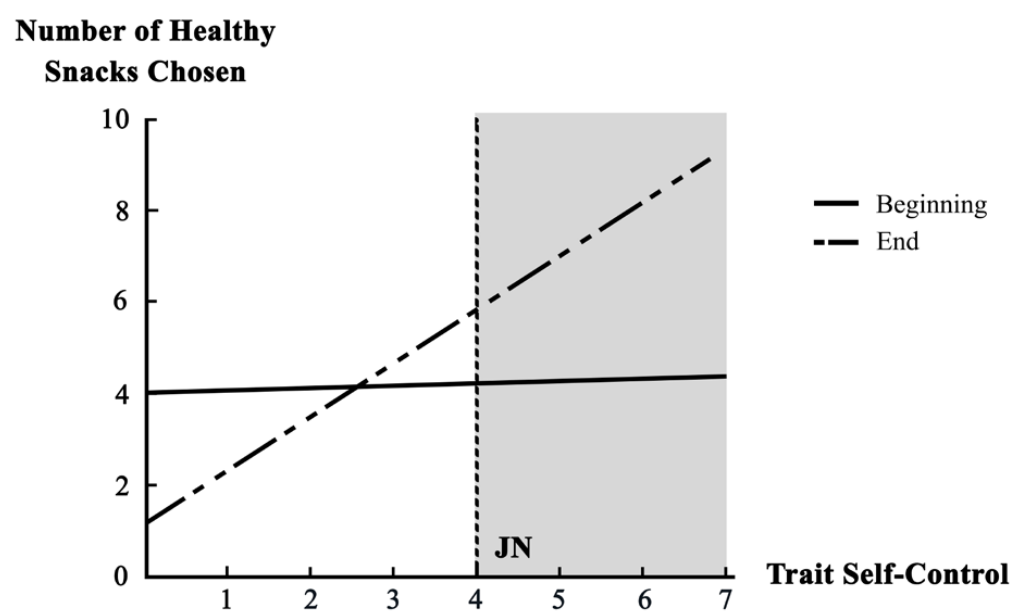

Figure 5.1: Number of healthy snacks chosen, depending on product location and trait self-control

Note: Vertical line represents the Johnson-Neyman region of significance $(\mathrm{JN})$. Grey area represents the region at the self-control scale from 4 to 7 where the two conditions significantly differ.

\section{Results after the exclusion of outliers based on total snack choices}

In addition to the above analysis, we also analysed the data without participants who chose a very low or very high number of snacks. These outliers were detected based on absolute deviation around the median (median \pm 2.5 median absolute deviation (MAD); Leys et al., 2013). This method is preferred for statistical reasons over using a mean plus or minus three standard deviations (Leys et al., 2013) and is also more likely to detect outliers in small samples like the sample in this study (Cousineau \& Chartier, 2010). Following the MAD method, three participants who chose more than 12.41 snacks were excluded from the analysis. In total, 58 participants remained in the dataset.

Results showed similar effects of product location, self-control and their interaction on perceptions toward snacks. As before, we found no significant effects on the number of indulgent snacks chosen (all $F_{\mathrm{s}}<1.78$, $p \mathrm{~s}>.188$ ). 
For healthy snacks, the main effect of product location and of self-control remained significant (location: $F(1,54)=4.35, p=.042, \eta_{\mathrm{p}}^{2}=.08$; self-control: $\left.\mathrm{F}(1,54)=5.07, \mathrm{p}=.028, \eta_{\mathrm{p}}^{2}=.09\right)$ and showed the same pattern that participants chose more healthy snacks at the end than in the beginning $\left(\mathrm{M}_{\text {end }}=\right.$ 5.33, $\mathbf{M}_{\text {beginning }}=3.89$ ). The high self-control participants chose more healthy snacks than low self-control participants $(b=0.59)$. The interaction effect between product location and self-control after excluding the potential outliers, however, was no longer significant $\left(F(1,54)=1.82, p=.183, \eta_{\mathrm{p}}^{2}=.03\right)$.

\subsubsection{Discussion}

This study discovered an interesting interplay between product location and trait self-control on the number of healthy snacks chosen. Results suggest that individuals with a relatively high level of trait self-control who encounter snacks after making a series of choices are more likely to buy a higher number of healthy snacks than those who encounter snack products in the beginning of the store. This effect, in contrast, does not appear for participants with a lower level of self-control. This suggests that high self-control participants who are under ego-depletion may try to control themselves against over-purchasing for unhealthy options but not for healthy options. As participants seem to like healthy snacks to a similar extent as indulgent snacks and think that the healthy options are healthy, high self-control participants under ego-depletion may impulsively choose more healthy snacks. Although this result is intriguing, we have to note that the interaction effect is no longer significant when three participants with a relatively high number of chosen snacks are excluded from the dataset. Therefore, this interaction should be interpreted with care and replication of the effect is important. 
There were no significant effects found on the number of indulgent products chosen. This may be caused by the relatively large package sizes of indulgent snacks, which led most participants to choose only one or two of these products, and left little variance to be explained. Preference ratings for indulgent snacks placed at the end, however, were slightly higher than ratings for those placed in the beginning, offering some suggestion that location might influence the attractiveness of indulgent snacks.

O ur next study is set up to remedy the limited variance on the choice measure for indulgent snacks and will use smaller packages of indulgent products. Moreover, it will attempt to replicate the effect that we found for the number of healthy snacks that were chosen. A potential alternative explanation for the effects on healthy choices could be that the increase in number of healthy snacks chosen at the end of a store is because participants see it as a last chance to shop or to fulfil their health goal. In contrast, when participants entered the store and chose snacks, they may anticipate seeing more healthy categories later on in the store. They may limit their choices of healthy snacks to some extent because they want to shop for other healthy foods. In the next study, other products and one healthy food category are included at the end of the store. Thus, we can rule out this potential alternative explanation, an 'end of task' effect in which people may choose more healthy snacks at the end to fulfil their health goal or rush through the last choice task in order to finish. 


\subsection{Study 3}

The objective of this study is to replicate the results of Study 2 for healthy snack choices, and to further examine effects for indulgent snack choices.

\subsubsection{Method}

\section{Participants}

Undergraduate and graduate students at a D utch University participated in the study for a snack incentive $(n=122)$. Ten participants were excluded from analysis because they did not complete the task, nor because the virtual shop malfunctioned. Therefore 101 participants (22 males and 90 females, age 18 - 30) were included in the analyses.

\section{Design}

As in Study 2, participants were randomly assigned to one of two store layouts in which snacks were placed either in the beginning or in the end of the store. Some changes were applied to the products in the store compared to the second study. This study provided snack alternatives in a single serve portion instead of using a large portion size. Moreover, a larger variety of options was used for both healthy and indulgent snacks. This ensures that snack choices are not limited because of boredom or idiosyncratic preferences for specific snack products. In addition to the product categories used in Study 1 in which one condition presented snacks as the last categories, three food and non-food categories (including a healthy category of salads) were added to the end of the store. Figure 5.2 depicts snack options in the store. 


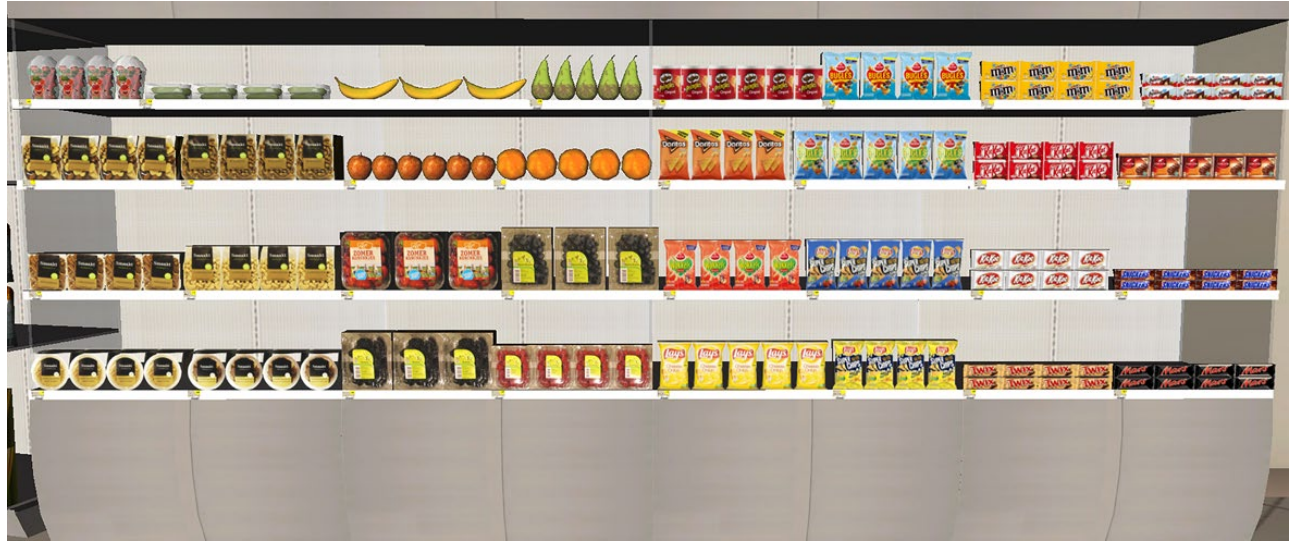

Figure 5.2: Snack options in the store, Study 3

Moreover, we explored the perception about snacks in more detail (i.e., perceived harmfulness and perceived tastiness) and the reasons behind the snack choices, specifically the intention to balance or highlight either the health or the enjoyment goal of consumption. It has been proposed that the effect of ego-depletion and self-control may be derived by shifts in goal pursuit or in motivation (e.g., shifts from pursuing the long-term goal (being healthy) to pursuing the short-term goal (getting immediate pleasure; Inzlicht \& Schmeichel, 2012). As evidence to support this proposition, Schmeichel, Harmon-Jones, and Harmon-Jones (2010) showed that the strength of approach-motivation impulses increases under ego-depletion. Thus, it is relevant to examine which goal participants are trying to pursue, as this may provide additional insight into the underlying process. Reallocation of resources due to depletion, which we argued could underlie effects on product choice, should be reflected in the goals that people pursue. The results of the previous study may have occurred because people who are high in self-control reallocated resources, and consequently shifted their goals pursuit, when depleted: they focused more exclusively on the health goal (which increased the number of healthy options that they chose). By testing whether the interaction between self-control and product location affects goal pursuit, we can examine this. 


\section{Procedure}

The same procedure as Study 2 was applied in this study. In addition, participants were asked to indicate their reasons behind snack choices in an online questionnaire. This questionnaire was administered after they finished their shopping task, together with the other questions used in a Study 2. At the end, the same demographic background (age, gender and education) as in Study 2 was recorded.

\section{Measures}

Self-control was measured with the same items as in Study $2(\alpha=.83)$. In addition to rating the perceived healthfulness and preference toward the snack categories, as in Study 2, participants also rated to what extent they thought each of the snack categories was tasty and was harmful (7-point scales ranging from 'not at all' to 'very tasty' / 'very harmful' respectively). Taste and harmfulness are relevant attributes for food choice.

In addition, goal pursuit was measured to explore the reason behinds snack choices using the items shown in Table 5.2. The relevant goals that were taken up in the study were the intention to balance between health and enjoyment $(\alpha=.79)$, intention to highlight a health goal $(\alpha=.85)$ and intention to highlight an enjoyment goal $(\alpha=.74)$. Participants were asked "Plese think abat your consideations when you wee sdecting the snadks and indicate to what extent you agee or disagrewith thefdlowingstatements", with 0 - 100 slider bars $(0=$ totally disagree, $100=$ totally agree). 
Table 5.2: Items measuring goal pursuit as an underlying process for snack choices

\section{Goal pursuit}

Intention to
balance between
healthy and
indulgent goals.

Intention to

highlight a health

goal

\section{Items}

a) I plan to eat healthy snacks, and this will allow me to indulge in unhealthy snacking at other times.

b) It is okay to choose unhealthy snacks as long as I also choose healthy snacks.

c) I experienced conflict between buying healthy snacks and buying unhealthy snacks.

d) I chose healthy snacks to compensate for my choice of unhealthy snacks.

e) I choose healthy snacks and I have never considered compensating with unhealthy snacks.

f) I plan to eat unhealthy snacks sometimes and then I will compensate by eating healthier snacks later on.

g) I tried to balance my choices between healthy and unhealthy snacks.

a) I mainly chose healthy snacks instead of unhealthy snacks because I want to sustain my healthy diet.

b) Being healthy is really important for me, so I mainly chose healthy snacks.

c) I avoided choosing unhealthy snacks because I did not want to interfere with my goal of eating healthy food.

a) I based my snack choices on the taste I like because eating tasty snacks will give me pleasure.

b) I chose the tasty snacks I like without being worried about the healthiness of the snacks.

c) I wanted to enjoy my snacks, so I chose mainly tasty snacks regardless of how healthy they are. 


\subsubsection{Analysis plan}

Analyses were similar to those in Study 2. Univariate ANOVAs were used to explore effects of product location, self-control and their interaction on goal pursuit. In addition, univariate ANOVAs were also applied to test effects of product location, self-control and their interaction on the number of healthy and the number of indulgent chosen that were made, as in the previous study.

\subsubsection{Results}

\section{Perceptions toward snacks}

In line with the previous study, the manipulation checks on perceptions toward snacks confirmed that participants rated the healthy snacks category $(M=6.10)$ as significantly healthier than the indulgent snacks $(\mathrm{M}=1.50 ; \mathrm{F}(1,108)=$ 3082.79, $\mathrm{p}=.000, \eta_{\mathrm{p}}^{2}=.97$ ). As expected, participants also perceived healthy snacks as less harmful to their health $(\mathrm{M}=1.94)$ than indulgent snacks $\left(\mathrm{M}=5.33 ; \mathrm{F}(1,108)=678.74, \mathrm{p}=.000, \eta_{\mathrm{p}}^{2}=.86\right)$. Moreover, we found a marginally significant main effect (negative effect) of self-control on perceived harmfulness of snacks. $\mathrm{On}$ average, high self-control participants rated snacks as less harmful than low self-control participants $(b=-0.09, F(1,108)=3.13$, $\left.\mathrm{p}=.075, \eta_{\mathrm{p}}^{2}=.03\right)$.

Regarding perceived tastiness of snacks, we found a marginally significant interaction effect of product location and snack category $(F(1,108)=2.85$, $\left.\mathrm{p}=.094, \eta_{\mathrm{p}}{ }^{2}=.03\right)$, and a significant interaction effect of self-control and snack category $\left(F(1,108)=15.68, p=.000, \eta_{p}^{2}=.13\right)$. Participants rated indulgent snacks to be tastier than healthy snacks when the snacks were placed at the end $\left(\mathrm{M}_{\text {ndulgent }}=5.29, \mathrm{M}_{\text {healthy }}=4.65 ; \mathrm{t}(108)=-2.18, \mathrm{p}=.032\right)$. Perceived tastiness was not different when the snacks were placed in the beginning of the store $\left(\mathrm{M}_{\text {ndulgent }}=5.56, \mathrm{M}_{\text {healthy }}=5.52 ; \mathrm{t}(108)=0.23, \mathrm{p}=.822\right)$. This suggests that 
tastiness perceptions of the snacks were influenced by the depletion due to making other choices. In addition, the interaction effect of self-control and snack category showed that higher self-control participants rated healthy snacks as tastier than indulgent snacks ( $\mathrm{b}_{\mathrm{iL}-\mathrm{Ind}}=0.34, \mathrm{p}=.068$ ). In contrast, low selfcontrol participants rated healthy snacks as less tasty than indulgent snacks $(b=-0.70, p<.001)$. The moderate self-control participants, however, did not perceived differences between tastiness of those snacks ( $\left.\mathrm{b}_{\mathrm{rL}-\mathrm{Ind}}=-0.18, \mathrm{p}=.175\right)$. Apart from these, there was no significant effect of location, of self-control or of their interaction on perceptions toward snacks (Fs $<1.24$, ps $>$.268).

\section{Preference toward snacks}

Even though a larger variety of snacks were provided, participants still reported a higher preference toward healthy snacks $(M=5.20)$ than indulgent snacks ( $M$ $=4.83 ; \mathrm{F}(1,108)=5.19, \mathrm{p}=.025, \eta_{\mathrm{p}}^{2}=.05$ ). The marginally significant (main) effect of self-control revealed that on average higher self-control participants rated lower scores on snack preferences than lower self-control participants $\left(b=-0.09, F(1,108)=3.13, p=.080, \eta_{\mathrm{p}}^{2}=.03\right)$. Moreover, we also found $\mathrm{a}$ marginally significant interaction effect of snack category and product location $\left(\mathrm{F}(1,108)=2.90, \mathrm{p}=.092, \eta_{\mathrm{p}}^{2}=.05\right)$ and a significant interaction effect of snack category and trait self-control $\left(\mathrm{F}(1,108)=18.11, \mathrm{p}=.000, \eta_{\mathrm{p}}^{2}=.14\right)$. MEMORE showed that participants preferred healthy snacks to indulgent snacks when they saw snacks in the beginning of a store $\left(\mathrm{M}_{\text {healthy }}=5.29, \mathrm{M}_{\text {ndulgent }}=4.65 ; \mathrm{t}(108)=\right.$ $2.79, \mathrm{p}=.006)$. In contrast, they like both snacks to the same extent when they saw snacks at the end of a store $\left(\mathrm{M}_{\text {healthy }}=5.11, \mathrm{M}_{\text {ndulgent }}=5.01 ; \mathrm{t}(108)=0.41\right.$, $\mathrm{p}=.682$ ). This again suggests that preference toward snacks was influenced by depletion. Moreover, the interaction effect of self-control and snack category confirmed that participants with moderate and high self-control preferred healthy snacks to indulgent snacks (moderate self-control: $b=0.37, p=.025$; high self-control: $\mathrm{b}=1.06, \mathrm{p}=.000$ ). Low self-control participants liked healthy and indulgent snacks to the same extent $(b=-0.32, p=.161)$. 


\section{Number of indulgent snacks chosen}

D espite providing smaller packages and a larger variety of indulgent snacks, the average number of indulgent snacks chosen was only slightly larger than in the previous study. Slightly different from the Study 2, results showed that selfcontrol negatively affected the number of indulgent snacks chosen $(b=-0.31$, $\left.F(1,108)=7.99, p=.006, \eta_{p}^{2}=.07\right)$. Similar to Study 2, neither the effect of product location $\left(\mathrm{F}(1,108)=1.84, \mathrm{p}=.177, \eta_{\mathrm{p}}^{2}=.02\right)$, nor the interaction effect of product location and self-control was significant $(F(1,108)=2.44, p=.121$, $\left.\eta_{\mathrm{p}}^{2}=.02\right)$.

\section{Number of healthy snacks chosen}

None of the effects on number of healthy snack chosen was significant including the effect of product location $\left(\mathrm{F}(1,108)=0.00, \mathrm{p}=.985, \eta_{\mathrm{p}}^{2}=.00\right)$, the effect of trait self-control $\left.F(1,108)=0.39, p=.534, \eta_{p}^{2}=.00\right)$, and their interaction $\left(\mathrm{F}(1,108)=2.51, \mathrm{p}=.116, \eta_{\mathrm{p}}^{2}=.02\right)$. O $\mathrm{n}$ average, participants chose 6.81 pieces of healthy snacks. This is slightly more than the number of healthy snacks chosen in Study 2 (5.02 packages).

\section{Goal pursuit}

Regarding the intention to balancebetween a helth and an enjoment goal, a univariate ANOVA showed a significant negative effect of self-control on the intention to balance between health and indulgent goals $(b=-4.39, F(1,108)=15.26$, $\mathrm{p}=.000, \eta_{\mathrm{p}}^{2}=.12$ ). The effect of product location and the interaction effect of product location and self-control on intention to balance between goals was not significant (all Fs $<1.44$, ps $>$.232).

For intentiontohighight thehealthgoal, the effect of product location was marginally significant $\left(F(1,108)=2.95, p=.089, \eta_{\mathrm{p}}^{2}=.03\right)$. Participants reported slightly higher intentions to highlight the health goal when they chose snacks in the beginning of the store than at the end $\left(\mathrm{M}_{\text {beginning }}=57.43\right.$ and $\left.\mathrm{M}_{\text {end }}=50.06\right)$. 
Moreover, self-control positively influenced the intention to highlight the health goal $\left(b=3.85, F(1,106)=6.93, p=.010, \eta_{\mathrm{p}}^{2}=.00\right)$. The interaction effect of product location and self-control was not significant $(F(1,106)=0.17$, $\left.\mathrm{p}=.684, \eta_{\mathrm{p}}^{2}=.00\right)$.

For intention to higlight the ejigment goal, the effect of product location was marginally significant $\left(\mathrm{F}(1,108)=3.41, \mathrm{p}=.068, \eta_{\mathrm{p}}^{2}=.03\right)$. Participants who chose snacks at the end of a store reported higher intentions to highlight the enjoyment goal than those who chose snacks in the beginning $\left(\mathrm{M}_{\text {end }}=60.47\right.$ and $M_{\text {eeginning }}=53.25$ ). The effect of self-control and the interaction between product location and self-control did not significantly affect the intention to highlight the enjoyment goal (all Fs $<0.51$, ps $>$.475).

In conclusion thus, people with a high level of self-control are more likely to pursue the goal to choose the healthy option and less likely to balance health versus enjoyment goal than people with low self-control. In addition, and in line with the depletion account, prior choices tend to lead people to pursue an enjoyment goal more and a health goal less.

\section{Results after the exclusion of outliers based on total snack choices}

Following the procedure in Study 2, we screened for potential outliers. Based on the MAD method, seven participants who chose more than 16.77 snacks were excluded from analysis. Separate analyses were performed on the remaining 105 participants. Results showed consistent effects of product location, self-control and their interaction on perceptions toward snacks and on goal pursuit. Likewise, for the number of indulgent snacks chosen the effects were in line with those reported for the full dataset. Moreover, for the number of healthy snacks chosen, the interaction effect of product location and self-control became significant $\left(F(1,101)=5.05, p=.027, \eta_{\mathrm{p}}^{2}=.05\right)$. 
This interaction effect was probed using the Johnson-Neyman region of significance. This indicated a lower bound of the region of significance with mean-centred self-control at 0.27 (corresponding score on the self-control scale is 4.16). In opposite to Study 2, this study showed that participants who scored moderately high to high $(\geq 4.16)$ on self-control chose more healthy snacks when they encountered the snacks in the beginning of a store than at the end of a store. For participants scoring moderately low to low on self-control $(<4.16)$, the number of healthy snacks bought did not depend on product location. See Figure 5.3 for a graphical display. Apart from this, none of effects was significant including the effect of product location $\left(F(1,101)=2.57, p=.112, \eta_{p}^{2}=.03\right)$, and the effect of trait self-control $\left.F(1,101)=2.45, p=.121, \eta_{p}^{2}=.02\right)$.

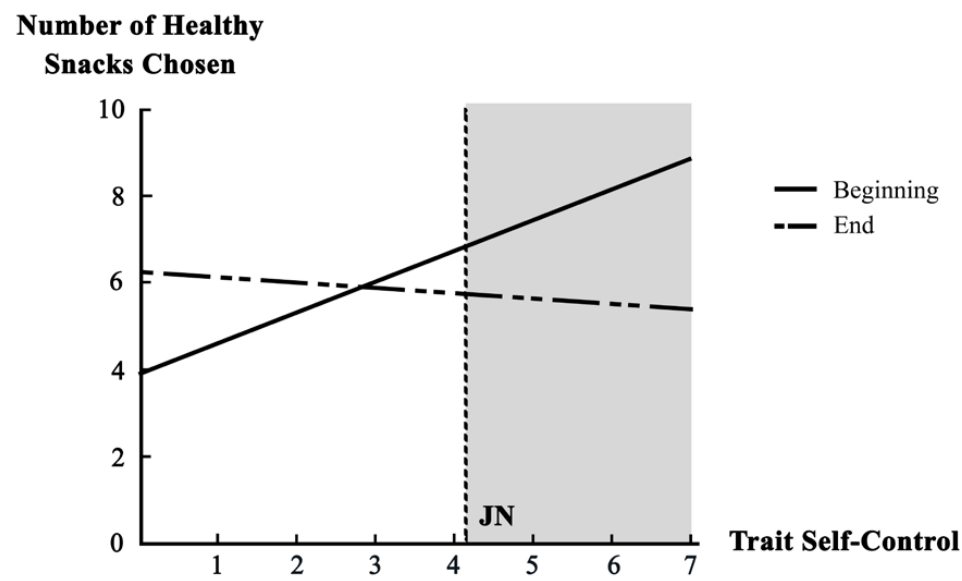

Figure 5.3: Number of healthy snacks chosen, depending on product location and trait self-control (cut outliers based on MAD method)

Note: Vertical line represents the Johnson-Neyman region of significance (JN). Grey area highlights the region at the self-control scale from 4.16 to 7 where the two conditions significantly differ.

\subsubsection{Discussion}

The results of this study show main effects of self-control. People who are high in self-control usually prefer healthy snacks more, report a higher intention to highlight the health goal, and a lower intention to balance health and enjoyment 
goals, and choose fewer indulgent snacks, than people who are low in self-control. Yet, we did not replicate the results of Study 2: we did not find an effect of product location, self-control nor their interaction on the number of healthy snacks chosen in this study. If anything, controlling for potential influencing cases indicates an interaction effect that is in opposite direction to the effect found in Study 2. In contrast to our hypothesis, the interaction between depletion and self-control also does not influence the number of indulgent choices in this study.

Alternatively, we may speculate that due to the inclusion of another healthy category and other product categories at the end of the shopping trip, the interaction effect of product location and trait self-control became nonsignificant. Thus, the findings of Study 2 may have been influenced by the proposed 'end of task' effect (instead of ego-depletion). In other words, participants in Study 2 may have chosen more healthy snacks because they have no other option to fulfill their health goal when reaching the end of the shopping trip. However, the self-report of goal pursuit did not support this assumption.

When examining the goals that participants pursued, we found that participants were (marginally) more likely to highlight health and (marginally) less likely to highlight enjoyment when snacks were placed at the beginning of the store than when these were located in the end. This is consistent with the notion of product choices leading to depletion. Thus, our manipulation of product location appeared to affect the goals that participants pursued, although not very strongly.

In our studies so far, we used product location (the amount of preceding choices made) as a task involving the reduction of self-control resources. Although Study 1 has indicated that this manipulation indeed affects state self-control and we find indications for this in the current study as well, in the next study we will use a different and more commonly researched task (Baumeister, 2002a; Tice, 
Baumeister, Shmueli, \& Muraven, 2007) to induce a state of depleted self-control. This established task will help us to rule out a rival explanation for the inconsistency in our findings, namely that the repeated choice task may have been a too weak manipulation of the state of ego-depletion.

\subsection{Study 4}

This study is a full replication of Study 3, except for the manipulation of the ego-depleting task. Instead of using product location to induce ego-depletion, we applied another self-control task, the "crossing out of a letter" protocol that has been frequently and successfully used in previous ego-depletion research (Baumeister, 2002a, Tice et al., 2007).

\subsubsection{Method}

\section{Participants}

Participants ( $\mathrm{n}=106)$ were recruited in the same way as in the prior studies and given the same snack incentive. Nine participants were excluded from analysis as they were following a special diet that influences snack choices. Thus 97 participants (27 males and 70 females, age 18 - 30) were included in the analyses.

\section{Design}

The study had a 2 group between-subject design. Participants were randomly assigned to one of the two ego-depletion conditions (ego-depletion vs. no egodepletion conditions). They were asked to do two crossing letter tasks, which influences the level of ego-depletion, before choosing snacks. Snack stimuli and the questionnaires were the same as in Study 3. 


\section{Procedure}

Participants were informed that they were going to participate in two separated studies. The first study was introduced as a study about the written media and the second as a marketing study about product choices. After signing a consent form, participants were moved to a first area and asked to read a dense text. While reading, they were asked to cross out every " $\mathrm{e}$ " they found. Every participant was asked to do this task for 5 minutes. Then the participants did the following task where ego-depletion was manipulated. Participants in a no egodepletion group were asked to perform the same task with a new text, in contrast, participants in the ego-depletion group were asked to use new rules about when to cross out the " $\mathrm{e}$ ". The rules were to cross out the " $\mathrm{e}$ " if it was not followed or preceded by a vowel (a, e, i, o, or $\mathrm{u}$ ) in the same word and if the " $\mathrm{e}$ " was located two or more places (letters, spaces or punctuation marks) from a vowel.

Compared to no ego-depletion group, participants in ego-depletion group had to regulate themselves to not follow their habit of crossing out every " $\mathrm{e}$ ", but to use the more complicated role to complete the task. Previous research has shown that the latter task is more cognitively demanding and that these two conditions lead to significant differences in depletion (Baumeister, Bratslavsky, Muraven, \& Tice, 1998; Fennis, 2011). The second letter crossing task was performed for a maximum of 5 minutes to avoid that participants would feel a time pressure and rush through the shopping task.

After finishing reading and the letter crossing task, participants were moved to the virtual supermarket. They were given an instruction and followed a short training session (2 minutes). The same instructions as used in Studies 2 and 3 were given, but the shopping list was shorter. Participants were asked to choose the snack products which they needed for one week. Again, participants were informed that one of their choices would be given as a reward for participation in order to motivate them to make realistic choices, and their shopping time was 
unlimited. After the choice task was over, they filled in a final questionnaire that contained the same questions as in Study 3. Finally, participants were thanked and they could pick one of the snack products they had chosen during the shopping task as their reward.

\section{Measures}

All measurement items from Study 3 were applied in this study. Reliability analysis showed reasonable to good reliability scores for all constructs: self-control $(\alpha=.85)$, intention to balance between health and enjoyment goal $(\alpha=.80)$, intention to highlight a health goal $(\alpha=.83)$ and intention to highlight an enjoyment goal $(\alpha=.63)$.

\subsubsection{Analysis plan}

A nalyses were the same as those in Study 3.

\subsubsection{Results}

\section{Perceptions toward snacks}

As expected, the manipulation checks confirmed participants' perceptions toward snacks. Participants perceived the healthy snacks category $(M=6.08)$ to be healthier than the indulgent snacks $(\mathrm{M}=1.60 ; \mathrm{F}(1,93)=2194.41, \mathrm{p}=.000$, $\left.\eta_{\mathrm{p}}^{2}=.96\right)$. In addition, we found a significant main effect of self-control $(\mathrm{b}=0.08$, $\left.\mathrm{F}(1,93)=6.58, \mathrm{p}=.012, \eta_{\mathrm{p}}^{2}=.07\right)$ and a significant interaction effect of self-control and snacks category on perceived healthiness $(F(1,93)=0.04$, $\mathrm{p}=.037, \eta_{\mathrm{p}}^{2}=.05$ ). This interaction showed that participants with low, moderate and high self-control perceived healthy snacks to be healthier than indulgent snacks (low self-control: $\mathrm{b}=4.69, \mathrm{p}<.001$; moderate self-control: $\mathrm{b}=4.48$, $\mathrm{p}<.001$; high self-control: $\mathrm{b}=4.28, \mathrm{p}<.001$ ). 
Regarding perceived harmfulness of snacks, participants also rated the healthy snacks to be less harmful $(M=1.79)$ than indulgent snacks $(M=5.18 ; F(1,93)$ $\left.=808.43, \mathrm{p}=.000, \eta_{\mathrm{p}}^{2}=.90\right)$. On average, high trait self-control participants rated lower scores on harmfulness of snacks than low trait self-control participants $\left(\mathrm{b}=-0.17, \mathrm{~F}(1,93)=11.47, \mathrm{p}=.001, \eta_{\mathrm{p}}^{2}=.11\right)$. Moreover, the interaction effect between ego-depletion and snack category was significant $\left(\mathrm{F}(1,93)=4.21, \mathrm{p}=.043, \eta_{\mathrm{p}}^{2}=.04\right)$. This interaction showed that under both conditions of ego-depletion, participants still rated healthy snacks to be less harmful than indulgent snacks (No ego-depletion: $b=-3.16, t(93)=-19.16$, $\mathrm{p}<.001$; ego-depletion: $\mathrm{b}=-3.65, \mathrm{t}(93)=-21.02, \mathrm{p}<.001)$.

In terms of perceived tastiness of snacks, participants rated indulgent snacks to have a better taste $(M=5.74)$ than healthy snacks $(M=5.31 ; F(1,93)=9.62$, $\mathrm{p}=.003, \eta_{\mathrm{p}}^{2}=.09$ ), regardless of product location. For the main effect of self-control, high trait self-control participants gave lower score on tastiness of snacks than low trait self-control participants $(b=-0.11,(F(1,93)=7.49$, $\left.\mathrm{p}=.007, \eta_{\mathrm{p}}^{2}=.06\right)$. Moreover, the interaction effect of self-control and snack category showed that indulgent snacks were rated to be tastier than healthy snacks only when participants had moderate and low self-control (low self-control: $\mathrm{b}=-0.68, \mathrm{p}=.001$; moderate self-control: $\mathrm{b}=-0.41, \mathrm{p}=.003$ ). Perceived tastiness of healthy and indulgent snacks was not significantly different when participants had high self-control $(b=-0.15, p=.428)$. In addition, we also found a significant interaction effect of self-control and egodepletion on perceived tastiness of snacks $\left(F(1,93)=6.06, p=.016, \eta_{p}^{2}=.06\right)$. This interaction showed that ego-depletion negatively influenced tastiness of snacks rated by high self-control participants $(b=-0.47, p=.009)$. Perceived tastiness of snacks rated by low and moderate self-control participants did not depend on ego-depletion (low self-control: $\mathrm{b}=0.14, \mathrm{p}=.414$; moderate self-control: $b=-0.16, p=.194)$. A part from these, there was no significant main effect of ego-depletion on perceptions toward snacks (Fs $<1.73$, ps $>$.192). 


\section{Preference toward snacks}

We did not find a significant main effect of snack category on snack preference $\left(\mathrm{M}_{\text {healthy }}=5.06, \mathrm{M}_{\text {ndulgent }}=4.82, \mathrm{~F}(1,93)=2.44, \mathrm{p}=.122, \eta_{\mathrm{p}}^{2}=.03\right)$. The significant main effect of self-control $\left(F(1,93)=10.68, p=.002, \eta_{\mathrm{p}}^{2}=.10\right)$ showed that high trait self-control participants gave lower scores on preference toward snacks than low trait self-control participants $(b=-0.15)$. Moreover, there were significant two-way interaction effects of snack category and self-control $\left(\mathrm{F}(1,93)=10.88, \mathrm{p}=.001, \eta_{\mathrm{p}}^{2}=.11\right)$ and of self-control and ego-depletion $\left(\mathrm{F}(1,93)=9.78, \mathrm{p}=.002, \eta_{\mathrm{p}}^{2}=.10\right)$ as well as a significant three-way interaction effect of snack category, self-control and ego-depletion $\left(\mathrm{F}(1,93)=6.86, \mathrm{p}=.010, \eta_{\mathrm{p}}^{2}=.07\right)$.

The interaction effect of snack category and self-control showed that only high self-control participants preferred healthy snacks to indulgent snacks $(b=0.82$, $\mathrm{p}=.001)$. The low and moderate self-control participants liked healthy and indulgent snacks to the same extent (low self-control: $b=-0.29, p=.219$; moderate self-control: $b=0.26, p=.122$ ). Moreover, the interaction effect of self-control and ego-depletion showed only significant effects of ego-depletion on snack preference rated by high self-control participants. Specifically, high self-control participants liked snacks less when they were depleted than when they were not depleted $(b=-0.54, p=.010)$. Snack preference rated by low and moderate self-control participants was not affected by ego-depletion (low self-control: $b=0.32, p=.102$; moderate self-control: $b=-0.11, p=.424$ )

Moreover, the three-way interaction showed that the effects of self-control on preference toward healthy and indulgent snacks were significant only in the egodepletion condition. Probing the interaction effect further revealed that under ego-depletion high self-control participants preferred healthy snacks to indulgent snacks $(b=1.29, p<.001)$. In contrast, under ego-depletion low trait self-control participants preferred indulgent snacks to healthy snacks $(b=-0.70$, 
$p=.035)$. Moderate self-control participants liked them to the same extent $(b=0.29, p=.230)$.

\section{Number of indulgent snacks chosen}

Unlike prior studies, results showed a significant interaction effect of ego-depletion and self-control on the number of indulgent snacks chosen $\left(F(1,93)=5.80, p=.018, \eta_{p}^{2}=.06\right.$; shown in Figure 5.4). The interaction effect was probed using the Johnson-Neyman region of significance. Results indicated a lower bound of the region of significance with mean-centred self-control at 0.53 (corresponding score on the self-control scale is 4.52). Moderately high to high self-control participants $(\geq 4.52)$ chose fewer indulgent snacks when they were depleted than when they were not depleted. In contrast, the indulgent snack choices of low self-control participants were not significantly affected by ego-depletion. Neither the main effect of ego-depletion nor the main effect of self-control on indulgent snacks choices was significant (ego-depletion: $(F(1,93)$ $=1.56, p=.215, \eta_{p}^{2}=.02$; self-control: $\left(F(1,93)=0.18, p=.673, \eta_{p}^{2}=.00\right)$.

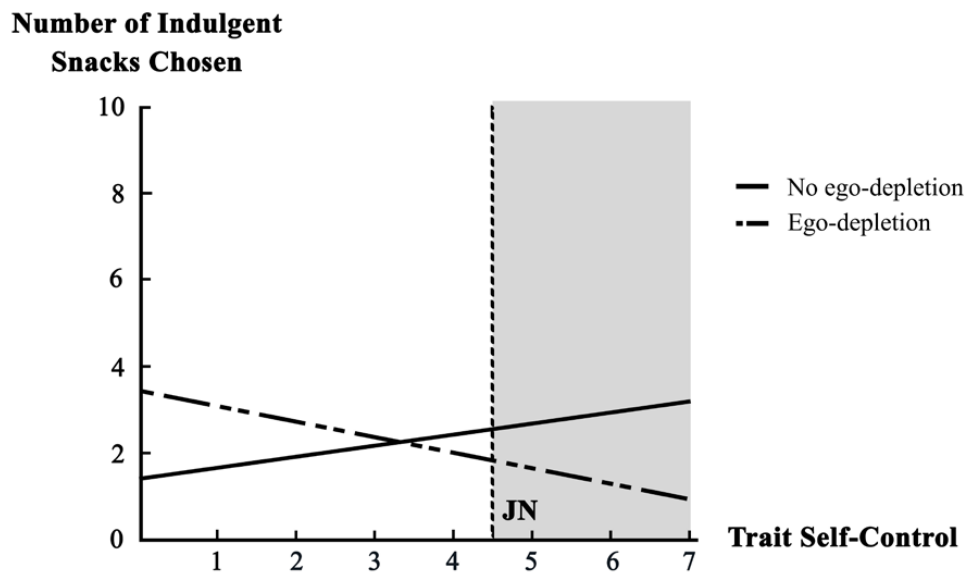

Figure 5.4: Number of indulgent snacks chosen, depending on ego-depletion and trait self-control

Note: Vertical line represents the Johnson-Neyman region of significance (JN). Grey area indicates the region at the self-control scale from 4.52 to 7 where the two conditions significantly differ. 


\section{Number of healthy snacks chosen}

Similar to Study 3, none of the variables had a significant effect on the number of healthy snacks chosen (ego-depletion: $F(1,93)=0.03, p=.870, \eta_{\mathrm{p}}^{2}=.00$; self-control: $F(1,93)=2.12, p=.149, \eta_{p}^{2}=.02$; interaction of ego-depletion and self-control: $\left.F(1,93)=0.00, p=.971, \eta_{\mathrm{p}}^{2}=.00\right)$. $0 \mathrm{n}$ average, participants chose 8.79 healthy snacks.

\section{Goal pursuit}

Results confirmed the finding in Study 3 that there was a significant negative effect of self-control on intention to balance between a helth and an eijgment goal $\left(b=-5.96, F(1,93)=28.90, p=.000, \eta_{p}^{2}=.23\right)$. The effect of ego-depletion and the interaction effect between ego-depletion and self-control on intention to balance between goals were again not significant (all Fs $<0.49$, ps $>$.486). In contrast to Study 3, ego-depletion, self-control, nor their interaction had a significant effect on either intention tohiglight a health goal or intention to highlight an eijgment goal (all Fs $<2.59$, ps $>$.111).

\section{Results after the exclusion of outliers based on total snack choices}

Similar to the prior studies, we also checked results for robustness against potential outliers (MAD method). Two participants who chose more than 24.83 snacks were excluded from the analysis, leaving 95 participants. This did not meaningfully change the results in any of the analyses. 


\subsubsection{Discussion}

This study aimed to confirm the effects of ego-depletion and trait self-control on snack choices by using a crossing letter task that has been popular in ego-depletion studies. The findings show an interaction between ego-depletion and self-control for indulgent choices. Results of this study show some support that self-control may work as a buffer against ego-depletion. People high in trait self-control appear to have the ability to regulate themselves from temptation and limit indulgent choices after depletion. Yet, main effects of self-control and depletion were not significant, and no significant main or interaction effect was found for the number of healthy products chosen. Overall then, the results of this study are inconsistent with those of the prior studies, and there appears not enough empirical support to conclude that trait self-control can act as a buffer against depletion, as will be elaborated upon in the general discussion.

\subsection{General discussion}

The current study examines ego-depletion in the context of product choices. According to research on self-control and ego-depletion (Baumeister, 2002a, 2002b; Muraven, Tice, \& Baumeister, 1998; Vohs \& Baumeister, 2004), decision making expends the same finite cognitive resource that individuals use to exert control over undesired behaviors. The main objective of this study is to explore the interplay between product location and trait self-control in the food choice domain. Based on prior research (D eWall et al., 2007; D vorak \& Simons, 2009), we predicted that the location of snacks, which determines the number of choices made before choosing snacks, generates ego-depletion and that this egodepletion will impair subsequence self-control choices in the snack categories. We furthermore expected that the impairment of self-control choices differs among individuals that possess different levels of trait self-control. The effects of product location, trait self-control and their interaction on perceptions toward 
snacks, snack choices and goal pursuit are summarized in Tables 5.3 - 5.4 (p. 202 - 203).

Extending the research of Vohs and colleagues (2008), we find that even a small number of day-to-day shopping decisions, involving common and familiar products, still leads to self-control impairment in a subsequent task (Study 1). Moreover, the findings tend to confirm the effects of trait self-control such that people with high trait self-control may opt for healthy snacks over indulgent snacks. As evidence (see Table 5.3), we found that higher trait self-control consumers reported either higher preference for healthy than indulgent snacks (Studies 3 and 4) or equal liking toward healthy snacks and indulgent snacks (Study 2). They also reported a higher intention to highlight the health goal (Study 3), and a lower intention to balance health and enjoyment goals (Studies 3 and 4), and chose fewer indulgent snacks, than people who were low in self-control (shown in Table 5.4). Besides, there is evidence to support that high trait self-control consumers tend to buy more healthy snacks and few indulgent snacks on average. However, it should be noted that the effect on healthy snacks was only significant in Study 2 and those on indulgent snacks was only significant in study 3 (See Table 5.4).

Moreover, this thesis speculated that merchandise layout (location near the end of a shopping trip) triggers an effect of ego-depletion on snack choices. In contrast to the speculation, there were inconsistent findings regarding effects of merchandise layout and its interaction with trait self-control on healthy and indulgent snack choices across three studies (Studies 2 - 4, shown in Table 5.4). Looking into details, Study 2 suggests that placing snacks at the end of the store increases the number of healthy snacks chosen whereas Study 3 failed to replicate this effect. Like Study 3, Study 4 did not show effects of ego-depletion on healthy snack choices. Besides, none of the studies show the main effect of 
merchandise layout (Studies 2 and 3) or ego-depletion (Study 4) on indulgent snack choices.

Additionally, the current studies also show inconclusive findings of the interaction effects of product location/ ego-depletion and self-control. Evidence found in this chapter seems to support that self-control likely acts as a buffer against ego-depletion. High trait self-control people tend to possess the ability to regulate themselves from temptation and limit indulgent choices after depletion (Study 4), but they inversely increase healthy choices (Study 2). Again, this interpretation should be in caution as the presented effects were not replicated across studies.

All in all, the inconsistent findings across Studies 2 to 4 leads us to conclude that snack choices in the supermarket are not significantly influenced by ego-depletion, and its interaction with trait self-control. Several factors, namely the potential non-existence of ego-depletion as a phenomenon, the effect of trait self-control, the nature of future choices and the process involved in choices, and the characteristics of our sample, may potentially explain the inconsistent findings.

First, the phenomenon of ego-depletion may not really exist. This study used different tasks, including choice and letter crossing tasks, to manipulate egodepletion, but effects of self-control impairment were not replicable. In recent years, after our empirical data was collected, there have been many debates about the existence and limitation of the strength model of self-control and egodepletion. Carter, Kofler, Forster, and McCullough (2015) performed a metaanalysis (including published and unpublished studies of ego-depletion) and argued that the effect size of ego-depletion is approximately zero. It is important, however, to note that the analyses conducted by Carter et al. (2015) have been criticized due to the inappropriate usage of the analyse method and the criteria 
to include the studies (D ang, 2018). However, an updated meta-analysis of the ego-depletion effect ( $\mathrm{D}$ ang, 2018) with stricter rules still yields a similar finding to Carter et al. (2015). The study points to the ineffective manipulation of egodepletion. D ang (2018) shows that after exclusion of studies with the ineffective manipulation task, the ego-depletion has small-to-medium effect sizes. Others also show the possibility that publication bias and phacking may have severely inflated published effect sizes of ego-depletion (see detailed arguments in Friese, Loschelder, Gieseler, Frankenbach, \& Inzlicht, 2018). Xu and colleagues (2014) also failed to replicate the ego-depletion effect. In addition, Hagger and colleagues (2016) ran a multilab study to replicate the ego-depletion effect and showed that effects were close to zero.

This has left some scholars to argue that ego-depletion does not exist, and that impairment of self-control depends on people's long-term goal or belief about limited resources. Job and colleagues provided evidence against the strength model of self-control (Job, Walton, Bernecker \& D weck, 2013). They showed that only people who believe in the limited resources of self-control get affected by self-control impairment. O ther scholar argued that the effect of ego-depletion depends on whether the prior self-control task is strong enough or not. For example, Hagger et al.'s study (2016) has been criticized because they failed to create a prior habit in crossing out the letter. Thus, their manipulation may not induce enough depletion (unlike our study). A complementary analysis of the replicating data from different labs (with the e-crossing task) was conducted (D ang, 2016). The analysis found that the effort that participants exert during the initial depleting task negatively influences their performance in the subsequent self-control task. All in all, the existence of self-control and egodepletion remains inconclusive. The inconsistent results of our studies seem to support the argument that ego-depletion may not exist or that its effect is weak. 
Second, our results regarding the impact of trait self-control on perceptions toward snacks and snack choices are generally in support of prior studies, which have indicated that people high in trait self-control can successfully control themselves in the food domain (de Ridder et al, 2011; Honkanen et al., 2012). Even though the effects of trait self-control were not significant in all studies, the results show a similar trend supporting that high trait self-control consumers tend to choose more healthy snacks and fewer indulgent snacks than low trait self-control consumers. In addition to effects on snack choices, trait self-control likely affects perceptions toward snacks and snack preference. In line with prior research (Hofmann, Baumeister, Forster \& Vohs, 2012), we find that high trait self-control is related to a higher preference toward healthy snacks and higher perceived tastiness of healthy snacks than low trait self-control. This finding partly supports Gillebaart and de Ridder's (2015) new perspective on effortless self-control. They have proposed that the success of people with high trait self-control in retraining themselves from temptations is due to effortless strategies that help them to strategically avoid potential conflicts by downgrading the impulsiveness of indulgent snacks. As people with high trait self-control report fewer temptations to indulge and higher temptations to eat healthy snacks than people with low trait self-control, they experience less conflict and therefore are more likely to successfully pursue their health or long-term goal. In line with this, we find that consumers with high trait self-control report higher intentions to highlight a health goal and lower intentions to highlight an enjoyment goal as well as to balance between a health and an enjoyment goal, than low trait self-control. 
Third, the process involved in making a series of choices for the future may be different than the process involved in immediate choice or immediate consumption. When consumers make choices for the future, they may be less vulnerable to ego-depletion effects, for two reasons. One reason is that consumers experience less conflict when making choices for the future, whereas self-control is vital to respond to a conflict between immediate urges and longterm goals (Baumeister, 2002b). When the conflict is not strong, people may not need or need less self-control resources to pursue their goals (Myrseth \& Fishbach, 2009). The current study focuses on snack choices in a supermarket context for future consumption, whereas the majority of studies on self-control usually focus on situations when goal conflict is salient and immediate (e.g. choice between immediate consumption of healthy or indulgent food, or choice to continue eating or not eating indulgent snacks). Prior studies also support that the process during grocery shopping is more than an independent decision of each choice, but it is dynamic and influenced by prior choices (Gilbride et al., 2015; van der Heide et al., 2016). Consumers can manage their goals when making a series of choices. Thus, in the current study, the conflict may not have been strong enough to interfere with self-control capacity. Another reason could be that the task of making choices for the future can activate and motivate consumers to think about their long-term goal instead of immediate pleasure. Thus, consumers tend to go for a higher proportion of virtues when making a set of choices for the future (Read, Loewenstein, \& Kalyanaraman 1999). Construal level theory supports this proposition and indicates that people more often employ self-control when making decisions for the future than decisions for the present (Fujita, Trope, Liberman, \& LevinSagi, 2006). Laran (2010) has also shown that current and future choices are different and that effects of selfcontrol on food choices depend on information (self-control related or indulgent-related) that is active at the decision-making moment. 
Fourth, another critical factor that could play a role in snack choices is habits of participants (Brug, de Vet, de Nooijer, \& Verplanken, 2006). The participants in this study are students who appear to be relatively high in health orientation. Adriaanse, Kroese, Gillebaart, and de Ridder (2014) have shown that habits can mediate the relationship between self-control and indulgent snack consumption. They argue that the motivation to eat healthy fruit can be translated to routine behavior, which requires less or no self-control as there is no self-control conflict. When consumers develop healthy eating habits, they tend to perceive healthy snacks as more attractive. This is in line with our results that, on average, participants in our studies preferred healthy snacks to indulgent snacks. If our participants have created habits of healthy eating, this implies that they may need less effort in making healthy snack choices than other segments of the population. They may be less vulnerable to self-control depletion as they can effortlessly continue their healthy choices even after depletion.

\subsection{Limitations and recommendations for future research}

First, as mentioned, this study has focused on a specific group of participants who are young and health oriented. D e Ridder and colleagues (2011) have shown that effects of self-control are smaller in student samples than in non-student samples. Thus, future research should try to repeat this study with the larger and more diverse group of participants.

Second, another limitation relates to the measurement of the mood state as a manipulation check of ego-depletion (cf. Mayer \& Gaschke, 1988) and the measurement of trait self-control. In Study 1, the mood states have shown low reliability even after removal of some items $(\alpha=.510)$. Therefore, there is not enough evidence to conclude whether the insignificant difference of mood states after choice task (compared to no choice task) is caused by either a weak effect 
of ego-depletion or a poor measurement scale. Additional measurement of mood states, as well as other objective measures of self-control depletion or of effort invested in the first self-control task (e.g. pupillometry; Beatty, 1982; Hopstaken, van der Linden, Bakker, \& Kompier, 2015; Rondeel, van Steenbergen, Holland, \& van Knippenberg, 2015) should be included in future research (Lurquin \& Miyake, 2017).

Moreover, the trait self-control in this study was based on self-reports, which may contain bias. Even though we have used an existing scale suggested by Hofmann et al. (2012), this measurement is still subjective. The extent of self-control that participants evaluate themselves may depends on individual strictness or comparison with others in their community. More objective measurement of self-control and the use of other types of indicators (e.g., BMI or food diary in period before the study) could be included to better assess trait self-control.

Third, the studies in this chapter are laboratory experiments that used a virtual supermarket to present products. As a result, the attractiveness of snacks may be less vivid than in a real supermarket where consumers can touch products. The less vividness of alternative products may decrease consumers' desire for immediate pleasure, consequently leading to fewer indulgent snack purchases than in a real supermarket (Huyghe, Verstraeten, Geuens, \& van Kerckhove, 2017). Additionally, our findings may be restricted to assortment size and composition (Koelemeijer \& O ppewal, 1999; Oppewal, \& Koelemeijer, 2005). D ue to smaller assortments, consumers may not be exposed to indulgent snacks that they really like, leading to less experienced conflicts than in real life. To give a more accurate prediction about the effect of product location or ego-depletion on snack choices in supermarkets, a study in a real supermarket should be conducted. 
O ther avenues for future research are to assess whether effects of state and trait self-control differ between choices for immediate consumption versus for the future, and to assess effects for consumption versus purchasing decision. In the current study, people could choose both healthy and indulgent products in any number, and both types of products are chosen by most participants. It would be interesting to examine their subsequent consumption pattern, especially within the context of choosing and eating a set of products over time. Whereas prior research has either examined the choice of healthy versus indulgent food (e.g., Vohs \& Baumeister, 2004) or the consumption of indulgent food products only (Imhoff et al., 2014), the consumption of multiple products over time has received far less research attention. When depleted, people may choose or eat an indulgent food product if they can choose only one product, but they may be able to balance across healthy and indulgent altematives when given the chance to do so.

For another reason as well, consumption of chosen products can be interesting for future research. Because healthy products such as fruit and vegetables are perishable in a short period of time, buying more healthy food may also increase food waste if consumers do not consume them in time. Food waste is a mounting problem (Parfitt, Barthel \& Macnaughton, 2010), and a promising direction for future research is to examine whether consumers who buy more healthy products will also consume these. 


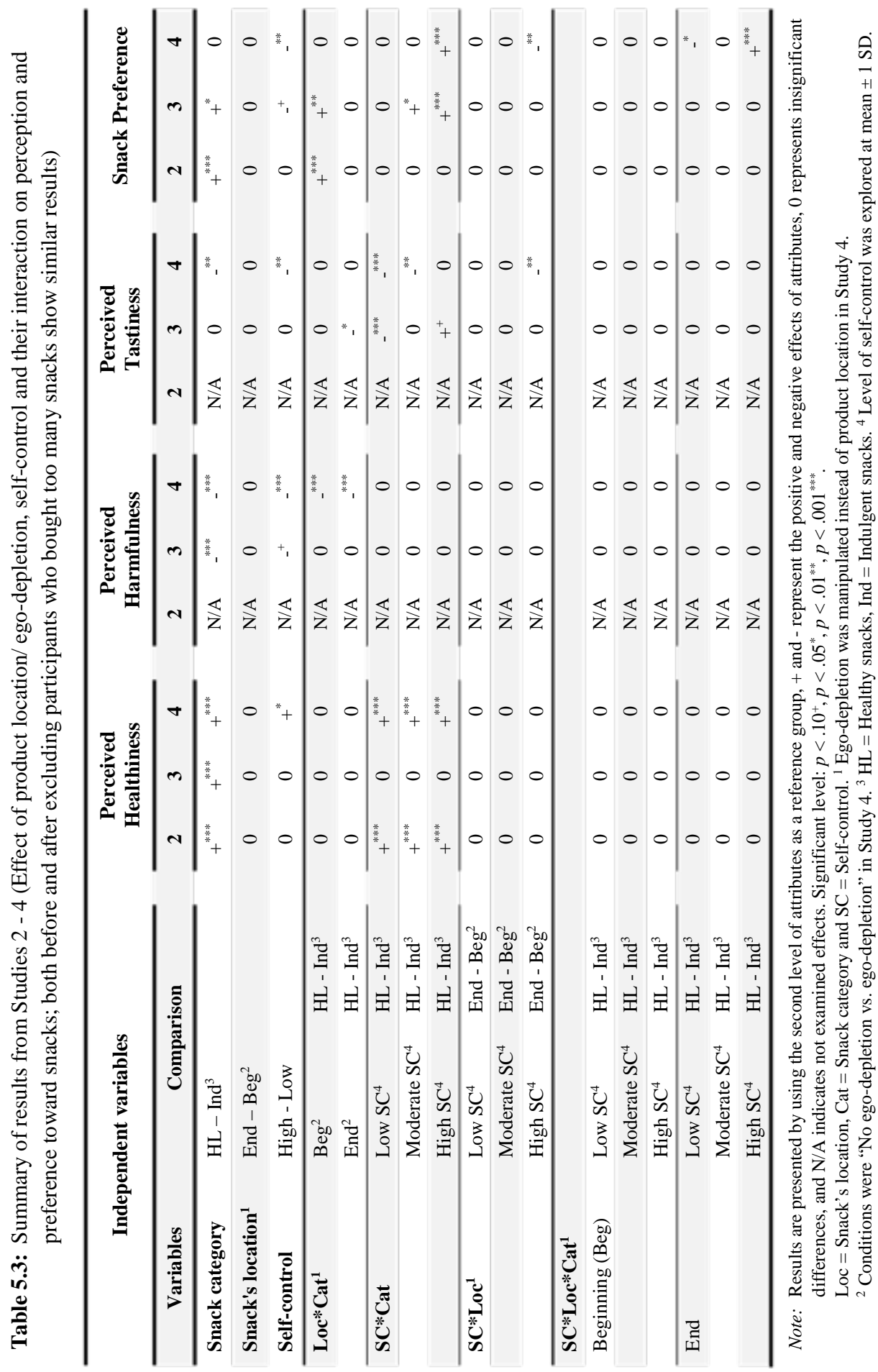




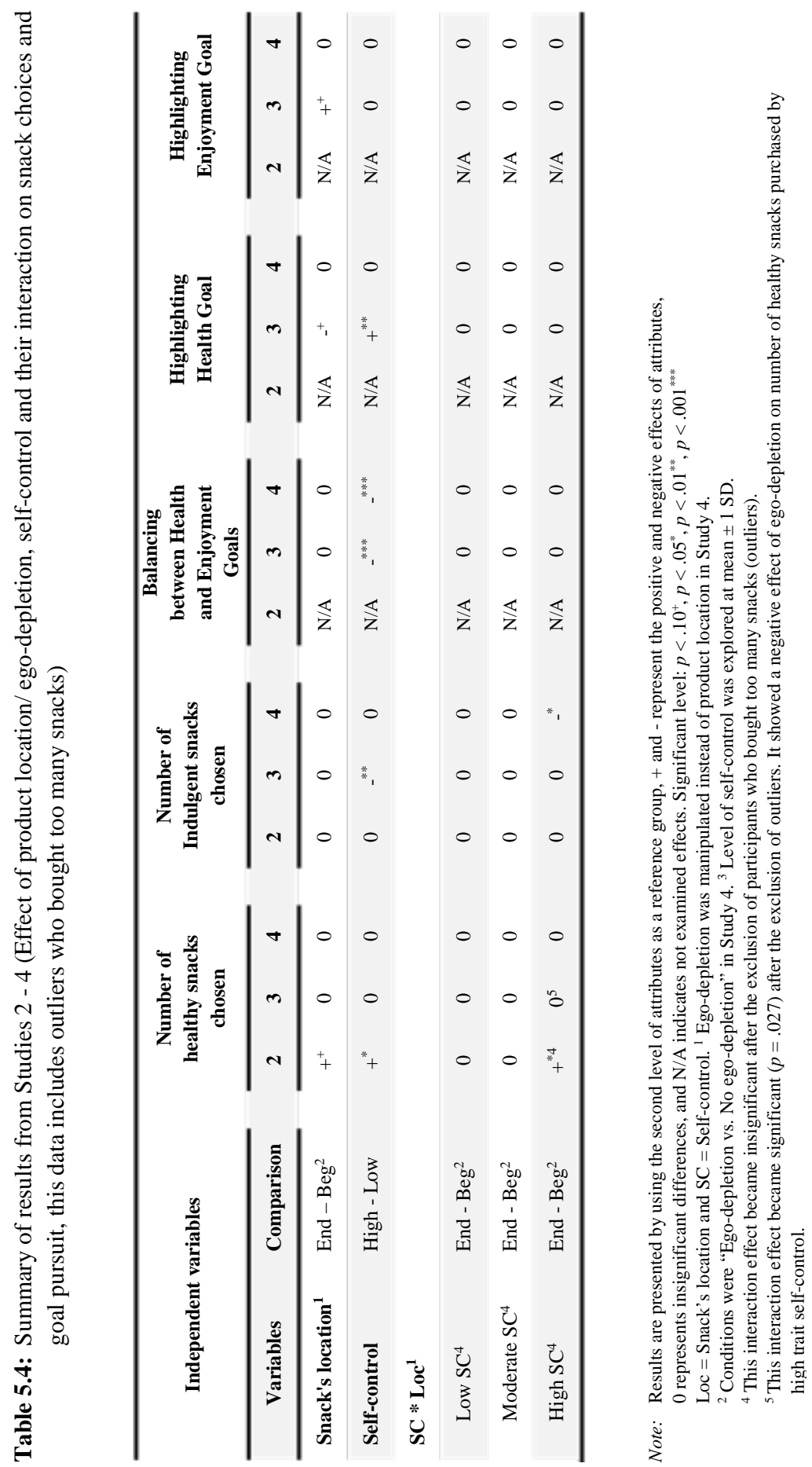



Chapter 6

\section{General discussion}

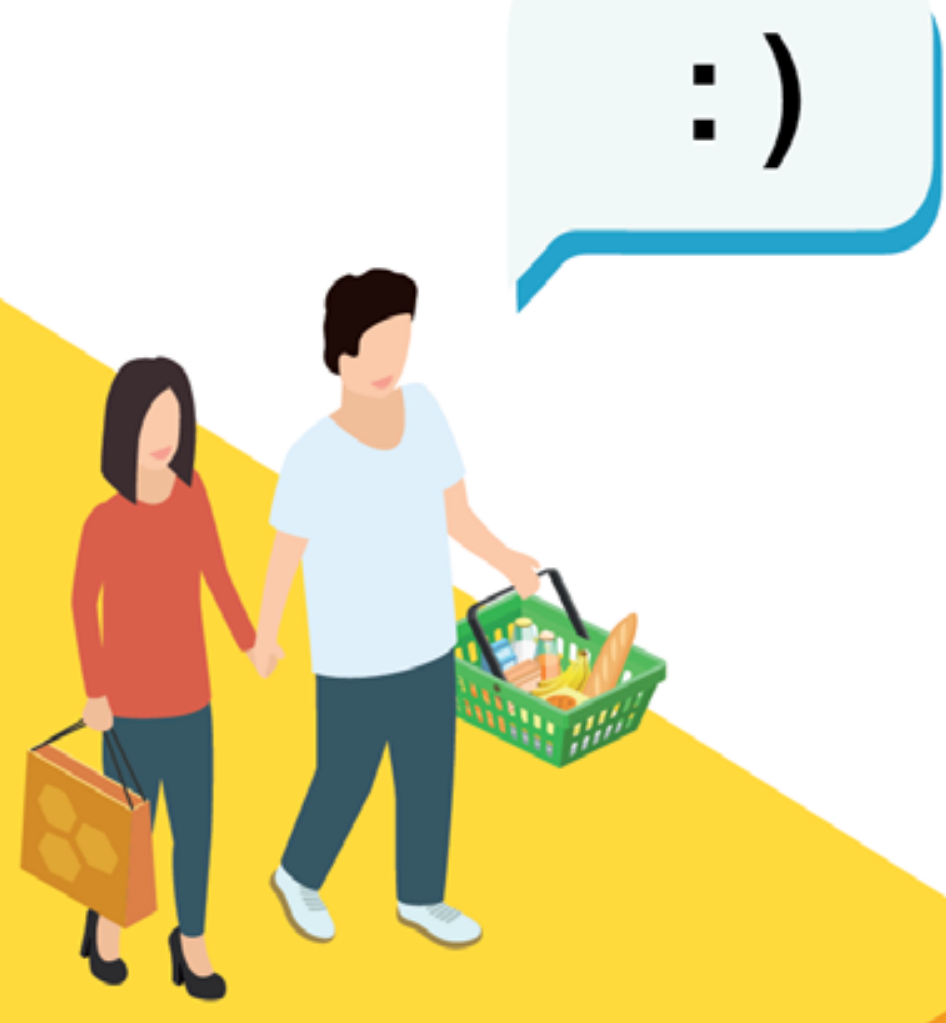


A physical store's spatial layout plays a critical role in consumers' responses to stores. Previous studies have typically focused on the effects of broad categories of spatial layout (i.e., grid/free-form layout, simple/ complex layout, spacious/ crowding) and the combined, rather than separated effects of spatial layout with other factors of the store environment (e.g., decoration, signage, product or atmospheric factors). Intriguingly, there is no systematic empirical evidence to comprehensively explain how the specific attributes of a store's spatial layout determine consumers' responses. This is presumably because research on spatial layout is elusive in terms of difficulties and expensiveness in manipulating the store's spatial layout. This hindrance can be circumvented by the use of virtual reality technology. Hence, the present research provided an initial step to systematically examine the impacts of the store's spatial layout (i.e., store layout design and merchandise layout) on consumer's cognitive responses, intention to visit the store, and purchasing behaviors.

The overall objective of this thesis was to investigate the impacts of store layout design and merchandise layout on consumers' responses. The research questions regarding the impacts of store layout design and merchandise layout on consumers' intention to visit the store and on product choices as well as the underlying processes and a potential moderator were addressed. A combination of quantitative and qualitative studies was used. Virtual reality technology (3D models of the stores and virtual store) was applied to manipulate store's spatial layout for data collection via online surveys and lab experiments.

This chapter presents an overview of the main findings. The chapter is organized as follows. First, the answers to the research questions 1 regarding store layout design and the corresponding sub-research questions 1a - 1c are presented. Afterwards, several inconsistent findings of the store layout design studies that require further investigation are discussed. Second, the answers to the research questions 2 regarding merchandise layout and the corresponding sub-research 
questions $2 \mathrm{a}-2 \mathrm{~b}$, as well as inconsistencies in the findings of the studies on merchandise layout are elaborated upon. Third, the practical and methodological implications are identified. Finally, the limitations and recommendations for further research are discussed.

\subsection{Summary and conclusion}

\section{$R Q$ 1: How does store layout design determine consumers' intention to visit the store?}

It has been proposed in this thesis that with an absence of prior knowledge, the store layout design is used by consumers as a cue to form expectations of the offered benefits (shopping efficiency and shopping enjoyment) and perceived image of stores. These expectations subsequently determine consumers' intention to visit the store (cf. Baker et al., 2002). The findings presented in Chapters 2 and 3 support the expectations that store layout design determines consumers' intention to visit the store via consumers' expected shopping enjoyment, expected shopping efficiency and perceived store image.

Typically, store layout design has been categorized into three main typologies of layout, namely grid, free-form (to be investigated in this thesis) and racetrack layout (Levy \& Weitz, 2012). Their impacts on consumers' responses are explained based on these typologies. O verall, the grid layout has been stated to bring higher shopping efficiency, but lower shopping enjoyment and lower perceived store image than the free-form layout (Levy \& Weitz, 2012).

Chapter 2 attempted to replicate the existing knowledge regarding the overall impacts of the grid versus free-form layout on consumers responses. The grid and free-form layouts were initially manipulated by diverse attributes (i.e., length, shape, orientation and height of shelves). Subsequently, in Chapter 2 the specific 
effects on consumers' responses of shelf length and shelf orientation, as the major distinct concrete attributes of the grid and free-form layouts, were explored. By systematically varying store layout designs and controlling for other store environmental factors (e.g., decorations and products), the limitations of using the grid and free-form layout typology (Levy \& Weitz, 2012) to predict consumers' responses and intention to visit the store are highlighted. As empirical studies showed manifold effects of store layouts categorized as free-form, it seems that the typology of free-form layout is too broad to meaningfully and consistently predict consumers' responses (Chapter 2). For example, the free-form layouts consisting of short, parallel orientated, shelves that allow consumers to make a short cut induce higher expectations of shopping efficiency and shopping enjoyment, more upscale image and higher intention to visit than the grid layouts. In opposite, the free-form layouts consisting of long shelves which are oriented in diverse angles (asymmetry and inconsistent orientation pattern) bring more negative expectations and a lower intention to visit the store than the grid layouts. In contrast to the typology of layout, the concrete attributes of store layout design tend to provide more insight into the impacts of store layout on consumers' responses. They, however, cannot fully explain the complex interaction effects of store layout design.

Chapters 2 and 3 suggest that perceived orderliness and perceived complexity are more abstract attributes that retailers should consider in the design of their stores. Perceived orderliness and perceived complexity are more informative than the grid and free-form layout typology. Retailers can measure and manipulate these abstract attributes to differentiate within the free-form layout typology. Perceived orderliness and perceived complexity are also more useful than the concrete attributes because they can better explain why store layout triggers specific expectations. More detailed explanations associated with the impacts of specific store layout design (and their attributes) on consumers' responses are provided in response to the specific sub-research questions below: 


\section{SQ 1a: How do store layout design's attributes explain the impacts of store layout on consumers' cognitive responses and intention to visit the store?}

Chapters 2 and 3 showed strong impacts of the store layout design's concrete attributes on consumers' expected shopping efficiency (such as, shelf height (Chapter 2), and shelf length, shelf orientation and shelf shape (Chapter 2 and 3)). They also showed moderate impacts of store layout design on consumers' expected shopping enjoyment and intention to visit the store. In contrast, the store layout design had minor impacts on perceived store image, except for one study in which it showed a moderate impact on perceived store image (Study 1, Chapter 2).

Chapters 2 (Study 3) and 3 revealed that the impacts and direction of store layout design on consumers' expectations and intention to visit were predominantly explained by consumers' perception of store's orderliness. Chapter 2 (Study 3) showed that consumers used perceived orderliness and perceived complexity in addition to concrete attributes to evaluate stores with different layouts. Consumers (Chapter 2 and 3) expected more orderly stores to offer higher benefits (i.e., higher shopping efficiency, shopping enjoyment, store image) than less orderly stores. O verall, they also reported higher intention to visit the more orderly stores. Even though perceived complexity of the store and its interaction with perceived orderliness showed significant impacts on consumers' expectations of the store and intention to visit (a qualitative study in Chapter 2 and a quantitative study in Chapter 3), their contributions were only minor (Chapter 3).

The role of perceived orderliness can provide additional insights into the impacts of store layout on consumers' responses as presented in Chapters 2 and 3. In particular, among concrete attributes of store layout design, we found the 
strongest impacts of shelf orientation (based on effect sizes of shelf orientation compared to shelf length and shelf shape) on consumers' expected shopping efficiency, expected shopping enjoyment and consumers' intention to visit the store. The random or diverse angles' orientation (placing shelves in an asymmetric pattern or unparalleled to each other) led to the worst expected shopping efficiency, expected shopping enjoyment, a discount store image and the lowest intention to visit (Chapters 2 and 3). In contrast, both the parallel orientation (placing shelves straight and parallel to each other) and playful orientation (placing the middle shelves perpendicular to shelves on the sides) introduced positive expectations and intention to visit the store. These impacts can be explained by the relationship between consumers' perceived orderliness of the store and shelf orientation. Chapter 3 showed that consumers' perceived orderliness is mainly influenced by shelf orientation. The parallel orientation led to the highest perceived orderliness, followed by the playful orientation and the diverse angles' orientation. Since perceived orderliness always brings positive responses, the parallel and playful orientations that lead to moderate to high perceived orderliness thus result in positive expectations and high intention to visit.

In addition, we also found strong effects of shelf orientation on perceived complexity. The random orientation led to the highest perceived complexity, followed by the playful and the parallel orientation. Apart from the effects of shelf orientation and perceived orderliness, other effects of concrete and abstract attributes on consumers' expectation and intention to visit were either small or negligible. Additionally, the effects of shelf length, shelf shape and their interaction on perceived complexity and perceived orderliness were also small or negligible. Therefore, our findings suggest that shelf orientation in an orderly format (either in parallel or playful format) should be prioritized when designing a store's layout. 
This thesis provides more insight into the relationship between individual store layout design's attributes and perceived complexity/ perceived orderliness, as well as their corresponding effects on consumers' cognitive responses to the store. We go beyond previous studies (Gilboa \& Rafaeli, 2003; Jang et al., 2018) that only examine the overall impacts of store environments on perceived complexity/ perceived orderliness and on affective responses. Since previous studies manipulated their stimuli by changing multiple environmental factors at once, there are many confounding effects involved in those studies. Thus, they cannot disentangle the impacts of each individual factor.

\section{$S Q 1 b:$ What are the underlying processes explaining the impacts of store layout design on intention to visit the store?}

Chapters 2 and 3 showed that, in line with the model of Baker et al. (2002), with limited prior knowledge about the store, the effect of store layout design on intention to visit was predominantly driven by expected shopping enjoyment and moderately driven by expected shopping efficiency and insignificantly to negligibly driven by perceived store image. These findings suggest that retailers should focus on providing an enjoyable shopping experience in order to attract more consumers.

\section{SQ1c: How does the underlying process differ among consumers with utilitarian and hedonic motivation?}

Consumers' shopping motivation (i.e., utilitarian or hedonic motivation) influences the type of store benefits that consumers search for. The shopping motivation was proposed to determine how the underlying factors of store layout design shape the intention to visit the store. 
In particular, it was predicted in this thesis that shopping motivation moderates the effects of consumers' expectations (expected shopping efficiency, expected shopping enjoyment and perceived store image) on intention to visit the store. The extreme case in which a specific type of motivation was dominant was considered in our work. We predicted that under a utilitarian motivation the effects of store layout design on intention to visit are mainly driven through the expected shopping efficiency. Moreover, we predicted that under a hedonic motivation, the effects of store layout design on intention to visit the store are predominantly driven through the expected shopping enjoyment and perceived store image (Babin et al., 1994; Li et al., 2004).

Chapter 2 supports our prediction that consumers' intention to visit the store under utilitarian motivation was dominantly driven by expected shopping efficiency, whereas consumers' intention to visit the store under hedonic motivation was dominantly driven by expected shopping enjoyment. Additionally, consumers' intention to visit the store under utilitarian motivation was also driven by expected shopping enjoyment (Chapter 2). In other words, expected shopping enjoyment initiates consumers' intention to visit the store, regardless of shopping motivation. Yet, the results of Chapter 3 are not completely in line with the findings of Chapter 2. In Chapter 3, results showed insignificant moderation of shopping motivation for the effect of consumer expectations on intention to visit. Consumers' intention to visit a store is dominantly determined by expected shopping enjoyment and marginally driven by expected shopping efficiency, regardless of shopping motivation.

Moreover, it has also been discovered in Chapter 3 that shopping motivation moderated the direct effect of perceived complexity and perceived orderliness on intention to visit the store. Consumers with hedonic motivation accepted more complex or less orderly stores than consumers with utilitarian motivation. This finding agrees with previous research (van Rompay et al., 2012) discovering 
that consumers with hedonic motivation can handle a more arousing store environment (more complex environment) than those with utilitarian motivation.

In addition to the previously presented findings that help us answer research questions (RQ1 and SQ1a - 1c), there are other inconsistent impacts of store layout design on consumers' responses found in Chapters 2 and 3. These discrepancies can motivate future research. The results are summarized in Tables 6.1 - 6.3 (p. 216 - 218) and discussed in the following sections:

\section{Inconsistent findings regarding the effects of store layout design on consumers' expectations and intention to visit the store}

Several impacts of concrete attributes are inconsistent across studies. First, the comparative impacts of parallel and playful orientation on consumers' responses (which orientation is better) remain inconclusive. Based on retailing handbooks (e.g., Levy \& Weitz, 2012), the parallel orientation was predicted to bring higher expected shopping efficiency whereas the playful orientation was predicted to bring higher expected shopping enjoyment and more upscale image. In contrast to the literature, the findings of Chapter 2 (Studies 1 and 3) reveal that the playful orientation performs better on all expectations, whereas Chapter 3 reveals that the parallel orientation is better for all expectations. Second, the impacts of shelf length and the interaction effects of store layout design's concrete attributes (shelf height, shelf length, shelf shape, and shelf orientation) are also inconsistent across studies (Chapters 2 and 3). The results in Chapter 2 suggest that short shelves providing space for people to make shortcut perform better (on all expectations) than long shelves, whereas the findings in Chapter 3 oppositely indicate that long shelves are better. In addition, the two-way and three-way interactions of concrete attributes show different patterns as well. These inconsistencies underpin the importance of abstract attributes in addition to 
concrete attributes to provide insight into the effects of store layout design on consumers' expectations and intention to visit the store.

Despite using a systematic approach, we cannot establish consistent relationships among concrete attributes, abstract attributes and consumers' responses except for the relationship between shelf orientation, perceived orderliness, and consumers' responses. Empirical evidence shows that perceived complexity and perceived orderliness can be influenced by the combination of various store layout design attributes (shelf length, shelf shape and two-way and three-way interactions effects of those with shelf orientation). However, the exclusive formula on how these effects combine cannot be simply built (there are many different patterns found in Chapters 2 and 3). These inconsistent findings may be explained by several reasons as follows.

First, the inconsistent findings may suggest that more abstract attributes (not measured in Chapters 2 and 3) are needed to fully explain the impacts of store layout design. Abstract attributes such as perceived aesthetics, perceived novelty of the store, perceived crowding and perceived spaciousness may help explain the different impacts of combinations among concrete attributes. The perceived aesthetics and perceived novelty of the store are likely relevant to the shape of shelves whereas the perceived crowding and perceived spaciousness may be related to the length of shelves. Such more abstract constructs may help to extend our studies and to elucidate the detailed effects of store layout design.

Second, the findings may indicate that the impacts of store layout design, as well as the relationship between store layout design with perceived complexity and with perceived orderliness, differ among individual participants in Chapters 2 and 3. Whereas participants in Chapter 2 preferred the store layouts with more playful design (short shelves, a variety of shelf shape and playful orientation), those in Chapter 3 favored the store layouts with less playful and neater design 
(long shelves and parallel orientation in any shapes). Personality traits such as novelty seeking or consumer innovativeness that links to the desire for new and different experiences rather than familiar ones (H. Kim, Fiore, Niehm, \& Jeong, 2010; Venkatraman, 1991) may help explain these diverging findings between chapters.

Third, our findings may highlight that the relationship between store layout design and their corresponding impacts on consumers' responses is very subtle. There is no golden formula that can simply capture the relationship of store layout design with perceived complexity and perceived orderliness. Addition of one concrete attribute may either magnify or suppress the effects of other attributes of store layout design. Future research should attempt to substantiate this explanation. 


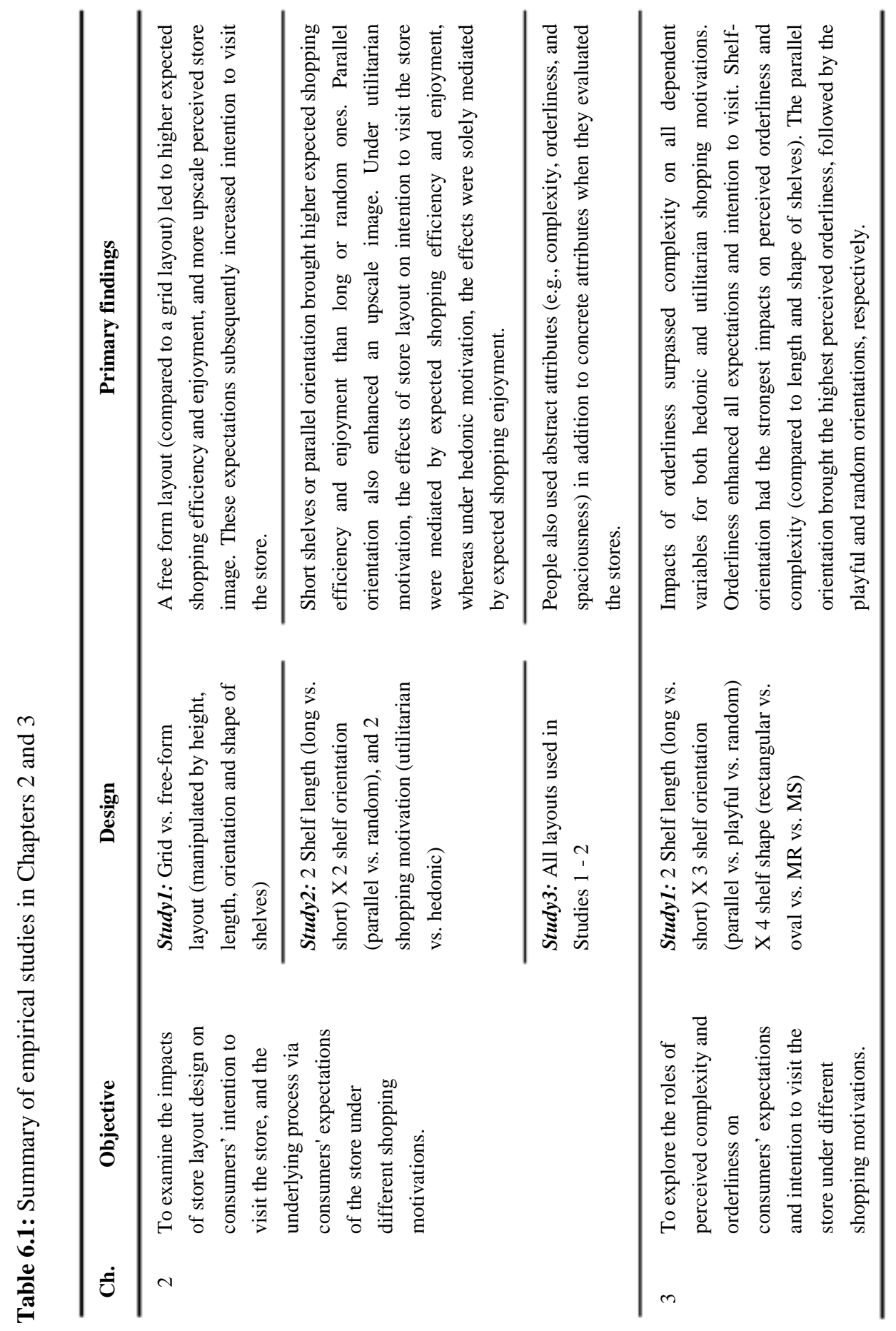




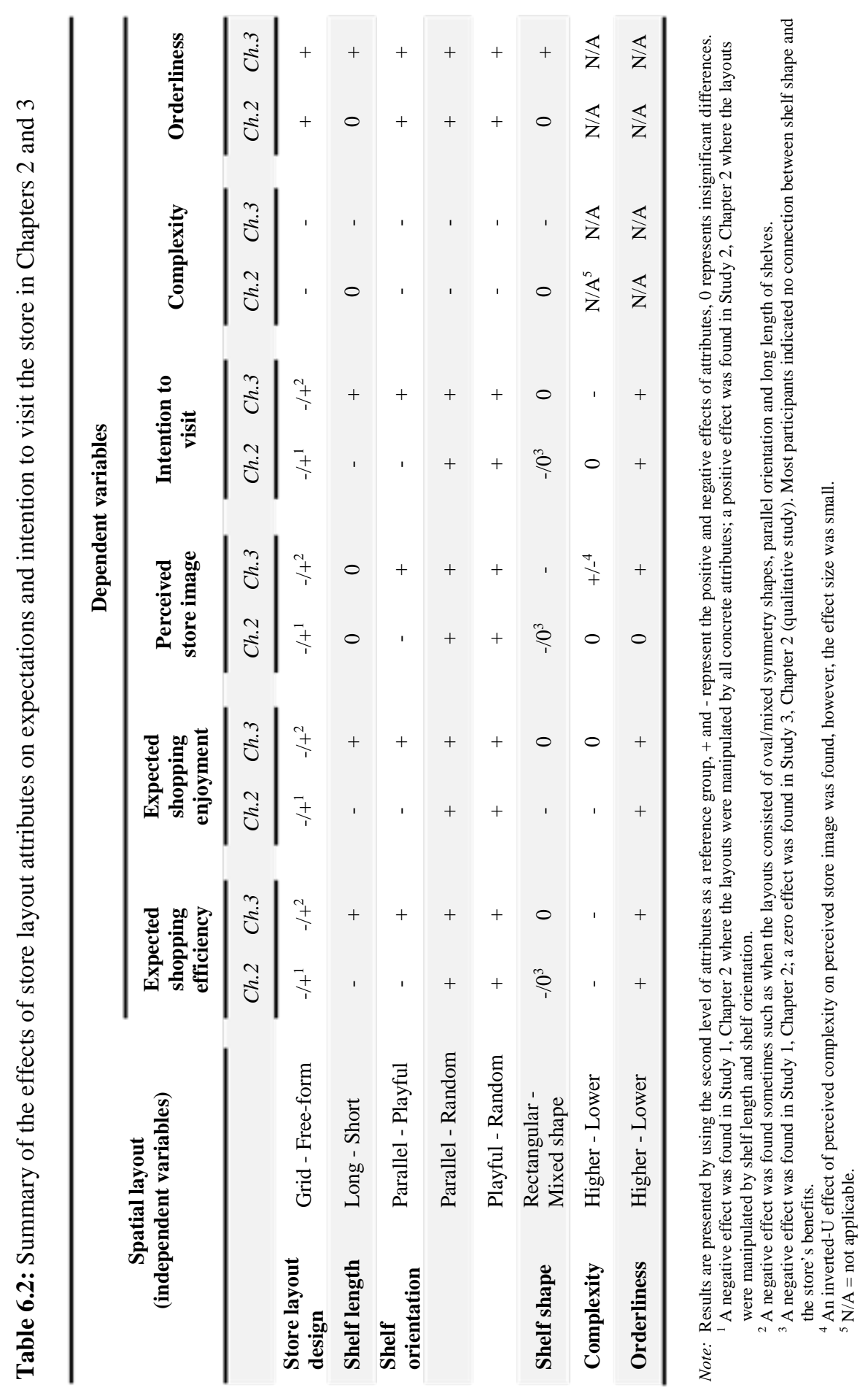




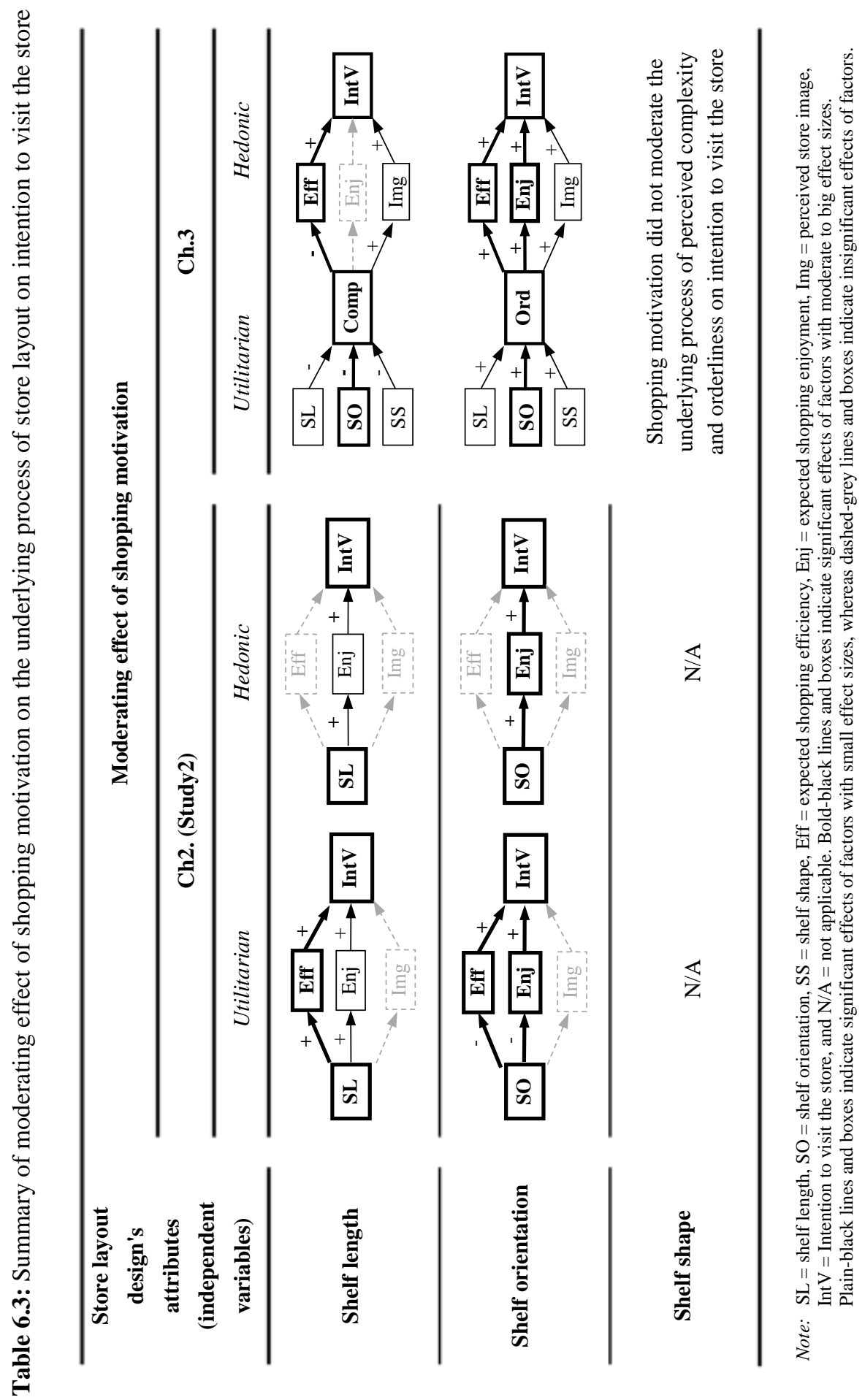




\section{RQ2: How does the merchandise layout (location of snacks in the store) shape consumers' purchasing choices of healthy and indulgent snacks?}

Chapter 5 explored how merchandise layout, in particular, the location of snacks in stores can be used as a choice architecture strategy to assist consumers in making healthy food choices. The relationship between decision-making and self-control/ ego-depletion are confirmed. Making choices has been shown to affect later decisions (Baumeister, 2002a, 2002b; Muraven, Tice, \& Baumeister, 1998; Vohs \& Baumeister, 2004). We speculated that the location of snack categories can generate different levels of ego-depletion because it influences the number of choices that consumers have made before reaching the (conflicting) snack choices. It thus likely determines self-control ability in choosing snacks. This thesis predicted that placing snacks at the entrance (the end) of the shopping trip may increase (decrease) healthiness of snack choices. However, in contrast to the speculation, there are inconsistent effects of merchandise layout on healthy and indulgent snack choices across two studies (Studies 2 and 3 in Chapter 5). Study 2 indicated that placing snack at the end of the store increases the number of healthy snacks chosen whereas Study 3 failed to replicate this effect. Besides, both studies did not show the effect of merchandise layout on indulgent snack choices. These findings suggest that snack choices in the supermarket are insignificantly influenced by merchandise layout (the beginning versus the end of the shopping trip).

\section{SQ2a: How does self-control depletion drive the effects of merchandise layout on purchasing choices?}

Chapter 5 aimed at exploring the possible mediating role of ego-depletion to expand Vohs and Baumeister's study (2004) by examining whether making choices in the supermarket can induce ego-depletion and subsequently increase 
indulgent snack purchases or not. Study 1 of Chapter 5 confirms that ego-depletion and self-control impairment occur even after making a small number of day-to-day shopping decisions that involve common and familiar products. However, when we employed another self-control task to study egodepletion effects on snack choices, we neither found the effect of ego-depletion on healthy snack choices nor indulgent snack choices. These findings may support that product location does not influence the healthiness of snack choices, particularly not via ego-depletion.

\section{SQ2b: How does self-control depletion impact healthy and indulgent choices of consumers with different trait self-control?}

It was predicted that snack choices, especially indulgent snack choices, made by high trait self-control consumers should be less influenced by merchandise layout than those made by low trait self-control consumers. In contrast to our expectation, Chapter 5 showed inconsistent moderating effects of trait self-control on impacts of merchandise layout/ ego-depletion on snack choices across three studies (Studies 2 - 4).

In conclusion, the inconsistent results in Chapter 5 (summarized in Tables 6.4 and 6.5) seem to suggest that snack choices in the supermarket are insignificantly influenced by merchandise layout (the beginning versus the end of shopping trip), ego-depletion, trait self-control, and their interactions. The lack of evidence possibly supports the current debate that ego-depletion does not exist (Carter \& McCullough, 2014; Hagger et al., 2016; Xu et al., 2014). The failure in self-control may rather be caused by other underlying processes such as shifts in motivation and attention to perform the self-control task (Inzlicht \& Schmeichel, 2012). Future research is recommended to replicate our studies to further substantiate our conclusion. Moreover, numerous relevant factors such as impacts of ego-depletion on snack choices for immediate consumption versus 


\section{snack choices for future consumption, and the impacts of trait self-control or food habits of different samples (restrain eaters or overweight versus normal weight sample) should be explored.}

Table 6.4: Summary of empirical studies in Chapter 5

\begin{tabular}{|c|c|c|}
\hline Objective & Design & Primary findings \\
\hline \multirow{4}{*}{$\begin{array}{l}\text { To examine the } \\
\text { potential impacts of } \\
\text { merchandise layout } \\
\text { (of snacks) on } \\
\text { healthy/ indulgent } \\
\text { snack choices in the } \\
\text { supermarket, and } \\
\text { the underlying } \\
\text { process via ego- } \\
\text { depletion under } \\
\text { different levels of } \\
\text { trait self-control. }\end{array}$} & $\begin{array}{l}\text { Study1: Product } \\
\text { choice vs. store } \\
\text { evaluation task }\end{array}$ & $\begin{array}{l}\text { Making a series of choices impairs people's self- } \\
\text { control performance on another self-control task } \\
\text { (puzzle solving). }\end{array}$ \\
\hline & $\begin{array}{l}\text { Study2: } \\
\text { Beginning vs. end } \\
\text { location of snacks } \\
\text { (Big pack of snacks) }\end{array}$ & $\begin{array}{l}\text { Participants with moderately high to high trait } \\
\text { self-control bought more healthy snacks placed at } \\
\text { the end of the store than at the beginning. Product } \\
\text { location and trait self-control had a negative and a } \\
\text { positive effect on healthy snack choices. No other } \\
\text { effect on indulgent snack choices was found. }\end{array}$ \\
\hline & $\begin{array}{l}\text { Study3: } \\
\text { Beginning vs. end } \\
\text { location of snacks } \\
\text { (Small pack of } \\
\text { snacks for one } \\
\text { consumption) }\end{array}$ & $\begin{array}{l}\text { Trait self-control negatively influenced the } \\
\text { number of indulgent snacks chosen. No other } \\
\text { effect on number of healthy or indulgent snacks } \\
\text { choices was found. }\end{array}$ \\
\hline & $\begin{array}{l}\text { Study4: } \\
\text { Yes vs. no ego- } \\
\text { depletion (e-letter } \\
\text { crossing task) }\end{array}$ & $\begin{array}{l}\text { Moderately high to high self-control participants } \\
\text { bought fewer indulgent snacks when they were } \\
\text { depleted than when they were not depleted. No } \\
\text { other effect on number of healthy or indulgent } \\
\text { snack choices was found. }\end{array}$ \\
\hline
\end{tabular}

Table 6.5: Summary of the main results of merchandise layout studies (Chapter 5)

\begin{tabular}{|c|c|c|c|c|c|c|c|c|}
\hline \multirow{3}{*}{\multicolumn{2}{|c|}{$\begin{array}{c}\text { Spatial layout (independent } \\
\text { variables) }\end{array}$}} & \multicolumn{7}{|c|}{ Dependent variables } \\
\hline & & \multirow{2}{*}{$\begin{array}{c}\begin{array}{c}\text { Ego- } \\
\text { depletion }\end{array} \\
\text { Study } 1\end{array}$} & \multicolumn{3}{|c|}{$\begin{array}{l}\text { Number of healthy } \\
\text { snacks purchases }\end{array}$} & \multicolumn{3}{|c|}{$\begin{array}{c}\text { Number of } \\
\text { Indulgent snacks } \\
\text { purchases }\end{array}$} \\
\hline & & & 2 & 3 & 4 & 2 & 3 & 4 \\
\hline Choice task & No vs. Yes & - & N/A & N/A & N/A & N/A & N/A & N/A \\
\hline $\begin{array}{l}\text { Location of } \\
\text { snacks }(\mathbf{L o c})^{1}\end{array}$ & $\begin{array}{l}\text { Beginning (Beg) } \\
\text { vs. End }{ }^{2}\end{array}$ & N/A & - & 0 & 0 & 0 & 0 & 0 \\
\hline $\begin{array}{l}\text { Trait self- } \\
\text { control (SC) }\end{array}$ & High vs. Low & N/A & + & 0 & 0 & 0 & - & 0 \\
\hline \multicolumn{9}{|l|}{$\operatorname{Loc}^{1 *} \mathrm{SC}$} \\
\hline Low SC & Beg vs. End ${ }^{2}$ & N/A & 0 & 0 & 0 & 0 & 0 & 0 \\
\hline High SC & Beg vs. End ${ }^{2}$ & N/A & - & + & 0 & 0 & 0 & + \\
\hline
\end{tabular}

Note: Results are presented by using the second level of attributes as a reference group, + and - represent the positive and negative effects of attributes, 0 represents insignificant differences, and N/A indicates not examined effects.

${ }^{1}$ Ego-depletion was manipulated instead of product location in Study 4

${ }^{2}$ Conditions were "No ego-depletion vs. ego-depletion" in Study 4 


\subsection{Practical contributions}

This thesis shows that store managers can stimulate consumers' intention to visit the store by enhancing expectations of shopping enjoyment and shopping efficiency. In other words, the appropriate store layout design should be used because store layout can influence consumers' expectation. The thesis suggests that store managers should focus on abstract attributes and use a combination of concrete attributes as manipulations to influence the abstract attributes. The concrete and abstract attributes provide more insight into the impacts of store layout than the traditional typology of the grid and free-form layout. Specifically, store managers should design the store in a high orderly pattern in order to promote positive expectations and stimulate intention to visit the store. Perceived orderliness can be primarily created by the orientation of shelf arrangement. Our findings support the use of parallel and playful orientations because these orientations introduce positive expectations and intention to visit the store. In contrast, random orientation where the shelves are placed in diverse angles should be avoided because it leads to the worst expectations and lowest intention to visit.

Moreover, we also suggest the store manager to keep perceived complexity in mind even though it has weaker effects on consumers' responses than perceived orderliness. When combining other store environmental factors or products with store layout design, the effects of perceived complexity on consumers' responses may become stronger. $\mathrm{O}$ ur findings indicate that a parallel orientation of shelves leads to lower perceived complexity than a playful orientation. Store managers are therefore recommended to employ a parallel orientation in order to maintain an acceptable level of complexity when planning to include more store elements that may increase perceived complexity. In contrast, they are recommended to choose a playful orientation to slightly increase perceived complexity and attract consumers' intention to visit if they plan to display only 
a few products or use minimal decorations.

Giving the inconsistency of the results regarding merchandise layout, no practical recommendations can be justified regarding which location of snacks (the beginning versus the end of shopping trip) leads to healthier snack choices, other than for further research.

\subsection{Methodological contributions}

\section{The uses of the virtual store in consumer research}

A virtual store is a promising tool that provides numerous benefits to consumer research. It facilitates researchers to flexibly create and manipulate virtual environments in which people can react to close-to-reality objects/ environment (Berneburg, 2007; Khan et al., 2011) and interact with other people (interactive situation; Pan \& Hamilton, 2018). It makes possible the study of in-store behaviors in a more controllable, easier, faster and cheaper setting than a field study could do (Ung et al., 2018). Moreover, it enables the reproducibility (Pan \& Hamilton, 2018) and confidentiality of research. For example, marketers can use a virtual store when testing new products that may create negative perceptions of consumers in a public space (Breen, 2009). O ne of the most important advantages is that the virtual store can stimulate a sense of presence (Siegrist et al, 2018). It thus can evoke actual cognitive/ affective responses and provoke behaviors that are comparable to those in real life (Siegrist et al, 2018; van Herpen, van den Broek et al., 2016).

D espite the promising benefits of the virtual store, there are some disadvantages that should be considered. Compared to more traditional research methods (e.g., survey or lab experiment with pictorial stimuli), the cost of using virtual reality is higher, especially when one wants to create a more complex environment (Breen, 2009). Setting up the project with a virtual store requires higher technical 
skills than traditional research methods. Moreover, the virtual store can stimulate motion sickness (feeling of nausea) in some people. Lastly, several differences from real life behaviors still intrinsically exist despite the use of a virtual store (Siegrist et al, 2018; van Herpen, van den Broek et al., 2016). Consumers' behavior in the virtual store environment likely depends on features of the virtual store (vividness, interactivity, and immersion; Steuer, 1992; Witmer \& Singer, 1998).

Regarding the benefits and costs of a virtual store and the experiences derived from conducting this thesis, we suggest that virtual reality is not always the best research tool for all consumer studies. Researchers should rather consider using virtual reality only when it is useful. The virtual store appears especially suitable for the following topics in marketing and consumer research:

1). Research with an aim to examine consumer responses (cognitive, affective and behaviors) to environmental factors that are costly or difficult to create and change in real life. For example, research on the impacts of store layout design, merchandise layout (this thesis), new interior design or combinations of store environmental factors (scent, music, and design) on consumers' responses.

2). Research with an aim to investigate consumers' responses to products, packaging, labels or marketing strategies that are not yet available in the market. Product development research in an early stage is an appropriate example. Moreover, a virtual store can help marketing researchers to test how consumers respond to the promotion of the products (marketing strategies: price reduction or advertisement at the point of sale).

3). Research with an aim to examine the application of virtual reality itself as a marketing tool. Virtual reality may be used to change food consumption by controllably creating an environment suitable for a specific group of consumers. For example, marketers could use virtual reality to create a restaurant environment according to the retro $20^{\text {th }}$ century fashion (not existing anymore 
in the real market) to activate past experiences and simultaneously stimulate food consumption of elderly people.

4). Research with an aim to test stimuli in the store or other environments without establishing any negative outcomes that may harm people or harm perceptions of people toward the store or environment. For example, research investigating the impacts of different social interactions between a salesperson and a customer.

5). Research with an aim to examine affective responses (consumers' emotions in the store). The high feeling of presence generated by the virtual store may help obtain a genuine emotional response, compared to traditional research methods (e.g., showing images of the stores and measuring consumers' anticipated feeling).

It is important for researchers to note that virtual reality has been rapidly developing. The techniques, applications, and limitations presented in this thesis may quickly become outdated with future developments in the ICT field. Researchers should continuously stay up-to-date about the applicability of the virtual reality before designing a study. Virtual reality will soon provide more opportunities for advanced research design. Moreover, rapid developments in computing technology can decrease the cost of performing research by virtual reality. It is likely to become a routine tool in the near future.

\subsection{Limitations and recommendations for future research}

The present thesis has established an initial step in the understanding of the impacts of spatial store layout (store layout design and merchandise layout) on consumers' responses and behaviors. The predictions and research plans were based on very scarce literature related to the effects of spatial store layout. Therefore, there are several inherent limitations that should be considered. This 
part is devoted to discussing the limitations associated with store layout design and merchandise layout. In particular, the main emphasis is the building blocks of the conceptual model of store environmental impacts as presented in Chapter 1 (i.e., store environment (spatial layout), internal response and approachavoidance behaviors), and related moderators that influence their relationships. In addition, recommendations for future research are provided. The conceptual framework of the store's spatial layout studied in this thesis and the potential areas for future research are displayed in Figure 6.1.

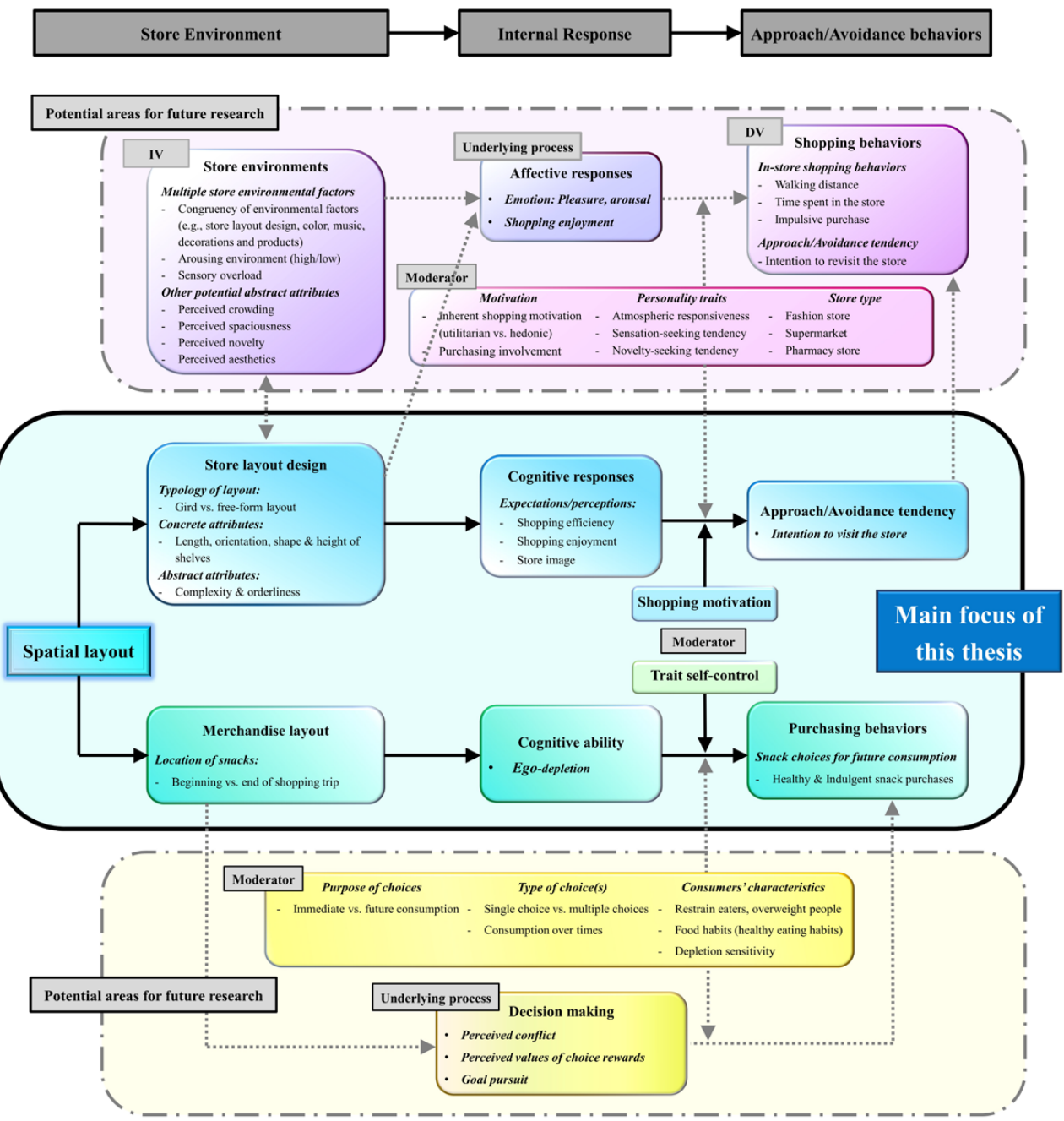

Figure 6.1: The conceptual framework of store' spatial layout and potential areas for future research 


\subsubsection{Limitations and recommendations for the store layout design studies}

\section{Store environment: Focus on the effect of single store layout design factors}

This thesis has focused on the unique effects of store layout design while controlling for other environmental factors in order to understand the impacts of store layout. However, we acknowledge that the impacts of store layout may differ depending on whether the store layout is combined with other environmental factors (such as color, lighting, interior design, decoration, music, or number of salespersons). Future research should elaborate on how store layout design interacts with other environmental factors. The interesting topic is to address how store layout design influences the congruency of the entire store environment and how it correspondingly affects consumer behavior. Retailing studies suggest that congruent store environments can increase positive responses (Spence, Puccinelli, Grewal, \& Roggeveen, 2014). However, a congruent combination of many environmental factors may increase the risk of sensory overload (too high arousal; Homburg, Imschloss, \& Kühnl, 2012). $\mathrm{O}$ ur findings suggest that orderliness of store layout brings positive expectations and perceptions. Thus, an orderly store layout design (e.g., parallel orientation) may reduce the negative impacts of a highly arousing store environment. It may allow store managers to include more environmental factors (e.g., music, color, and scent) or to intensify the arousal level of the store environment to stimulate impulsive purchases.

\section{Intemal response: Measurement of shopping enjoyment}

This thesis classified consumers' expectation of shopping enjoyment as a cognitive response instead of an affective response. This is because we argue that an expectation or anticipation is constructed from a cognitive evaluation when seeing the store. However, we cannot guarantee that our results are not 
confounded with people's emotions when evaluating the store. In other words, the available data cannot explain whether participants have emotions involved when they report their expectation of shopping enjoyment. Participants with enjoyment emotions involved may provide more positive ratings all stores that they have been asked to evaluate as compared with those without emotion involved and vice versa (Clore \& Huntsinger, 2007). The cognitive and affective responses should be disentangled in future research. Moreover, the emotion of participants before and after evaluating the store could be tracked.

\section{Approach-avoidance behaviors: Focus on initial approach- avoidance tendencies}

It should be noted that the findings of this thesis are restricted to consumers' responses and approach-avoidance tendencies (first expectations and anticipated intention to visit) under limited prior knowledge about the store. The findings are applied to predict responses of new consumers or responses of consumers to a store after remodeling. The impacts of store layout found in this thesis may differ from those of store layout on shopping behaviors, on consumers' perceptions after the visit, and on intention to revisit the store. Previous research has shown that the impacts of the store environments, especially store design, can change over time (i.e., become weaker) after consumers are repeatedly exposed to the store (Brüggen, Foubert, \& G remler, 2011). Future research is recommended to employ the virtual store to further examine changes in the effect of store layout design on consumers' shopping experiences over multiple visits.

\section{Moderator: Shopping motivation was manipulated instead of being measured}

This thesis assigned shopping motivation to participants by informing them about the (hypothetical) purpose of their store visit instead of measuring participants' shopping motivation. The manipulated shopping motivation may 
not have been sufficiently strong to change the inherent motivations that participants have developed. This may be the reason why we have found an inconsistent moderating role of shopping motivation in Chapters 2 and 3. Future research should, therefore, measure participants' shopping motivation and investigate its moderating effects to verify our findings.

\subsubsection{Limitations and recommendations for merchandise layout studies}

Chapter 5 has shown inconsistent and inconclusive findings about the impacts of merchandise layout on snack choices. The discrepancies probably originated from various relevant factors which can be regarded as the intrinsic limitations of our research approach. This section focuses on the most relevant limitations associated with the internal responses (underlying process) and moderators.

\section{Intemal response: Cognitive ability (self-control) may not be the night process}

This thesis restricts the predictions of impacts of merchandise layout to the self-control process which may not actually be the process determining choices in the supermarket (choices for future consumption). When designing the studies, most of the prior studies on food choices or food consumption, especially on conflicting choices between healthy and indulgent food, have highlighted the role of self-control and ego-depletion on choices (Imhoff et al., 2014; Vohs \& Baumeister, 2004). However, the choices focused on in Chapter 5 may differ from those studied by the previous works. Chapter 5 focuses on snack choices in a supermarket context for future consumption, whereas the majority of self-control studies usually focus on situations when goal conflict is salient (e.g., choice between immediate consumption of healthy or indulgent food (Vohs \& Baumeister, 2004), or the choice to continue eating or not eating indulgent snacks (Imhoff et al., 2014)). Therefore, the impacts of merchandise 
layout and the process involved in those choices may be dissimilar. For example, choices for future consumption may introduce fewer conflicts than those for immediate consumption. If people do not experience conflict in choosing options for the future, they may not need self-control for making choices (Baumeister, 2002b; Laran, 2010; Read et al., 1999). This argument is supported by previous research showing that people can control themselves more effectively when making decisions for the future than for the present (Fujita et al., 2006; Read et al., 1999). Future research should measure perceived conflict at the moment of choice to address this point.

\section{Moderator: Characteristics of participants}

O ur conclusion that merchandise layout and ego-depletion do not affect healthiness of choices in the supermarket may be limited by the specific characteristics of the participants. Chapter 5 recruited students from Wageningen University who reported moderate to high trait self-control and had a relatively high health orientation. This health orientation can subsequently be translated to routine healthy eating habits (Adriaanse et al., 2014). Moreover, participants also indicated a higher preference for healthy snacks as compared to indulgent snacks. The high trait self-control, healthy eating habits and/ or preference toward healthy snacks may rule out the effects of merchandise layout on food choices. Participants who have healthy eating habits and prefer healthy snacks to indulgent snacks may feel no conflict at all when making choices. Besides, previous research (Gillebaart \& de Ridder, 2015) has supported that high trait self-control people succeed in the food domain because they tend to strategically downgrade the impulsiveness of indulgent snacks. This is to help themselves reduce potential conflicts between a health and an indulgent goal (called the effattess seff-contrd strategy; Gillebaart \& de Ridder, 2015). Therefore, our participants are likely less vulnerable to ego-depletion than other segments of the population since this group of people may be able to effortlessly sustain their healthy choices even after depletion. The findings of this thesis should be 
verified further with another group of people such as restrained eaters or overweight people who have been suffering from choice conflicts among healthy and indulgent foods.

\subsubsection{Additional recommendations for future research}

\section{Potential moderators of store layout design's impacts on intention to visit the store}

In addition to shopping motivation, the impacts of store layout design on consumer responses may also depend on other characteristics or traits of consumers such as purchasing involvement (Ohanian \& Tashchian, 1992), atmospheric responsiveness (McKechnie,1974), sensation-seeking tendency (Grossbart, Mittelstaedt, Curtis \& Rogers, 1975), or novelty-seeking (H. Kim et al., 2010). Behaviors of consumers with high purchasing involvement or high atmospheric responsiveness seem to be affected by store environment more than the behaviors of consumers with a lower level of such traits (McKechnie,1974; O hanian \& Tashchian, 1992). Moreover, consumers with a high sensation-seeking or high novelty-seeking tendency possibly have a higher preference toward more complex or lower orderly store layout design than those with lower sensation-seeking or lower novelty-seeking tendency. Therefore, these traits likely moderate the effects of store environment on consumers' cognitive and affective responses (Eroglu, Machleit, \& D avis, 2003). Further research is required to comprehend the moderating role of such motivations or personality traits on impacts of store layout design.

Another potential moderator is the store type. This thesis studied the impacts of store layout design in the context of pharmacy stores because these stores in the Netherlands provide both utilitarian (medicine and vitamins) and hedonic products (cosmetics and accessories). Therefore, we speculate that they can serve either a utilitarian or a hedonic motivation. Moreover, the layout design of 
the pharmacy stores is diverse in reality and thus enabled us to realistically employ many layouts in the studies. However, consumers' responses are likely context-specific. Some types of stores may be more utilitarian-oriented whereas others may be more hedonic-oriented (e.g., fashion store; Jang et al., 2018). The impacts of store layout design may depend on the utilitarian versus hedonic focus of stores. For stores with a hedonic focus (utilitarian focus), a high complexity of store layout may be more (less) acceptable whereas orderliness may bring more boredom (higher preference) to consumers. Moreover, since a specific layout is traditionally applied to a certain type of stores, consumers likely develop their expectations and preferences toward a specific layout (stereotype of the store). Introducing a novel layout for a specific type of store may change consumers' perceptions towand the store (either negatively or positively). For example, a grid layout is typically used in supermarket whereas a free-form layout is more widely used in fashion stores. Applying a free-form layout in a supermarket may increase impulsiveness, but may also introduce discomfort because people are unfamiliar with the layout. Follow-up research is required to examine the generalizability of our findings.

\section{Potential moderators of merchandise layout impacts on snack choices}

The number of products that consumers can choose on a single occasion (a single product versus multiple products) is expected to bring a significant impact on the healthiness of snack choice(s). The number of products that can be chosen is likely associated with the conflict that consumers feel and the goal that consumers pursue during making choice(s). When consumers choose a single product, they likely feel more conflict than when they have the option to choose multiple products. Moreover, the goal of enjoying indulgent snacks may become salient when consumers can choose only one product, especially when they are depleted from another choice task. In contrast, consumers may be able to balance among health and enjoyment goals or to highlight health or 
enjoyment goals when given the chance to choose multiple products. Up-to-date, there has been only one study that examines the healthiness of choices when multiple products are chosen (dynamic choices of drinks; van der Heide et al., 2016). That particular study showed that when choosing multiple drinks, overweight shoppers tended to choose more healthy drinks at the beginning of the choice task rather than at the end of the choice task. However, this work did not examine how the choice is influenced by merchandise layout. Further research on a single versus multiple products dynamic, especially in relation to merchandise layout, is hence required to understand the impacts of merchandise layout on consumers' food choices.

In relation to the type of choice, the consumption of chosen products over time is also intriguing. Specifically, future research is suggested to examine whether consumers who buy more healthy products also consume them. This thesis shows that consumers tend to buy more healthy products when choosing multiple products. Many healthy products such as fruit and vegetables are perishable in a short time period. If consumers change their mind when choosing a product at the time of consumption (e.g., go for indulgent food instead), buying more healthy food may also increase the food waste problem (Parfitt et al., 2010). Consumer consumption after purchase is a promising direction for future research to solve food waste issues that may occur.

In addition, the personal characteristic that should receive more attention in future research is depletion sensitivity (Salmon, Adriaanse, de Vet, Fennis, \& de Ridder, 2014). D epletion sensitivity refers to the extent to which individuals are sensitive to ego-depletion. In other words, it indicates the differences in speed with which individual's self-control resources become depleted. This moderator has been suggested and shown to insightfully predict the effect of self-control depletion on food choices, especially indulgent choices, even better than trait self-control (Salmon, Adriaanse, Fennis, de Vet, de Ridder, 2016; 
Salmon, Adriaanse, de Vet, et al., 2014). The studies have shown that individuals who report high in depletion sensitivity perform worse in the subsequent self-control task after the exertion of self-control in the first task. This effect has been discovered on various subsequent tasks, including critical thinking in a lab study (Salmon, Adriaanse, de Vet, et al., 2014), and on unhealthy snack purchases in a field study (Salmon, Adriaanse, Fennis et al., 2016). Future research should include depletion sensitivity when one wants to investigate the impacts of merchandise layout on choices. This moderator may also help explain the underlying process of merchandise layout and ego-depletion on choices.

\subsection{Final conclusion}

This thesis has established a first step to systematically disentangle the impacts of the store's spatial layout, especially store layout design and merchandise layout on consumers' expectations, patronage intention, and product choices. This thesis shows that when designing the store layout, perceived orderliness should receive the most attention because it brings positive expectations of shopping efficiency, shopping enjoyment, store image and intention to visit the store. Parallel and playful orientations should be employed to enhance perceived orderliness, whereas the random orientation should be avoided. Apart from these findings, impacts of store layout design on perceived complexity and impacts of merchandise layout on snack choices require a more comprehensive investigation. O ur findings underpin opportunities and challenges for future research on the spatial layout of physical stores. 


\section{Summary}

The spatial layout of a physical store can potentially be exploited as part of the marketing tool box to communicate the store's offered benefits to consumers. In that sense spatial store layout operates like the package of a product (Bitner, 1992; Kotler, 1973) and can shape consumers' purchasing choices. D esigning an attractive and efficient spatial layout to serve retailers' purposes and reach consumers' expectations is a challenging task because knowledge about the effects of layout designs is limited. In-depth understanding of the impacts of spatial layout on consumer responses is required to help retailers build attractive physical stores.

The purpose of this thesis is to provide empirical evidence for understanding the impacts of store spatial layout on consumer responses to stores, especially the impacts of store layout design and the merchandise layout. Two main research questions are addressed: First, the thesis addresses Howdbes strelayaut design detemineconsumer' intention tovisit stores? Accordingly, the thesis investigates consumers' expectations and perceptions toward the stores as underlying processes driving store layout design's effects on intention to visit. Moreover, the underlying processes under utilitarian and hedonic shopping motivations are explored. Second, the thesis addresses Howdoes the medhandiselayat (location of snadksin thestare) shapeconsumes' purchasingdhices of hellthyandindulgent snadks? The role of self-control depletion as an underlying process and the role of consumers' trait self-control as a moderator are explored.

The thesis shows that under limited knowledge about the store, consumers use store layout design as a cue to base their expectations of shopping enjoyment, shopping efficiency, and perceived store image on. These expectations (especially expected shopping enjoyment and expected shopping efficiency) 
positively influence consumers' intention to visit the store. Using a systematic approach focusing on store layout design, we reveal the limitations of using the more traditional typology that distinguishes between grid and free-form layouts. Specifically, as free-form layouts can be constructed in many different ways, the distinction is not very informative about consumers' likely responses to grid versus free-form layout. Rather than using this broad typology, we relate concrete attributes (e.g., shelf length, shelf shape, and shelf orientation) with consumers' responses to the store layouts (Chapters 2 and 3). Moreover, both qualitative (Chapter 2) and quantitative research (Chapter 3) manifest that perceived orderliness and perceived complexity are potential abstract attributes providing a better understanding of the impacts of store layout design on consumers' responses than either the typology of the grid and free-from layouts or the concrete attributes of store layout design would do.

O rderliness of stores is the most impactful abstract attribute of store layout design that retailers should target, because high orderly stores bring positive consumer expectations of the stores and enhance intentions to visit. Consumers' perceptions of store's orderliness can mainly be influenced by shelf orientation. The playful orientation (Chapter 3) and parallel orientation (Chapter 3) induce high expectations of shopping efficiency, shopping enjoyment, perceived store image and intention to visit. In contrast, a random orientation in which the shelves are arranged in an asymmetric and less organized pattern should be avoided (Chapters 2 and 3). Apart from the main impacts of shelf orientation, this thesis cannot attain a golden formula describing how the concrete attributes of store layout design (main and interaction effects) contribute to consumers' perceptions of store complexity and orderliness.

O ur findings suggest that shopping motivation moderates the impacts of store layout design on intention to visit the store. The evidence shows that consumers with a utilitarian shopping motivation prefer store layouts that enhance expected 
shopping efficiency and expected shopping enjoyment. Consumers with hedonic shopping motivation prefer store layouts that provide high expected shopping enjoyment (Chapter 2). Moreover, consumers with a hedonic motivation prefer more complex layouts than those with a utilitarian motivation (Chapter 3). However, it remains inconclusive whether shopping motivation moderates the underlying process (indirect effects), the direct effects of store layout, or both.

In terms of merchandise layout, Chapter 5 examines the impacts of merchandise layout and a possible underlying process (self-control depletion) on snack choices. This chapter reveals the relationship between merchandise layout (location of snacks) and self-control depletion measured by the impairment on a subsequent self-control task. It is found that self-control impairment occurs even after making a small number of choices in a day-to-day shopping reality. This would seem to imply that placing snacks at the end likely leads to self-control impairment because consumers would make more prior choices before reaching that spot. However, Chapter 5 finds inconclusive effects of merchandise layout (or self-control depletion) and inconclusive interactions effects of merchandise layout and trait self-control on snack purchases in the supermarket.

Overall, this thesis shows that the store's spatial layout influences consumers' cognitive response and intention to visit the store. However, the most preferable store layout design may depend on consumers' characteristics that are not covered in this thesis. Moreover, the impacts of merchandise layout on food choices seem to be overwhelmed by other factors such as food habits and goal that people have for future consumption. D espite inconclusive results, this thesis provides a direction for future research to further explore the impacts of store's spatial layout on consumers' responses and product choices. Moreover, the guideline of the use of a virtual store to investigate consumers' in-store behaviors can help researchers advance the research in this area. 



\section{References}

Adriaanse, M. A., Kroese, F. M., Gillebaart, M., \& de Ridder, D . T. D ., (2014).

Effortless inhibition: Habit mediates the relation between self-control and unhealthy snack consumption. Fronties in Psychdogy, 5(444), 1-6.

doi:10.3389/ fpsyg.2014.00444.

Aghazadeh, S. M. (2005). Layout strategies for retail operations: A case study.

Management ResearchNens, 28(10), 31-46. doi:10.1108/ 01409170510785002

Ainslie, G. W. (1975). Specious reward: A behavioral theory of impulsiveness and impulse control. Psychdog்al Bullein 82(4), 463-495. doi:10.1037/ h0076860

Alawadhi, A., \& Yoon, S. Y. (2016). Shopping behavioral intentions contributed

by store layout and perceived crowding: An exploratory study using computer walk-through simulation. Jaumal of Inteior Design 41(4), 29-46. doi:10.1111/ joid.12077

Alexander, C. (1979). A Timdess Way of Building London: Oxford University Press. Aloysius, G., \& Binu, D . (2013). An approach to products placement in supermarkets using PrefixSpan algorithm. Jaumal of KingSaudUnivesity Computer and Infomation Saiences, 25(1), 77-87.

doi:10.1016/j.jksuci.2012.07.001

Arnheim, R. (1971). Entropyand art: An essayondisarder and order. Berkeley, California: University of California Press.

Arnold, M. J., \& Reynolds, K. E. (2003). Hedonic shopping motivations. Jaumal of Reailing 79(2), 77-95. doi:10.1016/ S0022-4359(03)00007-1

Babin, B. J., D arden, W. R., \& G riffin, M. (1994). Work and/ or fun: Measuring hedonic and utilitarian shopping value. Jaumal of Consumer Reserch 20(4), 644-656. doi:10.1086/ 209376

Bäckström, K., \& Johansson, U. (2006). Creating and consuming experiences in retail store environments: Comparing retailer and consumer perspectives. Jaumal of Reailingand Consumer Services 13(6), 417-430. doi:10.1016/ j.jretconser.2006.02.005

Baker, J., G rewal, D ., \& Parasuraman, A. (1994). The influence of store environment on quality inferences and store image. Jaumal of theAcadamy of MarkeingSaiene, 22(4), 328-339. doi:10.1177/ 0092070394224002

Baker, J., Parasuraman, A., G rewal, D ., \& Voss, G . B. (2002). The influence of multiple store environment cues on perceived merchandise value and patronage intentions. Jaumal of Markeing 66(2), 120-141. doi:10.1509/ jmkg.66.2.120.18470 
Ballester, N., Guthrie, B., Martens, S., Mowrey, C., Parikh, P. J., \& Zhang, X. (2014). Effect of retail layout on traffic density and travel distance. In IIE Annual Conference Procedings(pp. 798-807). Norcross, G A: Institute of Industrial and Systems Engineers (IISE).

Baños, R. M., Botella, C., Garcia-Palacios, A., Villa, H., Perpiñá, C., \& Alcaniz, M. (2000). Presence and reality judgment in virtual environments: A unitary construct? CybarPsydhogy \& Behavior, 3(3), 327-335. doi:10.1089/ 10949310050078760

Baron, R. A. (1994). The physical environment of work settings: Effects on task performance, interpersonal relations, and job satisfaction. Reserchin Organizational Behavior, 16, 1-46.

Baron, R. M., \& Kenny, D . A. (1986). The moderator-mediator variable distinction in social psychological research: Conceptual, strategic, and statistical considerations. Jaumal of Pessonalityand Social Psychdogy, 51(6), 1173-1182.

Baumeister, R. F. (2002a). Ego depletion and self-control failure: An energy model of the self's executive function. Seff and Idantity, 1(2), 129-136. doi:10.1080/ 152988602317319302

Baumeister, R. F. (2002b). Yielding to temptation: Self-control failure, impulsive purchasing and consumer behaviour. Jamal of Consumer Rearch, 28(4), 670-676. doi:10.1086/ 338209

Baumeister, R. F., Bratslavsky, E., Muraven, M., \& Tice, D . M. (1998). Ego depletion: Is the active self a limited resource? Jaumal of Pesonalityand Soial Psychology, 74(5), 1252-1265. doi:10.1037/ / 0022-3514.74.5.1252

Baumeister, R. F., Heatherton, T. F., \& Tice, D . M. (1994). Losing antrd: Howand whypeeplefail at sdf-regilation San D iego, CA, US: Academic Press.

Baumeister, R. F., Sparks, E. A., Stillman, T. F., \& Vohs, K. D. (2008). Free will in consumer behavior: Self-control, ego depletion, and choice. Jaumal of Consumer Psychdogy, 18(1), 4-13. doi:10.1016/ j.jcps.2007.10.002

Beames, J. R., Schofield, T. P., \& D enson, T. F. (2018). A metaanalysis of improving self-control with practice. In D . T. D . de Ridder, M. A. Adriaanse, \& K. Fujita (E ds.), Handbook of self-contrd inhelthand well-being (pp. 405-417). Abingdon, UK: Routledge.

Beatty, J. (1982). Task-evoked pupillary responses, processing load, and the structure of processing resources. Psydhogical bullein, 91(2), 276-292. doi:10.1037/ 0033-2909.91.2.276 
Beauchamp, M. B., \& Ponder, N. (2010). Perceptions of retail convenience for instore and online shoppers. MarkeingManagenentJaumal, 20(1), 49-65. doi:10.1007/ s11274-015-1903-5

Berlyne, D . E. (1971). Aesthetis and Psydhdidogy. New Y ork: Appleton-CenturyCrofts.

Berneburg, A. (2007). Interactive 3D simulations in measuring consumer preferences: Friend or foe to test results? Jamal of InteradiveAdketising 8(1), 1-13. doi:10.1080/ 15252019.2007.10722132.

Bitner, M. J. (1992). Servicescapes: The impact of physical surroundings on customers and employees. TheJaumal of Markeing 56(2), 57-71. doi:10.1177/ 002224299205600205

Bloch, P. H., \& Richins, M. L. (1983). Shopping without purchase: An investigation of consumer browsing behavior. In R. Bagozzi \& A. Tybout (Eds.), Advancesin consumer rearch (vol. 10, pp. 389-393). Ann Abor, MI: Association for Consumer Research.

Botsali, A. R., \& Peters, B. A. (2005). A network based layout design model for retail stores. In IIE Annual Conferene Proceelings(pp. 1-6). Institute of Industrial and Systems Engineers (IISE).

Breen, P. (2009). Shaping retail: The use of virtual store simulations in marketing research and beyond. StareMarketingInstitutewhitepaper, 1-23. Retrieved from https:/ / kelley.iu.edu/ cerr/ files/ 09ismi virtualretailing.pdf

Brug, J., de Vet, E., de Nooijer, J., \& Verplanken, B. (2006). Predicting fruit consumption: cognitions, intention, and habits. Jaumal of Nutrition Eduration andBehavior, 38(2), 73-81. doi:10.1016/ j.jneb.2005.11.027

Brüggen, E. C., Foubert, B., \& G remler, D. D . (2011). Extreme makeover: Shortand long-term effects of a remodeled servicescape. Jamal of marketing 75(5), 71-87. doi:10.1509/jmkg.75.5.71

Burstiner, I. (1986). BasicReailing Homewood, IL: Irwin.

Carter, E. C., \& McCullough, M. E. (2014). Publication bias and the limited strength model of self-control: Has the evidence for ego depletion been overestimated? FrontiessinPsychdogy, 5, 1-11. doi:10.3389/ fpsyg.2014.00823

Carter, E. C., Kofler, L. M., Forster, D . E., \& McCullough, M. E. (2015). A series of meta-analytic tests of the depletion effect: self-control does not seem to rely on a limited resource. Jaumal of Expeimental Psydhogy: Geneal, 144(4), 796-816. doi:10.1037/ xge0000083

Cil, I. (2012). Consumption universes based supermarket layout through association rule mining and multidimensional scaling. Expet Systems with Applications, 39(10), 8611-8625. doi:10.1016/ j.eswa.2012.01.192. 
Clore, G. L., \& Huntsinger, J. R. (2007). How emotions inform judgment and regulate thought. Trendsin CognitiveSciences 11(9), 393-399. doi:10.1016/ j.tics.2007.08.005

Cohen, D .A., \& Babey, S. H. (2012). Cash at the candy register- a risk factor for obesity and chronic disease. NewEngandJaumal of Mediane, 367(15), 1381-1383. doi:10.1056/ NEJMp1209443

Croll, J. K., Neumark-Sztainer, D ., \& Story, M. (2001). Healthy eating: What does it mean to adolescents? Jaumal of Nutrition Eduration, 33(4), 193-198. doi:10.1016/ S1499-4046(06)60031-6

D abholkar, P. A., Thorpe, D. I., \& Rentz, J. O . (1995). A measure of service quality for retail stores: Scale development and validation. Jaumal of the Academy of MarkeingSaience, 24(1), 3-16. doi:10.1177/ 009207039602400101.

D ang, J. (2016). Commentary: A multilab preregistered replication of the egodepletion effect. FrontiersinPsychdogy, 7, 1-2. doi:10.3389/ fpsyg.2016.01155 D ang, J. (2018). An updated meta-analysis of the ego depletion effect.

Psychdogical Reserch, 82(4), 645-651. doi:10.1007/ s00426-017-0862-x

D avis, L., Peyrefitte, J., \& Hodges, N. (2012). From motivation to store choice:

Exploring Northwest Chinese consumers' shopping behavior. Intemational Jarmal of China Marketing 3(1), 71-87.

Demirgüneş, B. K. (2015). Ethical behavior of salesperson: The impact of consumer's perception on trust, satisfaction and repeat purchasing behavior. TurkishJaumal ofBusiness Ethics, 8(1), 26-46. doi:10.12711/ tjbe.2015.8.1.0009

de Ridder, D . T. D ., Lensvelt-Mulders, G., Finkenauer, C., Stok, F. M., \& Baumeister, R. F. (2011), Taking stock of self-control: A meta-analysis of how trait self-control relates to a wide range of behaviors. Pescolityand Soial Psychdogy Review, 16(1), 76-99. doi:10.1177/ 1088868311418749

D evlin, K., \& Nasar, J. L. (1989). The beauty and the beast: Some preliminary comparisons of 'high' versus 'popular' residential architecture and public versus architect judgments of same. Jaumal of Enviranmental Psydhdogy, 9(4), 333-344. doi:10.1016/ S0272-4944(89)80013-1

DeWall, C. N., Baumeister, R. F., Stillman, T. F., \& Gailliot, M. T. (2007).

Violence restrained: Effects of self-regulation and its depletion on aggression. Jaumal of Experimental Social Psydhdogy, 43(1), 62-76. doi:10.1016/ j.jesp.2005.12.005 
Diehl, K., van Herpen, E., \& Lamberton, C. (2015). Organizing products with complements versus substitutes: Effects on store preferences as a function of effort and assortment perceptions. Jaumal of Reailing 91(1), 1-18. doi:10.1016/ j.jretai.2014.10.003.

D odds, W. B., Monroe, K. B., \& G rewal, D . (1991). Effects of price, brand, and store information on buyers' product evaluations. Jaumal of Markeing Reserch, 28(3), 307-319. doi: 10.2307/ 3172866.

D onovan, R. J., \& Rossiter, J. R. (1982). Store atmosphere: An environmental psychology approach. Joumal of Rezailing 58(1), 34-57.

D ucrot, P., Julia, C., Méjean, C., Kesse-G uyot, E., Touvier, M., Fezeu, L. K., ... \& Péneau, S. (2016). Impact of different front-of-pack nutrition labels on consumer purchasing intentions: A randomized controlled trial. American Jarmal of PreventiveMediane, 50(5), 627-636. doi:10.1016/ j.amepre.2015.10.020

D vorak, R. D ., \& Simons, J. S. (2009). Moderation of resource depletion in the self-control strength model: Differing effects of two modes of self-control. Pessanalityand Soial Psydhogy Bullein, 35, 572-583. doi:10.1177/ 0146167208330855

Eroglu, S. A., Machleit, K. A., \& D avis, L. M. (2003). Empirical testing of a model of online store atmospherics and shopper responses.

Psychdogy \& Markeing 20(2), 139-150. doi:10.1002/ mar.10064

Escaron, A. L., Meinen, A. M., Nitzke, S. A., \& Martinez-D onate, A. P. (2013). Supermarket and grocery store-based interventions to promote healthful food choices and eating practices: A systematic review. PreventingChronic Dises, 10, 1-20. doi:10.5888/ pcd10.120156

Fabregas, K. (2018, January 18). Planning your store layout: Step-by-step. Retrieved from https:/ / fitsmallbusiness.com/ planning-your-store-layout/

Fennis, B. M. (2011). Can't get over me: Ego depletion attenuates prosocial effects of perspective taking. EuropeanJaumal of Social Psychdogy, 41(5), 580-585. doi:10.1002/ ejsp.828

Fiore, A. M., Yah, X., \& Yoh, E. (2000). Effects of a product display and environmental fragrancing on approach responses and pleasurable experiences. Psychdogy \& Markeing 17(1), 27-54. doi:10.1002/ (SICI)1520-6793(200001)17:1<27::AID MAR3>3.0.CO ;2-C Fischer, E., \& Arnold, S. J. (1990). More than a labor of love: Gender roles and Christmas gift shopping. Jaumal of Consumer Reserch, 17(3), 333-345. doi:10.1086/ 208561 
Fiske, S. T. (2014). Schema-triggered affect: Applications to social perception. In M. S. Clark, \& S. T. Fiske (Eds.), Affet and œonition(pp. 65-88). New York, NY: Psychology Press.

Fiske, S. T., \& Linville, P. W. (1980). What does the schema concept buy

us? Pessonalityand Social Psychdogy Bullein, 6(4), 543-557.

doi:10.1177/ 014616728064006

Friedenberg, J., \& Liby, B. (2016). Perceived beauty of random texture patterns: A preference for complexity. Ada Psydhogica, 168, 41-49. doi:10.1016/ j.actpsy.2016.04.007

Friese, M., \& Hofmann, W. (2009). Control me or I will control you: Impulses, trait self-control, and the guidance of behavior. Jaumal of Researchin Pesconality, 43(5), 795-805. doi:10.1016/ j.jrp.2009.07.004

Friese, M., Loschelder, D . D ., G ieseler, K., Frankenbach, J., \& Inzlicht, M. (2018). Is ego depletion real? An analysis of arguments. Pesconalityand Social Psydology Review 1-26. doi:10.1177/ 1088868318762183

Fujita, K., Trope, Y., Liberman, N., \& Levin-Sagi, M. (2006). Construal levels and self-control. Jaumal ofPesconalityand Social Psydhdogy, 90(3), 351-367. doi:10.1037/ 0022-3514.90.3.351

Gailliot, M. T., \& Baumeister, R. F. (2007). Self-regulation and sexual restraint: Dispositionally and temporarily poor self-regulatory abilities contribute to failures at restraining sexual behavior. Pescnalityand Social Psychoog Bullein 33(2), 173-186. doi:10.1177/ 0146167206293472

Gailliot, M. T., Schmeichel, B. J., \& Baumeister, R. F. (2006). Self-regulatory processes defend against the threat of death: Effects of self-control depletion and trait self-control on thoughts and fears of dying. Jaumal of Pessonalityand Social Psychdogy, 91(1), 49-62. doi:10.1037/ 0022-3514.91.1.49 Gailliot, M. T., Schmeichel, B. J., \& Maner, J. K. (2007). Differentiating the effects of self-control and self-esteem on reactions to mortality salience. Joumal of Expeimental Social Psychdogy, 43(6), 894-901. doi:10.1016/ j.jesp.2006.10.011 Gardner, M. P., \& Siomkos, G. J. (1986). Toward a methodology for assessing effects of in-store atmospherics. R. J. Lutz (Eds.), Adwanes in consumer rearch (vol. 3, pp. 27-31). Provo, UT: Association for Consumer Research.

Garlin, F. V., \& O wen, K. (2006). Setting the tone with the tune: A meta-analytic review of the effects of background music in retail settings. Jaumal of Business Reserch 59(6), 755-764. doi:10.1016/ j.jbusres.2006.01.013

Geuens, M., Brengman, M., \& S'Jegers, R. (2003). Food retailing, now and in the future. A consumer perspective. Jaumal of Retailingand Consumer Services 10(4), 241-251. doi: 10.1016/ S0969-6989(02)00017-6 
G hosh, A. (1994). Reail management Forth Worth, TX: D ryden Press.

G hosh, P., Tripathi, V., \& K umar, A. (2010). Customer expectations of store attributes: A study of organized retail outlets in India. Jaumal of Reail \& LeisurePropety, 9(1), 75-87. doi:10.1057/ rlp.2009.27

Gilboa, S., \& Rafaeli, A. (2003). Store environment, emotions and approach behaviour: Applying environmental aesthetics to retailing. TheIntemational Reviewof Retail, Distribution and Consumer Reserch 13(2), 195-211. doi:10.1080/ 0959396032000069568

Gilbride, T. J., Inman, J. J., \& Stilley, K. M. (2015). The role of within-trip dynamics in unplanned versus planned purchase behavior.

Jaumal of Markeing 79(3), 57-73. doi:10.1509/ jm.13.0286

Gillebaart, M., \& de Ridder, D. T. (2015). Effortless self-control: A novel perspective on response conflict strategies in trait self-control. Soial and Personality PsychdogyCompass, 9(2), 88-99. doi:10.1111/ spc3.12160

Glass, D . C., Singer, J. E., \& Friedman, L. N. (1969). Psychic cost of adaptation to an environmental stressor. Joumal of Pessnalityand Social Psychoog, 12(3), 200-210. doi:10.1037/ h0027629

Gorini, A., G riez, E., Petrova, A., \& Riva, G . (2010). Assessment of the emotional responses produced by exposure to real food, virtual food and photographs of food in patients affected by eating disorders. Anmals of General Psydiatry, 9, 1-10. doi:10.1186/ 1744-859X-9-30

Greenland, S., \& McG oldrick, P. (2005). Evaluating the design of retail financial service environments. Intemational Jaumal of Bank Markeing 23(2), 132-152. doi:10.1108/ 02652320510584386

Grewal, D ., Baker, J., Levy, M., \& Voss, G . B. (2003). The effects of wait expectations and store atmosphere evaluations on patronage intentions in service-intensive retail stores. Joumal of Reailing 79(4), 259-268. doi:10.1016/ j.jretai.2003.09.006

G riffin, M., Babin, B. J., \& Attaway, J. S. (1996). Anticipation of injurious consumption outcomes and its impact on consumer attributions of blame. Jaumal of theAcademy of MarketingSaience, 24(4), 314-327. doi:10.1177/ 0092070396244003.

Groeppel-Klein, A., \& Bartmann, B. (2007). Anti-clockwise or clockwise? The impact of store layout on the process of orientation in a discount store. In S. Borghini, M. A. McG rath, \& C. O. D uluth (Eds.), E - EuropeanAdancesin Consumer Rearch (vol 8, pp. 415-416). D uluth, MN: Association for Consumer Research. 
Grossbart, S. L., Mittelstaedt, R. A., Curtis, W. W., \& Rogers, R. D . (1975). Environmental sensitivity and shopping behavior. Jaumal of Business

Reserch, 3(4), 281-294. doi:10.1016/ 0148-2963(75)90010-7

Gutman, J. (1982). A means-end chain model based on consumer categorization

processes. TheJaumal of Markiting 46(2), 60-72.

doi:10.1177/ 002224298204600207

Hagger, M. S., Chatzisarantis, N. L. D ., Alberts, H., Anggono, C. O ., Batailler, C., Birt, A. R., \& Z wienenberg, M. (2016). A multilab preregistered replication of the ego-depletion effect. Pespetives on Psydhdogical Saience, 11(4), 546-573. doi:10.1177/ 1745691616652873

Hagger, M. S., Wood, C., Stiff, C., \& Chatzisarantis, N. L. D . (2010). Ego

depletion and the strength model of self-control: A meta-analysis.

Psychdogical Bullein, 136(4), 495-525. doi:10.1037/ a0019486

Han, D . (2010). Theimpact of salesperson'sinfomation ovelcad on reationshipsedling

behaviaursand sales pefommee(D octoral dissertation, Auckland University of Technology, Auckland, New Zealand). Retrieved from

http:/ / aut.researchgateway.ac.nz/ handle/ 10292/ 931

Hayes, A. F. (2013). Introdurtion tomediation, moderation, and conditional process analysis

A regression-basedapproach New Y ork, NY: G uilford Press.

Heath, T., Smith, S. G., \& Lim, B. (2000). Tall buildings and the urban skyline:

The effect of visual complexity on preferences. Environment and

Behaviar, 32(4), 541-556. doi:10.1177/ 00139160021972658

Hekkert, P., \& Leder, H. (2008). Product aesthetics. In H. N. J., Schifferstein \& P.

Hekkert (Eds.), Prouluct expeience(pp. 259-285). Elsevier.

doi: 10.1016/ B978-008045089-6.50013-7

Helmefalk, M., \& Hultén, B. (2017). Multi-sensory congruent cues in designing retail store atmosphere: Effects on shoppers' emotions and purchase behavior. Jaumal of Reailingand Consumer Services 38, 1-11. doi:10.1016/ j.jretconser.2017.04.007

Hofmann, W., Baumeister, R. F., Förster, G., \& Vohs, K. D . (2012). Everyday temptations: An experience sampling study of desire, conflict, and selfcontrol. Joumal of Pessonalityand Social Psychdogy, 102(6), 1318-1335. doi:10.1037/ a0026545

Holbrook, M. B., \& Hirschman, E. C. (1982). The experiential aspects of consumption: Consumer fantasies, feelings, and fun. Jamal of Consumer Reserch, 9(2), 132-140. doi:10.1086/ 208906 
Holmqvist, J., \& Lunardo, R. (2015). The impact of an exciting store environment on consumer pleasure and shopping intentions. Intemational Joumal of Rearch inMarketing 32(1), 117-119. doi: 10.1016/ j.jiresmar.2014.12.001

Homburg, C., Imschloß, M., \& Kühnl, C. (2012). Of dollars and senses-D oes multisensory marketing pay off. IMU Resarch Insights 9, 1-14. Retrieved from https:/ / www.bwl.uni-mannheim.de/ media/ Einrichtungen/ imu/ Research_Insights/2012/RI 009.pdf

Honkanen, P., Olsen, S. O ., Verplanken, B., \& Tuu, H. H. (2012). Reflective and impulsive influences on unhealthy snacking. The moderating effects of food related self-control. Appeite, 58(2), 616-622. doi:10.1016/ j.appet.2011.11.019 Hopstaken, J. F., van der Linden, D ., Bakker, A. B., \& Kompier, M. A. (2015). The window of my eyes: Task disengagement and mental fatigue covary with pupil dynamics. Bidogical psydhdogy, 110, 100-106.

doi:10.1016/ j.biopsycho.2015.06.013

Huber, J., \& McCann, J. (1982). The impact of inferential beliefs on product evaluations. Jaumal of MarkeingReserch, 19(3), 324-333. doi:10.2307/ 3151566

Huffman, C., \& Kahn, B. E. (1998). Variety for sale: Mass customization or mass confusion? Jaumal of reailing 74(4), 491-513. doi:10.1016/ S0022-4359(99)80105-5

Huyghe, E., Verstraeten, J., G euens, M., \& van Kerckhove, A. (2017). Clicks as a healthy alternative to bricks: How online grocery shopping reduces vice purchases. Jaumal of MarketingReserth 54(1), 61-74. doi:10.1509/ jmr.14.0490

Im, H., Lennon, S. J., \& Stoel, L. (2010). The perceptual fluency effect on pleasurable online shopping experience. Jaumal of Reserchin Interadive Markeing 4(4), 280-295. doi:10.1108/ 17505931011092808

Imhoff, R., Schmidt, A. F., \& G erstenberg, F. (2014). Exploring the interplay of trait self-control and ego depletion: Empirical evidence for ironic effects. European Jaumal of Personality, 28(5), 413-424. doi:10.1002/ per.1899

Importance of physical stores' "Halo effect" brand awareness and sales boosted through store locations. (2017, 30 May). Retrieved from https:/ / www.icsc.org/ uploads/ t07-subpage/ Halo-Effect.pdf

Inzlicht, M., \& Schmeichel, B. J. (2012). What is ego depletion? Toward a mechanistic revision of the resource model of self-control. Pespetives an Psychdogcal Saience, 7, 450-463. doi:10.1177/ 1745691612454134

Iyengar, S. S., \& Lepper, M. R. (2000). When choice is demotivating: Can one desire too much of a good thing? Jamal of Pesanalityand Social Psydhogy, 79(6), 995-1006. doi: 10.1037/ 0022-3514.79.6.995 
Jang, J. Y., Baek, E., \& Choo, H. J. (2018). Managing the visual environment of a fashion store: Effects of visual complexity and order on sensation-seeking consumers. Intemational Jaumal of Reail \& Distribution Managenett, 46(2), 210-226. doi:10.1108/ IJRD M-03 2017-0050

Job, V., Walton, G. M., Bernecker K., \& D weck, C. S. (2013). Beliefs about willpower determine the impact of glucose on self-control. Procedngs of the National A cadany of Saienes of theUnited States of Amrica, 110(37), 14837-14842. doi:10.1073/ pnas.1313475110.

Johnson, P. O., \& Neyman, J. (1936). Tests of certain linear hypotheses and their applications to some educational problems. Statistical Rearch Memirs 1, 57-93.

Jones, M. A., Reynolds, K. E., \& Arnold, M. J. (2006). Hedonic and utilitarian shopping value: Investigating differential effects on retail outcomes. Jamal of Business Reserch 59(9), 974-981. doi: 10.1016/ j.jbusres.2006.03.006 Kaltcheva, V. D ., \& Weitz, B. A. (2006). When should a retailer create an exciting store environment? Jaumal of Markeing 70(1), 107-118. doi:10.1509/ jmkg.2006.70.1.107

Kaplan, R., \& Kaplan, S. (1989). Theexperienee of nature A poydhogical pespeetive New York: Cambridge University Press.

Kaplan, S. (1987). Aesthetics, affect, and cognition: Environmental preference from an evolutionary perspective. Enironment andBehavior, 19(1), 3-32. doi:10.1177/ 0013916587191001

Khan, V. J., Nuijten, K. C., \& Deslé, N. (2011). Pervasive application evaluation within virtual environments. In Procedings of Intemational Confereneon Embeedked Computingand Comminication Systens(pp. 261-264).

Kim, A. E., Nonnemaker, J. M., Loomis, B. R., Shafer, P. R., Shaikh, A., Hill, E., ... \& Farrelly, M. C. (2014). Influence of point-of-sale tobacco displays and graphic health warning signs on adults: Evidence from a virtual store experimental study. AmeicanJaumal of PubicHelth 104(5), 888-895. doi:10.2105/ AJPH.2013.301723

Kim, H. Y., \& Kim, Y. K. (2008). Shopping enjoyment and store shopping modes: The moderating influence of chronic time pressure. Jarmal of Reailingand Consumer Services, 15(5), 410-419. doi:10.1016/ j.jretconser.2007.10.003 
Kim, H., Fiore, A. M., Niehm, L. S., \& Jeong, M. (2010). Psychographic characteristics affecting behavioral intentions towards pop-up retail. Intemational Jaumal of Reail \& Distribution Managenent, 38(2), 133-154. doi:10.1108/ 09590551011020138

Koelemeijer, K., \& Oppewal, H. (1999). Assessing the effects of assortment and ambience: A choice experimental approach. Jaumal of Reailing 75(3), 319-345. doi:10.1016/ S0022-4359(99)00011-1

Kotler, P. (1973). Atmospherics as a marketing tool. Jaumal of Retailing 49(4), 48-64.

Kroese, F. M., Marchiori, D . R., \& de Ridder, D. T. (2015). Nudging healthy food choices: A field experiment at the train station. Joumal of PublicHelth 38(2), e133-e137. doi:10.1093/ pubmed/ fdv096

Kuhfeld, W. F. (2010). Marketing research methods in SAS. Cary, NC: SAS Institute Inc. http:/ / support.sas.com/ techsup/ technote/ mr2010.pdf Kumar, A., Gupta, S. L., \& Kishore, N. (2014). Measuring retailer store image: A scale development study. Intemational Jaumal of Business \& Economics 13(1). 25-38.

Landau, S., \& Everitt, B. S. (2004). A handbook of statistical analyses usingSPSS. Boca Raton, FL: Chapman \& Hall.

Laran, J. (2010). Choosing your future: Temporal distance and the balance between self-control and indulgence. Jamal of Consumer Rearch, 36(6), 1002-1015, doi:10.1086/ 648380

Larson, J. S., Bradlow, E. T., \& Fader, P. S. (2005). An exploratory look at supermarket shopping paths. Intemational Joumal of Reserchin Marketing 22(4), 395-414. doi:10.1016/ j.jjresmar.2005.09.005 Lauer, D . (1985). Design Basics(2nd ed.). New York, NY: Holt Lessiter, J., Freeman, J., Keogh, E., \& D avidoff, J. (2001). A cross-media presence questionnaire: The ITC-sense of presence inventory. Presence Tdeepeatars \& Virtual Environments, 10(3), 282-297. doi: 10.1162/ 105474601300343612 Levy, M., \& Weitz, B. A. (2012). RetailingManagment(8th ed.).

New Y ork: McGraw-Hill/ Irwin.

Lewison, D. M. (1994). Rłailing(5th ed.). New York: New York Macmillan.

Li, F., Zhou, N., Nicholls, J. A. F., Zhuang, G., \& Kranendonk, C. (2004).

Interlinear or inscription? A comparative study of Chinese and American mall shoppers' behavior. Jaumal of Consumer Marketing 21(1), 51-61. doi:10.1108/ 07363760410513969. 
Lin, L. Z., \& Y eh, H. R. (2013). A means-end chain of fuzzy conceptualization to elicit consumer perception in store image. Intemational Joumal of Hospitality Management, 33, 376-388. doi: 10.1016/ j.ijhm.2012.10.008

Liu, Y., \& Jang, S. S. (2009). The effects of dining atmospherics: An extended Mehrabian Russell model. Intemational Jaumal of Hospitality Management, 28(4), 494-503. doi:10.1016/ j.jjhm.2009.01.002

Logue, A. W. (1988). Research on self-control: An integrating framework.

Behavioral and Brain Saienes 11(4), 665-679. doi:10.1017/ S0140525X 00053978

Lu, Y., \& Seo, H. B. (2015). D eveloping visibility analysis for a retail store: A pilot study in a bookstore. Enmirammet andPlanningB: PlanningandDesign 42(1), 95-109. doi:10.1068/ b130016p

Lurquin, J. H., \& Miyake A. (2017) Challenges to ego-depletion research go beyond the replication crisis: A need for tackling the conceptual crisis. FrontiersinPsychdogy, 8, 1-5. doi:10.3389/ fpsyg.2017.00568

Lynch Jr, J. G., \& Zauberman, G. (2006). When do you want it? Time, decisions, and public policy. Jamal of PublicPdioy \& Markeing 25(1), 67-78. doi:10.1509/ jppm.25.1.67

Maas, J., de Ridder, D. T. D ., de Vet, E., \& de Wit, J. B. (2012). D o distant foods decrease intake? The effect of food accessibility on consumption.

Psychdogy \& Hœlth 27(2), 59-73. doi:10.1080/ 08870446.2011.565341

Machleit, K. A., \& Eroglu, S. A. (2000). D escribing and measuring emotional response to shopping experience. Jamal of Business Reerch, 49(2), 101-111. doi:10.1016/ S0148-2963(99)00007-7

Mannino, S. (2018, 11 April). O nline retailers: Why physical retail should be your next move. Retrieved from

https:/ / www.forbes.com/ sites/ forbesnycouncil/ 2018/ 04/ 11/ onlineretailers-why-physical-retail-should-be-your-next-move/ \#7d428f8f7f4d Mayer, J. D ., \& G aschke, Y. N. (1988). The experience and meta-experience of mood. Jaumal of Pessonalityand Social Psydhdogy, 55(1), 102-111. doi:10.1037/ 0022-3514.55.1.102

Mazursky, D., \& Jacoby, J. (1986). Exploring the development of store images. Jaumal of Retailing 62(2), 145-165.

McKechnie G . E . (1974). Manual for theEnuronmetal ResponseInventory. Palo Alto, CA: Consulting Psychologists Press.

Metcalfe, J., \& Mischel, W. (1999). A hot/ cool-system analysis of delay of gratification: The dynamics of willpower. Psydhogical Review 106(1), 3-19. doi:10.1037/ 0033-295X.106.1.3 
Mikkelsen, B. E., Høeg, E. R., Mangano, L., \& Serafin, S. (2016). The virtual foodscape simulator-gaming, designing and measuring food behaviour in created food realities. In A. Spink, G Riedel, L. Zhou, et al. (Eds.), Prowings of MeasuingBehavior 2016: 10th Inter-national Conference on Method and Techniques in Behavioral Research, (pp. 25-27).

Miočević, M., O’Rourke, H. P., MacKinnon, D. P., \& Brown, H. C. (2018).

Statistical properties of four effect-size measures for mediation models.

Behavior resch mothods 50(1), 285-301.

Mohan, G., Sivakumaran, B., \& Sharma, P. (2013). Impact of store environment on impulse buying behavior. European Jamal of Markeing 47(10), 1711-1732. doi:10.1108/ EJM 03-2011-0110

Moller, A. C., D eci, E. L., \& Ryan, R. M. (2006). Choice and ego-depletion: The moderating role of autonomy. Pessonalityand Social PsychdogyBullein, 32(8), 1024-1036. doi:10.1177/ 0146167206288008

Montoya, A. K. (2018). Moderation analysis in two-instance repeated measures designs: Probing methods and multiple moderator models.

Behavior regrch mothods 1-22. doi:10.3758/ s13428-018-1088-6

Montoya, A. K., \& Hayes, A. F. (2015). Two condition within-participant statistical mediation analysis: A path-analytic framework. Psychdogical Methook, 22(1), 6-27. doi:10.1037/ met0000086

Morales, A. C., Amir, O ., \& Lee, L. (2017). Keeping it real in experimental research-understanding when, where, and how to enhance realism and measure consumer behavior. Jaumal of Consumer Reerch 44(2), 465-476. doi:10.1093/ jcr/ ucx048

Muraven, M., Baumeister, R. F., \& Tice, D . M. (1999). Longitudinal improvement of self-regulation through practice: Building self-control strength through repeated exercise. TheJaumal of Social Psydhdogy, 139(4), 446-457. doi:10.1080/ 00224549909598404

Muraven, M., Collins, R. L., Shiffman, S., \& Paty, J. A. (2005). D aily fluctuations in self-control demands and alcohol intake. PsydhdogyofAddidiveBehavias, 19(2), 140-147. doi:10.1037/ 0893-164x.19.2.140

Muraven, M., Pogarsky, G., \& Shmueli, D . (2006). Self-control depletion and the general theory of crime. Joumal of QuantitativeCrimindogy, 22(3), 263-277. doi:10.1007/ s10940-006-9011-1

Muraven, M., Shmueli, D ., \& Burkley, E. (2006). Conserving self-control strength. Jaumal of Pessanalityand Social Psychdogy, 91(3), 524-537. doi:10.1037/ 0022-3514.91.3.524 
Muraven, M., Tice, D . M., \& Baumeister, R. F. (1998). Self-control as a limited resource: Regulatory depletion patterns. Jaumal of Pessomalityand Socal Psychdogy, 74(3), 774-789. doi:10.1037/ 0022-3514.74.3.774

Murray, J., Elms, J., \& Teller, C. (2015). Consumer perceptions of higher and lower-level designed store environments. TheIntemational Reviewof Reail, Distribution and Consumer Reseren, 25(5), 473-489.

doi:10.1080/ 09593969.2015.1088461

Myrseth, K. O . R., \& Fishbach, A. (2009). Self-control: A function of knowing when and how to exercise restraint, Curret Diretionsin Psychdogcal Säene, 18(4), 247-252. doi:10.1111/ j.1467-8721.2009.01645.x

Nadal, M., Munar, E., Marty, G., \& Cela-Conde, C. J. (2010). Visual complexity and beauty appreciation: Explaining the divergence of results.

Empinical Studies of theArts, 28(2), 173-191. doi:10.2190/ EM.28.2.d

Nakamura, R., Pechey, R., Suhrcke, M., Jebb, S. A., \& Marteau, T. M. (2014). Sales impact of displaying alcoholic and non-alcoholic beverages in end-of-aisle locations: An observational study. Social Saience\& Mediane, 108, 68-73. doi:10.1016/ j.socscimed.2014.02.032

Nasar, J. L. (1994). Urban design aesthetics: The evaluative qualities of building exteriors. Environment and Behavior, 26(3), 377-401. doi:10.1177/ 001391659402600305

Nasar, J. L. (2000). The evaluative image of places. In W. B. Walsh, K. H. Craik, \& R. H. Price (Eds.), Person-eniranment psydhdogy: Newdiretionsand perspetives (pp. 117-168). New York, NY: Psychology Press.

Nysveen, H., Pederson, P. E., \& Thorbjørnsen, H. (2005). Intentions to use mobile services: Antecedents and cross-service comparisons. Jaumal of the Acadamy of MarkeingSaience, 33(3), 330-346. doi:10.1177/ 0092070305276149.

O akes, M. (2005). Stereotypical thinking about foods and perceived capacity to promote weight gain. Appeite, 44(3), 317-324. doi:10.1016/ j.appet.2005.03.010

Oakes, M. \& Slotterback, C. S. (2005). Too good to be true: D ose insensitivity and stereotypical thinking of foods' capacity to promote weight gain. FoodQuality andPreference, 16(8), 675-681. doi:10.1016/ j.foodqual.2005.03.010

O hanian, R., \& Tashchian, A. (1992). Consumers' shopping effort and evaluation of store image attributes: The roles of purchasing involvement and recreational shopping interest. Jamal of Applied Business Research 8(4), 40-49. doi:10.19030/ jabr.v8i4.6123 
O ostendorp, A., \& Berlyne, D . E. (1978). Dimensions in the perception of architecture: Measures of exploratory behavior. ScandinavianJaumal of Psychdogy, 19(1), 83-89. doi:10.1111/ j.1467-9450.1978.tb00306.x

Oppewal, H., \& Koelemeijer, K. (2005). More choice is better: Effects of assortment size and composition on assortment evaluation.

Intemational Jamal of Reserchin Marketing 22(1), 45-60. doi:10.1016/ j.jiresmar.2004.03.002

Orth, U.R., \& Wirtz, J. (2014), Consumer processing of interior service environments: The interplay among visual complexity, processing fluency, and attractiveness, Joumal of ServiceReserrch 17(3), 296-309. doi:10.1177/ 1094670514529606

Pan, X., \& Hamilton, A. F. C. (2018). Why and how to use virtual reality to study human social interaction: The challenges of exploring a new research landscape. BritishJaumal of Psydhogy, 109(3), 395-417. doi:10.1111/ bjop.12290

Pan, Y., \& Zinkhan, G . M. (2006). D eterminants of retail patronage: A metaanalytical perspective. Jaumal of reailing 82(3), 229-243. doi:10.1016/ j.jretai.2005.11.008

Parfitt, J., Barthel, M., \& Macnaughton, S. (2010). Food waste within food supply chains: Quantification and potential for change to 2050. Philosphical Transadions of theRoyal Socidy B: Bidogial Saienes 365(1554), 3065-3081. doi:10.1098/ rstb.2010.0126

Park, C. W., Iyer, E. S., \& Smith, D . C. (1989). The effects of situational factors on in-store grocery shopping behavior: The role of store environment and time available for shopping. Jaumal of Consumer Research, 15(4), 422-433. doi:10.1086/ 209182

Petersen, C. (2018, September 24). Are big box retailers going too small with new store concepts? Retrieved from http:/ / www.theretailingmanagement.com/ ?p=1949.

Pine, B. J., \& Gilmore, J. H. (1998). Welcome to the experience economy. Harvard BusinessReview 76, 97-105.

Preacher, K. J., Curran, P. J., \& Bauer, D. J. (2006). Computational tools for probing interactions in multiple linear regression, multilevel modeling, and latent curve analysis. Jaumal of Educational andBehavioral Statistics 31(4), 437-448. doi:10.3102/ 10769986031004437 
Puccinelli, N. M., Goodstein, R. C., G rewal, D ., Price, R., Raghubir, P. \& Stewart, D . (2009). Customer experience management in retailing: Understanding the buying process. Jaumal of Retailing 85(1), 15-30.

doi:10.1016/ j.jretai.2008.11.003

Raghunathan, R., Naylor, R. W., \& Hoyer, W. D . (2006). The unhealthy = tasty intuition and its effects on taste inferences, enjoyment, and choice of food products. Jaumal of Markeing 70(4), 170-184. doi:10.1509/ jmkg.70.4.170

Rayburn, S. W., \& Voss, K. E. (2013). A model of consumer's retail atmosphere perceptions. Joumal of Reailingand Consumer Services, 20(4), 400-407. doi:10.1016/ j.jretconser.2013.01.012

Read, D. V., Loewenstein, G., \& Kalyanaraman, S. (1999). Mixing virtue and vice: Combining the immediacy effect and the diversification heuristic. Jamal of Behavioral Deeision Making 12(4), 257-273. doi:10.1002/ (SICI)1099-0771 (199912)12:4<257::AID -BD M327>3.0.CO ;2-6

Rebelo, F., D uarte, E., Noriega, P., \& Soares, M. M. (2011). Virtual reality in consumer product design: Methods and applications. In W. Karwowski, M. M. Soares, \& N. A. Stanton (Eds.), Human factors and egonomis in consumer product design (pp. 381-402). Boca Raton, FL: CRC Press.

Reber, R., Schwarz, N., \& Winkielman, P. (2004). Processing fluency and aesthetic pleasure: Is beauty in the perceiver's processing experience? Pesanalityand Social PsychdogyReview, 8(4), 364-382. doi:10.1207/ s15327957pspr0804_3

Rintamäki, T., Kanto, A., Kuusela, H., \& Spence, M. T. (2006). D ecomposing the value of department store shopping into utilitarian, hedonic and social dimensions. Intemational Jaumal of Retail \& Distribution Management, 34(1), 6-24. doi:10.1108/ 09590550610642792

Roininen, K., \& Tuorila, H. (1999). Health and taste attitudes in the prediction of use frequency and choice between less healthy and more healthy snacks.

FoodQualityandPrefeenee, 10(4-5), 357-365. doi:10.1016/ S0950-3293 (98)00057-3

Rondeel, E., van Steenbergen, H., Holland, R., \& van Knippenberg, A. (2015). A closer look at cognitive control: Differences in resource allocation during updating, inhibition and switching as revealed by pupillometry.

Frontiessin human natrosience, 9, 1-13. doi:10.3389/ fnhum.2015.00494 Rothenberg, E., Bosaeus, I., \& Steen, B. (1994). Food habits, food beliefs and socio-economic factors in an elderly population. ScandinavianJaumal of Nutrition, 38, 159-165. 
Rottenstreich, Y., Sood, S., \& Brenner, L. (2007). Feeling and thinking in memorybased versus stimulus-based choices. Jaumal of Consumer Rearch 33(4), 461-469. doi:10.1086/ 510219

Rozin, P., Scott, S., Dingley, M., Urbanek, J. K., Jiang, H., \& Kaltenbach, M. (2011). Nudge to nobesity I: Minor changes in accessibility decrease food intake. Judgement and Deeision Making 6(4), 323-332.

Runquist, W. N. (1965). O rder of presentation and number of items as factors in paired associate verbal learning. Jaumal of MemoryandLangage, 4(6), 535-540. doi:10.1016/ S0022-5371(65)80054-8

Ruppert, B. (2011). New directions in the use of virtual reality for food shopping:

Marketing and education perspectives. Joumal of Diabetes Saieneand Tehndogy, 5(2), 315-318. doi:10.1177/ 193229681100500217.

Salmon, S. J., Adriaanse, M. A., de Vet, E., Fennis, B. M., \& de Ridder, D. T. D. (2014). "When the going gets tough, who keeps going?" D epletion sensitivity moderates the ego-depletion effect. Frontiesin Psydhdogy, 5, 1-8. doi:10.3389/ fpsyg.2014.00647.

Salmon, S. J., Adriaanse, M. A., Fennis, B. M., de Vet, E., \& de Ridder, D. T. (2016). D epletion sensitivity predicts unhealthy snack purchases. Appetite, 96, 25-31. doi:10.1016/ j.appet.2015.08.027

Schmeichel, B. J., Harmon-Jones, C., \& Harmon-Jones, E. (2010). Exercising selfcontrol increases approach motivation. Joumal of Pessonality and Social Psychdogy, 99(1), 162-173. doi:10.1037/ a0019797

Seeley, E. A., \& Gardner, W. L. (2003). The "selfless" and self-regulation: The role of chronic other-orientation in averting self-regulatory depletion.

Seff andIdantity, 2(2), 103-118. doi:10.1080/ 15298860309034

Seiders, K., Berry, L., \& G resham, L. (2000). Attention retailers! How convenient is your convenience strategy? Sloan Management Review, 41(3), 79-89.

Selya, A. S., Rose, J. S., D ierker, L. C., Hedeker, D ., \& Mermelstein, R. J. (2012). A practical guide to calculating Cohen's $\mathrm{f}$, a measure of local effect size, from PRO C MIXED . FrontiessinPsyddogy, 3, 1-6. doi:10.3389/ fpsyg.2012.00111

Shamosh, N. A., \& G ray, J. R. (2007). The relation between fluid intelligence and self-regulatory depletion. Cognition \& Emation, 21(8), 1833-1843. doi:10.1080/ 02699930701273658

Shamsher, R. (2015). Store image and its impact on consumer behaviour. Elk Asia PaaificJaumal of MarketingandReail Management, 7(2), 1-27. doi:10.16962/ EAPJMRM/ issn 
Siegrist, M., Ung, C. Y., Zank, M., Marinello, M., Kunz, A., Hartmann, C., \& Menozzi, M. (2019). Consumers' food selection behaviors in threedimensional (3D) virtual reality. FoodReserch Intemational, 117, 50-59. doi:10.1016/ j.foodres.2018.02.033

Singh, P., Katiyar, N., \& Verma, G . (2014). Retail shoppability: The impact of store atmospherics \& store layout on consumer buying patterns.

Intemational Jaumal of Saientific\& Teehndogy Rearch, 3(8), 15-23.

Singh, R. (2006). An empirical investigation into the effects of shopping motivation on store environment-value relationship. (D octoral dissertation).

Retrieved from http:/ / purl.flvc.org/ fsu/ fd/ FSU migr etd-1707

SketchUp (2018). Retrieved from https:// www.sketchup.com/

Slater, M. (2009). Place illusion and plausibility can lead to realistic behaviour in immersive virtual environments. Philosquical Transactions of theRgal SocidyB:

Bidogial Sáences 364(1535), 3549-3557. doi:10.1098/ rstb.2009.0138

Solomon, M. R. (1985). Packaging the service provider. TheServiceIndustriesJamal, 5(1), 64-72. doi:10.1080/ 02642068500000006

Sorenson, H. (2009). Insidethemind of theshqpee. Upper Saddle River, NJ: Pearson Education.

Spence, C., Puccinelli, N. M., G rewal, D ., \& Roggeveen, A. L. (2014). Store atmospherics: A multisensory perspective. Psydhogy \& Markeing 31(7), 472-488. doi:10.1002/ mar.20709

Spies, K., Hesse, F., \& Loesch, K. (1997). Store atmosphere, mood and purchasing behaviour. Intemational Jaumal of Reserchin Markeing 14(1), 1-17. doi:10.1016/ S0167-8116(96)00015-8

Spiller, S. A., Fitzsimons, G. J., Lynch Jr., J. G., \& McClelland, G. H. (2013).

Spotlights, floodlights, and the magic number zero: Simple effects tests in moderated regression. Jarmal of MarketingResearch, 50(2), 277-288. doi:10.1509/ jmr.12.0420

Srivastava, R. K., \& Natu, A. (2014). A 7PS model of retail patronage: A metasynthesis of contemporary research. Intemational Joumal of Retail Management andReserch 4(1), 1-22.

Steenkamp, J. B. E. M., \& van Trijp, H. C. M. (1997). Attribute elicitation in marketing research: A comparison of three procedures. MarketingLettes 8(2), 153-165. doi:10.1023/ A:1007975518638

Steenkamp, J. B. E. M., van Trijp, H. C., \& Berge, J. M. T. (1994). Perceptual mapping based on idiosyncratic sets of attributes. Jaumal of Markeing Research, 31(1), 15-27. doi:10.2307/ 3151943 
Steuer, J. (1992). D efining virtual reality: D imensions determining telepresence. Jaumal of Commmication, 42(4), 73-93. doi:10.1111/ j.1460-2466.1992.tb00812.x

Stillman, T. F., Tice, D. M., Fincham, F. D ., \& Lambert, N. M. (2009). The psychological presence of family improves self-control. Jaumal of Social and Clinical Psychdogy, 28(4), 498-529. doi:10.1521/ jscp.2009.28.4.498

Sutherland, I. E. (1965). The ultimate display. Proceelings of theIFIP Congess 65 (pp. 506-508). Washington D C: Spartan Books.

Tangney, J. P., Baumeister, R. F., \& Boone, A. L. (2004). High self-control predicts good adjustment, less pathology, better grades, and interpersonal success. Jaumal of Pessonality, 72(2), 271-324. doi:10.1111/ j.0022-3506.2004.00263.x

The Essential Guide to Retail Store Layouts that Shape the Customer Experience. (n.d.) Retrieved from https:/ / www.smartsheet.com/ store-layout

Thomas L. (2017, 15 November). Target CEO : 'Stores are still important' for retail. Retrieved from https:/ / www.cnbc.com/ 2017/ 11/ 15/ target-ceostores-are-still-important-for-retail.html

Thorndike, A. N. (2017). O besity prevention in the supermarket-choice architecture and the supplemental nutrition assistance program. American Jamal of PublicHealth 107(10), 1582-1583. doi:10.2105/ AJPH.2017.303991

Tice, D . M., Baumeister, R. F., Shmueli, D ., \& Muraven, M. (2007). Restoring the self: Positive affect helps improve self-regulation following ego depletion. Jaumal of Experimental Social Psychdogy, 43(3), 379-384. doi:10.1016/j.jesp.2006.05.007

Tinio, P. P., \& Leder, H. (2009), Just how stable are stable aesthetic features? Symmetry, complexity, and the jaws of massive familiarization. Ada Psychdogंa, 130(3), 241-250. doi:10.1016/ j.actpsy.2009.01.001

Titus, P., \& Everett, P. (1995). The consumer retail search process: A conceptual model and research agenda. Jaumal of theAcadkmy of MarkeingSaience, 23(2), 106-119. doi:10.1177/ 0092070395232003

Tuch, A. N., Bargas-Avila, J. A., O pwis, K., \& Wilhelm, F. H. (2009). Visual complexity of websites: Effects on users' experience, physiology, performance, and memory. Intemational Jamal of Human-Computer Studies, 67(9), 703-715. doi:10.1016/ j.jjhcs.2009.04.002

Turley, L. W., \& Milliman, R. E. (2000). Atmospheric effects on shopping behavior: A review of the experimental evidence. Jaumal of Business Reserch, 49(2), 193-211. doi:10.1016/ S0148-2963(99)00010-7 
Underhill, P. (2000). WhyweBuy: TheScience of Shopping New Y ork: Touchstone. Ung, C. Y., Menozzi, M., Hartmann, C., \& Siegrist, M. (2018). Innovations in consumer research: The virtual food buffet. FoodQualityandPreference, 63, 12-17. doi:10.1016/ j.foodqual.2017.07.007

van den Berg, A. E., Vlek, C. A., \& Coeterier, J. F. (1998). Group differences in the aesthetic evaluation of nature development plans: A multilevel approach. Jaumal of Enironmental Psydhogy, 18(2), 141-157. doi:10.1006/ jevp.1998.0080

van der Heide, M., van Ittersum, K., \& van D oorn, J. (2016). Healthy-shopping dynamics: The relative healthiness of food purchases throughout shopping trips. In P. Moreau, \& S. Puntoni (Eds.), Advances in Consumer Reserch (vol. 44, pp. 207-212). D uluth, MN: Association for consumer research. van der Jagt, A. P., Craig, T., Anable, J., Brewer, M. J., \& Pearson, D . G . (2014). Unearthing the picturesque: The validity of the preference matrix as a measure of landscape aesthetics. LandscapeandUnban Planning 124, 1-13. doi:10.1016/ j.landurbplan.2013.12.006

van Gestel, L. C., Kroese, F. M., \& de Ridder, D. T. D . (2018). Nudging at the checkout counter-A longitudinal study of the effect of a food repositioning nudge on healthy food choice. Psychdogy \& Helth 33(6), 800-809. doi:10.1080/ 08870446.2017.1416116

van Herpen, E., Immink, V., \& van den Puttelaar, J. (2016). O rganics unpacked:

The influence of packaging on the choice for organic fruits and vegetables. FoodQualityandPreference, 53, 90-96.

doi:10.1016/ j.foodqual.2016.05.011

van Herpen, E., Pieters, R., \& Zeelenberg, M. (2009). When demand accelerates demand: Trailing the bandwagon. Jamal of Consumer Psydhogy, 19(3), 302-312. doi:10.1016/ j.jcps.2009.01.001

van Herpen, E., van den Broek, E., van Trijp, H. C., \& Yu, T. (2016). Can a virtual supermarket bring realism into the lab? Comparing shopping behavior using virtual and pictorial store representations to behavior in a physical store.

Appeite, 107, 196-207. doi:10.1016/ j.appet.2016.07.033

van Ittersum, K., Pennings, J. M., Wansink, B., \& van Trijp, H. (2005). The effect of primed and framed reference points on product attribute importance. In G. Menon \& A. R. Rao (Eds.), NA - Advances in Consumer Research (vol 32, pp. 113-114). D uluth, MN: Association for Consumer Research. 
van Kleef, E., \& van Trijp, H. C. (2018). Methodological challenges of research in nudging. In P. Varela, G. Ares (Eds.), Methook in consumer reserch volume1: Newapproades todassical mothods (pp. 329-349). UK: Woodhead Publishing. doi:10.1016/ B978-0-08-102089-0.00013-3

van Rompay, T. J., Tanja-D ijkstra, K., Verhoeven, J. W., \& van Es, A. F. (2012). On store design and consumer motivation: Spatial control and arousal in the retail context. Envirament andBehavior, 44(6), 800-820. doi:10.1177/ 0013916511407309

Vazquez, D ., \& Bruce, M. (2002). D esign management - The unexplored retail marketing competence. Intemational Jaumal of Reail \& Distribution Management, 30(4), 202-210. doi: 10.1108/ 09590550210423672

Venkatraman, M. P. (1991). The impact of innovativeness and innovation type on adoption. Jaumal of Reailing 67(1), 51-68.

Vieira, V. A. (2013). Stimuli-organism-response framework: A meta-analytic review in the store environment. Jaumal of Business Reserch 66(9), 1420-1426. doi:10.1016/ j.jbusres.2012.05.009

Vohs, K. D ., \& Baumeister, R. F. (2004). Ego-depletion, self-control, and choice. In J. G reenberg, S. L. Koole, \& T. Pyszczynski (Eds.), Handbodk of Expeimental Existential Psydhogy (pp. 398-410). New Y ork, NY : G uilford Press.

Vohs, K. D ., Baumeister, R. F., Schmeichel, B. J., Twenge, J. M., Nelson, N. M., \& Tice, D . M. (2008). Making choices impairs subsequent self-control: A limited-resource account of decision making, self-regulation, and active initiative. Jaumal of Personality and Social Psychdogy, 94(5), 883-898. doi:10.1037/ 0022-3514.94.5.883

Vohs, K. D ., \& Faber, R. F. (2007). Spent resources: Self-regulatory resource availability affects impulse buying. Jaumal of Consumer Reserch, 33(4), 537-547. doi:10.1086/ 510228

Vrechopoulos A. P., O'Keefe, R. M., D oukidis G. I., \& Siomkos G. J. (2004). Virtual store layout: An experimental comparison in the context of grocery retail. Jamal of Reailing 80(1), 13-22. doi:10.1016/ j.jretai.2004.01.006

Wagner, T. (2007). Shopping motivation revised: A means-end chain analytical perspective. Intemational Jaumal of Retail \& Distribution Management, 35(7), 569-582. doi:10.1108/09590550710755949

Wakefield, K. L., \& Baker, J. (1998). Excitement at the mall: D eterminants and effects on shopping response. Jamal of Reailing 74(4), 515-539. doi:10.1016/ S0022-4359(99)80106-7 
Walmsley, R., Jenkinson, D., Saunders, I., Howard, T., \& Oyebode, O . (2018). Choice architecture modifies fruit and vegetable purchasing in a university campus grocery store: time series modelling of a natural experiment. BMC PublicHelth, 18(1), 1149-1157. doi:10.1186/ s12889-018-6063-8 Wan, E. W., \& Sternthal, B. (2008). Regulating the effects of depletion through monitoring. Pesconalityand Sodal Psydhogy Bullein, 34(1), 32-46. doi:10.1177/ 0146167207306756

Wansink, B., \& Park, S.-B. (2002). Sensory suggestiveness and labeling: D o soy labels bias taste? Jaumal of Sensary Studies 17(5), 483-491. doi:10.1111/ j.1745-459X.2002.tb00360.x

Waterlander, W. E., Blakely, T., Nghiem, N., Cleghorn, C. L., Eyles, H., Genc, M., ... \& Michie, J. (2016). Study protocol: Combining experimental methods, econometrics and simulation modelling to determine price elasticities for studying food taxes and subsidies (The Price ExaM Study). BMC publichelth, 16(1), 1-13. doi:10.1186/ s12889-016-3277-5

Waterlander, W. E., Jiang, Y., Steenhuis, I. H. M., \& Mhurchu, C. N. (2015). Using a 3D virtual supermarket to measure food purchase behavior: A validation study. Jaumal of Medical Inteme Reserch 17(4), 1-17. doi:10.2196/ jmir.3774 Waterlander, W. E., Mhurchu, C. N., \& Steenhuis, I. H. (2012). The use of virtual reality in studying complex interventions in our every-day food environment. In X. Tang (Ed.), Virtual Reality-Human Computer Interadion IntechO pen. doi:10.5772/ 46410

Waterlander, W. E., Mhurchu, C. N., \& Steenhuis, I. H. (2014). Effects of a price increase on purchases of sugar sweetened beverages. Results from a randomized controlled trial. Appetite, 78, 32-39.

doi:10.1016/ j.appet.2014.03.012

Waterlander, W. E., Steenhuis, I. H., de Boer, M. R., Schuit, A. J., \& Seidell, J. C. (2012). The effects of a 25\% discount on fruits and vegetables: results of a randomized trial in a three-dimensional web-based supermarket. Intemational Jamal of Behavioral NutritionandPhysical Adivity, 9(1), 1-12. doi:10.1186/ 1479-5868-9-11

Weinswig D . (2018, 8 June). Weekly Store O penings and Closures Tracker 2018 \#23: Hudson's Bay Co. to Close 10 Lord \& Taylor Stores. Retrieved from https:/ / coresight.com/ wp-content/ uploads/ 2018/ 06/ Weekly-StoreOpenings-and-Closures-Tracker-23-June-8-2018.pdf 
Why online isn't the end of the physical retail store. (2017, 19 May). Retrieved from https:/ / knowledge-leader.colliers.com/ editor/ retail-spotlight-onlineisnt-end-physical-retail/

Why physical stores are still so important for retail brands in the digital age (n.d.).

Retrieved September 15, 2018, from http:// www.trulydeeply.com.au/ 2017/ 07/ physical-stores-retail-branding-digital-age/

Wills, T. A., Isasi, C. R., Mendoza, D., \& Ainette, M. G . (2007). Self-control constructs related to measures of dietary intake and physical activity in adolescents. Jaumal Adbescent Helth, 41(6), 551-558.

doi:10.1016/ j.jadohealth.2007.06.013

Winter, D . (2017, 15 November). Why digital brands need physical retail: An evening with Bulletin's Co-Founder and COO. Retrieved from https:/ / www.shopify.com/ blog/ why-digital-brands-need-physical-retail Wisdom, J., D owns, J. S., \& Loewenstein, G . (2010). Promoting healthy choices: Information versus convenience. Ameican EconamicJaumal: AppliedEcanomics, 2(2), 164-178. doi:10.1257/ app.2.2.164

Witmer, B. G., \& Singer, M. J. (1998). Measuring presence in virtual environments: A presence questionnaire. Presence, 7(3), 225-240. doi:10.1162/ 105474698565686

Xu X., Demos K. E., Leahey T. M., Hart C. N., Trautvetter J, Coward, P., ... \& Wing, R. R. (2014). Failure to replicate depletion of self-control. PLoS ONE, 9(10), 1-5. doi:10.1371/ journal.pone.01099

Zimmer, M. R., \& Golden, L. L. (1988). Impressions of retail stores: A content analysis of consume images. Jamal of Retailing 64(3), 265-293.

Zygouris, S., Giakoumis, D., Votis, K., D oumpoulakis, S., Ntovas, K., Segkouli, S., ... \& Tsolaki, M. (2015). Can a virtual reality cognitive training application fulfill a dual role? Using the virtual supermarket cognitive training application as a screening tool for mild cognitive impairment. Jaumal of Alzhime's Disse, 44(4), 1333-1347. doi:10.3233/ JAD-141260 



\section{Appendixes}

Appendix 2.1: Stimulus material used in Study 1, Chapter 2

\section{Description of the store with a grid layout}

Imagine that you are in a city where you have never been, and that you walk into this drugstore. When you walk through the store, you notice that there is a certain way where you go along, and that it is not easy to deviate from that. You are guided through all the aisles. The drugstore has high, long shelves in the store that are placed parallel to each other. Furthermore, the shelves are rectangular and all the same.

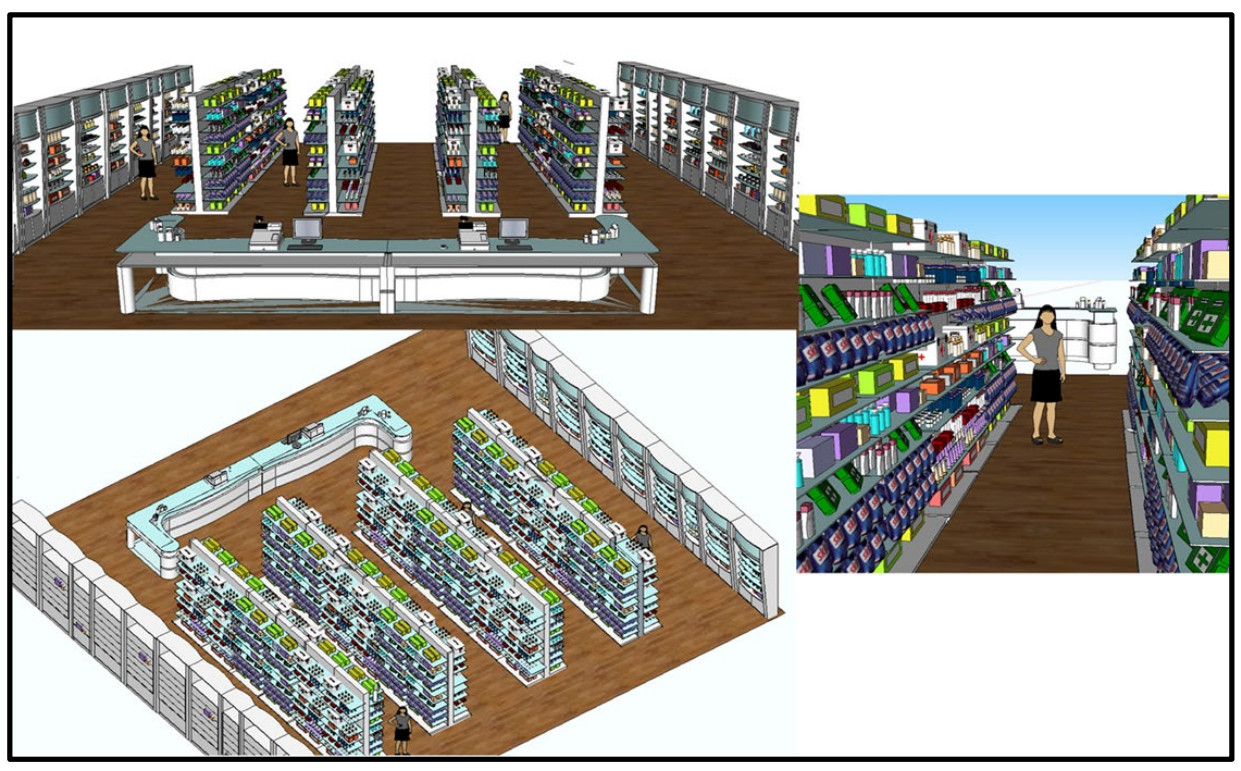

Figure A-2.1: The store with a grid layout 


\section{Description of the store with a free-form layout}

Imagine that you are in a city where you have never been, and that you walk into this drugstore. When you walk through the store, you notice that there is no fixed route; it is easy to walk from shelf to shelf. The drugstore has different types of shelves. On the walls you see high shelves, but in the middle of the store are somewhat lower and shorter shelves positioned in various ways. Furthermore, you also note that the shelves have different shapes. There are rectangular but also round shelves.

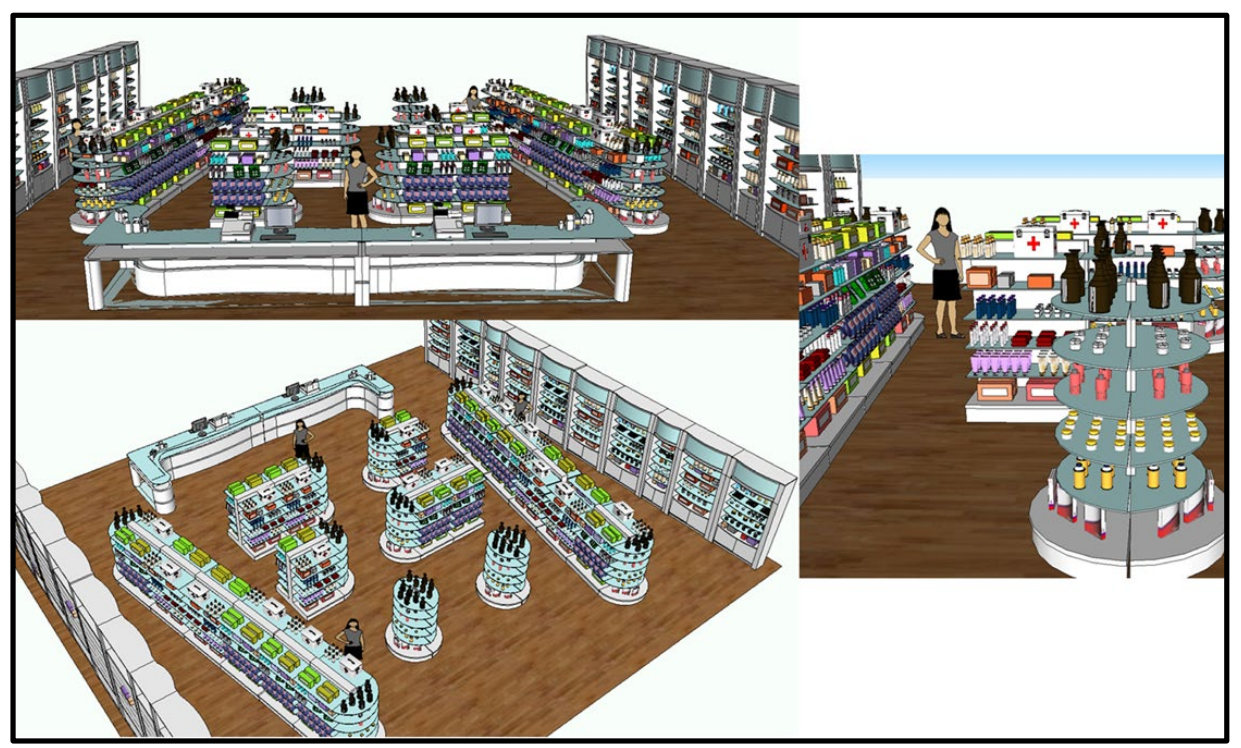

Figure A-2.2: The store with a free-form layout 


\section{Appendix 2.2: Itens used tomesurestareimage, Studies 1 and 2, Chapter 2}

\begin{tabular}{ll}
\hline Subdimension & Items \\
\hline
\end{tabular}

Merchandise $\quad 1$. I think that the products in this store are reliable.

quality

2. I think that the workmanship of the products in this store is very high.

3. I have the feeling that the products in this store are of good quality.

Merchandise 1. I have the feeling that the products in this store are price expensive.

2. I think that the products in this store are more expensive than in other stores.

Service quality 1 . I have the feeling that employees in this store have the knowledge to answer customers' questions.

2. I think that when this store promises to do something by a certain time, it will do so.

3. I think that employees in this store are never too busy to respond to customer's requests.

4. I think that when a customer has a problem, this store shows a sincere interest in solving it. 
Appendix 2.3: Stimulus material used in Study 2, Chapter 2

\section{Description of the store with long shelves placed straight and parallel} Imagine that you are in a city where you have never been, and that you walk into this drugstore. When you walk through the store, you notice that there is a certain way where you go along, and that it is not easy to deviate from that. You are guided through all the shelves. The drugstore has placed the shelves parallel to one another and they are long. You are not able to cut across and skip shelves you do not want to visit. You have to follow a fixed route through the store.

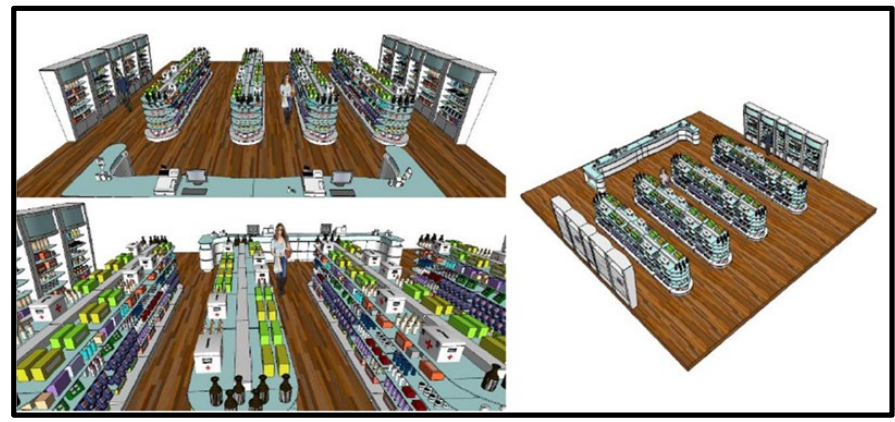

Figure A-2.3: The store with long shelves placed straight and parallel

\section{Description of the store with short shelves placed straight and parallel}

Imagine that you are in a city where you have never been, and that you walk into this drugstore. When you walk through the store, you notice that there is no fixed route; it is possible to walk from shelf to shelf. The drugstore has placed the shelves parallel to one another. The shelves are also short, so you can cut across and skip aisles you do not want to visit. You can determine your own shopping path in this store.

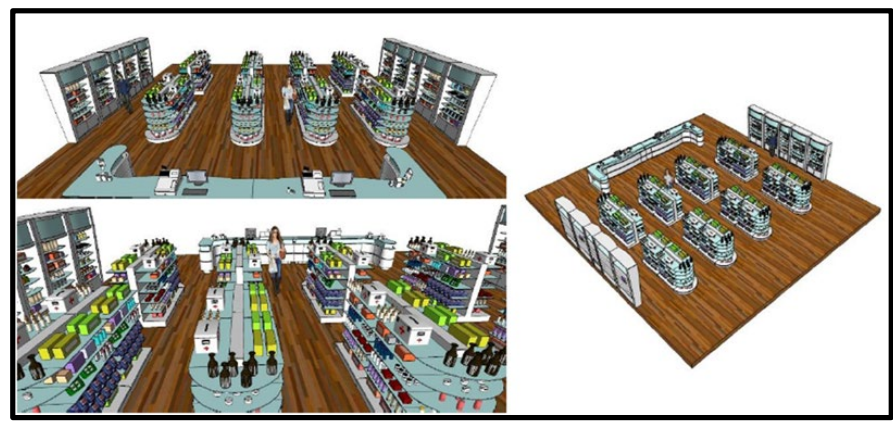

Figure A-2.4: The store with short shelves placed straight and parallel 


\section{Description of the store with long shelves placed in diverse angle}

Imagine that you are in a city where you have never been, and that you walk into this drugstore. When you walk through the store, you notice there is some sort of fixed route; the aisles are long but not parallel to one another. The drugstore has placed the shelves at an angle. Since the shelves are long, you cannot cut across and skip parts of an aisle when you have entered that aisle.

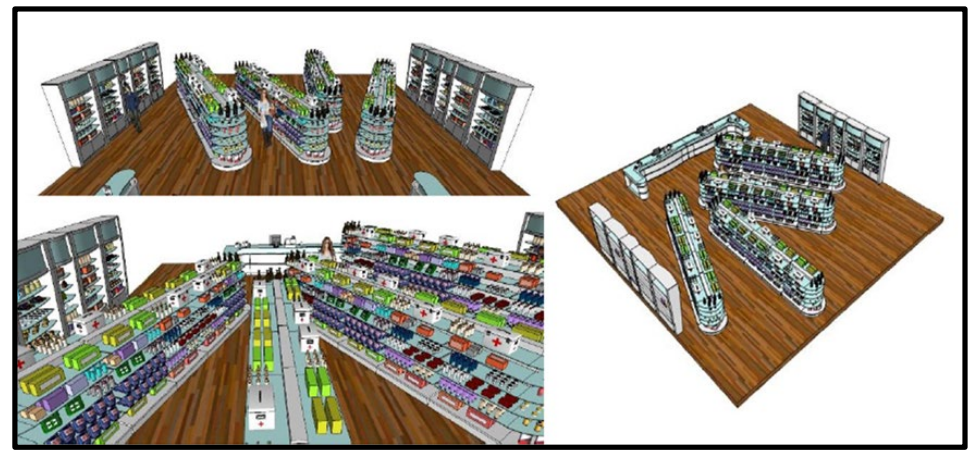

Figure A-2.5: The store with long shelves placed in diverse angle

\section{Description of the store with short shelves placed in diverse angle}

Imagine that you are in a city where you have never been, and that you walk into this drugstore. When you walk through the store, you notice there is no fixed route; it is easy to walk from shelf to shelf. The drugstore has placed the shelves at an angle; they are not parallel to one another. The shelves are also short, so you can cut across and skip aisles you do not want to visit. You can determine your own shopping path in this store.

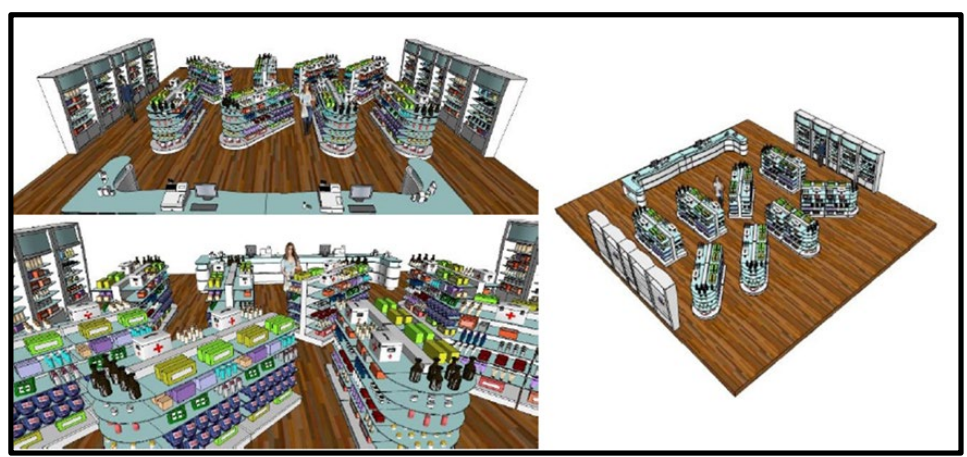

Figure A-2.6: The store with short shelves placed in diverse angle 
Appendix 3.1: Example of the store layout design presented to participants,

Chapter 3

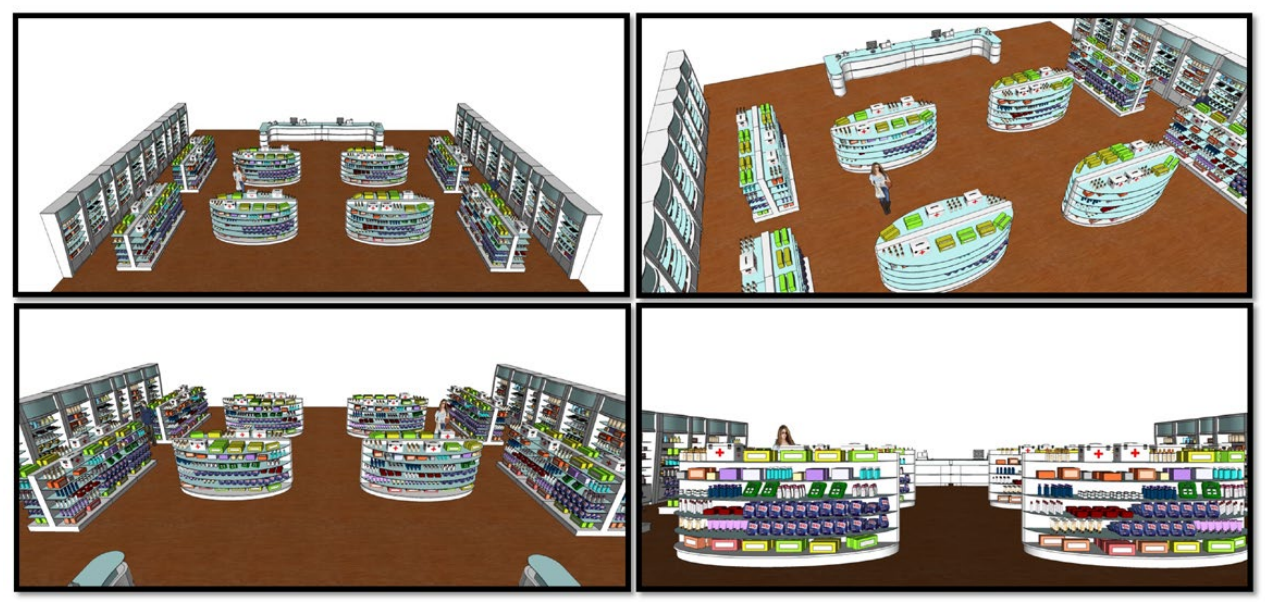

Figure A-3.1: Images of store layout design from a front view (top-left), a top view (topright), a back view (bottom-left) and a middle-aisle view (bottom-right) 


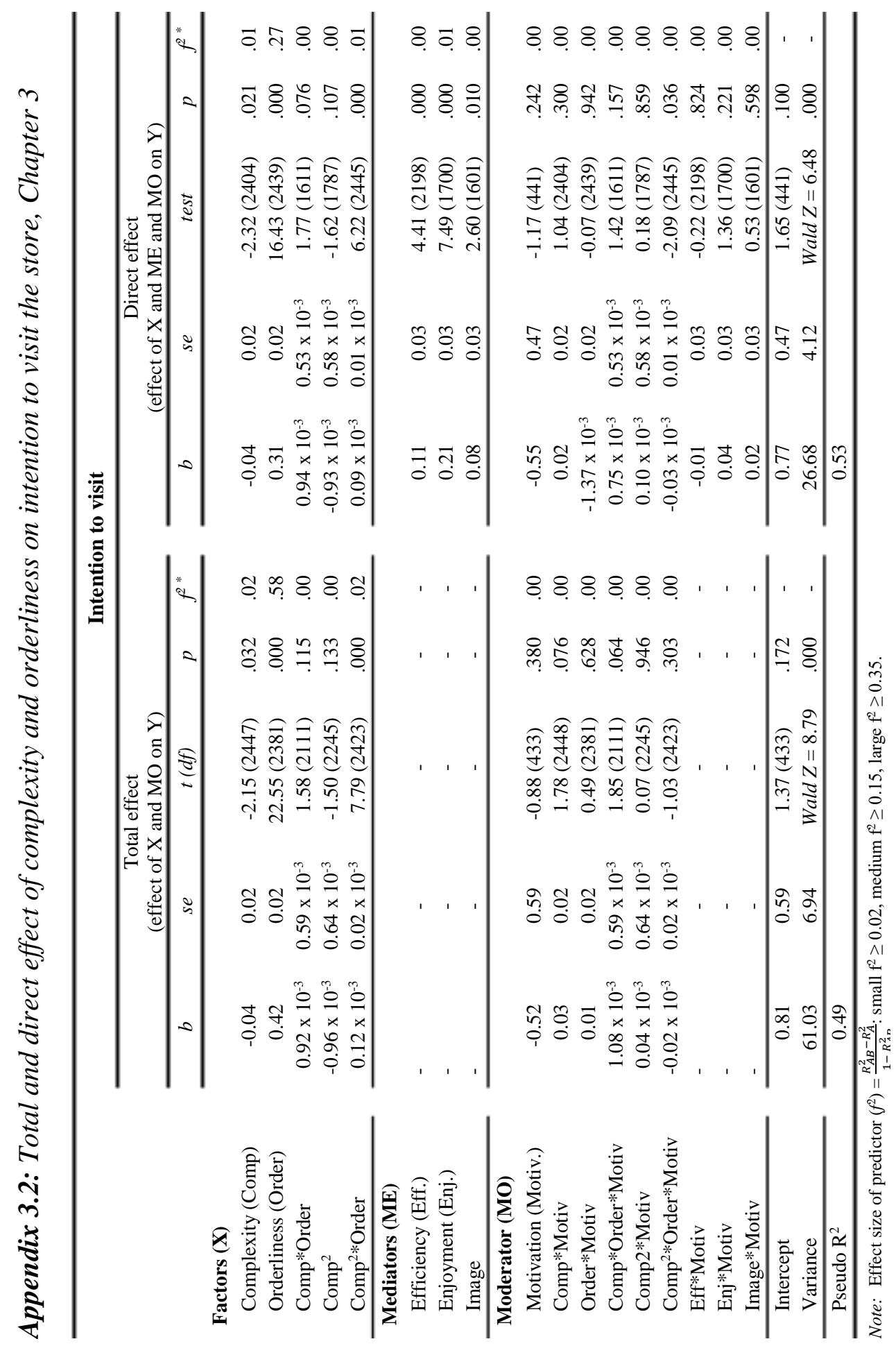




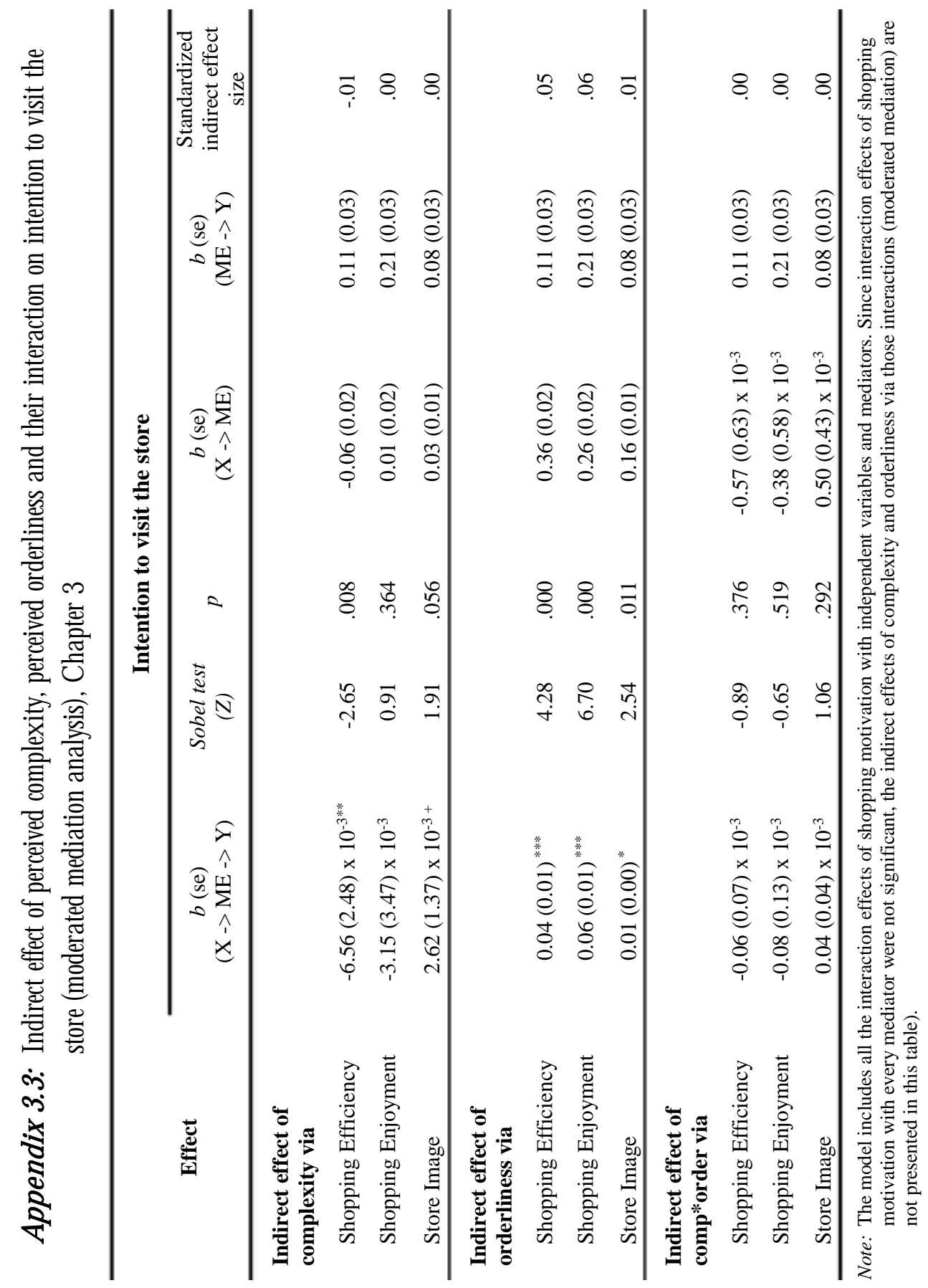




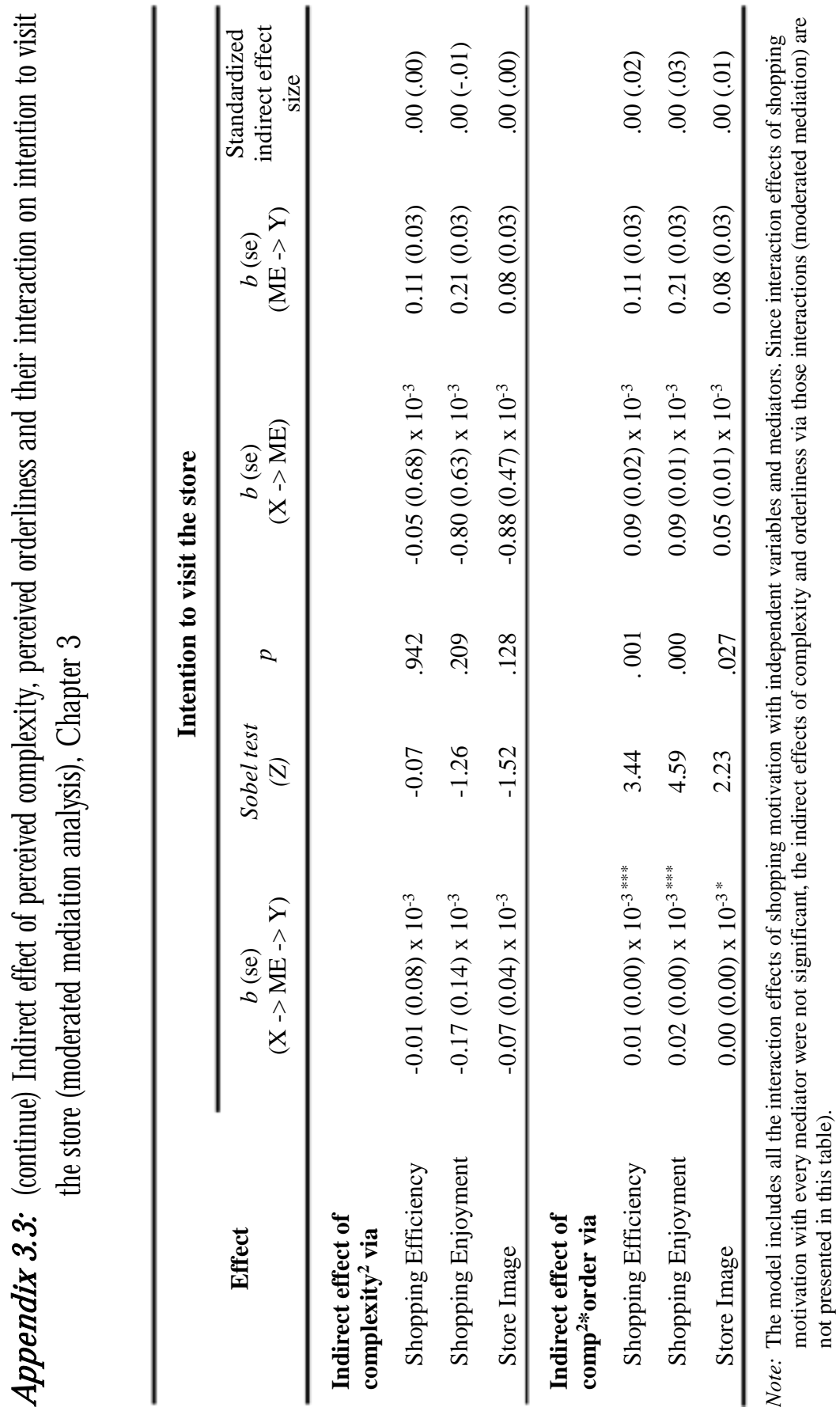




\section{Appendix 4.1: Mateials, Chapter 4}

\begin{tabular}{|c|c|c|c|}
\hline $\begin{array}{l}\text { Name of } \\
\text { Material/ } \\
\text { Equipment }\end{array}$ & Company & Catalog Number & Comments/Description \\
\hline $\begin{array}{l}\text { Virtual } \\
\text { Supermarket } \\
\text { Software }\end{array}$ & $\begin{array}{l}\text { GreenDino } \\
\text { BV }\end{array}$ & $\begin{array}{l}\text { http://www.greendino.nl/virtual- } \\
\text { labs.html }\end{array}$ & $\begin{array}{l}\text { This software consists of editor, } \\
\text { product library and consumer } \\
\text { interface. }\end{array}$ \\
\hline $\begin{array}{l}\text { Data } \\
\text { Management } \\
\text { Software: } \\
\text { Observer XT }\end{array}$ & $\begin{array}{l}\text { Noldus } \\
\text { Information } \\
\text { Technology }\end{array}$ & $\begin{array}{l}\text { http://www.noldus.com/human- } \\
\text { behavior-research/products/the- } \\
\text { observer-xt }\end{array}$ & $\begin{array}{l}\text { This software records } \\
\text { observational data and } \\
\text { facilitates the exportation of } \\
\text { researcher-specified data sets } \\
\text { using filters }\end{array}$ \\
\hline $\begin{array}{l}\text { 3D } \\
\text { SpaceNavigator }\end{array}$ & 3Dconnexion & $\begin{array}{l}\text { http://www.3dconnexion.eu/index.php? } \\
\text { id=26\&redirect2=www.3dconnexion.eu }\end{array}$ & $\begin{array}{l}\text { A 3D SpaceNavigator allows } \\
\text { participants to walk and make } \\
\text { turns in the virtual store. In } \\
\text { addition, it can be used by } \\
\text { participants to adjust their eye- } \\
\text { level during a shopping trip. }\end{array}$ \\
\hline $\begin{array}{l}\text { 3D moddeling } \\
\text { software (e.g. } \\
\text { Blender or 3DS } \\
\text { Max) }\end{array}$ & $\begin{array}{l}\text { Blender } \\
\text { Foundation / } \\
\text { Autodesk }\end{array}$ & $\begin{array}{l}\text { https://www.blender.org/ } \\
\text { http://www.autodesk.nl/products/3ds- } \\
\text { max/overview }\end{array}$ & $\begin{array}{l}\text { In case 3D models need to be } \\
\text { made or adjusted 3D modeling } \\
\text { software is needed. Many } \\
\text { objects can be found online } \\
\text { under different licencing } \\
\text { agreements. }\end{array}$ \\
\hline $\begin{array}{l}\text { Contract } \\
\text { Reseach }\end{array}$ & $\begin{array}{l}\text { Wageningen } \\
\text { Univeristy } \\
\text { and Research }\end{array}$ & $\begin{array}{l}\text { http://www.wur.nl/en/Expertise- } \\
\text { Services/Research-Institutes/Economic- } \\
\text { Research.htm }\end{array}$ & $\begin{array}{l}\text { The socio-economic research } \\
\text { institute (Wageningen } \\
\text { Economic Research) with } \\
\text { experience in conducting the } \\
\text { consumer research with the } \\
\text { virtual store. }\end{array}$ \\
\hline
\end{tabular}




\section{Appendix 4.2: Insturtion on howtomanexer in thevirtual stare, Chapter 4}

Before visiting the "real" virtual store for your shopping task, we would like to introduce the virtual store program to you through a training shop.

You will therefore receive 1) an instruction on how to control and maneuver in the virtual store (this page), and 2) an instruction for the practice session (on a separate sheet). The training shop in the practice session is almost empty because it is only made with the intention to introduce you to the program.

\section{Navigation instructions}

\section{Walking through the supermarket}

Walking can be done by using the '3D SpaceNavigator' and the mouse. The 3D SpaceNavigator works similarly to a joystick, which you can move in any direction.

\section{Changing the level of your eye view}

By pressing down or pulling up the 3D SpaceNavigator, you can change the level of your eye view. There are three levels (i.e, high (an average eye level of the Dutch population), middle and low level) of eye view where you can look at the products.

\section{Viewing and selecting the product}

Y ou can select the product to see its details and purchase it by using the mouse to move the red-circle-visor to the product you are interested in. Then double-click on the product (by left mouse button) to view it closer. To do this you must stand near the product.

After the product is shown, you can use the mouse to rotate the object (3D products only) and the scroll wheel to zoom in or zoom out. You can decide (at the bottom of the pop-up window) to buy or to return the product. By pressing the + and / or - button, you can indicate the number of products you want to buy.

\section{Choosing the walking direction}

When you approach an intersection, you will see arrows on the screen. The arrows point to a specific direction that you can take.

Y ou can select your walking direction by moving the mouse to a specific arrow (green arrow = active direction, red arrow $=$ inactive direction) and left-mouse-clicking on the green arrow pointing to your desired direction. After selecting the direction, you can use the 3D SpaceNavigator to continue walking. 


\section{Appendix 4.3: Instrution of thepradicesession, Chapter 4}

\section{Practice Session}

1. Start the program by clicking on 'start' with the left mouse button.

2. Walk to the end of the aisle by using the 3D SpaceNavigator.

3. Press down the 3D SpaceNavigator to obtain a better view of the O live oil (see Figure A-4.1). Turn the 3D SpaceNavigator so that you see the olive oil shelf in front of you.

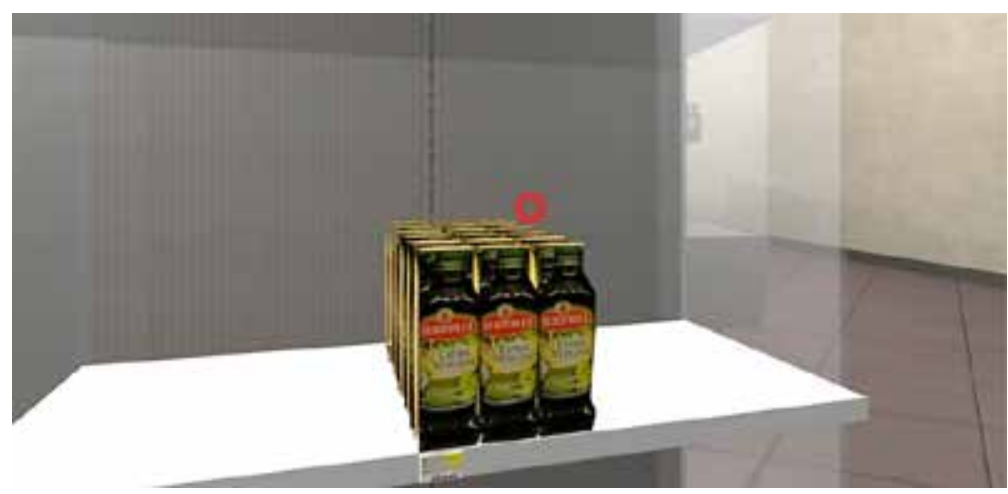

Figure A-4.1: Olive oil

4. Pull the 3D SpaceNavigator up to go back to the normal eye view.

5. Walk to the back of the store, where you see bottles of wine on the shelf.

6. Use the mouse to select the right arrow in order to turn to the wine shelf (when arrows appear on screen (see Figure A-4.2), you must first select an arrow by pressing the left mouse button before you can move again).

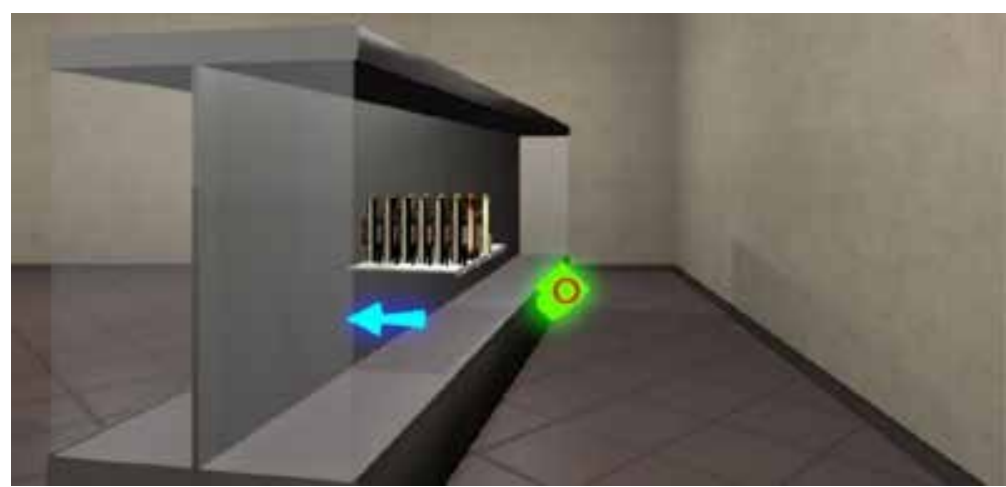

Figure A-4.2: Arrow at an intersection 
7. Walk to the wine shelf using the 3D SpaceNavigator.

8. Use the mouse to move the red-circle-visor on one of the wines. Practice with the + and - buttons to select the quantity and press either "Return" to return the wine, or press 'Buy' to make a purchase (see Figure A-4.3).

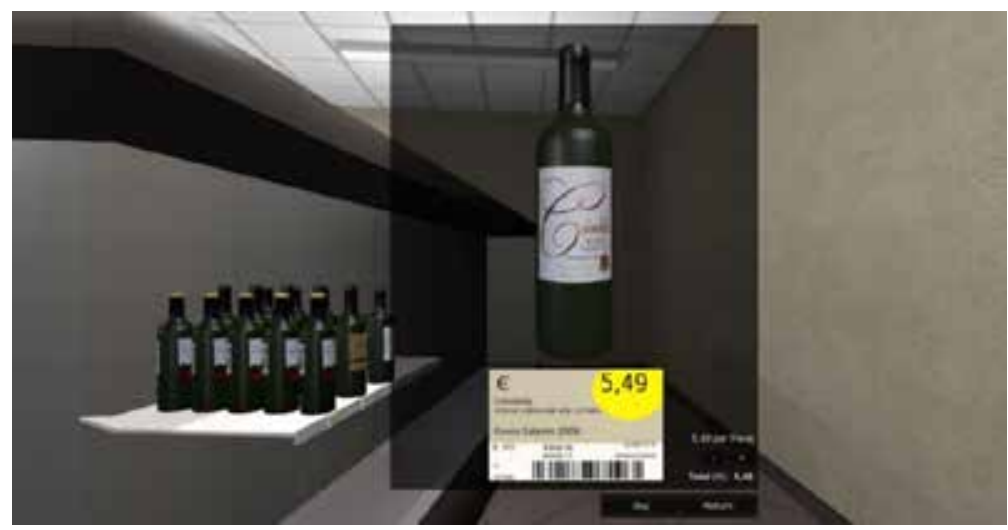

Figure A-4.3: Pop-up window to show selected product

9. Press "F1" to check your shopping basket and click "Close" to close it.

10. After you have bought all the products you want, press "Esc" to exit the store.

Now call the researcher to bring you to the next part of the study. 
Appendix 4.4: Instrution for thetask tomanipulatetheshopingmotivation, Chapter 4

\section{A: hedonic motivation}

"You have now been able to practice in the virtual supermarket. Before getting started with the actual task, we want to ask you to read the next text and describe a situation.

Can you remember thelast timeyou weeshopping vith a rdaxed feeding? Yau weend in a humy and not speifically lokkingfor somthing You weebrousing at eseand qpen to new experiences

Can you describethis situation? What type of storevas this? What did you seein this store? Howdidyoufed? Whichendionsdidyou have? Pleasetrytodescribethesituationinasmin deail as possible"

\section{B: utilitarian motivation}

"You have now been able to practice in the virtual supermarket. Before getting started with the actual task, we want to ask you to read the next text and describe a situation.

Can you remember thelast timeyau weeshopinguith samthingspeificin mind? Yau had a dear shoppinggoel and weetryingtofinishshopingasfast as possible Yau wereforinstance busyor tired and not willingtospend timebrousingarand

Can you describethis situation? What type of storevas this? What did you seein this store? Howdidyoufed? Whichentions didyou have? Pleasetrytodescribethesituationinasmich deail as possible" 


\section{Appendix 4.5: Instrution for theshqpingtask and theshoppinglist used in the main test, Chapter 4}

This instruction consists of two parts: a situation in which you will do grocery shopping and a list of needed supplies. After reading both parts you can start doing the groceries in the virtual supermarket.

\section{A: Instruction of a shopping task with a hedonic motivation:}

The instruction below describes the situation in which you enter the virtual store. Please read it carefully and try to imagine yourself shopping in this situation.

You are going to shop for dinner, additionally you want to buy some other products. You are having a wonderful day and are looking forward to doing grocery shopping. You have time to browse around. You are open for experiencing new and nice things.

\section{B: Instruction of a shopping task with a utilitarian motivation:}

The instruction below describes the situation in which you enter the virtual store. Please read it carefully and try to imagine yourself shopping in this situation.

Y ou have to do grocery shopping for dinner, additionally you need some other groceries. You have had a busy day and are not looking forward to going for groceries. Sadly, you have to because now is the last chance to go grocery shopping today. You have a clear goal and you want to shop as functional and efficiently as possible.

Note Participant should be assigned and read only one of the shopping motivation situations. 


\section{Shopping list}

You have made a list for your grocery shopping:

1 Bag of potato crisps

1 Pack of biscuits

1 Type of (sweet \& nonperishable) spreads

1 Pack of tea

Meal (for 2 persons):

- 1 D essert

o 1 Type of meat / fish / meat substitute

o 1 Sauce

o Vegetables for this meal

Fruit for the whole week (as many as you think you will need)

You can start your visit to the virtual store by calling the researcher.

When you're done shopping in the store, you can press $E S C$, and you can call one of the researchers for the last part of this study, a questionnaire. 


\section{Acknowledgments}

I would like to express my sincere gratitude to the great supports from the nice people whom I met during my study. Everything will be kept in my permanent memories.

First of all, I would like to acknowledge the financial sponsor, the Royal Thai Government via the Office of the Higher Education Commission (OHEC), for providing the opportunity to pursue my Ph.D . at world-renowned Wageningen University. My special thanks go to the associated staffs of OHEC and the O ffice of the Civil Service Commission (O CSC) for administrative assistance.

I am greatly indebted to my promoter Prof. Hans van Trijp and co-promoter E rica van Herpen for accepting me as a Ph.D . candidate under their supervision. They provided brilliant guidance and encouragement to make the naturally subtle Ph.D . study more enjoyable. Meetings with Hans were always excitingly fruitful because his excellent coaching skill ignites creative ideas that were subsequently organized to the concrete work plans. I have learned a lot of things from Erica. We worked together to initiate the ideas, develop research designs and questionnaires, handle advanced research tools, and draft the research articles. Both the supervisors have imparted a great deal of research skills, knowledge and experience to me. This helps me to gradually develop as an independent researcher. In addition, I would like to express my appreciation to the members of the committee, Emely de Vet, Kitty Koelemeijer, Koert van Ittersum, Maggie Geuens, for dedicating their time and efforts to read and evaluate my Ph.D. thesis. 
I would like to thank all the MCB staffs for constructive discussion, shared experience, inspiration, and encouragement. My special thanks also go to Ivo for spending time to help design the experiment and Ivo and Amout for guiding several issues related to statistics. I appreciated heartfelt sympathies and hugs from Ilona, Ynte, Betina and all MCB members during my sorrow. Thanks, Ellen, Liesbeth, Johnnatan, Marloes, and Leanne for all kinds of practical assistance and kindness.

I am thankful for all the supports and understanding from Ravipim Chaveesuk (my mentor in Thailand), Thanit Puthpongsiriporn (the head), Pornthipa O ngkunaruk (the deputy head), all the academic staffs of the Department of Agro-Industrial Technology, and my teachers at the Department of Food Science and Technology, Kasetsart University, Thailand. I am deeply grateful to Bram D ankaart and Karin Vaessen for taking a great care.

Living in a foreign country being remote from the homeland is generally a difficult task for most people. However, the nice and helful colleages at MCB and ECH made my Ph. D. life in the Netherlands easier than I anticipated. The officemates, Lotte and Naomi, always brough the sunshine and laughs to our office. O ur chatting and activities helped me get rid of stress at work. I felt the warm welcome from Roxanne and Nidhi which wiped away my loneliness right from the first day of my Ph.D. G race is an Asian colleague and friend who always understand me. Thanks Robert, Nigel and Lisanne for always being ready to listen, talk, and help whenever I need. Thanks Ph.D. fellows during my early Ph.D., Colin, Aleksandra, Gerben, Els, Evelien, Janette for kind help. Thanks Ph.D. fellows during my last state of Ph.D., Luz, Kristina, Giulia, Lenka, X in, Bastian, Beatrice, Roselinde and all 'Africans' for your friendliness and for sharing experiences, cultures, and food. 
Thanks to all participants that were willing to spend their spare time participating in my studies. Thanks Georgia Lavranou, Harmen van Essen, Aafke Smal, Maaike Kuipers, Robert de Haas and Anouk Beldhuis for your assistance regarding data collection. Thanks to the stafffs of GreenDino and Tobias Heffelaar of Noldus Information Technology for providing the technical support of the virtual store. Thanks to Jos van den Puttelaar for assisting in data collection, handling with the virtual store as well as significantly contributing to Chapter 4 of this thesis. Thanks to Angelo who helped me with the store layout design by Sketup3D. Thanks to Pathitta and Jatuporn for nice cover and insidecover designs.

I am thankful to all my friends and my second family in the Netherlands, especially the Thai-Wageningen community. Special thanks go to Kees and $\mathrm{P}^{\prime}$ Waew who kindly took a good care of me like my 'godfather' and 'godmother'. Thank you P' Sayam, P' O +, P' Rat, Marcel, P'Aor, Laurent, $\mathrm{P}^{\prime}$ Pam, P' Tan, P' Lek, Nicolas, P'Book, P'Nim, P' Tony, P' Pom, P' Yui, P' Aoeng, P'Arm, P' Off, P' Pla-0, P' Pai, P' Jeab, Gunnar, Mong, Im, Pla, Jug to turned the cold and rainy Wageningen to be the mentally warm home. I would also like to thank P' Nu, P' Noo, P' Nong, P' Pop, P' Tom+, P' Mam, Jae, Porkaew, Som, Pin, Ploy, Lum, Mo, Roald, Maitoe, Polly, UngIng, and others who made so valuable memories in Wageningen. Dear P' Good, P' Off, P' Ying, Mint, Pleece, Earb, Plub, Fai and Kahn, thank you all for the amazing moments you shared with me regardless of happiness or sadness.

I am deeply grateful to aunty Goy, uncle Chris, aunty Joke, uncle Ko+, Aj. Worrapat, P' Ohm, P' Tik, P' Au, P' Pum, P' Hoya, P' Louise, P' Jom, Mannu, Noon and their family for inspiration, life lesson, love and compassion you have given to me. Thank you for taking care of me like your family. 
Dear ThawinWal and Ploydanai families, $\mathrm{P}^{\prime}$ Tong, and P' Lab, I owed my deepest gratitude to you for standing by me and sending your love and supports from home. I could immediately feel the warmth from all of you despite the far distance between Thailand and the Netherland. Thank you for rooting for me when I faced so many failures and when my heart was filled with sorrows. Y our warmly encouraging words, smiles, and hugs really helped me overcome these difficulties. Of course, thanks to my SW and Kaset friends in Thailand and around the world for your mental encouragement and fun chat.

Last but not least, I would like to say thank you to the most important persons in my life, my parents, brother, sister-in-law and my boyfriend. I am indebted to Mom and D ad for your beliefs in me, unconditional love, mental, physical and financial support. I owed all kinds of success to you. D ear P' Tong and N'Praew, having you by my sides energized me to achieve my dream of finishing a Ph.D. without worrying about the well-being of mom and dad. Thank you, my passionate boyfriend, $\mathrm{M}$, who inspired, encouraged and helped me to accomplished Ph.D. and passed the tough times. I am very thankful to be your family. I love you. 


\section{About the author}

K unalai Ploydanai was born in Phuket, Thailand, on May 24 $4^{\text {th }}, 1984$. She obtained her bachelor's degree in Food Science and Technology at Kasetsart University in 2006 with the First-Class Honours. In 2008, she was awarded a scholarship under the program "Strategic Scholarships for Frontier Research Network" from Office of the Higher Education Commission, the Royal Thai G overnment to pursue both a master's degree and

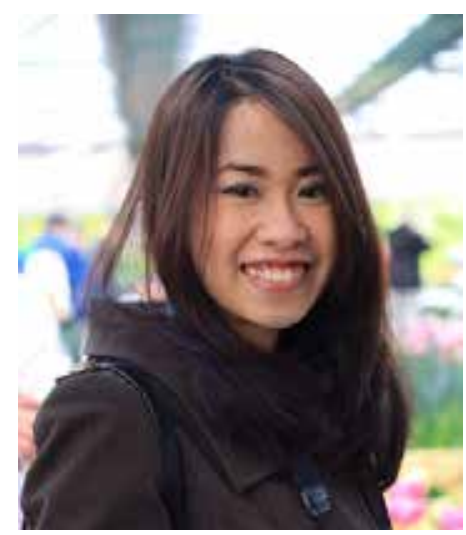
a Ph.D . degree.

In 2011, she finished her master's degree in Marketing and Consumer Behavior at Wageningen University. Her thesis investigated the effect of cognitive distraction on the uses of labels in product choice by applying an eye-tracker. Right after graduation, she continued her Ph.D. study at the Marketing and Consumer Behaviour group, Wageningen University. Her Ph.D. thesis focused on using the virtual store to unveil the underlying impacts of store layout design and merchandise layout on consumers' responses to stores. The findings obtained from her research were presented in several international conferences in Europe and the USA. She also published numerous research articles that constitute her Ph.D. thesis and finally Kunalai graduated Ph.D . in 2019.

After graduation, Kunalai will work at the Department of Agro-Industrial Technology, Faculty of Agro-Industry, Kasetsart University, Thailand. She will serve as a lecturer and a researcher with specialization in marketing and consumer behaviors in the food and agricultural domains. 



\section{Kunalai Ploydanai \\ Wageningen School of Social Sciences (WASS) \\ Completed Training and Supervision Plan}

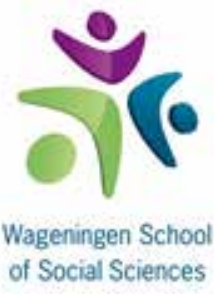

\section{Name of the leaming activity}

A) Project related competences

Introduction to Multilevel Analysis

Q uantitative D ata Analysis: Multivariate

Technique, YRM60306

Psychology of health and environmental behavior:

Self-regulation

Psychology of health and environmental behavior: Priming

Psychology of health and environmental behavior: Habits

Behavioral \& Experimental Economics, ECH51306

\section{B) General research related competences}

Research Methodology: from topic to proposal

Writing $\mathrm{PhD}$ research proposal

Scientific Writing

D octoral seminar on consumer behavior

$\mathrm{PhD}$ series: Consumer behaviour

'Stationingsnadksin thesupemarke: Howprodudt categry location affeets the(un)helthy snadk dhices madeby consumes with different deyees of trait sdfcontrd'

Effets of Produt Loationand Trait Seff-Contrd on HealthySnadk Chices When HighSef-Contrd IndvidualsBuyMoreHealthySnads'
Introduction course

\begin{tabular}{|c|c|}
\hline $\begin{array}{c}\text { Erasmus Research Institute of } \\
\text { Management }\end{array}$ & 2012 \\
\hline Wageningen University & 2013 \\
\hline WASS Masterclass, Wageningen & 2014 \\
\hline WASS Masterclass, Wageningen & 2015 \\
\hline WASS Masterclass, Wageningen & 2017 \\
\hline Wageningen University & 2014 \\
\hline
\end{tabular}

$\begin{array}{ccc}\text { WASS, Wageningen } & 2013 & 1 \\ \text { WASS, Wageningen } & 2012 & 4 \\ \text { Wageningen University } & 2012 & 6 \\ \text { Wageningen In'to Language } & 2014 & 2 \\ \text { ED EN } & 2013 & 4 \\ \text { MCB, Wageningen } & 2012-2016 & 1.2 \\ \text { EMAC conference, } & 2015 & 1 \\ \text { Leuven, Belgium } & & \\ \begin{array}{c}\text { ACR conference, } \\ \text { Baltimore, USA }\end{array} & 2014 & 0.5\end{array}$

\section{C) Career related competences/ personal development}

\begin{tabular}{lccc} 
Efficient writing Strategies & Wageningen In'to Languages & 2014 & 1.4 \\
$\begin{array}{l}\text { Techniques for writing and presenting a scientific } \\
\text { paper }\end{array}$ & WG S, Wageningen & 2014 & 1.2 \\
$\begin{array}{l}\text { Supervision of Bachelor and Master theses } \\
\text { (6 projects) }\end{array}$ & MCB, Wageningen & $2013-2016$ & 2 \\
$\begin{array}{l}\text { Teaching assistant: Sensory Perception and } \\
\text { Consumer Preference }\end{array}$ & MCB, Wageningen & 2015 & 2 \\
\hline
\end{tabular}

Total

37.8

*O ne credit according to ECTS is on average equivalent to 28 hours of study load 
The research described in this thesis was financially supported by the $\mathrm{O}$ ffice of the Higher Education Commission, the Royal Thai Government.

Financial support from Wageningen University \& Research for printing this thesis is gratefully acknowledged.

\section{Cover design:}

Pathitta Sirirerkratana and Kunalai Ploydanai

\section{Inside cover design:}

Jatuporn Ananlertsagul and Pathitta Sirirerkratana

\section{Publisher:}

Proefschriftmaken.nl || DigiForce Vianen 
